DANIEL DOS SANTOS MOTA

\title{
Técnicas de Ajuste de Estabilizadores de Sistemas de Potência
}

Dissertação apresentada à Escola Politécnica da Universidade de São Paulo para obtenção do Título de Mestre em Engenharia Elétrica. 


\title{
Técnicas de Ajuste de Estabilizadores de Sistemas de Potência
}

\author{
Dissertação apresentada à Escola Politécnica \\ da Universidade de São Paulo para obtenção \\ do Título de Mestre em Engenharia Elétrica. \\ Área de concentração: \\ Sistemas de Potência \\ Orientador: \\ Prof. Dr. Clovis Goldemberg
}




\section{FICHA CATALOGRÁFICA}

\section{Mota, Daniel dos Santos}

Técnicas de ajuste de estabilizadores de sistemas de potência / D.S. Mota. - - São Paulo, 2010.

$119 \mathrm{p}$.

Dissertação (Mestrado) - Escola Politécnica da Universidade de São Paulo. Departamento de Engenharia de Energia e Automação Elétricas.

1. Controle (Teoria de sistemas e controle) 2. Máquinas síncronas 3. Sistemas elétricos de potência. I. Universidade de São Paulo. Escola Politécnica. Departamento de Engenharia de Energia e Automação Elétricas. II. t 
À minha família. 


\section{Agradecimentos}

À Escola Politécnica da Universidade de São Paulo e ao Departamento de Engenharia e Automação Elétricas.

Ao Professor Doutor Clovis Goldemberg pela orientação. Seu apoio, suas sugestões, suas críticas e seus elogios foram imprescindíveis para que este trabalho pudesse ser realizado. Sou muito grato por toda sua dedicação e persistência. Tenho saudade.

Aos Professores Doutores Walter Kaiser e Wilson Komatsu pelo incentivo e apoio para a finalização deste trabalho.

A todos aqueles que contribuiram direta ou indiretamente para a realização deste trabalho escrito durante dois anos entre diferentes acampamentos de usinas, vilas, cidades, estados e países. 


\section{Resumo}

Esta dissertação apresenta técnicas de ajuste de estabilizadores de sistemas de potência (power system stabilizers - PSS) com um enfoque nos desafios encontrados por um engenheiro durante o comissionamento do sistema de excitação estático de uma unidade geradora de médio porte. Os métodos de ajuste tratados neste trabalho são principalmente os aplicáveis aos estabilizadores do tipo PSS2B (IEEE, 2005). É dada prioridade às situações nas quais o engenheiro não dispõe de dados detalhados do modelo do gerador e do sistema de potência. Simulações computacionais nos domínios do tempo e da frequência são empregadas com objetivos didáticos ao longo do texto. A estrutura do PSS2B é detalhada, explicitando-se a função de cada parâmetro. São apresentados diferentes métodos de estabilizadores, dentre eles ressaltam-se: os métodos de comparação de grandezas no domínio do tempo e o método de compensação de fase. São mostrados resultados práticos obtidos durante comissionamentos em duas usinas hidrelétricas distintas. Comparam-se os diferentes métodos com o auxílio destes resultados práticos e de simulações computacionais. 


\section{Abstract}

This work presents techniques for tuning power system stabilizers (PSS) with focus on the challenges faced by an engineer during the commissioning of a static excitation system of a medium sized hydro generator. The tuning methods discussed in this study are primarily those applicable to the PSS2B stabilizers (IEEE, 2005). Priority is given to circumstances in which the engineer does not have a detailed model of the generator and power system. Computer simulations in the time and frequency domains are presented with didactic purposes throughout the text. The structure of PSS2B is detailed, the function of each parameter is explained. Among the different methods for tuning the PSS2B, two aproaches stand out: the methods based on the comparison of magnitudes in the time domain and the method of phase compensation. The practical results obtained during commissioning of two hydroelectric power plants are presented. The different PSS tuning methods are compared with the aid of these practical results and computer simulations. 


\section{Sumário}

\section{Lista de Figuras}

Lista de Tabelas

Lista de Abreviaturas

\section{Lista de Símbolos}

1 Considerações iniciais 1

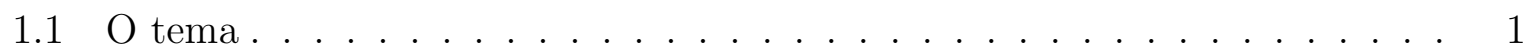

1.2 Motivações pessoais . . . . . . . . . . . . . . . . . . . . . 2

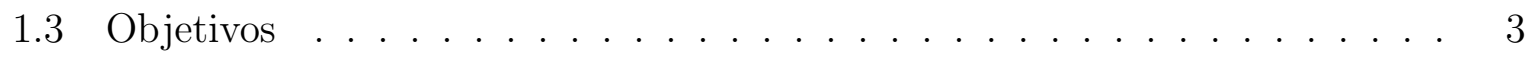

1.4 Organização do trabalho . . . . . . . . . . . . . . . . . 4

1.5 Observações gerais . . . . . . . . . . . . . . . 5

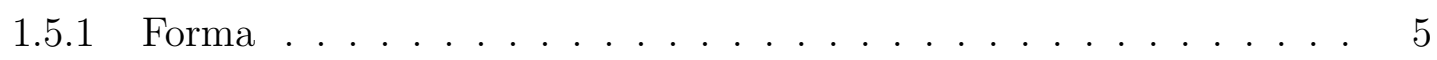

1.5.2 Ferramentas de simulação computacional . . . . . . . . . . . . 5

2 Estabilizadores de sistemas de potência $\quad 6$

2.1 Conceitos básicos . . . . . . . . . . . . . . . 6

2.1.1 Modos de oscilação de máquinas síncronas . . . . . . . . . . . . . 6

2.1.1.1 Oscilações locais entre máquina e sistema . . . . . . . . 7

2.1.1.2 Oscilações interáreas . . . . . . . . . . . . . . 7

2.1.1.3 Oscilações intraunidades . . . . . . . . . . . . . . 8

2.1.1.4 Oscilações torsionais . . . . . . . . . . . . . . . 8 
2.1.2 Modelo de uma máquina síncrona . . . . . . . . . . . . . . . . . . . 9

2.1.2.1 A influência do ponto operacional da máquina . . . . . . . 11

2.1.2.2 Simulações computacionais . . . . . . . . . . . . . 13

2.1.3 Torques amortecedor e sincronizante . . . . . . . . . . . . . 17

2.1.3.1 Dispositivos estabilizadores e o torque amortecedor . . . . 18

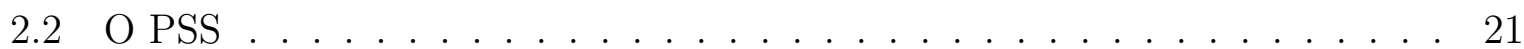

2.2.1 Histórico do PSS . . . . . . . . . . . . . . . . . . . . 22

2.2.1.1 A velocidade angular do rotor . . . . . . . . . . . 23

2.2.1.2 A frequência terminal . . . . . . . . . . . . . . 24

2.2.1.3 A potência ativa . . . . . . . . . . . 2 25

2.2.1.4 A integral da potência acelerante . . . . . . . . . . 25

2.2 .2 O PSS no Brasil . . . . . . . . . . . . . . . . . . 28

2.2.2.1 O tipo de PSS exigido no Brasil . . . . . . . . . . 29

2.2.2.2 O tipo de medição de frequência ou velocidade exigido para o PSS . . . . . . . . . . . . . . 29

3 Técnicas de ajuste de PSS

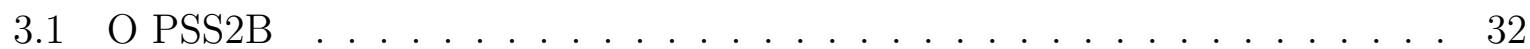

3.2 Ajuste do transdutor de integral da potência acelerante . . . . . . . . . . . 34

3.2.1 Filtros de washout . . . . . . . . . . . . . . . . . . . . . . . 34

3.2.2 Filtro passa-baixa para o sinal da frequência e ganho $K_{S 3} \ldots \ldots$. . 36

3.2.3 Integrador do sinal de potência ativa (filtro passa-baixa) . . . . . . 37

3.2.4 Filtro rastreador de rampa . . . . . . . . . . . . . . . . . . 39

3.3 Ajuste do estágio de ganho e avanço-atraso de fase . . . . . . . . . . . . 41

3.3.1 Tentativa e erro . . . . . . . . . . . . . . . . . 42

3.3.2 Comparação entre tensão e frequência para o amortecimento das oscilações interárea . . . . . . . . . . . . . . . . . . . . . . 43 
3.3.2.1 Os avanços de fase causados pelos filtros de washout e o modo interárea . . . . . . . . . . . . . . . . . 46

3.3.3 Comparação entre saída do PSS e potência ativa para amortecer oscilações locais . . . . . . . . . . . . . . . . . . . . . . 47

3.3.3.1 A influência do carregamento e do ajuste do AVR na aplicação do método de comparação entre saída do PSS e potência ativa . . . . . . . . . . . . . . . 49

3.3.4 Compensação de fase . . . . . . . . . . . . . . . . . . . . . . . . 51

3.3.4.1 Resposta em frequência entre a referência de tensão do AVR e o torque elétrico . . . . . . . . . . . . 52

3.3.4.2 Influência do ajuste do AVR nos ajustes propostos pelo método de compensação de fase . . . . . . . . . . . . . . 54

3.3.4.3 Aplicação do método de compensação de fase . . . . . . . 56

3.3.4.4 Influência do carregamento na aplicação do método de compensação de fase . . . . . . . . . . . . . . . . . 61

3.3.4.5 Influência das constantes de washout na aplicação do método de compensação de fase . . . . . . . . . . . . . 63

3.3.5 O ganho proporcional $K_{S 1} \ldots \ldots \ldots \ldots$

3.3.6 Os limites de saída do PSS . . . . . . . . . . . . . . . 66

3.4 Considerações sobre o ajuste de $K_{S 1}, T_{1}, T_{2}, T_{3}, T_{4}, T_{10}$ e $T_{11} \ldots \ldots$. . . 67

3.4.1 As relações $T_{1} / T_{2}, T_{3} / T_{4}$ e $T_{10} / T_{11} \ldots \ldots \ldots$. . . . . . . 67

3.4.2 Deslocamento dos autovalores do sistema em função do ajuste do PSS 68

3.4.2.1 Influência do ganho $K_{S 1} \ldots \ldots \ldots$. . . . . . . . . 69

3.4.2.2 Influência da supercompensação ou da subcompensação de fase ....................... . . . 72

$\begin{array}{lll}4 & \text { Resultados práticos e análises } & 77\end{array}$

4.1 Sistema de excitação testado . . . . . . . . . . . . . . . . . . . . 77

4.2 Descrição das usinas hidrelétricas . . . . . . . . . . . . . . . . . . . . 79 
4.2 .1 Usina hidrelétrica Minas . . . . . . . . . . . . . . . . . . . . . 79

4.2 .2 Usina hidrelétrica Espanha . . . . . . . . . . . . . . . 79

4.3 Ajuste da malha do AVR . . . . . . . . . . . . . 80

4.3.1 Ajuste da malha do AVR da UHE Minas . . . . . . . . . . . . . 80

4.3.2 Ajuste da malha do AVR da UHE Espanha . . . . . . . . . . . . . 81

4.4 Ajuste do transdutor de integral da potência acelerante . . . . . . . . . . 82

4.5 Ajuste do estágio de ganho e avanço-atraso de fase do PSS da UHE Minas 83

4.5.1 Método de ajuste de PSS baseado na tentativa e erro aplicado na UHE Minas . . . . . . . . . . . . . . . . . . . . . 83

4.5.2 Comparação entre o ajuste realizado e o ajuste proposto pelo método de compensação de fase . . . . . . . . . . . . . . . . 85

4.5.3 Resposta em frequência do sistema com PSS . . . . . . . . . . . . . 90

4.6 Ajuste do estágio de ganho e avanço-atraso de fase do PSS da UHE Espanha 92

4.6.1 Método de comparação de grandezas aplicado no ajuste do PSS da UHE Espanha . . . . . . . . . . . . . . . . . . . . 93

4.6.2 Método de comparação de grandezas e o método de compensação de fase . . . . . . . . . . . . . . . . . . . . . . 97

4.6.3 Resposta em frequência do sistema com PSS . . . . . . . . . . . . . 99

4.7 Análise do emprego dos diferentes métodos de ajuste de PSS . . . . . . . 100

5 Conclusões

A.1 Limitadores e compensadores . . . . . . . . . . . . . . . . 104

A.1.1 Compensadores de reativos . . . . . . . . . . . . 105

A.1.2 Limitador de subexcitação . . . . . . . . . . . . . . . . 105

A.1.3 Limitador de sobreexcitação . . . . . . . . . . . . . . . . . 105

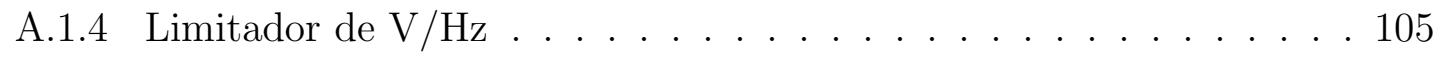


Apêndice B - Sistemas de excitação adequados para o emprego de PSS 106 Apêndice C - Ajuste da malha do AVR 108

Apêndice D - A interação entre PSS e limitador UEL

Referências 116 


\section{Lista de Figuras}

2.1 Áreas de controle de trasmissão brasileiras; reimpresso de ONS (2009). . . 8

2.2 Modelo de Heffron e Phillips (1952); reimpresso do artigo original. . . . . . 9

2.3 Modelo linearizado do gerador conectado a um barramento infinito via impedância externa; reimpresso de DeMello e Concordia (1969). . . . . . . 11

2.4 Simulação da resposta ao degrau de tensão com diferentes carregamentos. . 16

2.5 Modelo com $\Delta E_{q}^{\prime}$ constante e constante de amortecimento $D$; reimpresso de DeMello e Concordia (1969) . . . . . . . . . . . . . . . 18

2.6 Modelo empregado para a análise da influência da constante de amortecimento $D$; adaptado de DeMello e Concordia (1969) . . . . . . . . . . . . . 20

2.7 Simulação da resposta ao degrau de tensão com diferentes constantes de amortecimento D. . . . . . . . . . . . . . . . . . . . . . . . . . . . . . . 21

2.8 PSS baseado na velocidade do rotor; adaptado de Bérubé, Hajagos e Beaulieu (1999). . . . . . . . . . . . . . . . . . . . 23

2.9 Velocidade do rotor estimada a partir da frequência da tensão terminal e a partir da frequência da tensão interna; reimpresso de Schleif et al. (1969). . 24

2.10 Velocidade do rotor e torques mecânico, elétrico e acelerante. . . . . . . . . 26

2.11 Síntese da potência acelerante; adaptado de Murdoch et al. (1999a). . . . . 27

2.12 Síntese da integral da potência acelerante ou da velocidade angular do rotor; adaptado de Murdoch et al. (1999a). . . . . . . . . . . . . . 28

2.13 Influência do carregamento nos parâmetros $K$ do modelo da máquina síncrona; reimpresso de El-Sherbiny e Mehta (1973). . . . . . . . . . . . . . . 30

3.1 Modelo computacional do PSS2B; reimpresso de IEEE (2005). . . . . . . . 32

3.2 Blocos de washout do PSS2B. . . . . . . . . . . . . . . . . 34

3.3 Respostas em frequência do filtro de washout. . . . . . . . . . . . . 35 
3.4 Variações na saída do PSS em função das constantes de tempo dos filtros de washout; reimpresso de Murdoch et al. (1999b). . . . . . . . . . . . . . 36

3.5 Filtro passa-baixa para o sinal da frequência e ganho $K_{S 3}$ do PSS2B. . . . 37

3.6 Integrador do sinal de potência ativa. . . . . . . . . . . . . . . . 37

3.7 Comparação entre um integrador e um filtro passa-baixa. . . . . . . . . . . 38

3.8 Filtro rastreador de rampa. . . . . . . . . . . . . . . . . . . . . . . . . . 39

3.9 Respostas em frequência do filtro rastreador de rampa. . . . . . . . . . . . . 39

3.10 Blocos de ganho, avanço-atraso de fase e limites de saída do PSS2B. . . . . 41

3.11 Controle de tensão e amortecimento; adaptado e reimpresso de Schleif et al. (1968)

3.12 Respostas em frequência entre a entrada de frequência/velocidade e a integral da potência acelerante com diferentes constantes de washout. . . . . 46

3.13 Fase das respostas em frequência entre tensão de campo e torque elétrico. . 48

3.14 Fase das respostas em frequência entre tensão de campo e torque elétrico em função do carregamento. . . . . . . . . . . . . . . . . . . . . . . . . . 50

3.15 Fase das respostas em frequência $\Delta E_{f d} / \Delta e_{t r e f}$ em função do ajuste da constante $T_{i}$ do regulador PI do AVR . . . . . . . . . . . . . . . . 51

3.16 Respostas em frequência $\Delta e_{t} / \Delta e_{\text {tref }}$ e $\Delta T_{e K 2} / \Delta e_{t r e f}$, AVR ajustado com

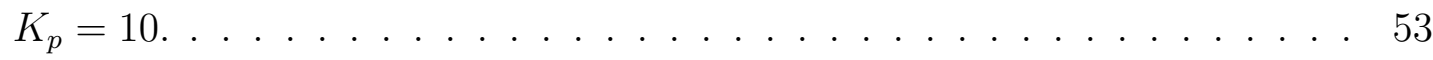

3.17 Respostas a um sinal senoidal de frequência variável. . . . . . . . . . . . . 54

3.18 Respostas em frequência $\Delta e_{t} / \Delta e_{\text {tref }}$ e $\Delta T_{e K 2} / \Delta e_{t r e f}$, AVR ajustado com

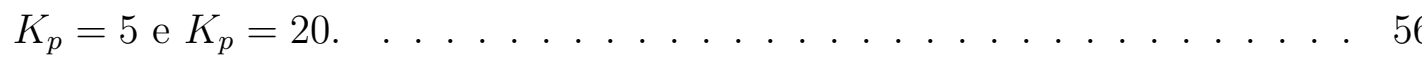

3.19 Modelo empregado para aplicação do método de compensação de fase; adaptado de DeMello e Concordia (1969) e de IEEE (2005). . . . . . . . . 58

3.20 Fase das respostas em frequência $\Delta e_{t} / \Delta e_{\text {tref }}$ e $G_{l e a d-l a g}$ e soma das características de fase. . . . . . . . . . . . . . . . . . . . . 59

3.21 Resposta ao degrau de 0,01p.u. na referência de tensão do AVR com e sem PSS. . . . . . . . . . . . . . . . . . . 60

3.22 Respostas em frequência $\Delta e_{t} / \Delta e_{\text {tref }}$ com e sem PSS. . . . . . . . . . . . 60 
3.23 Respostas em frequência $\Delta e_{t} / \Delta e_{\text {tref }}$ sem PSS considerando diferentes carregamentos.

3.24 Resposta ao degrau de 0,01p.u. na referência de tensão do AVR com e sem PSS considerando diferentes carregamentos.

3.25 Fase das respostas em frequência dos blocos de avanço-atraso, do filtro de washout e soma das características de fase; adaptado de Martins et al. (1999). 65

3.26 Respostas em frequência de um bloco de avanço de fase. . . . . . . . . . 67

3.27 Comportamento do ângulo de carga após aplicação de degrau de 0,01p.u. na referência de tensão do AVR, ganho $K_{S 1}$ do PSS variando de 5 a 40. . . 71

3.28 Localização no plano complexo dos autovalores do sistema em função do ganho $K_{S 1}$ do PSS.

3.29 Fase das respostas em frequência $\Delta e_{t} / \Delta e_{\text {tref }}, G_{\text {lead-lag }}$ e soma das características de fase empregadas no estudo da influência da sub e supercompensação de fase.

3.30 Localização no plano complexo dos autovalores do sistema em função do ganho $K_{S 1}$ do PSS considerando diferentes ajustes dos blocos de avançoatraso. . . . . . . . . . . . . . . . . . . . 75

4.1 Modelo computacional do regulador de tensão testado no capítulo 4. . . . 77

4.2 UHE Minas, respostas ao degrau de tensão com carga de 5MW. . . . . . . 80

4.3 UHE Minas, resposta ao degrau de 0,04p.u. na referência de tensão do AVR. 84

4.4 UHE Minas, levantamento de resposta em frequência $\Delta e_{t} / \Delta e_{\text {tref }}$ sem PSS 86

4.5 UHE Minas, resposta em frequência $\Delta e_{t} / \Delta e_{\text {tref }}$ sem PSS com potência de $61 \mathrm{MW}$

4.6 UHE Minas, resposta em frequência $\Delta e_{t} / \Delta e_{t r e f}$ sem PSS com potência de $82 \mathrm{MW}$

4.7 UHE Minas, comparação entre os blocos de avanço ajustados e a sugestão do método de compensação de fase.

4.8 UHE Minas, levantamento da resposta em frequência $\Delta e_{t} / \Delta e_{\text {tref }}$ com PSS. 90

4.9 UHE Minas, resposta em frequência da tensão estatórica para o ajuste final do AVR e PSS com potência de 82MW. . . . . . . . . . . . . . . . . . . . 91 
4.10 UHE Espanha, UG3, comparação da potência ativa e da saída do PSS após a aplicação de um degrau na referência do AVR. . . . . . . . . . . . . . . . 94

4.11 UHE Espanha, UG3, resposta ao degrau de 0,01p.u. na referência de tensão do AVR. . . . . . . . . . . . . . . . . . . . 95

4.12 UHE Espanha, UG3 e UG4, oscilações na potência ativa durante a aplicação de um degrau de 0,01p.u. na referência de tensão do AVR. . . . . . . . . . 96

4.13 UHE Espanha, UG4, resposta em frequência $\Delta e_{t} / \Delta e_{\text {tref }}$ sem PSS com potência de 86MW. . . . . . . . . . . . . . . . . . . . . . . . 98

4.14 UHE Espanha, UG4, comparação entre os blocos de avanço ajustados e a sugestão do método de compensação de fase. . . . . . . . . . . . . . . . . . . 98

4.15 UHE Espanha, resposta em frequência da tensão estatórica para o ajuste final do AVR e PSS com potência de 82MW. . . . . . . . . . . . . . . . . . 99

B.1 Máxima defasagem na resposta em frequência $\Delta e_{t} / \Delta e_{t r e f}$ para que o AVR seja adequado para o emprego de PSS (WSCC, 1992). . . . . . . . . . . . 107

C.1 Resposta do AVR ao degrau e resposta em frequência com o AVR em malha fechada; reimpresso de IEEE (1990). . . . . . . . . . . . . . . . . . . . . . 108

C.2 Modelo simplificado de uma máquina conectada a um barramento infinito com ângulo de carga constante; adaptado de DeMello e Concordia (1969). . 109

D.1 UHE Minas, ação do limitador UEL do tipo tomador de controle com e sem PSS. . . . . . . . . . . . . . . . . . . . . . . . . . 114

D.2 UHE Minas, ação do PSS com e sem o limitador UEL do tipo tomador de controle . . . . . . . . . . . . . . . . . . . 114

D.3 UHE Espanha, UG3, ação do limitador UEL do tipo somador com e sem PSS.

D.4 UHE Espanha, UG3, ação do limitador UEL do tipo tomador de controle com e sem PSS. 


\section{Lista de Tabelas}

2.1 Dados empregados no estudo da influência do carregamento nos parâmetros do modelo de Heffron e Phillips (1952) . . . . . . . . . . . . . . . . . . . . . 13

2.2 Dados do modelo do sistema de excitação empregados no estudo da influência do carregamento nos parâmetros do modelo de Heffron e Phillips (1952).

2.3 Dados do modelo simulado no estudo da influência do carregamento nos parâmetros do modelo de Heffron e Phillips (1952) . . . . . . . . . . . . . . 15

2.4 Autovalores do modelo de um gerador conectado a um barramento infinito em função da potência ativa. . . . . . . . . . . . . . . . . . . . . . . . . . . 16

2.5 Autovalores em função da constante $D$ de amortecimento do modelo de um gerador com carga de $0,8 p . u$. de potência ativa conectado a um barramento

3.1 Ajustes do filtro rastreador de rampa. . . . . . . . . . . . . . . . . . . . 41

3.2 Amortecimento de oscilações com controle de tensão ideal. . . . . . . . . . . 44

3.3 Amortecimento de oscilações com controle de tensão e sistema estabilizador ideais.

3.4 Ajuste dos blocos de avanço-atraso empregado para o estudo da influência do parâmetro $K_{S 1}$.

3.5 Autovalores do modelo de um gerador conectado a um barramento infinito sem PSS.

3.6 Autovalores do modelo de um gerador conectado a um barramento infinito com PSS em função do ganho $K_{S 1}$.

3.7 Ajustes empregados para os blocos de avanço-atraso no estudo da influência da supercompensação ou da subcompensação de fase.

4.1 Parâmetros usados para os testes apresentados na fig. 4.2. 
4.2 Parâmetros da malha do AVR da UHE Minas. . . . . . . . . . . . . . . . . 81

4.3 Parâmetros da malha do AVR das unidades 3 e 4 da UHE Espanha. . . . . 81

4.4 Ajustes do transdutor de integral de potência acelerante da UHE Minas e da UHE Espanha. . . . . . . . . . . . . . . . . . . . . . . . . . . . 82

4.5 Ajustes dos blocos de ganho e avanço-atraso da UHE Minas. . . . . . . . . . 83

4.6 Ajustes dos blocos de ganho e avanço-atraso da UHE Espanha. . . . . . . . 93 


\section{Lista de Abreviaturas}

AVR

ONS

PI

PSS

UG

UHE
Regulador automático de tensão (Automatic Voltage Regulator).

Operador Nacional do Sistema Elétrico.

Regulador do tipo proporcional-integral.

Estabilizador de sistemas de potência (Power System Stabilizer).

Unidade geradora.

Usina hidrelétrica. 


\section{Lista de Símbolos}

$\Delta$

$\delta$

D

$e_{t}$

$e_{\text {tref }}$

$E_{f d}$

$E_{q}^{\prime}$

f

$\psi_{f d}$

$G_{\text {avr }}$

$G_{a v r P}$

$G_{\text {avrPI }}$

$H$

$K_{A}$
Prefixo indicando variações de uma grandeza em torno do regime permanente.

Ângulo de carga.

Constante usada para modelar o efeito de enrolamentos amortecedores ou o efeito de PSSs ideais.

Tensão estatórica.

Referência de tensão estatórica para o regulador de tensão.

Tensão de campo.

Tensão interna do gerador no eixo de quadratura.

Frequência elétrica.

Fluxo magnético no eixo direto.

Função de transferência com o AVR em malha fechada entre a referência de tensão $\left(\Delta e_{\text {tref }}\right)$ e a tensão terminal do gerador $\left(\Delta e_{t}\right)$.

Função de transferência em malha aberta de um AVR com regulador do tipo proporcional.

Função de transferência em malha aberta de um AVR com regulador do tipo PI.

Constante de inércia da máquina síncrona.

Ganho proporcional de um AVR com um regulador do tipo proporcional.

$K_{1}, K_{2}, K_{3}, K_{4}$, Parâmetros do modelo de Heffron e Phillips (1952).

$K_{5}, K_{6}$

$K_{S 1}, K_{S 2}, K_{S 3}$

$K_{p}$

Parâmetros do PSS2B.

Ganho proporcional de um AVR com um regulador do tipo PI.

$M$

Dobro da constante de inércia da máquina síncrona.

$p$

Operador $d / d t$.

$P$

Potência ativa.

$P_{e}$

Potência elétrica (ativa).

$P_{m}$

Potência mecânica. 


\begin{tabular}{|c|c|}
\hline$P_{a c c}$ & Saldo entre potência elétrica e potência mecânica. \\
\hline$Q$ & Potência reativa. \\
\hline$s$ & Variável de Laplace. \\
\hline$s$ & $\begin{array}{l}\text { Unidade de tempo, segundos, diferenciam-se segundos da va- } \\
\text { riável de Laplace pelo contexto; o ajuste de constantes de } \\
\text { tempo é sempre em segundos. }\end{array}$ \\
\hline$T_{A}$ & $\begin{array}{l}\text { Aproximação de primeira ordem de todas as pequenas constan- } \\
\text { tes de tempo de um AVR com regulador do tipo proporcional. }\end{array}$ \\
\hline$T_{b}$ & $\begin{array}{l}\text { Aproximação de primeira ordem de todas as pequenas cons- } \\
\text { tantes de tempo de um AVR com regulador do tipo PI. }\end{array}$ \\
\hline$T_{i}$ & $\begin{array}{l}\text { Constante de tempo de integração de um AVR com regulador } \\
\text { do tipo PI. }\end{array}$ \\
\hline$T_{d 0}^{\prime}$ & $\begin{array}{l}\text { Constante de tempo do enrolamento de campo com a máquina } \\
\text { síncrona em vazio. }\end{array}$ \\
\hline$T_{d z}^{\prime}$ & $\begin{array}{l}\text { Constante de tempo efetiva do enrolamento de campo com a } \\
\text { máquina em carga, } T_{d z}^{\prime}=K_{3} T_{d 0}^{\prime} .\end{array}$ \\
\hline$T_{a c c}$ & Saldo entre torque elétrico e torque mecânico. \\
\hline$T_{D}$ & Torque amortecedor. \\
\hline$T_{e}$ & Torque elétrico. \\
\hline$T_{e K 2}$ & $\begin{array}{l}\text { Torque elétrico após o ganho } K_{2} \text { no modelo de Heffron e Phillips } \\
(1952) \text {. }\end{array}$ \\
\hline$T_{m}$ & Torque mecânico. \\
\hline$T_{S}$ & Torque sincronizante. \\
\hline $\begin{array}{l}T_{W 1}, T_{W 2}, T_{W 3}, \\
T_{W 4}, T_{1}, T_{2}, T_{3}, \\
T_{4}, T_{6}, T_{7}, T_{8}, T_{9}, \\
T_{10}, T_{11}\end{array}$ & Parâmetros do PSS2B. \\
\hline$V_{S T M A X}, V_{S T M I N}$ & Parâmetros do PSS2B. \\
\hline$X_{d}, X_{d}^{\prime}, X_{q}$ & Reatâncias da máquina síncrona. \\
\hline$X_{e}$ & $\begin{array}{l}\text { Reatância externa entre os terminais da máquina síncrona e } \\
\text { um barramento infinito. }\end{array}$ \\
\hline 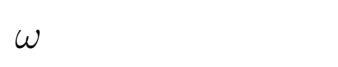 & Frequência angular. \\
\hline & Frequência angular do rotor. \\
\hline
\end{tabular}




\section{Considerações iniciais}

\subsection{O tema}

Uma das formas mais econômicas para se aumentar a estabilidade dinâmica de sistemas elétricos é escolher e aplicar apropriadamente sistemas de excitação e estabilizadores de sistemas de potência. Apesar da simplicidade e dos 50 anos de história, o estabilizador de sistemas de potência ou Power System Stabilizer (PSS) provavelmente é uma das ferramentas de controle de geradores mais mal entendidas e mal utilizadas (BÉRUBÉ; HAJAGOS; BEAULIEU, 1999; KUNDUR et al., 2003; HAJAGOS, 2003).

Em meados da década de 1960, estudos demonstraram (SCHLEIF et al., 1968) que sinais derivados do fluxo de potência ou diferença de frequência poderiam ser utilizados em reguladores de velocidade de certas máquinas para amortecer as oscilações de potência em uma linha de transmissão de $230 k \mathrm{~V}$. Estes mesmos estudos mostraram que quanto mais linhas de transmissão fossem construídas e conectadas ao sistema, maior seria a faixa de frequência das oscilações, podendo até mesmo exceder a banda passante dos reguladores de velocidade. As limitações mecânicas que dificultam o aumento da banda passante dos reguladores de velocidade levaram, naturalmente, à procura de outros meios para o amortecimento de oscilações no sistema de potência.

Durante o verão de 1967 (SCHLEIF et al., 1969), tornou-se difícil controlar ou suprimir oscilações no sistema elétrico de potência da parte oeste dos Estados Unidos da América. Testes demonstraram que se certos reguladores de tensão de ação contínua (sem banda morta) fossem colocados em modo de controle de corrente de campo, as oscilações desapareciam. Estava claro que sistemas de excitação de ação contínua podiam contribuir para desestabilizar o sistema de potência. Na época, o recente desenvolvimento de computadores analógicos permitiu a simulação de severas falhas e suas consequências (SCHLEIF et al., 1968). Verificava-se a perda de sincronismo em algumas máquinas segundos após a ocorrência do defeito. Os modernos sistemas de excitação de alta resposta inicial ${ }^{1}$ ajuda- $^{-}$

\footnotetext{
${ }^{1}$ IEEE (1986) define sistemas de excitação com alta resposta inicial (high initial response) como siste-
} 
vam a limitar o primeiro pico da oscilação, mas sem medidas adequadas para melhorar o amortecimento, a estabilidade era perdida nos picos subsequentes.

Na década de 1990, um episódio mostrou que a ausência do PSS pode ter consequências graves. Um aumento contínuo de oscilações eletromecânicas, em grande parte devido a reguladores de tensão com altos ganhos e grandes atrasos de fase, foi uma das causas do grande blecaute de agosto de 1996 (TAYLOR, 1999) no oeste dos Estados Unidos da América. Neste dia, 30GW de carga foram desconectados. Antes deste blecaute, os PSSs de uma grande usina nuclear haviam sido desligados e outros estabilizadores estavam inoperantes por causa de transdutores de frequência ruidosos.

Com o atual domínio de reguladores de tensão digitais, a grande maioria dos sistemas de excitação presentes no mercado possuem o PSS incorporado. É comum que os engenheiros que ajustam a malha do regulador automático de tensão (Automatic Voltage Regulator - AVR) também tenham que ajustar o PSS.

\subsection{Motivações pessoais}

No ramo de equipamentos para usinas hidrelétricas é comum que um empreendimento seja realizado por um consórcio de empresas. Apesar de unidas por razões comerciais em uma determinada usina, em geral, tais empresas são concorrentes. Equipamentos são projetados e fabricados em diferentes países. Nem sempre a informação flui como deveria entre departamentos de uma mesma empresa, entre filiais localizadas em países diferentes ou entre parceiros consorciais.

É comum, principalmente em modernização de máquinas antigas, que o comissionador não tenha disponível dados detalhados do gerador e do sistema elétrico. Apesar da falta de informações, o comissionamento deve proseguir. Após o ajuste da malha de controle de tensão, passa-se ao PSS. Surgem questões importantes nesta hora:

- De onde vieram os valores típicos empregados por comissionadores experientes?

- Qual o significado físico por trás de cada parâmetro do PSS?

- Qual a relevância de cada parâmetro?

- Como ajustar o PSS?

mas capazes de atingir $95 \%$ da diferença entre a máxima tensão fornecida ao enrolamento de campo e a tensão de campo nominal em menos do que $0,1 s$ sob condições específicas. 
Tempo para reflexões na obra é escasso. Foi necessário o mestrado para permitir a reflexão. Esta dissertação foi escrita por um engenheiro projetista e comissionador de reguladores de tensão de geradores hidrelétricos de médio porte.

\subsection{Objetivos}

A literatura sobre estabilizadores de sistema de potência é extensa. Diversas abordagens para o ajuste do PSS foram propostas desde o final da década de 1960, tais como:

- Schleif et al. (1968): critérios de variação da tensão terminal em função da variação da frequência;

- DeMello e Concordia (1969): compensação de defasagens entre o sinal de velocidade do rotor e o torque elétrico;

- Larsen e Swann (1981b): conceitos e métodos de ajustes de PSSs com entrada de velocidade do rotor, frequência ou potência ativa;

- Senger (1983): programação computacional baseada em uma abordagem por variáveis de estado;

- Zanetta (1984): métodos computacionais de resposta em frequência e sensibilidade a parâmetros;

- Murdoch et al. (1999a): método de compensação de defasagens aplicado em PSSs de múltiplas entradas;

- Gu, Smulders e Mushens (2000): critérios de variação do sinal de saída do PSS em função das variações de potência ativa.

Esta dissertação tem como propósito descrever técnicas de ajuste de PSSs empregados em geradores hidrelétricos de médio porte ${ }^{2}$. Com objetivo didático, são utilizadas simulações computacionais do modelo linearizado de um gerador conectado a um barramento infinito via uma impedância externa. Resultados práticos obtidos durante comissionamentos em duas usinas hidrelétricas contribuem para a comparação entre os diferentes métodos de ajuste de PSSs apresentados.

\footnotetext{
${ }^{2}$ As máquinas de médio porte analisadas nesta dissertação têm potências aparentes maiores do que 30MVA.
} 
Diversas referências apresentam técnicas de ajuste coordenado de PSSs visando o amortecimento de oscilações entre grandes áreas da Argentina, do Brasil, da América do Norte, etc. Tais estudos requerem um conhecimento profundo do sistema de potência e de seus modelos computacionais. Neste trabalho, é dada ênfase aos desafios enfrentados por um engenheiro durante o comissionamento de um único sistema de excitação equipado com PSS. Foi dada preferência a métodos que não dependam da simulação computacional da máquina e do sistema. Não são abordadas técnicas de ajuste coordenado de PSSs em diferentes máquinas ou usinas.

Nas Práticas Recomendadas para a Modelagem de Sistemas de Excitação de IEEE (2005) são definidos 4 tipos de PSS. Foi dado enfoque nesta dissertação aos métodos de ajuste que podem ser empregados para o tipo PSS2B. Foram priorizados métodos que são aplicáveis em máquinas síncronas com sistemas de excitação estáticos. Atualmente no Brasil, ONS (2008) exige que geradores de médio porte sejam equipados com sistemas de excitação estáticos e estabilizadores do tipo PSS2B.

\subsection{Organização do trabalho}

Este trabalho é divido em capítulos conforme a lista a seguir.

- 1 Considerações iniciais: apresenta o tema, as motivações do autor e os objetivos deste trabalho.

- 2 Estabilizadores de sistemas de potência: discute conceitos básicos para se compreender o funcionamento e os métodos de ajuste de PSSs.

- 3 Técnicas de ajuste de PSS: apresenta e analisa as técnicas de ajuste de PSSs.

- 4 Resultados práticos e análises: mostra resultados práticos obtidos durante comissionamentos realizados em duas usinas hidrelétricas distintas e discute a aplicação dos diferentes métodos de ajuste de PSS.

- 5 Conclusões: apresenta as conclusões desta dissertação. 


\subsection{Observações gerais}

\subsubsection{Forma}

Algumas variáveis e expressões foram escritas em inglês preservando-se a nomenclatura utilizada nas normas técnicas internacionais e nas referências bibliográficas. Em algumas das figuras apresentadas pode haver termos em língua inglesa.

\subsubsection{Ferramentas de simulação computacional}

Este dissertação apresenta resultados de simulações computacionais. A obtenção de respostas em frequência de modelos de máquinas síncronas conectadas a um barramento infinito por uma impedância externa, cálculos de autovalores e simulações no domínio do tempo foram realizadas com o auxílio da ferramenta de simulação computacional SimApp v1.3 da empresa suíça Buesser Engineering. 


\section{Estabilizadores de sistemas de potência}

\subsection{Conceitos básicos}

O PSS é um dispositivo que atua na malha de controle do AVR com o intuito de amortecer oscilações de baixa frequência em máquinas síncronas e no sistema de potência. Antes de se discutir o estabilizador de sistemas de potência, alguns conceitos básicos devem ser apresentados:

- Modos de oscilação de máquinas síncronas;

- Modelos de máquinas síncronas conectadas ao sistema de potência;

- Torques amortecedor e sincronizante.

Tais conceitos são necessários para se compreender os princípios de funcionamento do PSS e as diferentes alternativas adotadas desde o surgimento destes estabilizadores no final da década de 1960 .

\subsubsection{Modos de oscilação de máquinas síncronas}

As oscilações em máquinas síncronas e no sistema de potência que podem ser influenciadas pelo PSS são classificadas na literatura técnica em "modos". IEEE (1990) define tais modos como:

- Modo de oscilações locais entre máquina e sistema;

- Modo de oscilações interárea;

- Modo de oscilações intraunidades; 
- Modo de oscilações torsionais.

Os modos distinguem-se pela frequência de oscilação. A seguir é feita uma descrição geral de tais modos conforme definições de IEEE (1990).

\subsubsection{Oscilações locais entre máquina e sistema}

O modo local é caracterizado por oscilações eletromecânicas de uma ou algumas máquinas em conjunto conectadas a um sistema comparativamente muito grande. $\mathrm{O}$ ângulo de carga do gerador (ou dos geradores da usina) oscila enquanto a potência na linha que conecta a máquina ao sistema varia. Modelos de máquinas síncronas conectadas a um barramento infinito através de uma impedância externa são boas ferramentas para a compreensão dos fenômenos relacionados às oscilações locais.

O modo local torna-se problemático principalmente em máquinas com carga próxima à nominal conectadas ao sistema por longas linhas de trasmissão. Tal configuração é comum em sistemas de potência caracterizados por usinas distantes umas das outras e distantes dos centros de carga. Sistemas de excitação de alta resposta inicial podem tornar o modo local instável. Estes mesmos sistemas quando equipados com PSS são eficientes para amortecer as oscilações locais. Convém lembrar que ONS (2008) exige o emprego de sistemas de excitação estáticos no Brasil, tais sistemas apresentam alta resposta inicial.

A faixa de frequência das oscilações locais está entre $0,7 \mathrm{~Hz}$ até $2 \mathrm{~Hz}$ (IEEE, 1990).

\subsubsection{Oscilações interáreas}

O modo interárea ocorre quando muitas máquinas em uma região do sistema elétrico oscilam em conjunto com muitas máquinas em uma outra região. A potência transferida pelas linhas que conectam ambas as áreas varia enquanto o ângulo de carga das muitas máquinas oscila. A fig. 2.1 mostra uma parte do sistema de potência brasileiro. Oscilações interáreas seriam percebidas, por exemplo, como variações indesejadas no fluxo de potência nas linhas de $500 \mathrm{kV}$ da interligação Norte/Sudeste.

A faixa de frequência das oscilações interáreas está abaixo de 0,5Hz (IEEE, 1990). Por serem de baixa frequência, PSSs empregados tanto em sistemas de excitação rápidos (sistemas estáticos) como lentos (excitatrizes rotativas) podem contribuir para amortecer as oscilações interáreas. 


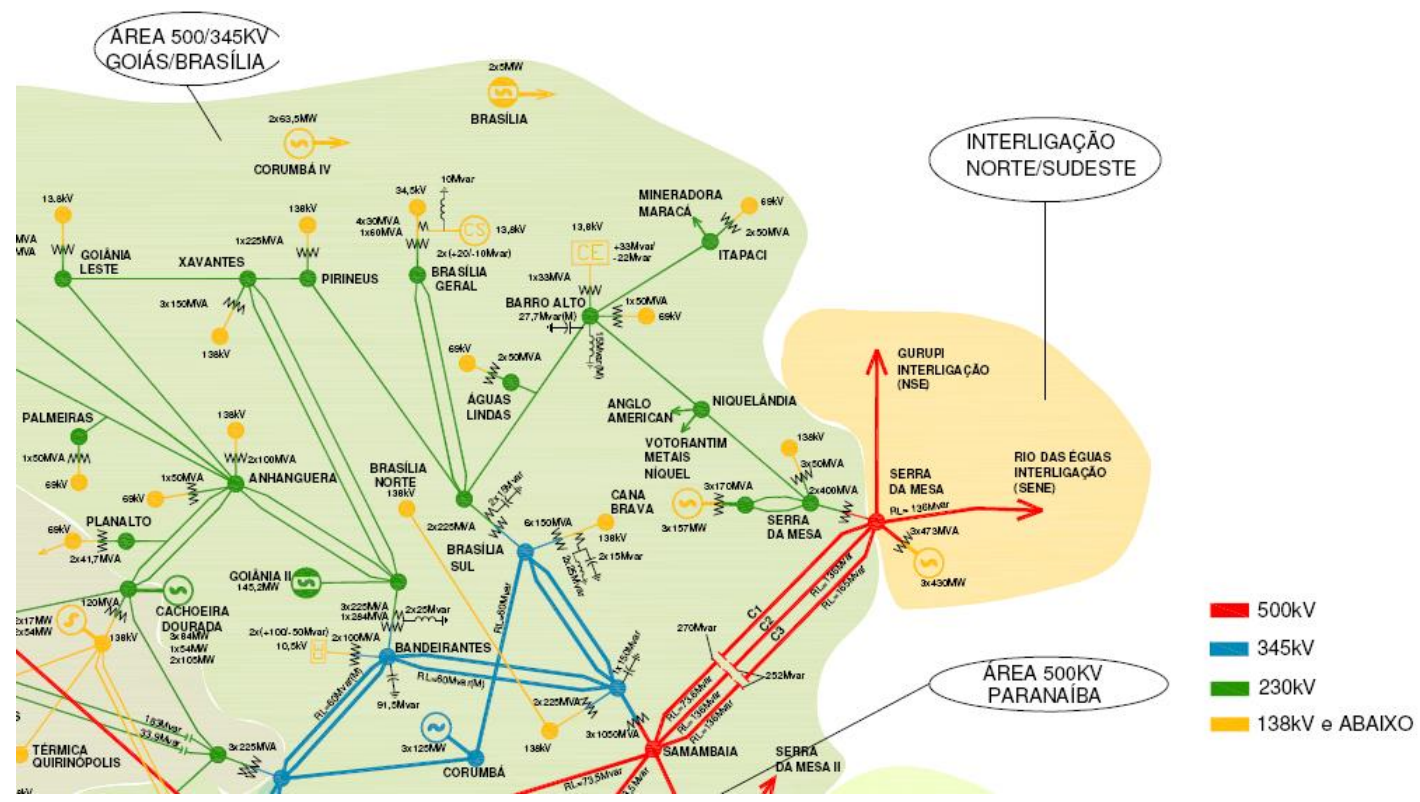

Figura 2.1: Áreas de controle de trasmissão brasileiras; reimpresso de ONS (2009).

O modo interárea é caracterizado por oscilações entre grandes regiões do sistema de potência. Cada uma das regiões é composta por muitos geradores. O amortecimento deste modo requer a aplicação coordenada de PSSs em diversas máquinas (IEEE, 1990), em especial, nos geradores de grande porte.

\subsubsection{Oscilações intraunidades}

As oscilações intraunidades ocorrem entre máquinas dentro de uma mesma usina ou em usinas próximas. O ângulo de carga dos geradores varia enquanto a potência ativa fornecida por cada gerador varia. Tais oscilações se restringem à usina ou às usinas próximas.

A faixa de frequência deste modo está geralmente entre 1, $5 \mathrm{~Hz}$ e $3 \mathrm{~Hz}$ (IEEE, 1990). O modo intraunidade pode ser desestabilizado por PSSs mal projetados ou mal ajustados.

\subsubsection{Oscilações torsionais}

As oscilações torsionais ocorrem entre os diversos elementos girantes de uma unidade geradora, tais como: rotor do gerador, rotor da excitatriz rotativa, eixos, turbinas de baixa pressão e de alta pressão. As oscilações torsionais são especialmente problemáticas em turbogeradores, tendo um amortecimento natural muito baixo.

Em geral, a frequência das oscilações torsionais situa-se acima dos 4Hz (IEEE, 1990). Tal modo pode ser desestabilizado por AVRs de larga banda passante. PSSs devem ser 
cuidadosamente projetados para não interferir nas oscilações torsionais.

\subsubsection{Modelo de uma máquina síncrona conectada a uma bar- ramento infinito por uma impedância externa}

A estabilidade dinâmica de máquinas síncronas é um problema que envolve o comportamento do ângulo de carga $(\delta)$ e da velocidade do rotor frente a pequenas perturbações no sistema. O sistema de excitação pode ser utilizado para amortecer oscilações em $\delta$.

Como ponto de partida para o estudo da influência do AVR na estabilidade do gerador, toma-se o famoso modelo de Heffron e Phillips (1952), fig. 2.2. Os primeiros PSSs surgiram a partir da análise detalhada deste modelo.

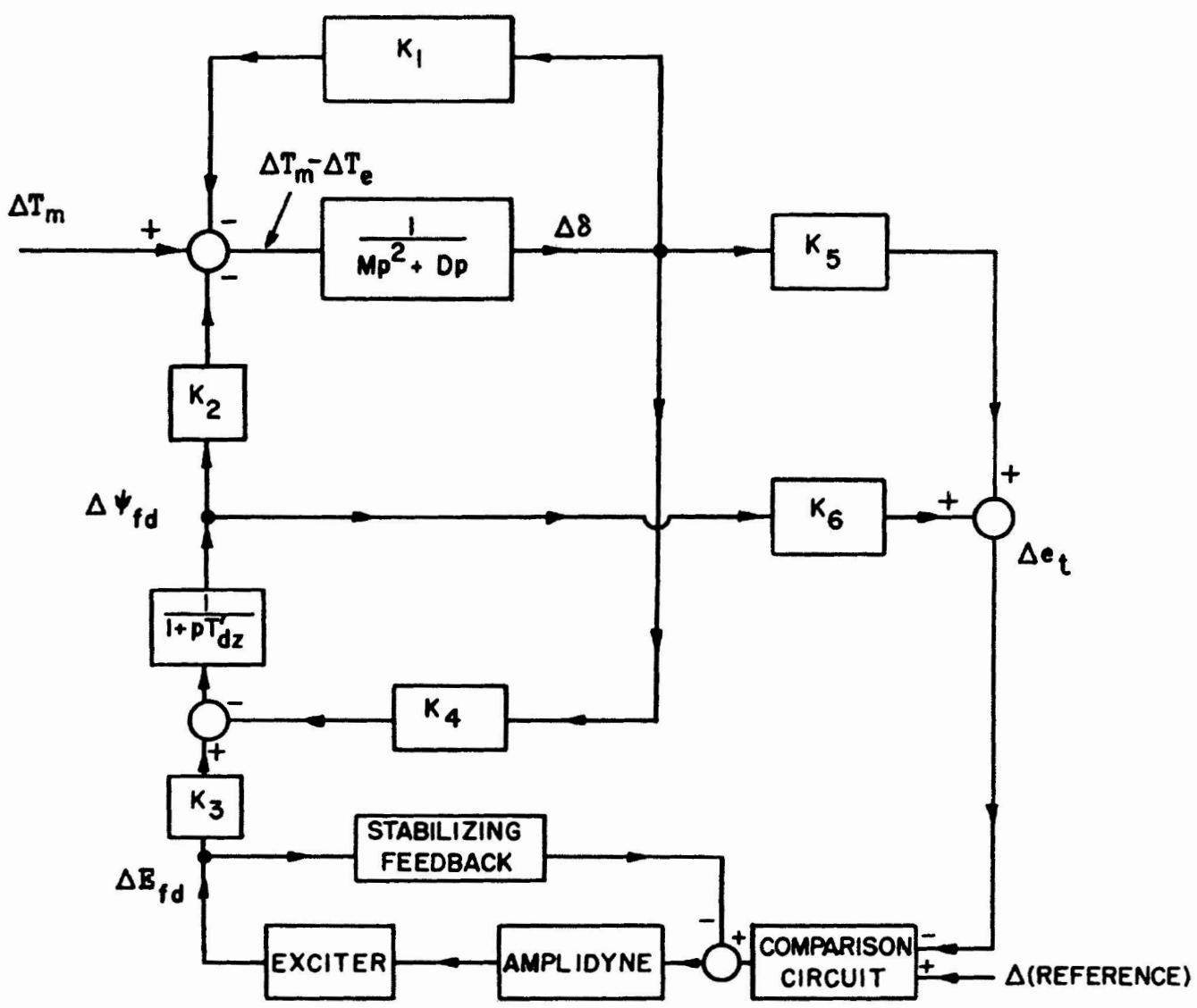

Figura 2.2: Modelo de Heffron e Phillips (1952); reimpresso do artigo original.

O modelo de Heffron e Phillips (1952) é obtido a partir da simplificação, assumindo a hipótese de pequenas pertubações, das equações que descrevem os fenômenos elétricos e mecânicos do funcionamento de um gerador síncrono. Senger (1983, p.127) apresenta os equacionamentos elétrico e mecânico que resultam no modelo.

As entradas e variáveis do modelo da fig. 2.2 representam variações (prefixo $\Delta$ ) em 
torno do regime permanente. A seguir é feito um resumo das variáveis do modelo.

- $\Delta T_{m}$ : Torque mecânico fornecido pela turbina ao gerador.

- $\Delta T_{e}$ : Torque elétrico modelado por $K_{1} \Delta \delta$ e por $K_{2} \Delta \psi_{f d}$.

- $\Delta T_{m}-\Delta T_{e}$ : Saldo entre os torques mecânico e elétrico (o torque acelerante).

- $\Delta \delta$ : Ângulo de carga.

- $\Delta e_{t}$ : Tensão estatórica.

- $\triangle$ (REFERENCE) : Entrada do AVR, referência de tensão estatórica.

- $\Delta E_{f d}$ : Tensão de campo.

- $\Delta \psi_{f d}$ : Fluxo magnético no eixo direto.

O ângulo de carga se relaciona com a diferença entre o torque mecânico e o torque elétrico $\left(\Delta T_{m}-\Delta T_{e}\right)$ via a constante $M$ da máquina e o amortecimento $D$ da turbina ${ }^{1}$. Neste modelo, $M$ é dado por $M=4 \pi f H$, onde $H$ é a constante de inércia do unidade geradora $^{2}$. O operador $p$ utilizado pelos autores representa a derivada em função do tempo. O tempo é contado em radianos.

A motivação principal de Heffron e Phillips (1952) foi comparar os limites de estabilidade em regime de máquinas síncronas excitadas por sistemas de ação contínua e os limites em máquinas excitadas por sistemas com banda morta. Os autores mostraram que a estabilidade em regime permanente de uma máquina na qual a tensão de campo é constante $\left(\Delta E_{f d}=0\right)$ é dada pela condição:

$$
K_{1}-K_{2} K_{4}=0
$$

Mantendo-se $\Delta T_{m}=0$ e $\Delta E_{f d}=0$, um aumento em $\Delta \delta$ é compensado por:

- $K_{1} \Delta \delta$ : Contribuição de torque elétrico devido ao aumento de $\Delta \delta$;

- $\frac{-K_{2} K_{4}}{1+p T_{d z}^{\prime}} \Delta \delta$ : Contribuição (negativa) de torque elétrico devido ao aumento de $\Delta \delta$.

\footnotetext{
${ }^{1}$ Apesar de ser tratada como constante, $M$ depende da velocidade angular do rotor (ANDERSON; FOUAD, 2003).

${ }^{2}$ Kundur (1993) e Anderson e Fouad (2003) definem $H$ como a energia cinética em joules acumulada na massa girante dividida pela potência aparente nominal do sistema em $V A ; H$ quando calculado na potência nominal de geradores varia entre $1 s$ e $5 s$.
} 
Convém lembrar que o atraso representado por $\left(1+p T_{d z}^{\prime}\right)$ não influi nas grandezas em regime permanente. Enquanto a contribuição de $K_{1} \Delta \delta$ for maior do que a contribuição de $K_{2} K_{4} \Delta \delta$, um aumento em $\Delta \delta$ representará um aumento do torque elétrico, freando o rotor e consequentemente diminuindo o ângulo de carga.

\subsubsection{A influência do ponto operacional da máquina nos parâmetros do modelo de Heffron e Phillips (1952)}

Os parâmetros $K$ do modelo de Heffron e Phillips (1952) dependem da carga da máquina e da impedância externa. Para se realizar uma simulação computacional com este modelo, é necessário calcular os parâmetros para o atual ponto operacional do gerador. Tal dependência dos parâmetros $K$ significa que o comportamento do AVR de uma máquina pode deixar de ser estável devido, por exemplo, ao aumento da potência ativa.

A análise da influência do ponto operacional nos parâmetros do modelo de Heffron e Phillips (1952) pode ser feita com a versão simplificada apresentada na fig. 2.3. Tal modelo foi empregado por DeMello e Concordia (1969) em um famoso artigo que propôs um estabilizador baseado na velocidade do rotor.

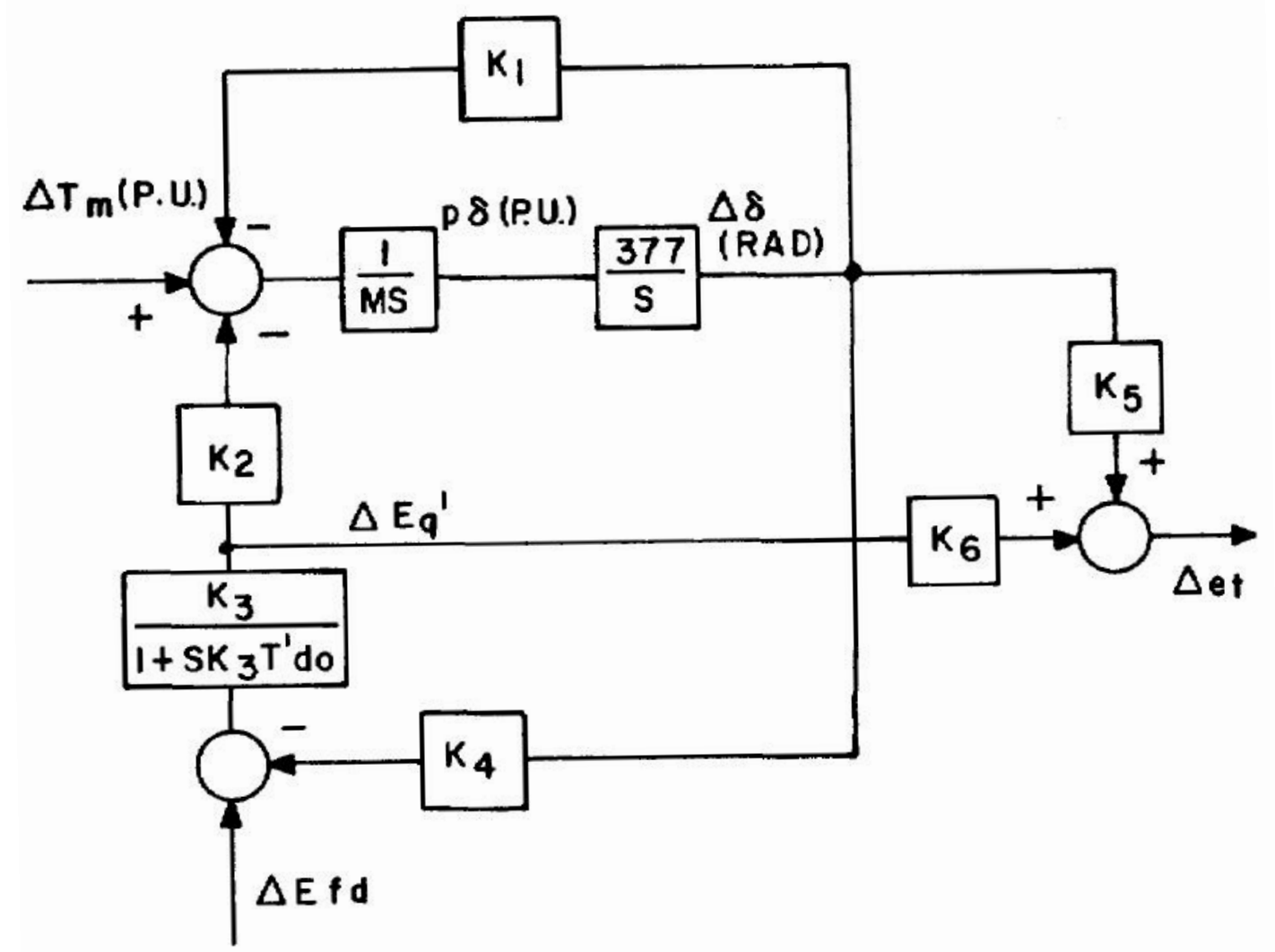

Figura 2.3: Modelo linearizado do gerador conectado a um barramento infinito via impedância externa; reimpresso de DeMello e Concordia (1969). 
A fig. 2.3 mostra o modelo linearizado de pequenas perturbações de um gerador síncrono conectado a um barramento infinito via uma impedância externa. Os efeitos do amortecimento do sistema mecânico da turbina, $D$ na fig. 2.2, foram desprezados. $\mathrm{O}$ saldo entre torque mecânico e torque elétrico $\left(\Delta T_{m}-K_{2} \Delta E_{q}^{\prime}-K_{1} \Delta \delta\right)$ integrado por $1 / M s$ resulta na "velocidade" do ângulo de carga $(p \delta)$. Assumiu-se frequência da rede constante e igual a $60 \mathrm{~Hz}$. Modificações em $\Delta \delta$ significam variações momentâneas na velocidade do rotor. A grandeza $p \delta$ representa a variação em torno do regime permanente da velocidade do rotor do gerador. O operador $p$ representa a derivada em função do tempo $d / d t$. DeMello e Concordia (1969) empregaram no artigo original $p$ para a derivada e $s$ para a variável de Laplace, tal prática foi mantida nesta seção.

A opção de representação de variáveis com letras maiúsculas e minúsculas adotada por Heffron e Phillips (1952) e DeMello e Concordia (1969) será mantida em toda a dissertação.

Há diferenças entre o modelo da fig. 2.3 e o de Heffron e Phillips (1952): o coeficiente de inércia é representado por $M$ que é igual a duas vezes a constante de inércia $H$ do grupo gerador em segundos e o parâmetro $K_{3}$ foi movido para o bloco que representa o enrolamento de campo. A seguir, é feita uma descrição dos parâmetros da fig. 2.3.

- $K_{1}=\left.\frac{\Delta T_{e}}{\Delta \delta}\right|_{E_{q}^{\prime}}:$ Mudanças no torque elétrico devido a mudanças no ângulo de carga $(\delta)$ com fluxo constante no eixo $d$.

- $K_{2}=\left.\frac{\Delta T_{e}}{\Delta E_{q}^{\prime}}\right|_{\delta}:$ Mudanças no torque elétrico devido a mudanças no fluxo no eixo $d$ $\operatorname{com} \delta$ constante.

- $K_{3}=\frac{X_{d}^{\prime}+X_{e}}{X_{d}+X_{e}}$ : Fator de impedância, fórmula válida para o caso de impedância externa $X_{e}$ puramente indutiva; onde $X_{d}$ e $X_{d}^{\prime}$ representam respectivamente a reatância no eixo direto e reatância transitória no eixo direto do gerador.

- $K_{4}=\frac{1}{K_{3}} \frac{\Delta E_{q}^{\prime}}{\Delta \delta}$ : Efeito desmagnetizante devido a mudanças em $\delta$.

- $K_{5}=\left.\frac{\Delta e_{t}}{\Delta \delta}\right|_{E_{q}^{\prime}}:$ Mudanças na tensão terminal devido a mudança em $\delta$ com $E_{q}^{\prime}$ constante.

- $K_{6}=\left.\frac{\Delta e_{t}}{\Delta E_{q}^{\prime}}\right|_{\delta}:$ Mudanças na tensão terminal devido a mudança em $E_{q}^{\prime}$ com $\delta$ constante.

- $T_{d z}^{\prime}=K_{3} T_{d 0}^{\prime}$ : Constante efetiva de tempo do enrolamento de campo com o gerador em carga; $T_{d 0}^{\prime}$ representa a constante de tempo do enrolamento de campo com o gerador em vazio. 
El-Sherbiny e Mehta (1973) apresentaram um ótimo estudo sobre as variações das constantes $K$ do modelo da fig. 2.3 em função do carregamento. Considerando uma máquina síncrona conectada a um barramento infinito por uma impedância externa puramente indutiva, os autores calcularam os coeficientes $K$ de acordo com o as potências ativa e reativa fornecidas pelo gerador. A fig. 2.13 na pág. 30 apresenta as curvas dos parâmetros $K_{1}, K_{2}, K_{4}, K_{5}, K_{6}$ e o modelo do gerador com a impedância externa $X_{e}$. As curvas foram obtidas de um sistema com os dados presentes na tab. 2.1. Nota-se que $K_{3}$ não está entre os gráficos pois tal parâmetro depende apenas das impedâncias $X_{d}$ e $X_{d}^{\prime}$ da máquina e da impedância $X_{e}$.

Tabela 2.1: Dados empregados no estudo da influência do carregamento nos parâmetros do modelo de Heffron e Phillips (1952).

\begin{tabular}{cc} 
Parâmetro & Valor \\
\hline$X_{d}$ & $1,6 \mathrm{p} . \mathrm{u}$. \\
$X_{d}^{\prime}$ & $0,32 \mathrm{p} . \mathrm{u}$. \\
$X_{q}$ & $1,55 \mathrm{p} . \mathrm{u}$. \\
$T_{d 0}^{\prime}$ & $6,0 \mathrm{~s}$ \\
$H$ & $5 \mathrm{~s}$ \\
$X_{e}$ & $0,4 \mathrm{p} . \mathrm{u}$.
\end{tabular}

\subsubsection{Simulações computacionais de uma máquina síncrona conectada a um barramento infinito por uma impedância externa.}

Com o objetivo de ilustrar a influência do carregamento nos parâmetros do modelo de Heffron e Phillips (1952) são apresentados neste tópico resultados de simulações computacionais.

Considerou-se um sistema como o da fig. 2.3 com as características apresentadas na tab. 2.1. Foram analisados 4 pontos operacionais distintos com potência ativas de $0,2 p . u$., 0,4p.u., 0,6p.u. e 0,8p.u. A potência reativa foi mantida constante em 0,1p.u.

DeMello e Concordia (1969) e El-Sherbiny e Mehta (1973) empregaram em seus estudos modelos simplificados de sistemas de excitação com controle do tipo proporcional associado a um filtro passa baixa. Tais modelos são caracterizados por uma função de transferência dada pela eq. 2.2. 


$$
G_{\text {avrP }}=\frac{K_{A}}{1+s T_{A}}
$$

Onde:

- $K_{A}$ : Ganho transitório do regulador de tensão;

- $T_{A}$ : Constante de tempo do regulador de tensão, representa uma aproximação de primeira ordem de todas as pequenas constantes de tempo e tempos mortos do sistema de excitação ${ }^{3}$.

As simulações computacionais apresentadas nesta dissertação empregam um AVR com um regulador do tipo proporcional-integral com a função de transferência dada pela eq. 2.3 .

$$
G_{a v r P I}=\frac{K_{p}\left(1+s T_{i}\right)}{s T_{i}} \frac{K_{b}}{1+s T_{b}}
$$

Onde:

- $K_{p}$ : Ganho proporcional do regulador de tensão;

- $T_{i}$ : Constante do integrador do regulador de tensão;

- $K_{b}$ : Ganho da ponte de tiristores;

- $T_{b}$ : Constante de tempo do regulador de tensão, representa uma aproximação de primeira ordem de todas as pequenas constantes de tempo e tempos mortos do sistema de excitação.

O capítulo 4 mostra resultados práticos obtidos durante comissionamentos em duas usinas hidrelétricas distintas. Os AVRs implantados nestas usinas empregam um regulador do tipo PI. A eq. 2.3 representa uma simplificação da função de transferência de tal AVR. A comparação entre os ganhos transitórios dos reguladores $G_{\text {avrP }}$ e $G_{\text {avrPI }}$ deve ser feita entre $K_{A}$ e a multiplicação dos ganhos $K_{p}$ e $K_{b}$.

As simulações computacionais apresentadas nesta seção consideraram os parâmetros de $G_{\text {avrPI }}$ dados pela tab. 2.2 .

\footnotetext{
${ }^{3}$ Pequenas constantes de tempo e pequenos atrasos podem ser modelados como um filtro passa-baixa de primeira ordem com uma constante de tempo igual à soma das pequenas constantes de tempo e tempos mortos (FRÖHR; ORTTENBURGER, 1970).
} 
Tabela 2.2: Dados do modelo do sistema de excitação empregados no estudo da influência do carregamento nos parâmetros do modelo de Heffron e Phillips (1952).

\begin{tabular}{cc} 
Parâmetro & Valor \\
\hline$K_{p}$ & 10 \\
$T_{i}$ & $2 s$ \\
$K_{b}$ & 5 \\
$T_{b}$ & $0,02 s$
\end{tabular}

Com o auxílio dos gráficos da fig. 2.13 na pág. 30, foram levantados os parâmetros $K$ considerando diferentes pontos operacionais do gerador conectado à rede de transmissão. A tab. 2.3 mostra o resultado em função da potência ativa. O parâmetro $K_{5}$ diminui com o aumento de carga. El-Sherbiny e Mehta (1973) citam que a mudança de sinal de $K_{5}$ torna o sistema instável, fazendo necessário o uso de um PSS. Convém lembrar que esta é uma abordagem conservadora do ponto de vista da estabilidade, pois não é levada em conta a influência dos enrolamentos amortecedores.

Tabela 2.3: Dados do modelo simulado no estudo da influência do carregamento nos parâmetros do modelo de Heffron e Phillips (1952).

\begin{tabular}{cccccccc} 
Potência ativa & Potência reativa & $K_{1}$ & $K_{2}$ & $K_{3}$ & $K_{4}$ & $K_{5}$ & $K_{6}$ \\
\hline 0,2 p.u. & 0,1 p.u. & 0,65 & 0,47 & 0,36 & 0,58 & 0,04 & 0,53 \\
0,4 p.u. & 0,1 p.u. & 0,82 & 0,81 & 0,36 & 1,06 & 0,05 & 0,52 \\
0,6 p.u. & 0,1 p.u. & 1,00 & 1,08 & 0,36 & 1,43 & 0,03 & 0,52 \\
0,8 p.u. & 0,1 p.u. & 1,10 & 1,24 & 0,36 & 1,66 & $-0,04$ & 0,48
\end{tabular}

A fig. 2.4 apresenta o resultado da simulação da resposta ao degrau de 0,01p.u. na referência de tensão. A variação da tensão estatórica $\left(\Delta e_{t}\right)$ é apresentada em p.u. Nota-se que há uma considerável diminuição do amortecimento das oscilações associada ao aumento de potência ativa.

Verifica-se, na fig. 2.4, instabilidade na resposta ao degrau do gerador com carga de 0,8p.u. A amplitude das oscilações para este carregamento após a aplicação do degrau é crescente. O resultado do cálculo computacional dos autovalores do modelo confirma a instabilidade. A tab. 2.4 apresenta os autovalores em função da potência ativa. Os autovalores complexos se movem em direção ao semiplano dos números reais positivos quando a carga aumenta. O sistema com potência igual a 0,8p.u. contém autovalores com a parte real positiva ${ }^{4}$.

\footnotetext{
${ }^{4}$ Um sistema linear, fixo e de tempo contínuo é assintoticamente estável se e somente se a parte real de todos os autovalores for menor que zero (ORSINI, 1980).
} 


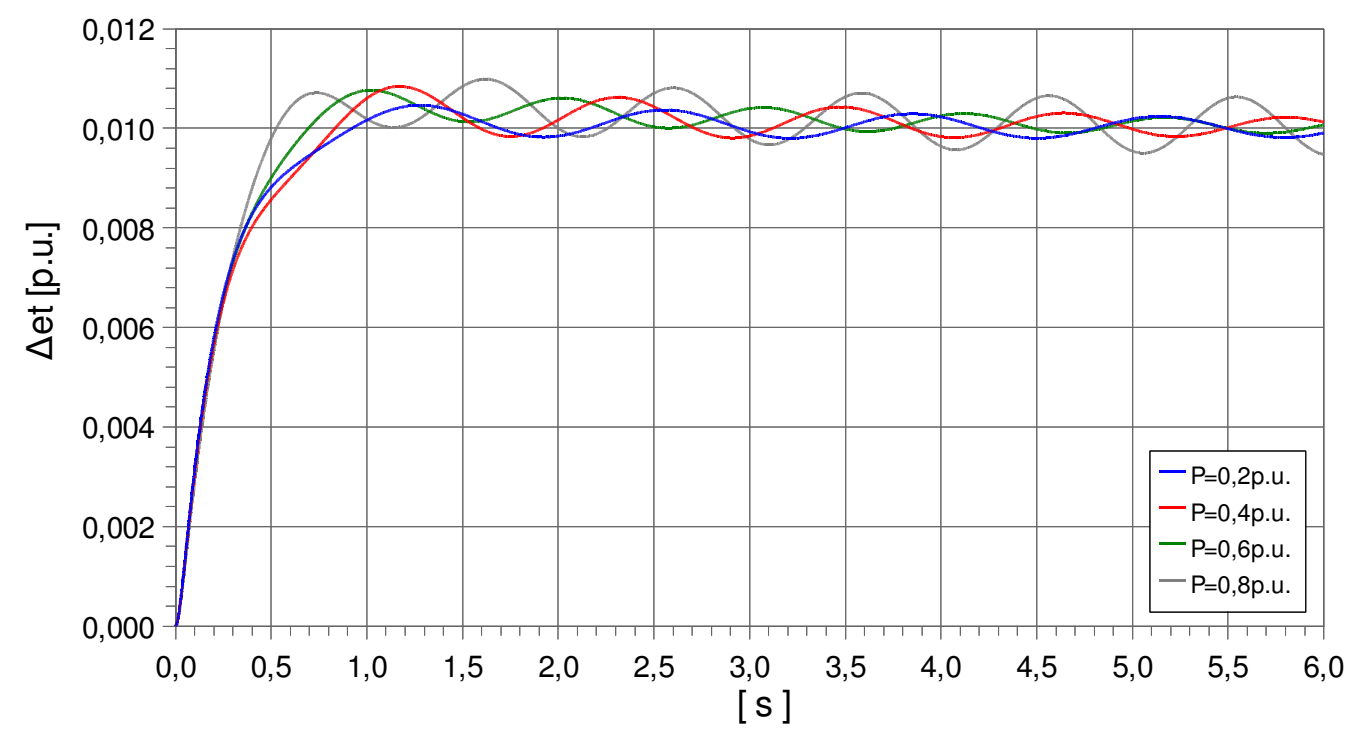

Figura 2.4: Simulação da resposta ao degrau de tensão com diferentes carregamentos.

Nota-se na tab. 2.4 que o módulo da parte imaginária dos autovalores complexos conjugados aumenta conforme a potência ativa aumenta. A frequência natural de oscilação do sistema é influenciada pelo carregamento. Verifica-se na fig. 2.4 que o período das oscilações é ligeiramente diferente para as diferentes potências. O projeto de um dispositivo estabilizador das oscilações do sistema simulado tem que levar em conta este fato. Senger (1983) discute detalhadamente a localização dos autovalores no plano complexo e o amortecimento dos modos de oscilação do modelo de um gerador conectado a um barramento infinito por uma impedância externa.

Tabela 2.4: Autovalores do modelo de um gerador conectado a um barramento infinito em função da potência ativa.

$$
\begin{array}{cccc}
P=0,2 p . u . & P=0,4 p . u . & P=0,6 p . u . & P=0,8 p . u . \\
\hline-45,0810 & -45,2000 & -45,1970 & -45,6330 \\
-0,1034+j 4,8631 & -0,2214+j 5,4100 & -0,1771+j 6,0152 & +0,0219+j 6,4183 \\
-0,1034-j 4,8631 & -0,2214-j 5,4100 & -0,1771-j 6,0152 & +0,0219-j 6,4183 \\
-4,6602 & -4,2880 & -4,3682 & -4,3242 \\
-0,5147 & -0,5325 & -0,5439 & -0,5501
\end{array}
$$




\subsubsection{Torques amortecedor e sincronizante}

Oscilações no ângulo de carga de uma máquina síncrona são acompanhadas de variações na velocidade do rotor. Assumindo torque mecânico constante, um gerador que está acelerando será freado se o PSS for capaz de aumentar o torque elétrico, um gerador freando será acelerado se o PSS for capaz de diminuir o torque elétrico. Analisando em detalhes o modelo da fig. 2.2 mostrado na pág. 9, DeMello e Concordia (1969) apresentaram os fundamentos de um PSS baseado na velocidade do rotor do gerador. Um conceito interessante apresentado por estes autores é o de torque amortecedor e torque sincronizante.

- Torque sincronizante: componente de torque em fase com a variação do ângulo de carga $\Delta \delta$

- Torque amortecedor: componente de torque em fase com a "velocidade" de $\Delta \delta$, ou em fase com as pequenas variações de velocidade do rotor.

Os torques sincronizante e amortecedor podem ser compreendidos a partir da análise de um sistema massa-mola em repouso que é perturbado. Se a massa do sistema for deslocada por um distúrbio qualquer, a mola exercerá uma força proporcional à distância da massa até o ponto de repouso. Esta força corresponde à "força sincronizante". Somente a "força sincronizante" não é capaz de diminuir a amplitude as oscilações provocadas pelo distúrbio. É necessário considerar um outro fenômeno, uma "força amortecedora" representada pelo atrito dinâmico. Tal atrito introduz uma força no sistema que se opõe ao movimento e é proporcional à velocidade da massa.

O comportamento livre do sistema análogo massa-mola com atrito dinâmico após um distúrbio qualquer é ditado pelas duas "forças":

- A "força sincronizante" se opõe à permanência da massa em uma posição fora da posição de repouso;

- A "força amortecedora" impede que as oscilações se estabeleçam permanentemente.

Na década de 1960 (DEMELLO; CONCORDIA, 1969), os critérios tradicionais de estabilidade levavam em conta apenas o torque sincronizante. Não havia um guia para determinar instabilidade devido à falta de torque amortecedor. O surgimento de sistemas de excitação estáticos equipados com pontes de tiristores trouxe novos problemas para os 
engenheiros de sistemas de potência. Estes sistemas, que possuem alta resposta inicial, podem diminuir o torque amortecedor ou até mesmo torná-lo negativo. Ao invés de optar por reguladores de tensão lentos, foram buscadas soluções alternativas que aumentassem o amortecimento do sistema e ao mesmo tempo empregassem AVRs rápidos.

\subsubsection{Dispositivos estabilizadores e a influência do torque amortecedor}

A influência do torque amortecedor na estabilidade de uma máquina síncrona conectada a um barramento infinito por uma impedância externa pode ser analisada, primeiramente, considerando-se $\Delta E_{q}^{\prime} \approx 0$ no modelo da fig. 2.3 mostrado na pág. 11. Introduz-se neste modelo uma constante de amortecimento $D$ que produz torque elétrico em fase com a velocidade do rotor. A fig. 2.5, reimpressa de DeMello e Concordia (1969), mostra o resultado das modificações sugeridas. Os autores empregaram no artigo original $p$ para a derivada e $s$ para a variável de Laplace.

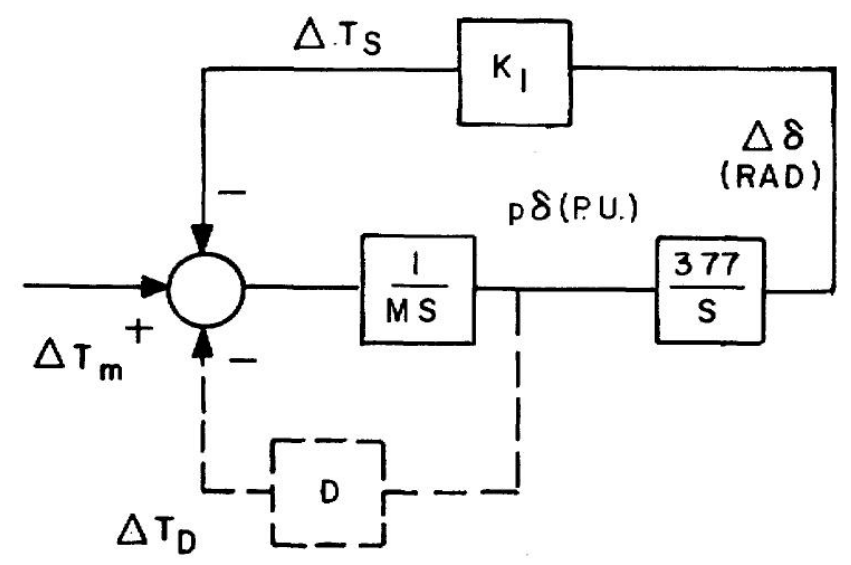

Figura 2.5: Modelo com $\Delta E_{q}^{\prime}$ constante e constante de amortecimento $D$; reimpresso de DeMello e Concordia (1969).

A equação característica do sistema modelado pela fig. 2.5 é dada por:

$$
s^{2}+\frac{D}{M} s+\frac{K_{1} 377}{M}=0
$$

A frequência natural de oscilação deste sistema, considerando $D=0$, é dada pela eq. 2.5:

$$
\omega=\sqrt{\frac{K_{1} 377}{M}}[\mathrm{rad} / \mathrm{s}]
$$

Tal frequência está na faixa de $0,5 H z$ até $2 H z$ (mínimo de $0,1 H z$ e máximo de 
$4 H z)$ para valores típicos de inércia, impedâncias e cargas. A introdução do coeficiente $D$, representando dispositivos amortecedores, tem muito pouca influência na frequência de oscilação (DEMELLO; CONCORDIA, 1969).

As simulações apresentadas na seção 2.1.2.2 mostraram que o aumento da potência ativa pode tornar instável o comportamento de uma máquina conectada à rede. É interessante analisar a influência que um dispositivo adicional capaz de gerar torque amortecedor pode ter no funcionamento da máquina modelada. Tal dispositivo representa a atuação de duas entidades desconsideradas no modelo da fig. 2.3 na pág. 11:

- Enrolamentos amortecedores;

- Dispositivo ideal estabilizador do sistema de potência (um PSS ideal).

Com o intuito de analisar a influência da introdução da constante $D$ mostrada na fig. 2.5, foram realizadas simulações computacionais do modelo de uma uma máquina síncrona conectada a um barramento infinito a partir de uma impedância externa. A fig. 2.6 apresenta o modelo do sistema simulado. Tal modelo possui as seguintes características:

- Dados da máquina e do sistema de potência conforme a tab. 2.1 na pág. 13;

- Dados do sistema de excitação segundo a tab. 2.2 na pág. 15;

- Parâmetros do modelo do gerador definidos para a potência ativa de $0,8 p . u$. na tab. 2.3 na pág. 15 ;

- Frequência da rede $(f)$ considerada constante e igual a $60 H z$;

- Incluído um dispositivo capaz de gerar torque elétrico em fase com a velocidade, o ganho $D$, representando a ação dos enrolamentos amortecedores e de um PSS ideal. 


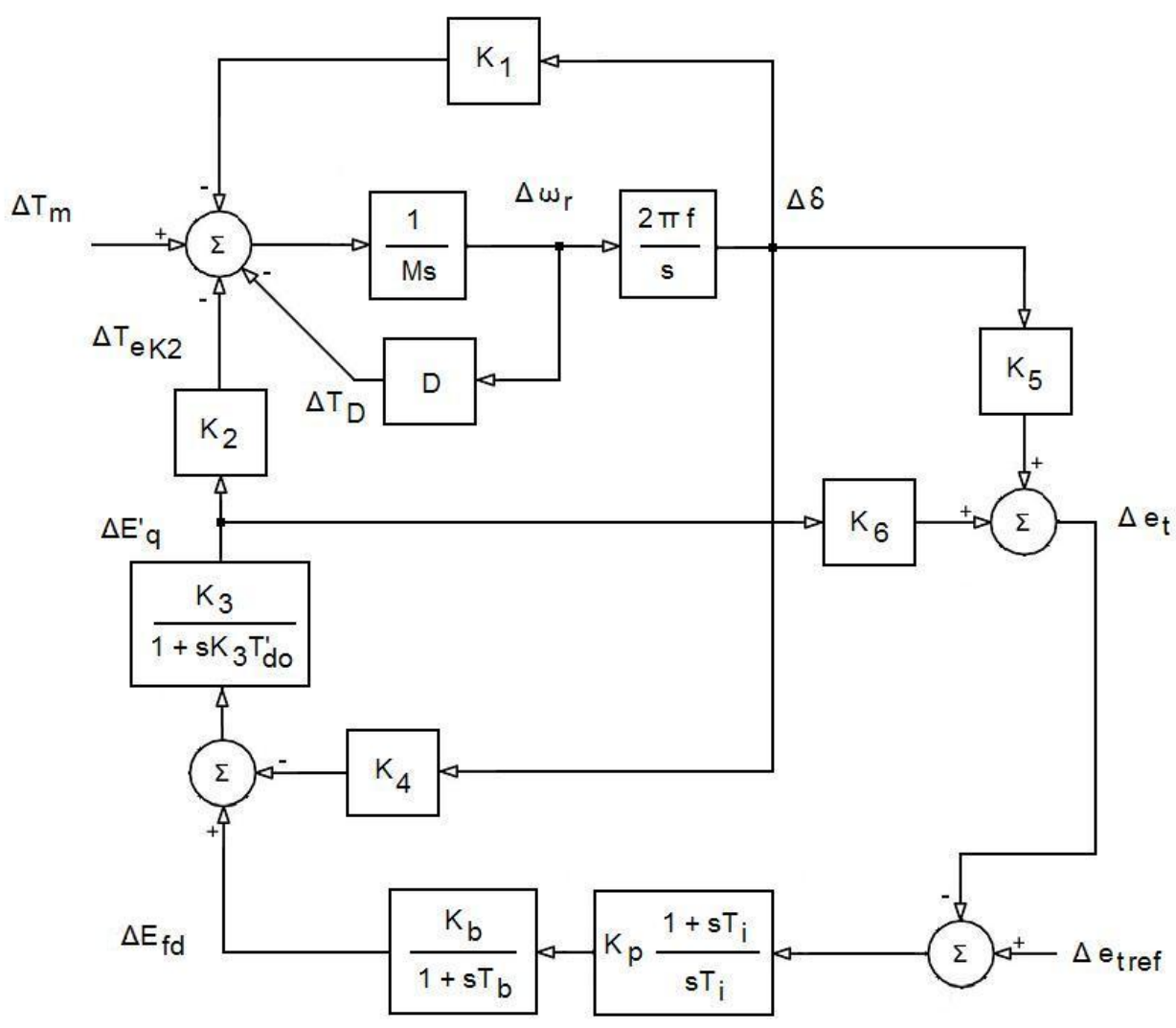

Figura 2.6: Modelo empregado para a análise da influência da constante de amortecimento $D$ na estabilidade do gerador; adaptado de DeMello e Concordia (1969).

A fig. 2.7 apresenta simulação computacional da resposta ao degrau de 0,01p.u. na referência de tensão do gerador considerando diferentes ganhos $D$ do dispositivo amortecedor. Nota-se que as oscilações são consideravelmente amortecidas após a inclusão do dispositivo.

A inclusão do dispositivo amortecedor torna estável o sistema modelado com potência ativa de $0,8 p . u$. O resultado do cálculo computacional dos autovalores confirma este fato. A tab. 2.5 apresenta os autovalores do sistema em função da constante $D$. Os autovalores complexos se movem do semiplano dos números reais positivos para o semiplano dos números reais negativos. O sistema com $D=0$ é instável pois tem autovalores com parte real positiva. O sistema com $D=1$ tem resposta oscilatória fracamente amortecida, porém é estável.

Nota-se na tab. 2.5 que o módulo da parte imaginária dos autovalores complexos conjugados se modifica pouco em função de $D$, a frequência natural de oscilação do sistema é pouco influenciada. Isto é notado na fig. 2.7, o período das oscilações é praticamente igual para os diferentes valores de $D$. 


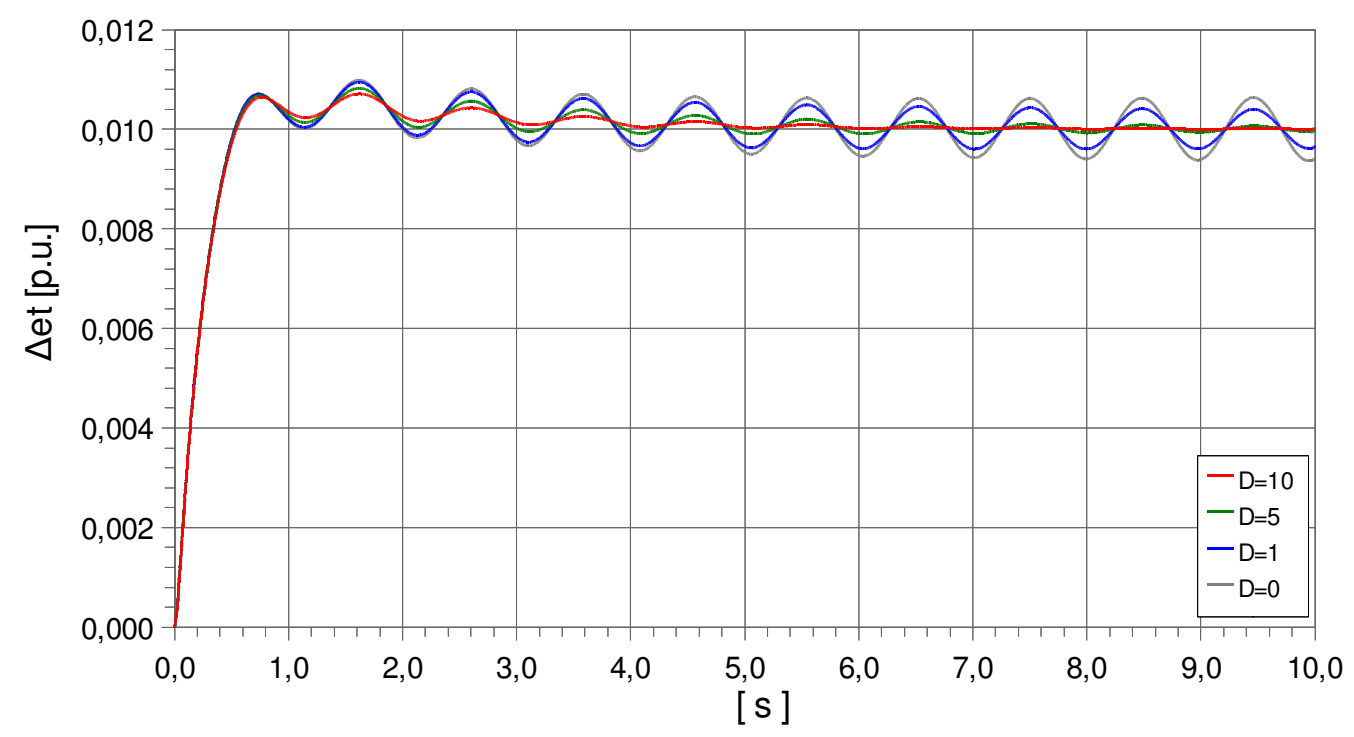

Figura 2.7: Simulação da resposta ao degrau de tensão com potência ativa de $0,8 p . u$. e diferentes constantes de amortecimento $D$.

Tabela 2.5: Autovalores em função da constante $D$ de amortecimento do modelo de um gerador com carga de $0,8 p . u$. de potência ativa conectado a um barramento infinito.

\begin{tabular}{cccc}
$D=0$ & $D=1$ & $D=5$ & $D=10$ \\
\hline$-45,6330$ & $-45,6330$ & $-45,6320$ & $-45,6320$ \\
$+0,0219+j 6,4183$ & $-0,0280+j 6,4179$ & $-0,2279+j 6,4124$ & $-0,4776+j 6,3967$ \\
$+0,0219-j 6,4183$ & $-0,0280-j 6,4179$ & $-0,2279-j 6,4124$ & $-0,4776-j 6,3967$ \\
$-4,3242$ & $-4,3242$ & $-4,3244$ & $-4,3247$ \\
$-0,5501$ & $-0,5501$ & $-0,5504$ & $-0,5507$
\end{tabular}

\subsection{O PSS}

A seção 2.1.3.1 apresentou a influência de dispositivos geradores de torque amortecedor na estabilidade de máquinas síncronas. Um destes dispositivos, os enrolamentos amortecedores, faz parte do projeto de hidrogeradores e está presente na máquina. O outro dispositivo é um estabilizador ideal do sistema de potência. Tal PSS ideal é capaz de "produzir" torque elétrico em fase com a velocidade do rotor para todo o espectro de oscilações (constante $D$ na fig. 2.6 na pág. 20).

Convém rever o modelo de um gerador conectado a um barramento infinito por uma impedância externa mostrado na fig. 2.3 na pág. 11 com enfoque nos conceitos de torque amortecedor e torque sincronizante.

- O torque elétrico produzido pela constante $K_{1}$ é sempre torque sincronizante;

- O torque elétrico produzido por $\Delta E_{f d}$ e por $-K_{4} \Delta \delta$ sofrem a influência da constante 
de tempo do enrolamento de campo $\left(K_{3} T_{d 0}^{\prime}\right)$.

O PSS não é capaz de "produzir" torque amortecedor diretamente. Emprega-se o regulador de tensão como intermediário. O projeto de um estabilizador real deve levar em conta alguns problemas práticos:

- A frequência natural das oscilações varia conforme o ponto de operação da máquina;

- Há um considerável atraso de fase devido ao enrolamento de campo da máquina (constante de tempo $\left.K_{3} T_{d 0}^{\prime}\right)$;

- A constante $K_{3}$ depende da impedância de conexão da máquina ao barramento infinito.

O principal desafio para o projeto e ajuste de um PSS é fazer com que o estabilizador cause torque elétrico em fase com a velocidade do rotor (KUNDUR et al., 2003) para todas as faixas de oscilação do gerador.

\subsubsection{Histórico do PSS}

A função primária do PSS é amortecer oscilações eletromecânicas a partir da atuação no AVR. Qualquer sinal que contenha indícios de tais oscilações é um candidato para a entrada do PSS (MURDOCH et al., 1999a), como por exemplo:

- Velocidade de rotação do eixo da máquina;

- Frequência terminal;

- Potência ativa.

Susceptibilidade a ruído e interações com outros modos de oscilação do gerador influem na escolha do sinal de entrada do PSS (MURDOCH et al., 1999a). Outras considerações importantes são a disponibilidade do sinal, a confiabilidade do transdutor e a existência prévia ou as dificuldades de instalação do equipamento de medição.

A escolha do sinal de entrada caracterizou os diferentes tipo de PSSs propostos entre as décadas de 1960 e 1990. A seguir é feita uma descrição das diferentes opções. 


\subsubsection{A velocidade angular do rotor}

DeMello e Concordia (1969) propuseram um PSS que utiliza a velocidade do rotor da máquina como sinal de entrada. A fig. 2.8 apresenta os blocos básicos de tal estabilizador. Os blocos de tratamento de sinal, avanço de fase e ajuste de ganho estão presentes em praticamente todos os PSSs atuais, inclusive nos PSSs com outros tipos de entrada (BÉRUBÉ; HAJAGOS; BEAULIEU, 1999).

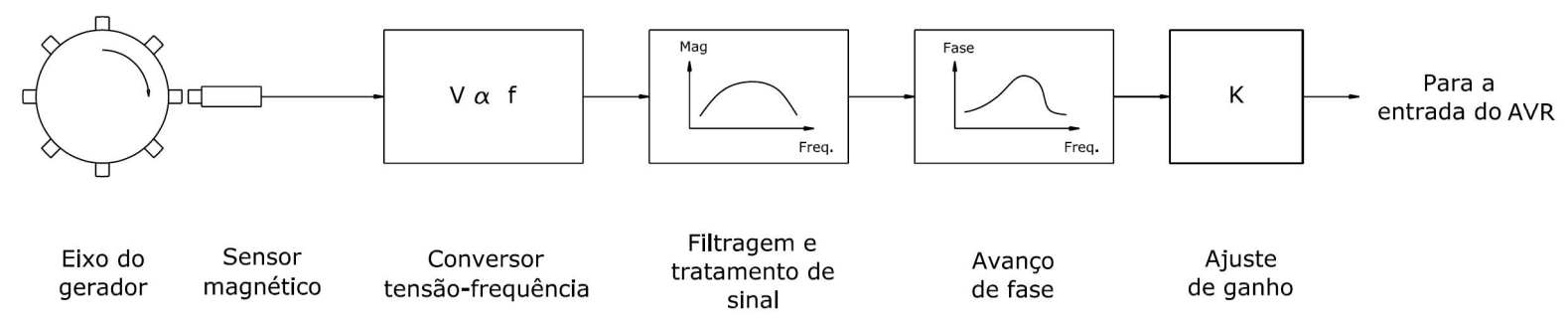

Figura 2.8: PSS baseado na velocidade do rotor; adaptado de Bérubé, Hajagos e Beaulieu (1999).

A velocidade de hidrogeradores é medida utilizando-se uma roda dentada instalada no eixo, um sensor de proximidade e um dispositivo contador de pulsos (BÉRUBÉ; HAJAGOS; BEAULIEU, 1999; KUNDUR et al., 2003). O equipamento de medição de velocidade é complexo e requer delicados ajustes mecânicos, há problemas para montagem, alinhamento e manutenção (KEAY; SOUTH, 1971). A roda dentada e os sensores de proximidade são usados pelo regulador de velocidade da turbina e já estão presentes no projeto. Não necessariamente a empresa que fornece o sistema de excitação é a mesma que fornece o regulador de velocidade. Problemas comerciais podem impedir o uso de um sensor de proximidade pré-existente ou a instalação de um sensor de proximidade exclusivo para o PSS.

A utilização da velocidade do rotor como entrada do PSS em turbogeradores requer cuidados especiais com as oscilações torsionais. Tal modo de oscilação ocorre devido à geometria alongada do eixo de turbogeradores e à troca de energia entre as diferentes partes girantes da unidade. A escolha do posicionamento do sensor de velocidade influi muito no conteúdo de oscilações torsionais presentes na medição. As oscilações na ponta do eixo do gerador têm amplitudes diferentes das oscilacões observadas entre o gerador e a turbina. Sem o emprego de filtros, a ação do PSS e do AVR podem desestabilizar os modos torsionais (KUNDUR, 1993; BÉRUBÉ; HAJAGOS; BEAULIEU, 1999; KUNDUR et al., 2003). 


\subsubsection{A frequência terminal}

PSSs baseados na medição da frequência terminal do gerador são descritos por Schleif et al. (1968), Schleif et al. (1969) e por Keay e South (1971). A escolha do sinal de frequência ao invés da velocidade do rotor elimina alguns problemas, tais como: alinhamento das peças mecânicas e ruído devido a movimentos excêntricos ou laterais do eixo.

A frequência terminal do gerador não é exatamente igual à velocidade do rotor. Considerando um modelo de máquina síncrona do tipo tensão interna atrás de uma reatância, a frequência da tensão interna é proporcional à velocidade do rotor. Durante transitórios, a excursão das fases da tensão terminal e da tensão interna é diferente. Isto leva a diferenças transitórias entre as frequências de tais tensões. Por esta razão, há dispositivos opcionais chamados de compensadores de reatância que simulam a tensão interna da máquina. A fig. 2.9 mostra os resultados da medição de frequência com e sem a compensação de reatância interna.

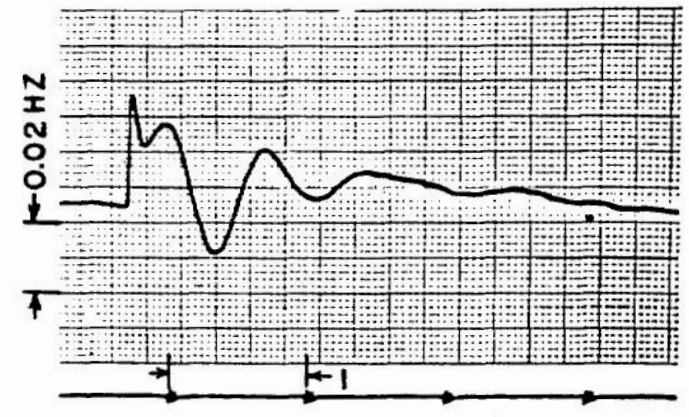

(a) A partir da tensão terminal

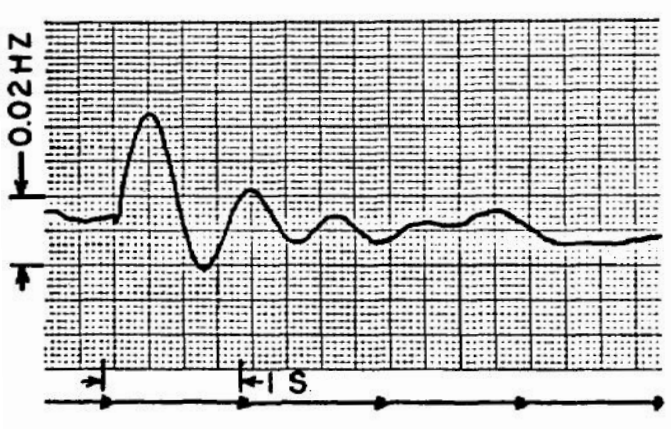

(b) A partir de tensão interna

Figura 2.9: Velocidade do rotor estimada a partir da frequência da tensão terminal e a partir da frequência da tensão interna; reimpresso de Schleif et al. (1969).

Apesar de largamente aplicados, os PSSs baseados na frequência sofrem de alguns problemas. Mudanças de fase da tensão terminal devido a mudanças na configuração da rede são transferidas para a tensão de campo. A frequência terminal possui componentes de oscilações torsionais o que implica no uso de filtros passa-baixa. Há grande susceptibilidade a ruído causado por cargas industriais não lineares, o que pode forçar o emprego de ganhos baixos no PSS. A frequência terminal sofre mais influência do modo interárea do que do modo local, isto pode ser positivo ou negativo dependendo do tipo de aplicação do PSS (BÉRUBÉ; HAJAGOS; BEAULIEU, 1999; KUNDUR et al., 2003). 


\subsubsection{A potência ativa}

A potência ativa oscila quando há variações no ângulo de carga $(\delta)$. É natural que se procure empregar a potência como uma entrada para o PSS. Porém, isto implica em um problema prático de difícil solução. A carga de uma unidade geradora pode variar relativamente rápido, especialmente em hidrogeradores. Tais variações fazem parte da operação normal do sistema elétrico e não podem ser transferidas para a tensão de campo. Durante um aumento rápido de carga, devido a mudanças no torque fornecido pela turbina, um PSS baseado somente na potência elétrica causa uma afundamento da tensão estatórica (DEMELLO; HANNET; UNDRILL, 1978).

\subsubsection{A integral da potência acelerante}

O uso da potência acelerante como entrada para o PSS recebeu atenção considerável já em meados da década de 1970 (LARSEN; SWANN, 1981a) devido às vantagens significativas proporcionadas por este sinal, entre elas a baixa interação com os modos torsionais.

A verdadeira potência acelerante, calculada a partir da potência elétrica e da potência mecânica, é de difícil obtenção. É possível estimar a potência mecânica medindo-se a abertura do distribuidor em hidrogeradores ou a pressão do vapor em turbogeradores. DeMello, Hannet e Undrill (1978) propuseram um método baseado apenas em grandezas elétricas: a velocidade do rotor estimada a partir da frequência terminal e a potência elétrica.

Larsen e Swann (1981a), Bérubé, Hajagos e Beaulieu (1999) e Murdoch et al. (1999a) tratam muito bem da síntese e do uso da integral da potência acelerante. A seguir é apresentado o equacionamento deste sinal.

Considerando que a velocidade do rotor se mantém praticamente igual a nominal durante a operação do gerador, assume-se que o torque é aproximadamente igual à potência ativa em p.u. ${ }^{5}$ (ANDERSON; FOUAD, 2003). Obtém-se a fig. 2.10, na qual:

- Prefixo $\Delta$ : variação da grandeza em torno do regime permanente;

\footnotetext{
${ }^{5}$ Esta afirmação não é válida para qualquer base de representação em $p . u$. Supondo que se escolha a potência aparente nominal do gerador como base da representação em $p . u$, a potência ativa nominal em p.u. será igual ao fator de potência nominal do gerador $\left(\cos \Phi_{n o m}\right)$. Em geral, o torque mecânico nominal fornecido pela turbina é o torque que resulta na potência ativa nominal do gerador. Se o torque mecânico nominal for adotado como base para a representação em p.u., $1 p . u$. de torque resultará em $\cos \Phi_{n o m}$ de potência ativa.
} 
- $M$ : dobro da constante de inércia $H$ da unidade geradora;

- $T_{m}$ : torque mecânico fornecido pela turbina;

- $P_{m}$ : potência mecânica fornecida pela turbina;

- $T_{e}$ : torque elétrico;

- $P_{e}$ : potência elétrica fornecida ao sistema pelo gerador;

- $T_{a c c}$ : saldo entre os torques mecânico e elétrico, o torque acelerante;

- $P_{a c c}$ : saldo entre as potências mecânica e elétrica, a potência acelerante;

- $\omega_{r}$ : velocidade do rotor.

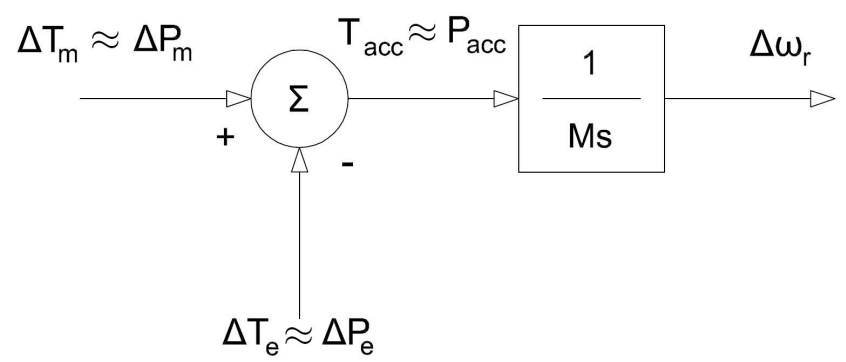

Figura 2.10: Velocidade do rotor e torques mecânico, elétrico e acelerante; adaptado da fig. 2.3 na pág. 11.

Deduz-se a potência acelerante $\left(P_{a c c}\right)$ diretamente da fig. 2.10.

$$
P_{a c c}=\Delta P_{m}-\Delta P_{e}
$$

Assumindo que a potência mecânica se mantém praticamente constante durante os fenômenos nos quais o PSS atua $\left(\Delta P_{m} \approx 0\right)$, obtém-se:

$$
P_{a c c}=-\Delta P_{e}
$$

Da fig. 2.10 e da eq. 2.7, pode-se deduzir a velocidade do rotor $\left(\Delta \omega_{r}\right)$ :

$$
\Delta \omega_{r}=-\Delta P_{e} \frac{1}{M s}
$$


A velocidade está $90^{\circ}$ a frente da potência ativa. Considerando um modo de oscilação, o local por exemplo, as variações na velocidade precedem em $90^{\circ}$ as variações de potência ativa, tal resultado será utilizado mais adiante na seção 3.3.3.

A potência acelerante $\left(P_{a c c}\right)$ pode ser obtida diretamente da fig. 2.10:

$$
P_{a c c}=\Delta \omega_{r} M s=\Delta \omega_{r} 2 H s
$$

Tal resultado possibilita sintetizar o sinal da potência mecânica $\left(\Delta P_{m}\right)$ a partir do sinal da velocidade $\left(\Delta \omega_{r}\right)$ e da potência ativa $\left(\Delta P_{e}\right)$. Das equações eq. 2.6 e 2.9 , obtém-se:

$$
\Delta P_{m}=P_{a c c}+\Delta P_{e} \Rightarrow \Delta P_{m}=M s \Delta \omega_{r}+\Delta P_{e}
$$

Subtraindo-se a potência mecânica $\left(\Delta P_{m}\right)$ obtida com a eq. 2.10 da potência elétrica $\left(\Delta P_{e}\right)$, obtém-se a potência acelerante $\left(P_{a c c}\right)$. Tal equacionamento é mostrado em forma de diagrama de blocos na fig. 2.11.

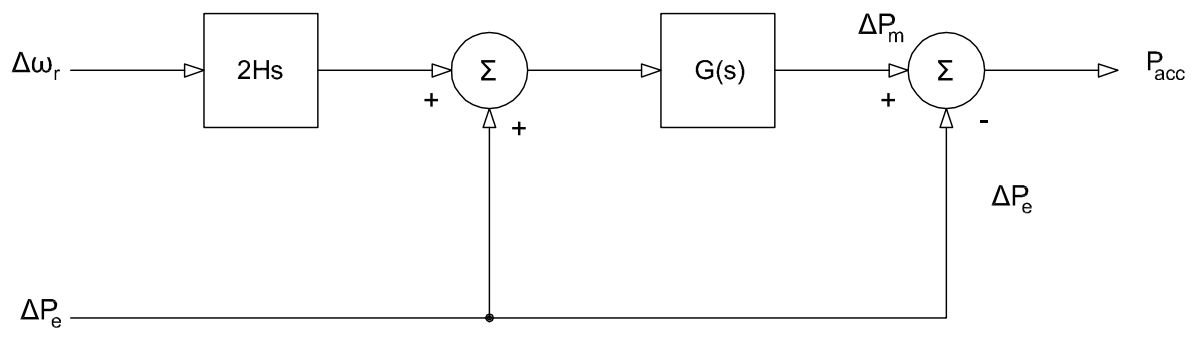

Figura 2.11: Síntese da potência acelerante; adaptado de Murdoch et al. (1999a).

A potência mecânica real não varia rapidamente. A potência mecânica calculada pela eq. 2.10 pode conter componentes de alta frequência indesejadas, tais como: oscilações torsionais no sinal de $\Delta \omega_{r}$ e variações rápidas da potência elétrica devido a transitórios na rede (MURDOCH et al., 1999a). É necessário filtrar o sinal sintetizado de $\Delta P_{m}$. Tal filtro é chamado de rastreador de rampa (ramp tracking filter) e é representado pela função de transferência $G(s)$ na fig. 2.11 .

O diagrama de blocos da fig. 2.11 contém um derivador $(2 H s)$. Como derivadores são muito sensíveis a ruído, emprega-se o sinal da integral da potência acelerante. Verifica-se pela eq. 2.9 que a integral de $\frac{P_{a c c}}{2 H}$ é igual à velocidade do rotor $\left(\Delta \omega_{r}\right)$.

A síntese do sinal de integral da potência acelerante, ou da velocidade do rotor, é mostrada em forma de diagrama de blocos pela fig. 2.12. 


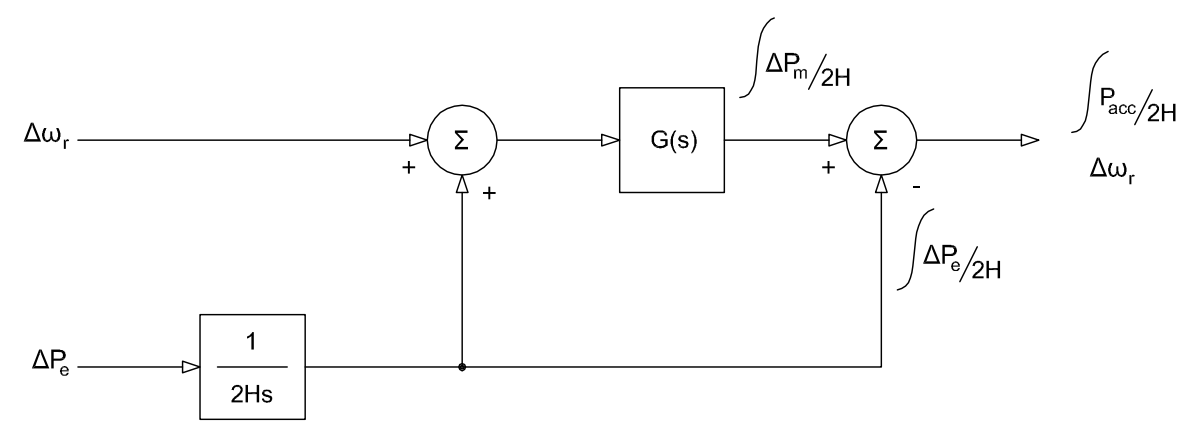

Figura 2.12: Síntese da integral da potência acelerante ou da velocidade angular do rotor; adaptado de Murdoch et al. (1999a).

A maneira como a integral da potência acelerante é sintetizada elimina as desvantagens apresentadas pela medição exclusiva de velocidade, frequência ou potência. A parte mais alta do espectro do sinal de $\Delta \omega_{r}$ é filtrada, evitando a influência dos modos torsionais. Quando a carga de um gerador é variada, as potências mecânica e elétrica variam concomitantemente. Como a potência acelerante é o saldo entre $P_{m}$ e $P_{e}$, o uso de tal sinal torna o PSS imune a mudanças na carga da unidade geradora.

\subsubsection{O PSS no Brasil}

PSSs podem ser empregados com sistemas de excitação de qualquer tipo, dos sistemas lentos aos rápidos, dos rotativos aos estáticos. Porém os estabilizadores são mais efetivos quando usados com sistemas de excitação de alta resposta inicial (KUNDUR et al., 2003), os mesmos tipos de excitação que podem contribuir para um comportamento oscilatório do sistema de potência.

Nas Referências para a Elaboração de Especificações Técnicas de Sistemas de Excitação de IEEE (2004), afirma-se que o uso de PSS é ditado pelos seguintes requerimentos:

- "Para aumentar o amortecimento positivo de oscilações de baixa frequência que ocorrem entre a máquina e o sistema;"

- "Mandatório baseado na potência da máquina, como por exemplo, 50MVA ou mais;"

- "Mandatório baseado no nível de tensão de conexão à rede;"

• "Ou de acordo com as agências reguladoras para o uso de sistemas de excitação."

Nos Requisitos Mínimos para a Conexão à Rede Básica de 2004 (ONS, 2004a) havia os seguintes tópicos sobre o tamanho das máquinas ou da usina às quais se aplicavam as exigências: 
- "6.1.9 De acordo com o Submódulo 3.1, para unidades geradoras com capacidade instalada igual ou superior a $50 \mathrm{MW}$ ou centrais de geração com capacidade instalada igual ou superior a 150 MW conectadas fora da Rede Básica que celebram o Contrato de Uso do Sistema de Transmissão (CUST), valem os mesmos requisitos mínimos aplicáveis à conexão de geradores à Rede Básica."

- "6.1.10 Do mesmo modo, centrais de geração com capacidade instalada inferior a 150 MW compostas de unidades geradoras com capacidade instalada inferior a $50 \mathrm{MW}$ devem cumprir os requisitos que os respectivos CUST determinem como aplicáveis."

A atualização Requisitos Técnicos Mínimos para a Conexão à Rede Básica de 2008 (ONS, 2008) não define um limite mínimo de potência nominal da máquina a partir do qual o PSS é exigido.

\subsubsection{O tipo de PSS exigido no Brasil}

O Submódulo 3.6 com os requisitos técnicos mínimos para a conexão à rede básica (ONS, 2008) solicita PSS do tipo de integral de potência acelerante:

- "A estrutura ideal ... deve ser baseada na integral de potência acelerante, com rastreador de rampa capaz de propiciar um bom amortecimento na faixa de 0,2 a 2,0 Hz."

\subsubsection{O tipo de medição de frequência ou velocidade exigido para o PSS}

É interessante citar que a medição de frequência do PSS devia atender à seguinte solicitação dos Requisitos Mínimos para a Conexão à Rede Básica de 2004 (ONS, 2004a):

- "No caso da utilização de frequência ao invés da velocidade, a frequência deve ser tomada em barra virtual, sintetizada através das tensões e correntes terminais, que emulam a tensão interna da máquina."

Na atualização dos Requisitos Mínimos de 2008 (ONS, 2008), tal exigência foi removida. 


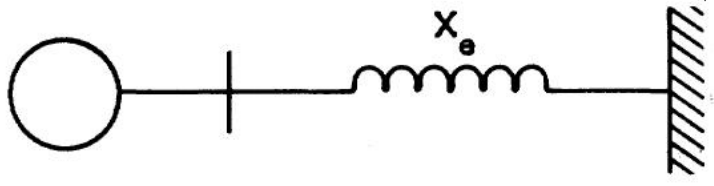

(a) Modelo da máquina

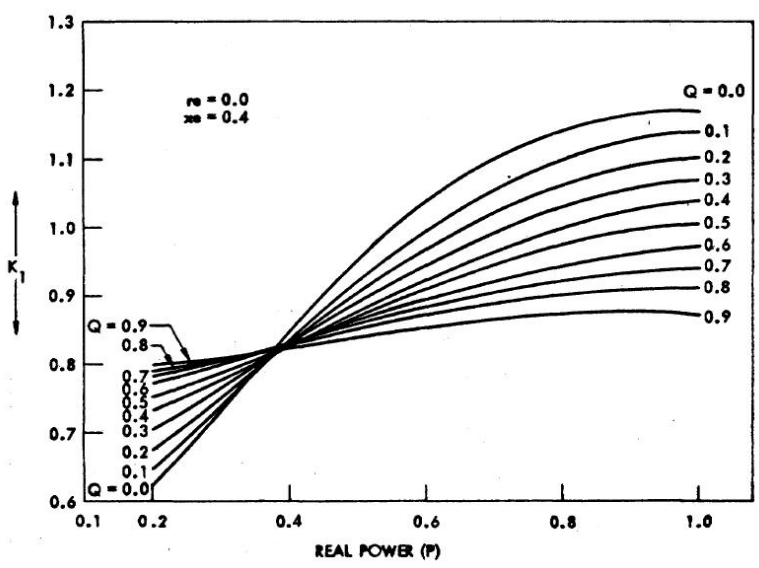

(c) $K_{1}$

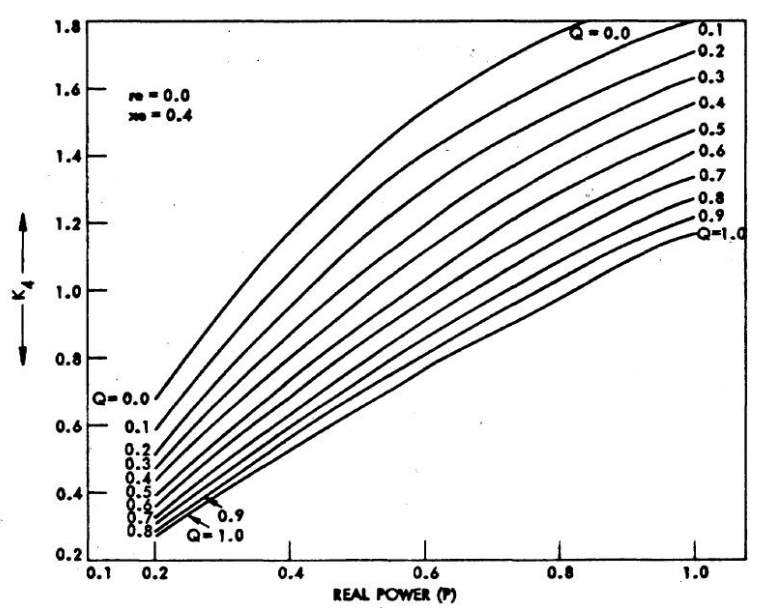

(e) $K_{4}$

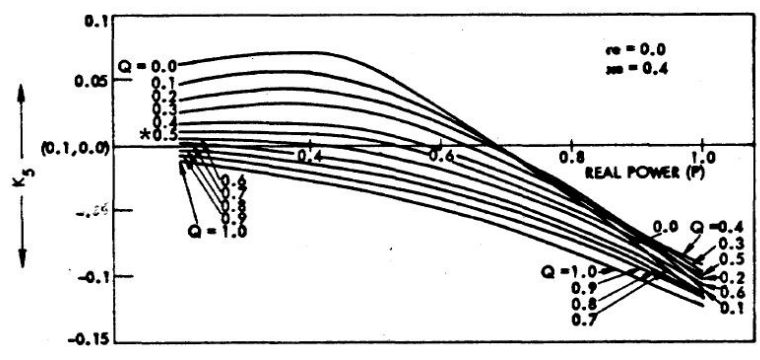

(b) $K_{5}$

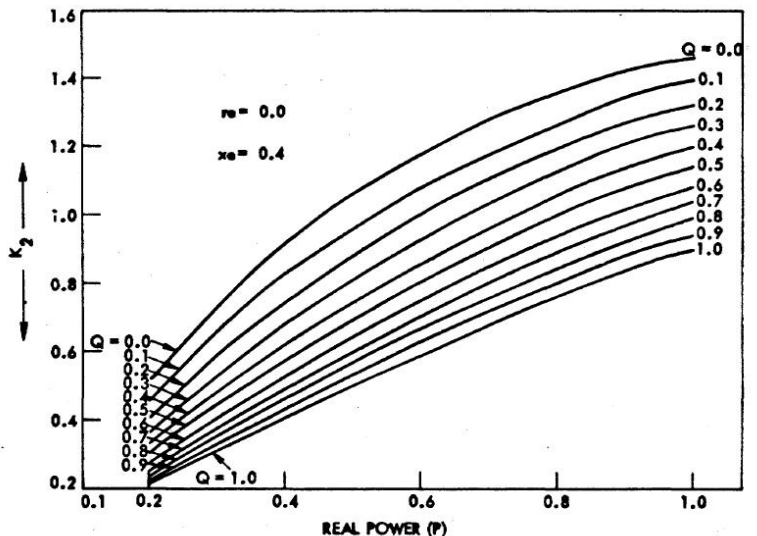

(d) $K_{2}$

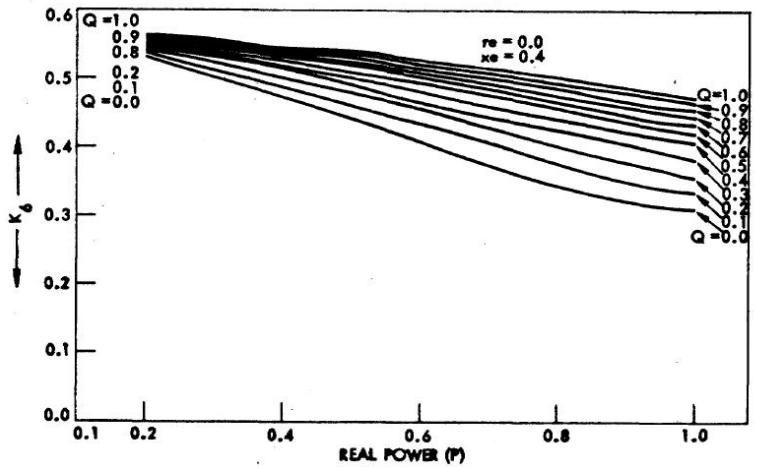

(f) $K_{6}$

Figura 2.13: Influência do carregamento nos parâmetros $K$ do modelo de uma máquina síncrona conectada a um barramento infinito por uma impedância externa; reimpresso de El-Sherbiny e Mehta (1973). 


\section{Técnicas de ajuste de PSS}

Independente da técnica utilizada para o ajuste do PSS, é necessário reconhecer que o sistema de potência possui um comportamento não linear e que o principal objetivo do ajuste é extender os limites de transmissão de energia a partir da estabilização das oscilações do sistema. Aumentar o amortecimento das oscilações não é um fim em si mesmo, mas uma maneira de extender os limites de operação do sistema elétrico (LARSEN; SWANN, 1981b).

Em operação, as máquinas estão submetidas a vários modos de oscilação simultaneamente. Os modos de oscilação locais são dominantes. Como uma unidade ou usina é dominante no modo local, o PSS tem uma grande capacidade de amortecer tal modo. Em contraste, uma unidade sozinha somente pode contribuir para o amortecimento de um modo interárea na mesma proporção que o tamanho da unidade em relação ao sistema ao qual está conectada (LARSEN; SWANN, 1981b). A controlabilidade do modo interárea com o PSS depende de vários fatores: localização da unidade geradora, característica e localização das cargas e robustez do controle de tensão da rede. A seleção de quais unidades devem ser empregadas para amortecer o modo interárea pode ser estabelecida por programação computacional e teoria de controle (KUNDUR et al., 2003).

O PSS é obrigatório (ONS, 2008) em usinas de médio porte no Brasil. Em tais usinas, a opção por ajustar o PSS visando amortecer os modos locais é a mais simples. Oscilações locais são produzidas pela aplicação de degraus na referência de tensão do AVR. A comparação da resposta ao degrau com e sem o PSS demonstra a atuação do estabilizador.

Comprovar que o PSS amortece também o modo interárea requer a cooperação de comissionador, proprietário da usina e operador do sistema elétrico. Potência instalada e localização influenciam na capacidade de uma usina contribuir para o amortecimento de tais modos. É necessário empregar simulações de sistemas multi-máquinas (WECC, 2009) ou causar transitórios como o desligamento de linhas de transmissão. Tempo e recursos são em geral escassos em um comissionamento, a decisão por testar o PSS para o modo 
interárea não é somente técnica.

\subsection{O PSS2B}

O Submódulo 3.6 com os requisitos técnicos mínimos para a conexão à rede básica (ONS, 2008) exige o emprego de PSS do tipo de integral de potência acelerante no Brasil. A norma IEEE (2005) denomina tal estabilizador de PSS2B. Esta dissertação trata principalmente de técnicas de ajuste deste tipo de PSS. Convém salientar que as técnicas de ajuste não são necessariamente exclusivas, ou seja, podem ser usadas para mais de um tipo de PSS.

O PSS2B de integral da potência acelerante pode ser dividido em duas partes:

- Transdutor de "integral da potência acelerante" ou de velocidade do rotor; tal transdutor foi apresentado na seção 2.2.1.4;

- Estágio de ganho e avanço-atraso de fase.

A fig. 3.1 apresenta o modelo computacional do PSS2B. Neste trabalho, a entrada $V_{S I 1}$ é utilizada para a velocidade do rotor ou para a frequência terminal do gerador, a entrada $V_{S I 2}$ é utilizada para a potência elétrica.

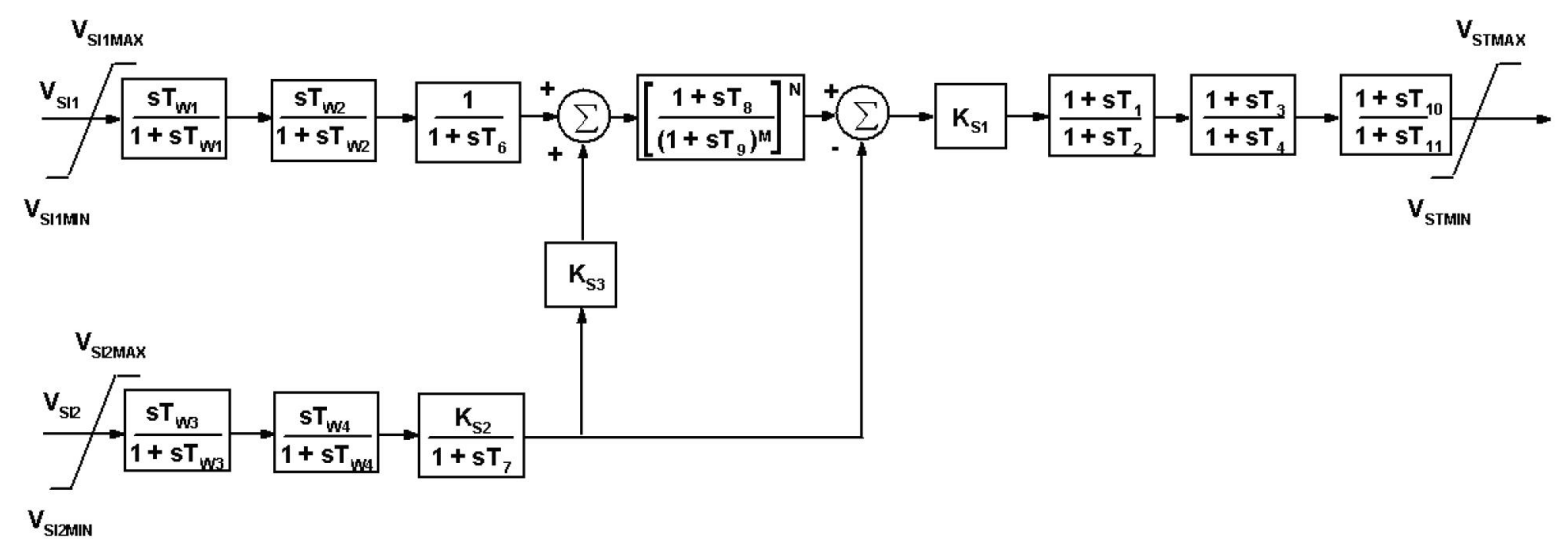

Figura 3.1: Modelo computacional do PSS2B; reimpresso de IEEE (2005). 
O transdutor da integral da potência acelerante é composto por:

- Filtros passa-alta ou filtros de washout ${ }^{1}: T_{W 1}, T_{W 2}, T_{W 3}$ e $T_{W 4}$;

- Filtro passa-baixa para a entrada de frequência: $T_{6}$;

- Ganho proporcional: $K_{S 3}$;

- Integrador da potência ativa: $K_{S 2}$ e $T_{7}$;

- Filtro rastreador de rampa ou ramp track filter: $T_{8}, T_{9}, M$ e $N$.

O estágio de ganho e avanço-atraso de fase é composto por:

- Ganho proporcional: $K_{S 1}$;

- 3 blocos de avanço-atraso de fase em série: $T_{1}, T_{2}, T_{3}, T_{4}, T_{10}$ e $T_{11}$;

- Limites para a saída do PSS: $V_{S T M A X}$ e $V_{S T M I N}$.

O pré-ajuste da primeira parte do PSS pode ser feito ainda em fase de projeto. É necessário definir quais modos de oscilação o PSS deve amortecer e conhecer a constante de inércia da máquina $H$. O ajuste final das duas partes do PSS requer ensaios em campo.

A seguir é feita uma descrição de técnicas de ajuste de cada uma das partes do PSS2B. São empregadas simulações computacionais no domínio do tempo e respostas em frequência com o objetivo didático.

\footnotetext{
${ }^{1} \mathrm{O}$ termo em inglês washout utilizado na literatura técnica sobre PSS vem do fato que estes filtros eliminam as componentes contínuas dos sinais de potência e velocidade/frequência.
} 


\subsection{Ajuste do transdutor de integral da potência ace- lerante}

\subsubsection{Filtros de washout}

Empregam-se normalmente os sinais de frequência, ou velocidade, e de potência elétrica como entradas para o PSS2B. Tais sinais possuem componentes contínuas que são filtradas pelos blocos de washout, ver fig. 3.2.

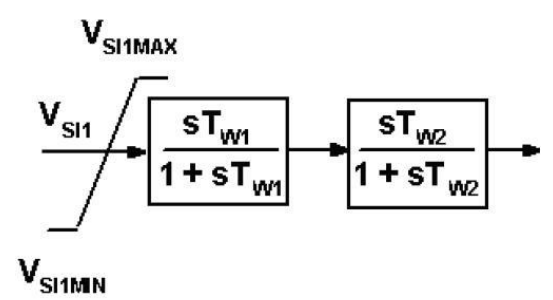

(a) Frequência ou velocidade

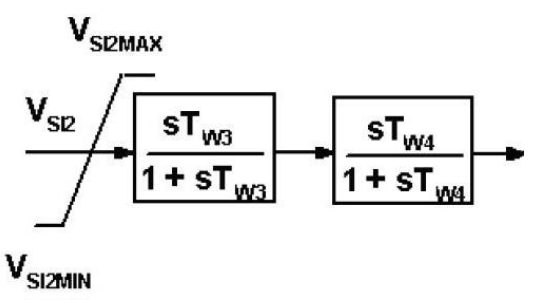

(b) Potência elétrica

Figura 3.2: Blocos de washout do PSS2B; extraídos da fig. 3.1 na pág. 32.

Há diversas citações na literatura técnica sobre como ajustar os filtros de washout, algumas delas são listadas a seguir.

- Murdoch et al. (1999a): as constantes de washout são normalmente ajustadas entre $2 s$ e $15 s$.

- Bérubé, Hajagos e Beaulieu (1999): os filtros de washout devem ser ajustados para permitir que uma oscilação de $0,1 H z$ não sofra alterações significativas em amplitude e fase.

- Hajagos (2003): ajusta-se o PSS para permitir o amortecimento de oscilações entre $0,1 H z$ e $3 H z^{2}$

- Kundur et al. (2003): os valores das constantes podem variar entre $1 s$ e $20 s$;

- $T_{W}=1,5 \mathrm{~s}$ é suficiente para amortecer o modo local que varia entre $4,4 \mathrm{rad} / \mathrm{s}$ e $12,6 \mathrm{rad} / \mathrm{s}$;

- $T_{W}=10 \mathrm{~s}$ ou maior é desejável para amortecer o modo interárea.

\footnotetext{
${ }^{2}$ Bérubé, Hajagos e Beaulieu (1999) e Hajagos (2003) adotam o mesmo valor para a frequência mínima das oscilações que devem ser amortecidas pelo PSS. Vale lembrar que os washouts são filtros passa-alta que tratam os sinais de entrada do PSS.
} 
- Kamwa, Grondin e Trudel (2005): é consenso entre os fabricantes que as constantes de washout devem ser maiores do que $3 s$, sendo que o valor de $10 s$ é o recomendado.

- IEEE (2005): valores típicos de $T_{W 1}=T_{W 2}=T_{W 3}=10 \mathrm{~s}$, com $T_{W 4}$ não utilizado.

As constantes de tempo dos filtros de washout definem a frequência de oscilações a partir da qual o PSS atua. Tais parâmetros devem ser grandes o suficiente para permitir que os modos de oscilação do rotor sejam detectados e pequenos o suficiente para que grandes excursões na tensão de campo não sejam causadas durante a operação em rede isolada (ou ilhamento) (KUNDUR et al., 2003; IEEE, 1990).

A fig. 3.3 apresenta respostas em frequência obtidas por simulação computacional de um filtro de washout. As constantes $T_{W 3}$ e $T_{W 4}$ foram ajustadas com valores iguais $\left(T_{W 3}=T_{W 4}=T_{W}\right)$. Variou-se $T_{W}$ entre $1 \mathrm{~s}$ e $10 \mathrm{~s}$. Verifica-se que as respostas para $T_{W}=3 s$ e $T_{W}=10 s$ apresentam menores atenuações e menores defasagens na parte de baixa frequência do espectro.

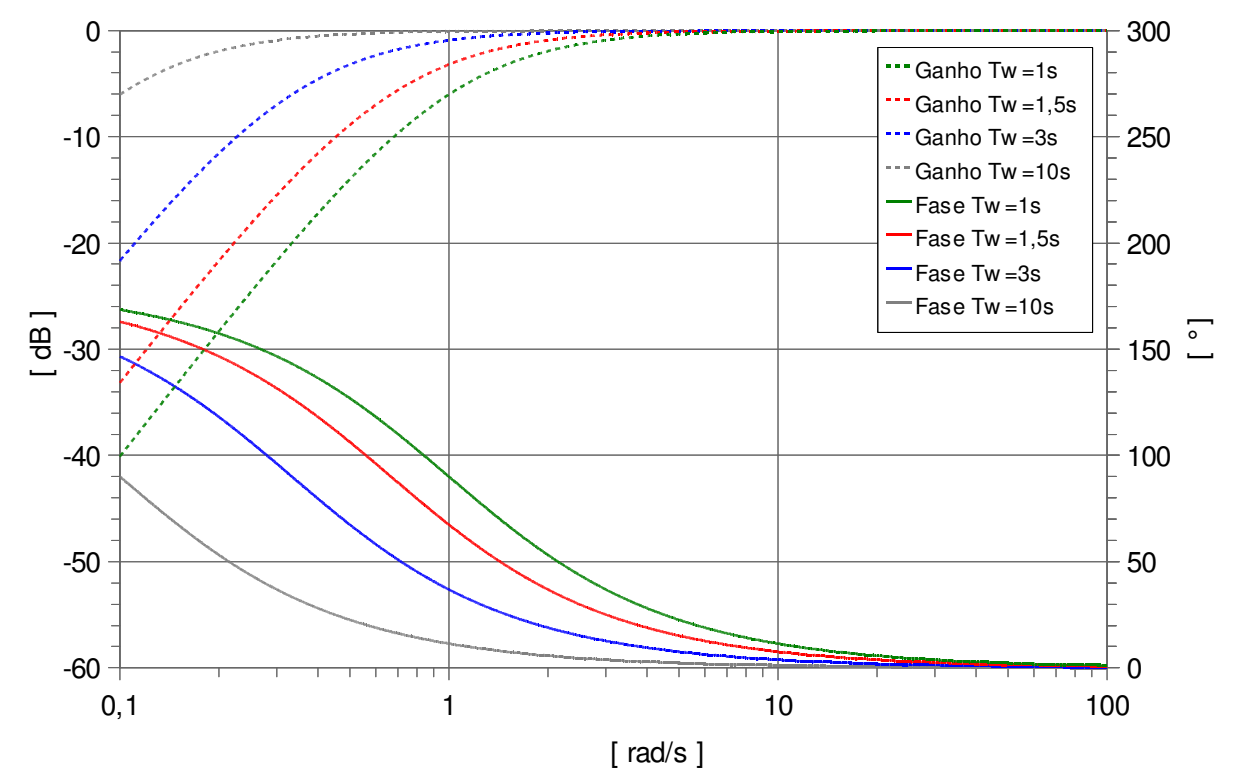

Figura 3.3: Respostas em frequência do filtro de washout com $T_{W 3}=T_{W 4}$ variando de $1 \mathrm{~s}$ a $10 \mathrm{~s}$; o ganho é expresso em $d B$ no eixo das ordenadas da esquerda e a fase em graus no eixo da direita.

Se o objetivo do PSS é amortecer oscilações interáreas, a escolha de $T_{W}$ iguais ou menores que $3 s$ representa a introdução de maiores avanços de fase no espectro abaixo de $3 \mathrm{rad} / \mathrm{s}$. Isto é verificado na fig. 3.3. A introdução deste avanços de fase na parte de baixa frequência do espectro piora a estabilidade transitória em situações nas quais os modos 
interáreas são dominantes (KUNDUR et al., 2003). Tal fato será discutido mais adiante na seção 3.3.2.1. Convém lembrar que a faixa de frequência das oscilações interáreas está abaixo de $0,5 \mathrm{~Hz}(3,14 \mathrm{rad} / \mathrm{s})$.

Ao amortecer as oscilações de potência ativa, o PSS causa oscilações na tensão terminal $\left(e_{t}\right)$ e na potência reativa $(Q)$. Quanto maiores as constantes $T_{W}$, maiores podem ser as oscilações em $e_{t}$ e em $Q$. Murdoch et al. (1999b) discutem este tema e apresentam diferentes respostas de um PSS com $T_{W}$ variando entre $10 s$ e $2 s$, ver fig 3.4.

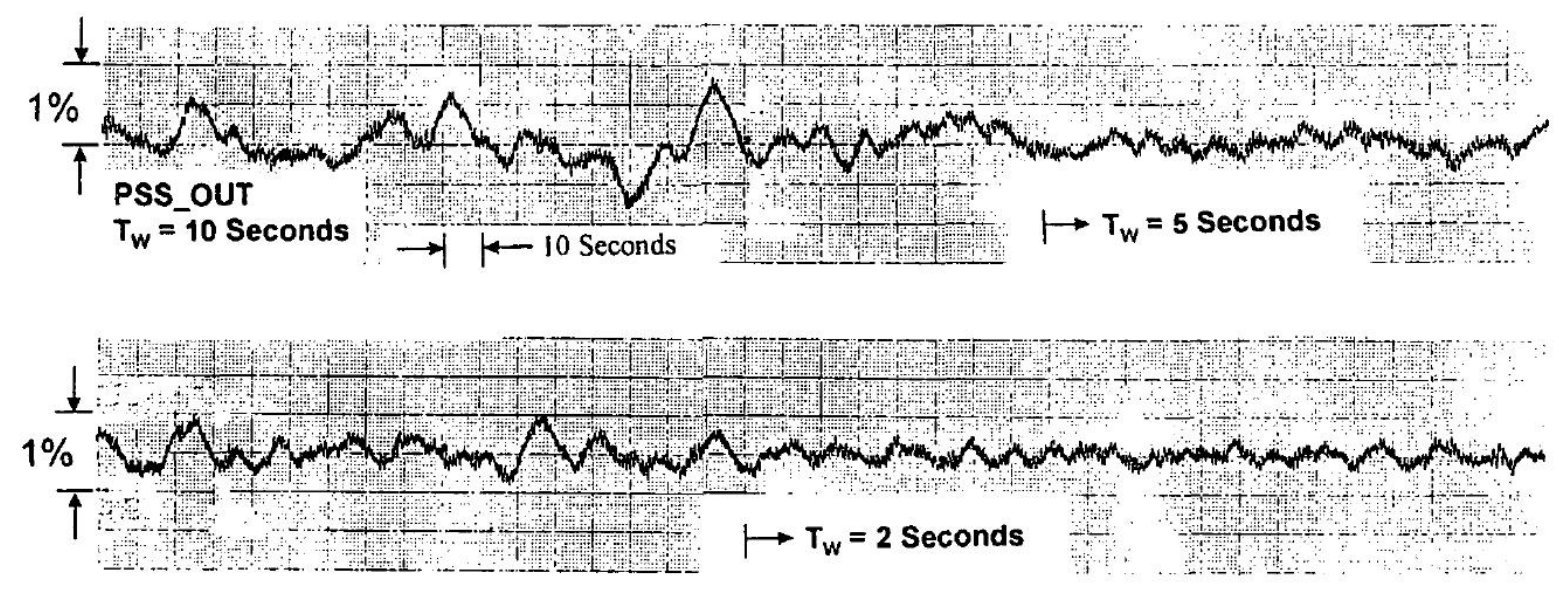

Figura 3.4: Variações na saída do PSS em função das constantes de tempo dos filtros de washout; reimpresso de Murdoch et al. (1999b).

Há um compromisso entre variações na potência reativa e o amortecimento do modo interárea. O ajuste de $T_{W}$ igual ou maior do que $10 \mathrm{~s}$ é recomendado. Entretanto, tal escolha pode levar a flutuações na potência reativa perceptíveis pela equipe de operação. Uma maneira de evitar as flutuações é diminuir $T_{W}$, em detrimento da estabilidade do modo interárea. Convém salientar que a influência de um gerador no modo interárea depende da localização e do tamanho da máquina comparada com a rede.

\subsubsection{Filtro passa-baixa para o sinal da frequência e ganho $K_{S 3}$}

Há um filtro passa-baixa dedicado ao sinal da frequência ou da velocidade no PSS2B, ver fig. 3.5a. Tal filtro modela computacionalmente o transdutor destes sinais. Dependendo do fabricante do sistema de excitação e do estabilizador de potência, a transdução e tratamento de sinais são definidas em fase de desenvolvimento do produto. Em geral, não é necessário ajustar $T_{6}$ em campo. 


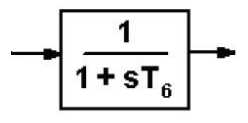

(a) Passa-baixa

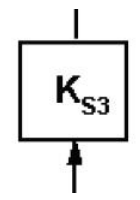

(b) Ganho $K_{S 3}$

Figura 3.5: Filtro passa-baixa para o sinal da frequência e ganho $K_{S 3}$ do PSS2B; extraídos da fig. 3.1 na pág. 32.

O ganho proporcional $K_{S 3}$, ver fig. 3.5b, é normalmente ajustado como 1 (IEEE, 2005). Algumas referências como Kamwa, Grondin e Trudel (2005) empregam ganho $K_{S 3}$ ligeiramente diferente de 1.

\subsubsection{Integrador do sinal de potência ativa (filtro passa-baixa)}

Os filtros de washout removem as componentes de baixa frequência da potência ativa $\left(P_{e}\right)$. A variação em torno do regime permanente da potência ativa $\left(\Delta P_{e}\right)$ passa em seguida por um integrador. Substitui-se tal integrador por um filtro passa-baixa (BÉRUBÉ; HAJAGOS; BEAULIEU, 1999; KUNDUR et al., 2003), ver fig. 3.6.

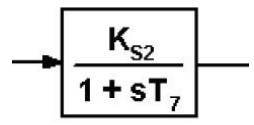

Figura 3.6: Integrador (filtro passa-baixa) do sinal de potência ativa; extraído da fig. 3.1 na pág. 32.

Caso um integrador puro fosse utilizado, a função de transferência deste bloco seria dada pela eq. 3.1:

$$
G_{\text {integrador }}=\frac{1}{2 H s}
$$

Porém, opta-se por:

$$
G_{\text {filtro }}=\frac{K_{S 2}}{1+s T_{7}}=\frac{T_{7} / 2 H}{1+s T_{7}}
$$

Faz-se $K_{S 2}=T_{7} / 2 H$ na eq. 3.2. A constante $T_{7}$ é ajustada para ser igual às constantes de tempo de washout (MURDOCH et al., 1999a; KAMWA; GRONDIN; TRUDEL, 2005; IEEE, 2005).

É interessante analisar o comportamento das funções de transferência do integrador 
puro e do filtro passa-baixa definidas nas equações 3.1 e 3.2. A fig. 3.7 compara a resposta em frequência obtida por simulação computacional de dois conjuntos compostos por:

- "Passa-baixa":

- Washout: $T_{W 3}=T_{W 4}=10 s$;

- Passa-baixa : $G_{\text {filtro }}$ dado pela eq. 3.2 onde $T_{7}=10 \mathrm{~s}$ e $H=5 s$;

- "Integrador":

- Washout: $T_{W 3}=T_{W 4}=10 \mathrm{~s}$;

- Integrador puro : $G_{\text {integrador }}$ dado pela eq. 3.1 onde $H=5 s$.

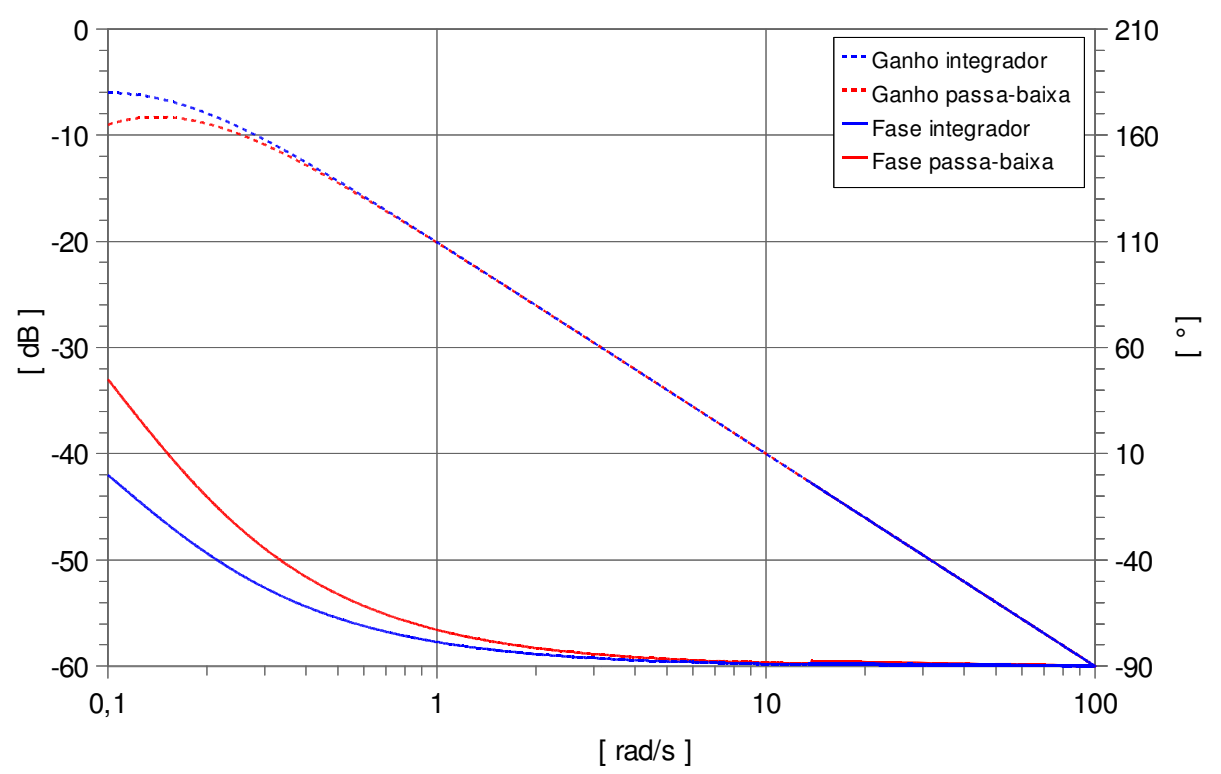

Figura 3.7: Comparação entre um integrador e um filtro passa-baixa; respostas em frequência de um washout em série com um integrador puro e um washout em série com um filtro passa-baixa.

Não se notam diferenças significativas entre as respostas em frequência dos conjuntos passa-baixa e integrador apresentados na fig. 3.7 no espectro acima de $1 \mathrm{rad} / \mathrm{s}$. Vale ressaltar que a parte de baixa frequência do sinal da potênca ativa é fortemente atenuada pelo próximo filtro do PSS2B, o rastreador de rampa. Tal fato será demonstrado na seção 3.2.4. 


\subsubsection{Filtro rastreador de rampa}

Após os estágios de passa-alta e integração, os sinais de potência elétrica e de frequência passam pelo filtro rastreador de rampa (ramp tracking filter), ver fig. 3.8. A parte central deste filtro é composta de um passa-baixa de ordem configurável. Há duas entradas: a primeira trata o sinal da frequência (representado por $f$ ) e a segunda trata o sinal da potência ativa (representado por $P$ ).

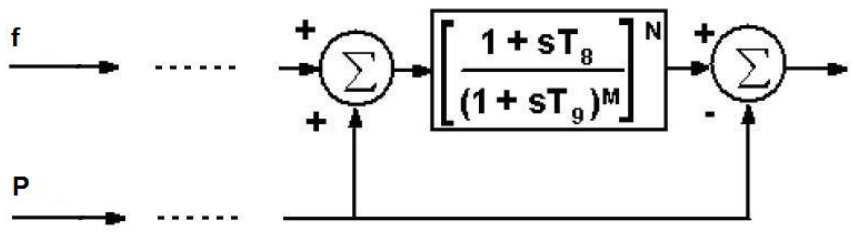

Figura 3.8: Filtro rastreador de rampa; extraído e adaptado da fig. 3.1 na pág. 32.

Com o intuito de compreender o funcionamento do filtro rastreador de rampa, foram levantadas por simulação computacional as respostas em frequência entre cada uma das entradas e a saída de tal filtro. Os resultados são apresentados na fig. 3.9. Os seguintes parâmetros foram considerados:

- $T_{8}=0,5 s, T_{9}=0,1 s, N=1$ e $M=5$.

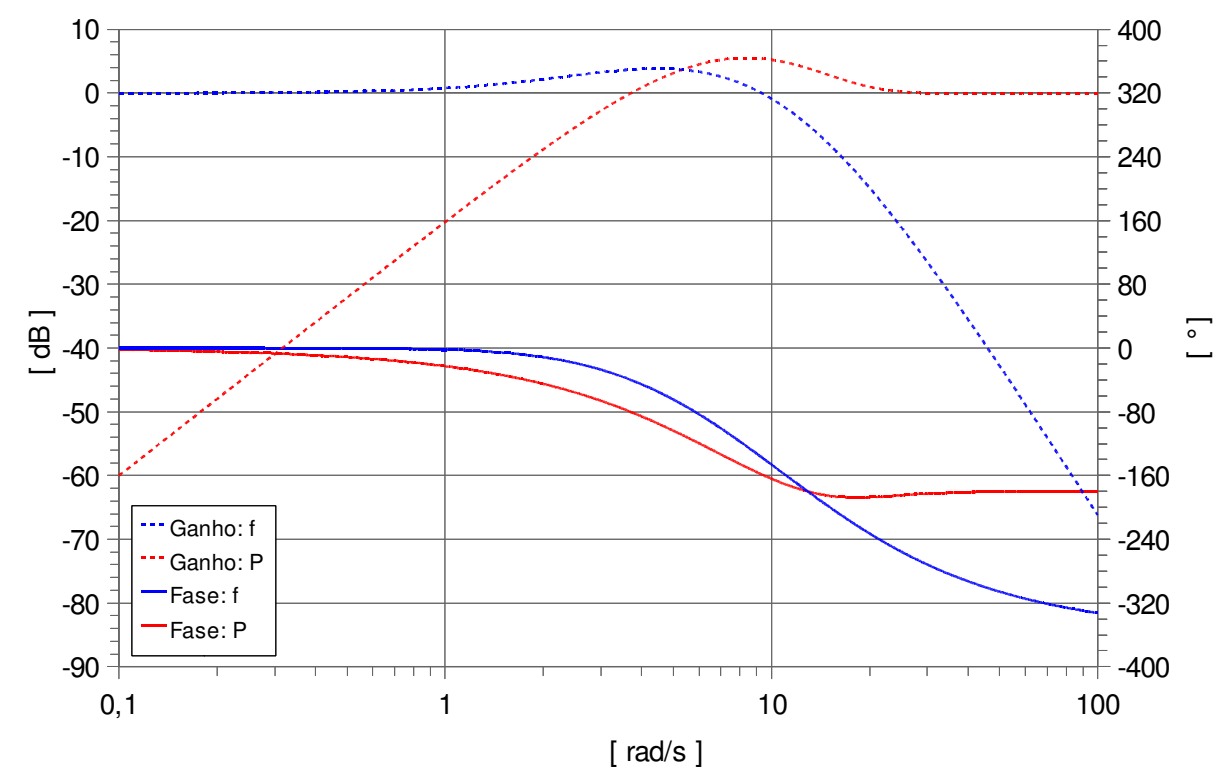

Figura 3.9: Respostas em frequência apenas do filtro rastreador de rampa; o ganho é expresso em $d B$ no eixo das ordenadas da esquerda e a fase em graus no eixo da direita. 
Não foi levada em conta nas respostas em frequência da fig. 3.9 a influência dos estágios prévios de washout, passa-baixa para frequência e integrador da potência ativa.

A influência do filtro rastreador rampa no sinal da integral da potência ativa é descrita de uma maneira bem simplificada a seguir:

- Há dois caminhos para o sinal da integral da potência ativa (ver fig. 3.8);

- Um dos caminhos segue pelo passa-baixa $\left(\frac{1+s T_{8}}{\left(1+s T_{9}\right)^{M}}\right)^{N}$;

- O outro caminho não é filtrado;

- A parte de baixa frequência (proveniente do passa-baixa) é somada ao espectro completo (com sinal negativo) na saída do ramp tracking.

A parte de baixa frequência do espectro da integral de potência ativa é cancelada pelo filtro rastreador de rampa. A parte de alta frequência do espectro da integral de $P$ sofre defasagem de $180^{\circ}$. Isto é verificado na resposta em frequência marcada por $P$ na fig. 3.9 .

A análise da influência do filtro rastreador de rampa no sinal da frequência ou velocidade é mais simples. Há apenas um caminho para o sinal. A parte alta do espectro é filtrada conforme se verifica na fig. 3.9.

Considerando a entrada $f$, o filtro rastreador de rampa deve ser ajustado para eliminar a influência de oscilações torsionais. A constante de tempo $T_{9}$ é escolhida para que a frequência de corte do filtro esteja abaixo das oscilações torsionais (KUNDUR et al., 2003). Tais oscilações não são um problema para hidrogeradores.

A discussão conjunta das referências Murdoch et al. (1999a) e Murdoch, Venkataraman e Lawson (1999) apresenta uma forma geral de ajustar o ramp tracking. Considerando entradas em rampa, aplica-se o teorema do valor final. A função de transferência do filtro rastreador de rampa a partir da entrada de potência elétrica é dada por:

$$
G_{p}(s)=G_{R T}(s)-1
$$

Onde $G_{R T}=\left(\frac{1+s T_{8}}{\left(1+s T_{9}\right)^{M}}\right)^{N}$.

A eq. 3.4 mostra a aplicação do teorema do valor final para a função de transferência 
$G_{p}(s)$

$$
\lim _{s \rightarrow 0} s\left(G_{p}(s) \frac{K}{s^{2}}\right)=0
$$

Onde $K / s^{2}$ representa a entrada em rampa.

A relação $T_{8}=M T_{9}$ satisfaz a eq. 3.4 (MURDOCH et al., 1999a; MURDOCH; VENKATARAMAN; LAWSON, 1999).

A tab. 3.1 apresenta valores empregados para o ajuste do filtro rastreador de rampa por diferentes fontes.

Tabela 3.1: Ajustes do filtro rastreador de rampa.

\begin{tabular}{lcccc} 
Fonte & $M$ & $N$ & $T_{8}$ & $T_{9}$ \\
\hline Paiva et al. (1999) & 1 & 4 & 0,4 & 0,1 \\
Murdoch et al. (1999a) & 1 & 5 & 0,5 & 0,1 \\
Ferraz et al. (2002) & 1 & 4 & 0,4 & 0,1 \\
ONS (2004b) & 1 & 4 & 0,4 & 0,1 \\
Kamwa, Grondin e Trudel (2005) & 1 & 5 & 0,5 & 0,1 \\
IEEE (2005) & 1 & 5 & 0,5 & 0,1
\end{tabular}

\subsection{Ajuste do estágio de ganho e avanço-atraso de fase}

O sinal da integral da potência acelerante é tratado pelos blocos de avanço-atraso de fase, ver fig. 3.10. O objetivo destes blocos é compensar a defasagem devido ao AVR e ao enrolamento de campo possibilitando a geração de torque elétrico em fase com as oscilações de velocidade do rotor.

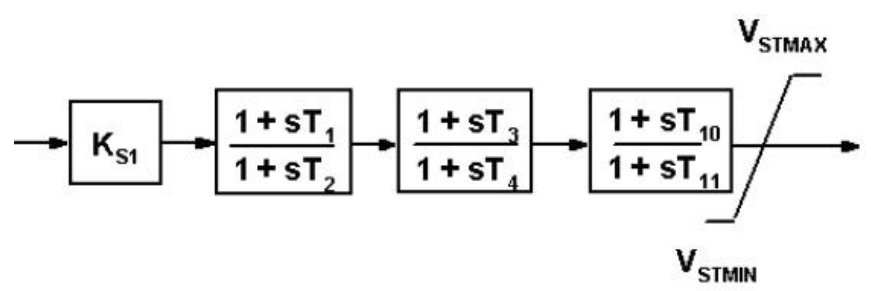

Figura 3.10: Blocos de ganho, avanço-atraso de fase e limites de saída do PSS2B; extraído da fig. 3.1 na pág. 32.

Esta dissertação classifica os métodos de ajuste dos blocos de avanço-atraso de fase do PSS em quatro tipos. 
- Métodos computacionais: encontram-se os ajustes ótimos de um ou vários PSSs a partir da modelagem de sistemas com uma ou mais máquinas e programação computacional; são empregadas técnidas de controle como análise do lugar geométrico das raízes.

- Tentativa e erro: método empírico e muitas vezes efetivo baseado na experiência do comissionador e em parâmetros de usinas similares.

- Comparação entre grandezas: métodos empíricos um pouco mais sofisticados do que a pura tentativa e erro; comparam-se a defasagem entre diferentes grandezas após a introdução proposital de pequenas perturbações.

- Compensação de fase: busca-se compensar as defasagens entre a entrada de referência de tensão do AVR e o torque elétrico.

Métodos computacionais exigem a modelagem e a simulação do gerador e do sistema de potência. A principal dificuldade deste tipo de abordagem é a obtenção rápida de um modelo confiável do gerador e do sistema de potência ${ }^{3}$. Esta dissertação prioriza os métodos com base teórica que podem ser empregados em condições nas quais há pouco tempo e há pouca informação disponível para a modelagem computacional da unidade geradora e do sistema de potência. Mais informações sobre métodos computacionais de ajuste de PSS podem ser encontradas em Senger (1983) e Zanetta (1984).

A seguir são apresentados os métodos de Tentativa e erro, Compensação de fase e Comparação entre grandezas. Posteriormente, são feitas considerações sobre o ajuste do ganho $K_{S 1}$ e dos limites de saída $V_{S T M A X}$ e $V_{S T M I N}$.

\subsubsection{Tentativa e erro}

Os métodos de ajuste baseados na tentativa e erro dependem muito da experiência do comissionador. Convém salientar que os ensaios durante o comissionamento não são realizados ao acaso. Há métodos em meio às tentativas e erros. Esta dissertação não pretende descrever em detalhes métodos puramente empíricos empregados por diferentes profissionais atuantes no mercado de ajuste de reguladores de tensão e PSSs. A intenção é apresentar os fundamentos teóricos que justifiquem os métodos de ajuste.

\footnotetext{
${ }^{3}$ Esta dificuldade pode ser contornada pelo uso de equipamentos digitais de identificação de sistemas. Os modelos identificados podem ser usados por programas dedicados de simulação computacional que encontram o ajuste ótimo do PSS. Tal abordagem de ajuste baseada em simulação computacional e no emprego de equipamentos digitais de identificação de sistemas não é discutida nesta dissertação.
} 
É interessante, entretanto, apresentar alguns passos já usados pelo autor desta dissertação durante ajustes realizados na base da tentativa e erro:

- Parte-se de ajustes feitos em usinas de porte semelhante;

- Provocam-se pequenos distúrbios na referência de tensão do AVR;

- Registram-se as respostas de diferentes variáveis como tensão estatórica, frequência, potência reativa e potência ativa;

- Verificam-se as oscilações nas respostas do sistema com e sem o PSS;

- Realizam-se ajustes finos nos parâmetros dos blocos de avanço-atraso;

- Comparam-se as respostas com diferentes ajustes do PSS.

\subsubsection{Comparação entre tensão e frequência para o amorteci- mento das oscilações interárea}

O ajuste dos blocos de avanço-atraso de fase pode ser feito empiricamente a partir da comparação entre diferentes grandezas durante pequenos distúrbios. Um exemplo é o método sugerido por Schleif et al. (1968):

- O PSS deve fazer as oscilações de tensão estarem em fase com as oscilações de frequência.

O método empírico consiste em:

- Provocar pequenas oscilações no sistema de potência;

- Registrar as respostas da tensão terminal e da frequência;

- Fazer pequenas alterações nos ajustes dos blocos de avanço-atraso;

- Provocar pequenas oscilações e comparar as respostas com os novos ajustes;

- Fazer novos testes se necessário.

Schleif et al. (1968) propuseram este método a partir da análise da influência do controle de tensão e do PSS na estabilidade do gerador. Os autores consideraram um modelo simplificado de um barramento infinito através de uma impedância $X_{L}$, fig. 3.11a. 
A transferência de potência entre as barras $T$ e $R$ é dada pela eq. 3.5, onde $\delta$ é a defasagem entre as tensões $E_{T}$ e $E_{R}$ (KUNDUR, 1993, p. 222).

$$
P=\frac{E_{T} E_{R}}{X_{L}} \operatorname{sen} \delta
$$

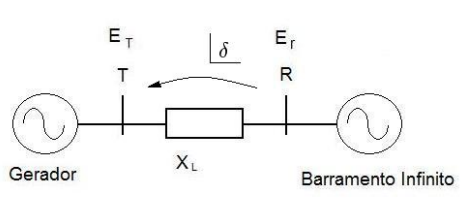

(a) Sistema

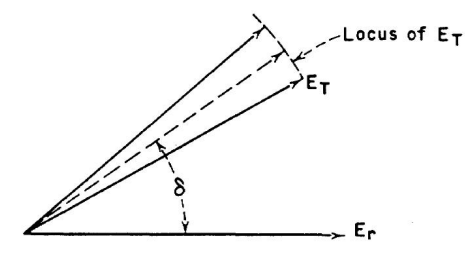

(b) Controle de tensão puro

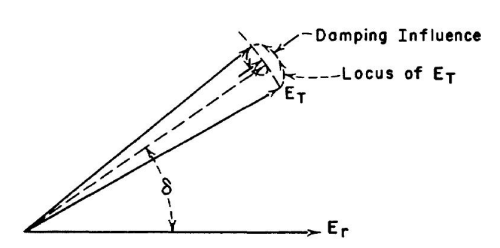

(c) Controle de tensão com amortecimento

Figura 3.11: Controle de tensão e amortecimento; adaptado e reimpresso de Schleif et al. (1968).

A primeira análise feita por Schleif et al. (1968) da estabilidade da máquina considera que o gerador da fig. 3.11a está equipado com um regulador de tensão ideal. Assumese que o sistema está em operação estável $\operatorname{com} \delta<\pi / 2$ e que o torque fornecido pela turbina ao gerador é constante. Pequenos distúrbios no fluxo de potência implicam em pequenos desbalanços entre a potência mecânica fornecida pela turbina e a potência elétrica absorvida pela rede, resultando em desvios na velocidade do gerador e em $\delta$. A fig. 3.11b mostra o comportamento da tensão do gerador durante pequenas oscilações em $\delta$. Ao manter a tensão na barra $T$ constante, o sistema de excitação não contribui para amortecer as oscilações. A tab. 3.2 resume a dinâmica deste sistema após um pequeno distúrbio.

Tabela 3.2: Amortecimento de oscilações com controle de tensão ideal.

\begin{tabular}{|c|c|c|c|c|}
\hline$\delta$ & $E_{T}$ & $\frac{E_{R}}{X_{L}}$ & $\operatorname{sen} \delta$ & Resultado da eq. 3.5 \\
\hline 介 & constante & constante & $\Uparrow$ & $\begin{array}{l}\text { A potência elétrica }(P) \text { aumenta devido a } \\
\operatorname{sen} \delta \text {, "freando" o gerador que acelerava. }\end{array}$ \\
\hline$\Downarrow$ & constante & constante & $\Downarrow$ & $\begin{array}{l}\text { A potência elétrica }(P) \text { diminui devido a } \\
\text { sen } \delta \text {, "acelerando" o gerador que freava. }\end{array}$ \\
\hline
\end{tabular}

A segunda análise feita por Schleif et al. (1968) considera que um dispositivo ideal amortecedor de oscilações foi instalado no sistema de excitação. Tal PSS ideal identifica o distúrbio e modifica a tensão gerador em fase com $d \delta / d t$. A tab. 3.3 descreve como o AVR com PSS contribui para amortecer as oscilações. O resultado gráfico da ação do 
regulador de tensão é representado na fig. 3.11c.

Tabela 3.3: Amortecimento de oscilações com controle de tensão e sistema estabilizador ideais.

\begin{tabular}{|c|c|c|c|c|}
\hline$\delta$ & $E_{t}$ & $\frac{E_{R}}{X_{L}}$ & $\operatorname{sen} \delta$ & Resultado da eq. 3.5 \\
\hline$\Uparrow$ & $\Uparrow$ & constante & $\Uparrow$ & $\begin{array}{l}\text { A potência elétrica }(P) \text { aumenta devido a } E_{t} \\
\text { e a sen } \delta \text {, "freando" o gerador que acelerava. }\end{array}$ \\
\hline$\Downarrow$ & $\Downarrow$ & constante & $\Downarrow$ & $\begin{array}{l}\text { A potência elétrica }(P) \text { diminui devido a } E_{t} \\
\text { e a sen } \delta \text {, "acelerando" o gerador que freava. }\end{array}$ \\
\hline
\end{tabular}

O PSS2B possui duas entradas, uma para a velocidade/frequência e outra para a potência ativa. A seção 3.2.4 discutiu a influência do filtro rastreador de rampa nos sinais de entrada do estabilizador. A fig. 3.9 na pág. 39 mostra que abaixo dos $2 \mathrm{rad} / \mathrm{s}$ a entrada de velocidade/frequência predomina na composição do sinal da integral de potência acelerante ${ }^{4}$. Nesta faixa do espectro, é possível adotar o seguinte procedimento para o ajuste das constantes $T_{1}, T_{2}, T_{3}, T_{4}, T_{10}$ e $T_{11}$ da fig. 3.10 na pág. 41:

- Caso as oscilações de tensão estejam atrasadas em relação às oscilações de frequência, ajustam-se os blocos de avanço-atraso como avançadores de fase;

- Caso as oscilações de tensão estejam adiantadas em relação às oscilações de frequência, ajustam-se os blocos de avanço-atraso como atrasadores de fase;

A fig. 3.9 mostra também que na faixa entre $2 \mathrm{rad} / \mathrm{s}$ e $20 \mathrm{rad} / \mathrm{s}$ a integral da potência acelerante é composta por ambas entradas de frequência/velocidade e potência. Em tal faixa do espectro, o sinal da potência interfere na aplicação do método de comparação das grandezas frequência e tensão do gerador para o ajuste do PSS2B.

O método sugerido por Schleif et al. (1968), tendo como objetivo o ajuste do PSS2B, é aplicável para o amortecimento de oscilações do modo interárea. Tanto sistemas de excitação lentos como rápidos equipados com PSS são capazes de contribuir para o amortecimento deste modo. É necessário lembrar que quanto maior a unidade geradora, maior é a capacidade de amortecer oscilações interárea.

\footnotetext{
${ }^{4}$ As oscilações interárea estão na faixa do espectro abaixo dos $3 \mathrm{rad} / \mathrm{s}$.
} 


\subsubsection{Os avanços de fase causados pelos filtros de washout e o modo inter- área}

Os filtros de washout introduzem avanços de fase na parte mais baixa do espectro (ver seção 3.2.1). Estes avanços podem ser prejudiciais para o amortecimento dos modos interárea se não forem levados em conta na hora do ajuste do estágio de ganho e avançoatraso do PSS2B.

A entrada para o estágio de avanço-atraso do PSS2B é o sinal da integral da potência acelerante, tal sinal equivale à velocidade do rotor. Diferentes ajustes para os blocos de avanço-atraso (fig. 3.10 na pág. 41) são necessários dependendo do ajuste das constantes de washout.

A influência das constantes de washout pode ser observada na fig. 3.12. São apresentadas as respostas em frequência obtidas por simulação computacional entre a entrada de velocidade/frequência do PSS2B e o sinal de integral de potência acelerante. Empregouse $T_{6}=0 s, T_{8}=0,5 s, T_{9}=0,1 s, N=1$ e $M=5$. As constantes de washout foram ajustadas com valores iguais $T_{W 1}=T_{W 2}=T_{W}$. Variou-se $T_{W}$ entre $3 \mathrm{~s}$ e $20 \mathrm{~s}$. O avanço de fase na parte baixa do espectro é maior quando $T_{W}$ é menor. Mostra-se também a resposta sem o tratamento prévio do washout.

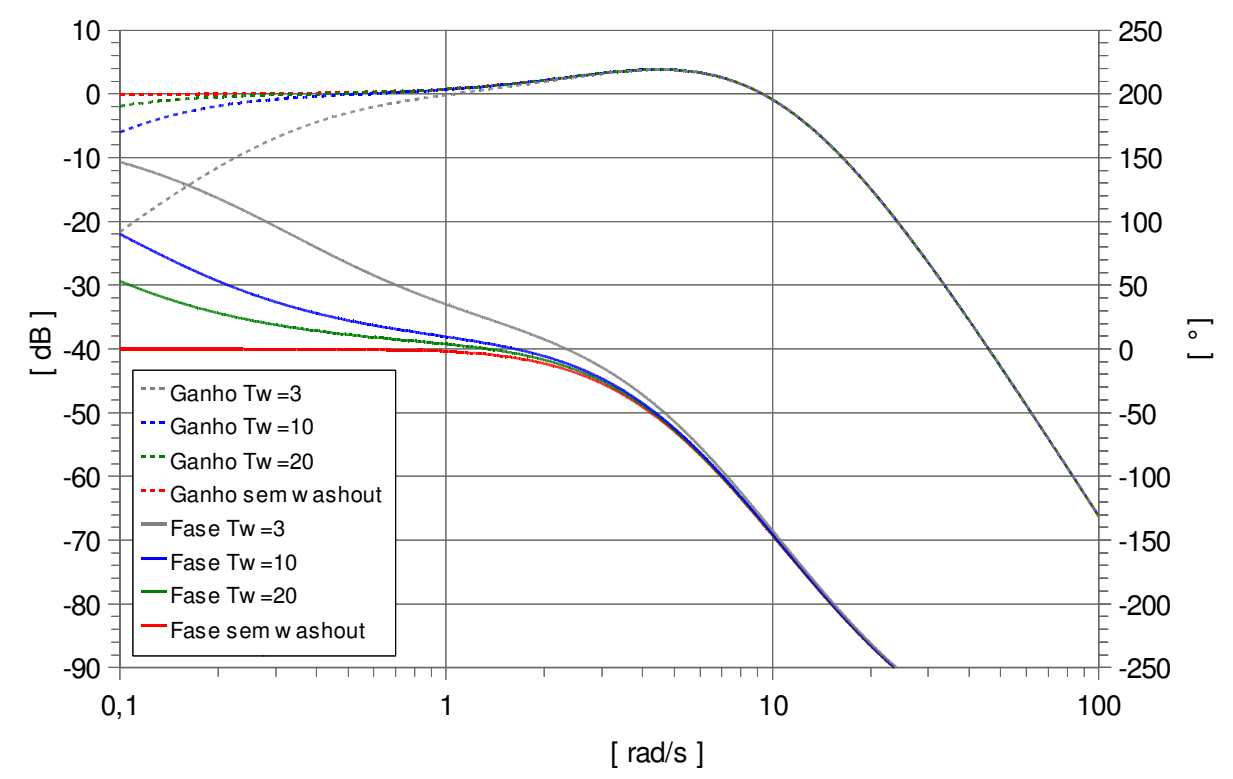

Figura 3.12: Respostas em frequência entre a entrada de frequência/velocidade e a integral da potência acelerante com diferentes constantes de washout; o ganho é expresso em $d B$ no eixo das ordenadas da esquerda e a fase em graus no eixo da direita.

A análise da fig. 3.12 leva a conclusão de que é necessário ajustar os blocos de avançoatraso para compensar a defasagem entre a frequência do gerador e a tensão terminal. 
Tal idéia de compensar defasagens será discutida mais adiante na seção 3.3.4. Deve-se lembrar que os avanços de fase causados pelos filtros de washout podem exigir que um dos blocos de avanço-atraso seja ajustado como atrasador de fase.

\subsubsection{Comparação entre saída do PSS e potência ativa para amortecer oscilações locais}

Gu, Smulders e Mushens (2000) apresentam um método de ajuste de um PSS2B aplicado em uma máquina equipada com sistema de excitação estático. Os autores afirmam que:

- "O amortecimento máximo das oscilações no sistema se dá quando a saída do PSS está em contra fase com a potência ativa."

Os resultados apresentados por Gu, Smulders e Mushens (2000) mostram apenas o amortecimento do modo local. A influência do método no amortecimento do modo interárea e a influência de diferentes ajustes do AVR não foram discutidas pelos autores.

Para se compreender o método sugerido por Gu, Smulders e Mushens (2000), convém analisar a relação entre o torque elétrico e a tensão de campo. Da fig. 2.3 na pág. 11, obtém-se:

$$
\Delta T_{e}=K_{1} \Delta \delta+\left(\frac{K_{2} K_{3}}{1+s K_{3} T_{d 0}^{\prime}}\left(\Delta E_{f d}-K_{4} \Delta \delta\right)\right)
$$

Levando em conta apenas os distúrbios com pequenas variações no ângulo de carga, $\Delta \delta \approx 0$, simplifica-se a eq. 3.6:

$$
\Delta T_{e}=\frac{K_{2} K_{3}}{1+s K_{3} T_{d 0}^{\prime}} \Delta E_{f d}
$$

A constante $K_{3}$ para sistemas nos quais o gerador é conectado a um barramento infinito por uma impedâncias puramente indutiva $\left(X_{e}\right)$ é dada por:

$$
K_{3}=\frac{X_{d}^{\prime}+X_{e}}{X_{d}+X_{e}}
$$

Com o intuito de analisar o comportamento da fase entre $\Delta T_{e} / \Delta E_{f d}$, simulou-se computacionalmente o comportamento de um sistema descrito pelas equações 3.7 e 3.8 . 
Considerou-se $X_{d}=1$ p.u., $X_{d}^{\prime}=0,3 p . u$. e $T_{d 0}^{\prime}=5 s$. A fig. 3.13 apresenta o comportamento da fase da função de transferência $\Delta T_{e} / \Delta E_{f d}$ para diferentes impedâncias externas. Variou-se $X_{e}$ entre 0,1p.u. e 0,7p.u. Nota-se na fig. 3.13 que o torque elétrico está praticamente $90^{\circ}$ atrasado da tensão de campo na faixa de frequência do modo local (entre $4,4 \mathrm{rad} / \mathrm{s}$ e $12,6 \mathrm{rad} / \mathrm{s})$.

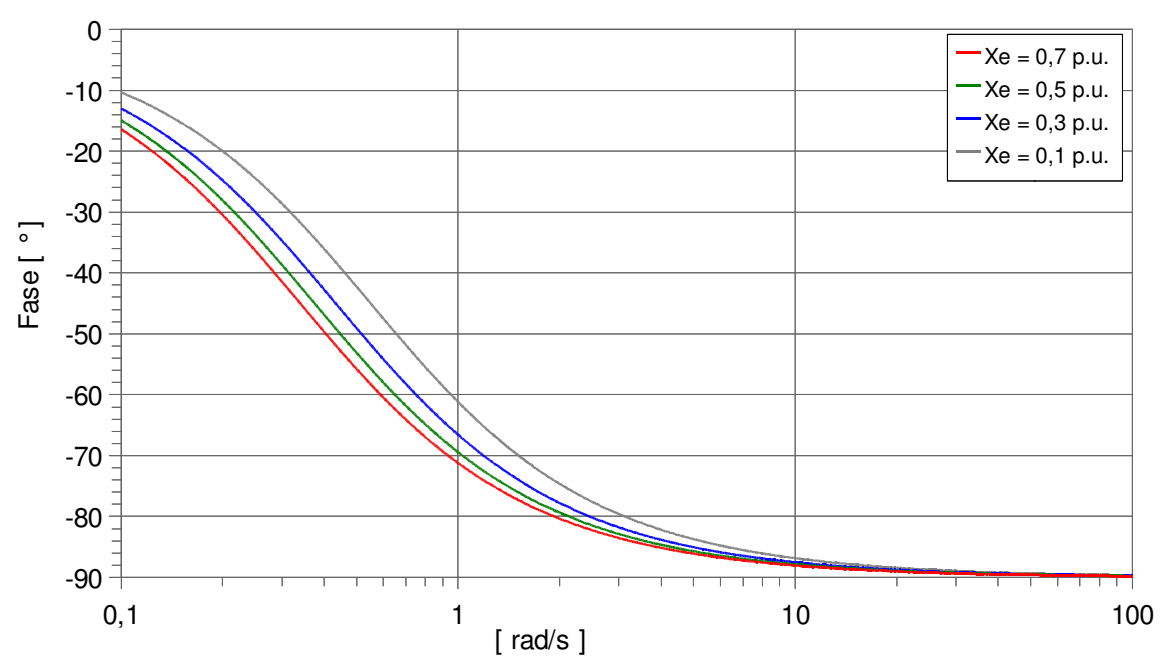

Figura 3.13: Fase das respostas em frequência entre tensão de campo e torque elétrico de um sistema descrito pelas equações 3.7 e 3.8 .

Esta dissertação trata principalmente de sistemas de excitação estáticos. O atraso entre a referência do AVR e a tensão de campo nestes casos é muito pequeno, da ordem de uma ou algumas dezenas de milissegundos. Tal atraso já considera os tempos de processamento de sinais e disparo da ponte de tiristores. Com os modernos reguladores de tensão digitais equipados com excitatrizes tiristorizadas, o PSS precisa "vencer" apenas um pequeno atraso entre referência de tensão estatórica e tensão de campo. No caso de sistemas equipados com excitatrizes rotativas, há um atraso de fase entre referência do AVR e $\Delta E_{f d}$ devido à característica indutiva do enrolamento de campo da excitatriz.

O funcionamento do método de ajuste baseado na comparação entre a saída do PSS e a potência ativa para o amortecimento do modo local de oscilações é resumido a seguir:

- A velocidade $\Delta \omega_{r}$ está $90^{\circ}$ a frente da potência ativa $\Delta P_{e}$ (ver eq. 2.8 na pág. 26);

- Mede-se $\Delta P_{e}$;

- Avança-se (atrasa-se) $\Delta P_{e}$ em $180^{\circ}$;

- Compensa-se o atraso quase nulo do regulador de tensão mais excitatriz tiristorizada; 
- Compensa-se o atraso de $90^{\circ}$ do enrolamento de campo;

- Produz-se torque elétrico em fase com a velocidade do rotor.

O método empírico de ajuste baseado na comparação entre potência ativa e sinal de saída do PSS2B consiste em:

- Causar pequenos distúrbios com o PSS desconectado da malha do AVR;

- Registrar e comparar os sinais de potência ativa e saída do PSS;

- Fazer pequenas modificações no ajuste dos blocos de avanço-atraso;

- Causar novos pequenos distúrbios;

- Registrar e comparar grandezas;

- Repetir os ensaios até que saída do PSS e potência ativa estejam em contra fase;

- Conectar o PSS à malha do AVR e realizar o ajuste da ganho $K_{S 1}$ (ver seção 3.3.5).

A análise da fig. 3.12 na pág. 46 levou a conclusão que o ajuste dos blocos de avanço-atraso deve ser feito para compensar a defasagem entre duas grandezas. A análise da fig. 3.13 também sugere o emprego de um método de compensar defasagens, neste caso, entre tensão de campo $\left(\Delta E_{f d}\right)$ e torque elétrico $\left(\Delta T_{e}\right)$.

O método de $\mathrm{Gu}$, Smulders e Mushens (2000) parte do princípio que a defasagem é quase nula entre a referência de tensão do $\operatorname{AVR}\left(\Delta e_{t r e f}\right)$ e a tensão de campo $\left(\Delta E_{f d}\right)$. Um ajuste mais criterioso compensaria a defasagem entre $\Delta e_{t r e f}, \Delta E_{f d}$ e $\Delta T_{e}$. Este conceito de compensar defasagens é a base do método descrito na seção 3.3.4.

\subsubsection{A influência do carregamento e do ajuste do AVR na aplicação do método de comparação entre saída do PSS e potência ativa}

A fig. 3.13 na pág. 48 mostrou o comportamento da defasagem da função de transferência $\Delta T_{e} / \Delta E_{f d}$ para diferentes impedâncias de conexão da máquina ao barramento infinito. Tal figura foi obtida a partir da hipótese de pequenas variações no ângulo de $\operatorname{carga}(\Delta \delta \approx 0)$.

É interessante verificar a validade da hipótese de pequenas variações em $\Delta \delta$ e da aproximação de atraso quase nulo entre $\Delta e_{t r e f}$ e $\Delta E_{f d}$. Com intuito de analisar tais questões, foram realizadas simulações computacionais de um sistema com as seguintes características: 
- Modelo computacional apresentado na fig. 2.6 na pág. 20;

- Dados da máquina e do sistema de potência conforme a tab. 2.1 na pág. 13;

- Parâmetros do modelo do gerador definidos na tab. 2.3 na pág. 15;

- Frequência da rede $(f)$ considerada constante e igual a $60 H z$;

- Incluído um dispositivo capaz de gerar torque elétrico em fase com a velocidade (ganho $D=5$ ) representando a ação dos enrolamentos amortecedores.

A fig. 3.14 apresenta a fase da função de transferência $\Delta T_{e K 2} / \Delta E_{f d}$ obtida para diferentes carregamentos. Desligou-se a malha de controle do AVR, fez $K_{p}=0$ na fig. 2.6 na pág. 20. Foram consideradas as potências ativa de 0,2p.u., 0,4p.u., 0,6p.u. e 0,8p.u. A potência reativa foi mantida constante em $0,1 p$.u. A inclusão dos efeitos da variação no ângulo de carga $(\Delta \delta)$ e da variação do carregamento não alteraram consideravelmente o comportamento da fase de $\Delta T_{e K 2} / \Delta E_{f d}$. A defasagem entre $\Delta E_{f d}$ e $\Delta T_{e K 2}$ é de aproximadamente $90^{\circ}$ na faixa de frequência das oscilações locais.

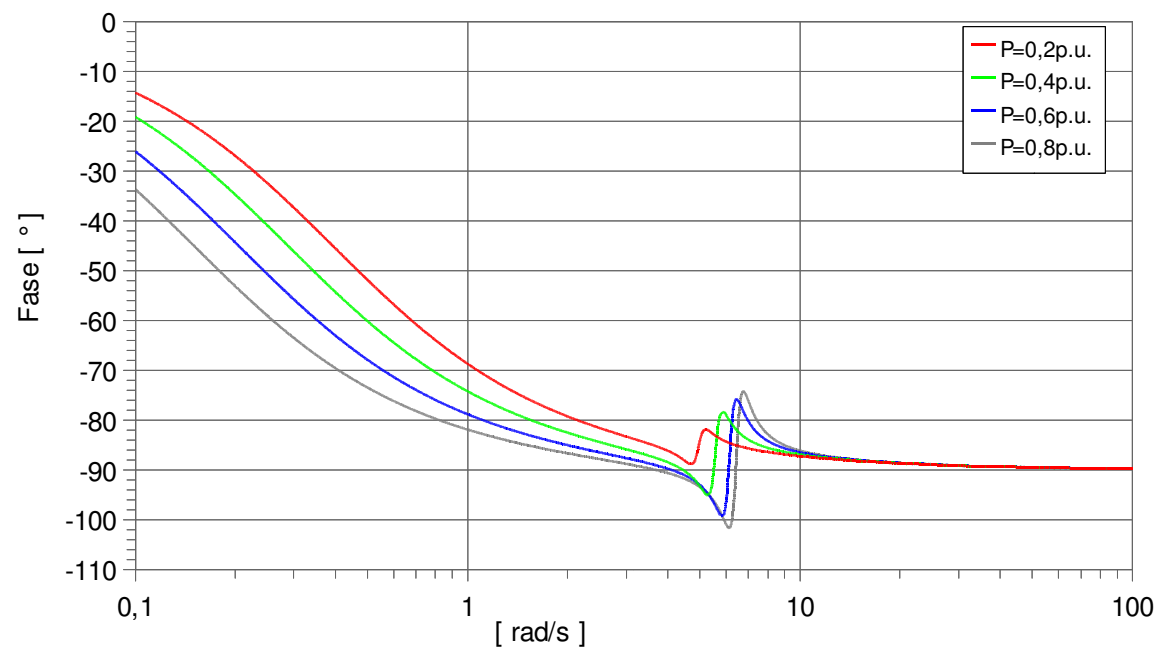

Figura 3.14: Fase das respostas em frequência $\Delta T_{e K 2} / \Delta E_{f d}$ em função do carregamento.

Ao se abrir a malha de controle do modelo simplificado do AVR apresentado na fig. 2.6 na pág. 20, verifica-se que a defasagem entre a referência de tensão do AVR $\left(\Delta e_{\text {tref }}\right)$ e a tensão de campo $\left(\Delta E_{f d}\right)$ depende das constantes de tempo $T_{b}$ e $T_{i}$. Os ganhos proporcionais $K_{p}$ e $K_{b}$ não alteram o comportamento da fase de $\Delta E_{f d} / \Delta e_{\text {tref }}$. A constante de tempo $T_{b}$ é uma aproximação de primeira ordem dos atrasos e tempos mortos inerentes ao regulador de tensão, para alterar tal constante é necessário alterar o 
hardware do sistema de excitação. A constante $T_{i}$ é um parâmetro ajustável do AVR. A influência do ajuste deste parâmetro na função de transferência $\Delta E_{f d} / \Delta e_{t r e f}$ do AVR em malha aberta é mostrada na fig. 3.15.

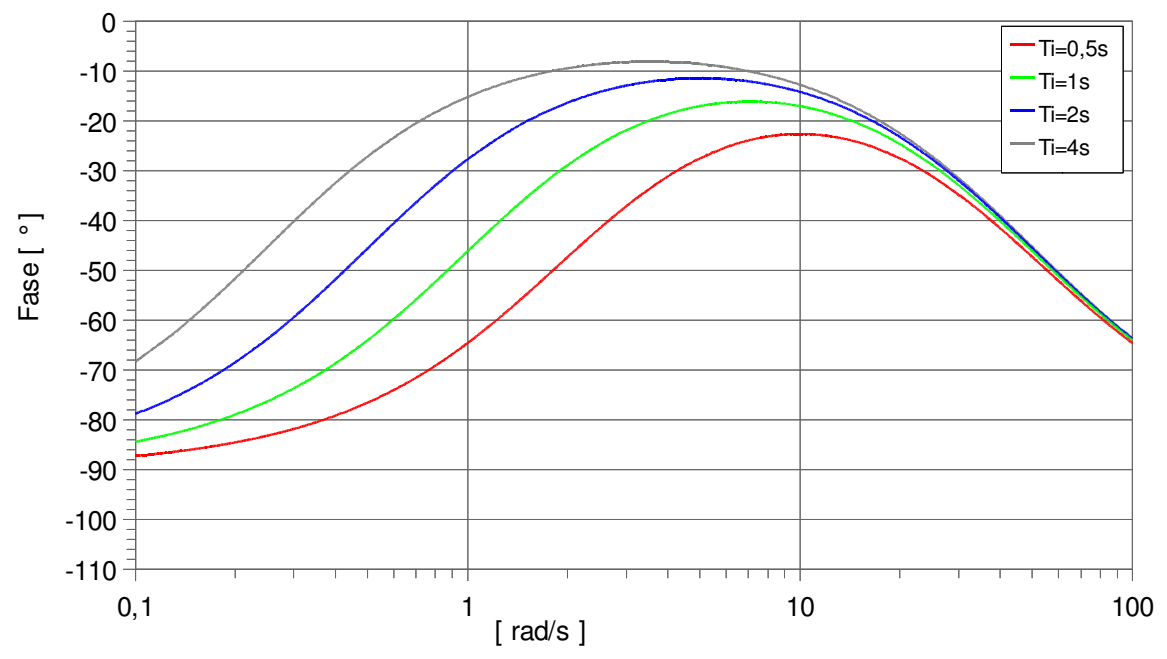

Figura 3.15: Fase das respostas em frequência $\Delta E_{f d} / \Delta e_{t r e f}$ em função do ajuste da constante $T_{i}$ do regulador PI do AVR.

A fig. 3.15 mostra que, para os ajustes de $T_{i}$ escolhidos, o atraso de fase entre $\Delta E_{f d}$ e $\Delta e_{t r e f}$ está entre zero e $30^{\circ}$ na faixa de frequência do modo local. A aplicação do método de ajuste do PSS baseado na comparação entre a saída do PSS e a potência ativa desconsidera este atraso. Tal método resulta, portanto, na produção de torque elétrico ligeiramente atrasado em relação às variações de velocidade do rotor. Há uma subcompensação de fase, este assunto será abordado mais adiante pela seção 3.4.2.2.

\subsubsection{Compensação de fase}

Desde os primeiros PSSs na década de 1960, busca-se uma maneira de se gerar torque elétrico em fase com as oscilações de velocidade do rotor. Para alcançar tal objetivo é necessário compensar a defasagem ocorrida entre a referência de tensão do $\operatorname{AVR}\left(\Delta e_{\text {tref }}\right)$ e o torque elétrico $\left(\Delta T_{e}\right)$. Larsen e Swann (1981a), Murdoch et al. (1999a) e Murdoch, Venkataraman e Lawson (1999) tratam deste tema.

Há desafios práticos para o emprego do método de compensação de fase em campo. Parte-se do princípio que a saída do transdutor de integral de potência acelerante é equivalente à velocidade do rotor do gerador. Basta ajustar os blocos de avanço-atraso do PSS2B para que estes compensem a defasagem entre $\Delta e_{\text {tref }}$ e $\Delta T_{e}$. Entretanto, estabelecer 
a relação entre torque elétrico e referência do AVR não é trivial.

\subsubsection{Resposta em frequência entre a referência de tensão do AVR e o torque elétrico}

Não é possível medir em campo a função de transferência $\Delta T_{e} / \Delta e_{\text {tref }}$. Uma solução apresentada na literatura técnica é fazer aproximações a partir do modelo linearizado da fig. 2.3 na pág. 11.

Da fig. 2.3, deduz-se que o torque elétrico é igual a:

$$
\Delta T_{e}=K_{2} \Delta E_{q}^{\prime}+K_{1} \Delta \delta
$$

A tensão terminal é dada por:

$$
\Delta e_{t}=K_{6} \Delta E_{q}^{\prime}+K_{5} \Delta \delta
$$

Assumindo que as variações de $\delta$ são desprezíveis, $\Delta \delta \approx 0$, tem-se:

$$
\Delta T_{e}=\frac{K_{2}}{K_{6}} \Delta e_{t}
$$

O que resulta na relação proporcional entre as funções de transferência:

$$
\frac{\Delta T_{e}}{\Delta e_{\text {tref }}}=\frac{K_{2}}{K_{6}} G_{a v r}
$$

Onde $G_{\text {avr }}$ representa a função de transferência com o AVR em malha fechada entre a referência de tensão $\left(\Delta e_{\text {tref }}\right)$ e a tensão terminal do gerador $\left(\Delta e_{t}\right)$. Assumindo que as variações em $\delta$ são desprezíveis para pequenos distúrbios, o comportamento da fase das funções $G_{a v r}$ e $\Delta T_{e} / \Delta e_{t r e f}$ é idêntico.

Com o objetivo de verificar a validade do equacionamento que resultou na eq. 3.12, foram levantadas computacionalmente respostas em frequência entre grandezas do modelo dado pela fig. 2.6 na pág. 20. A fig. 3.16 apresenta os resultados obtidos. São mostradas as respostas em frequência $\Delta e_{t} / \Delta e_{\text {tref }}$ e $\Delta T_{e K 2} / \Delta e_{\text {tref }}$. 


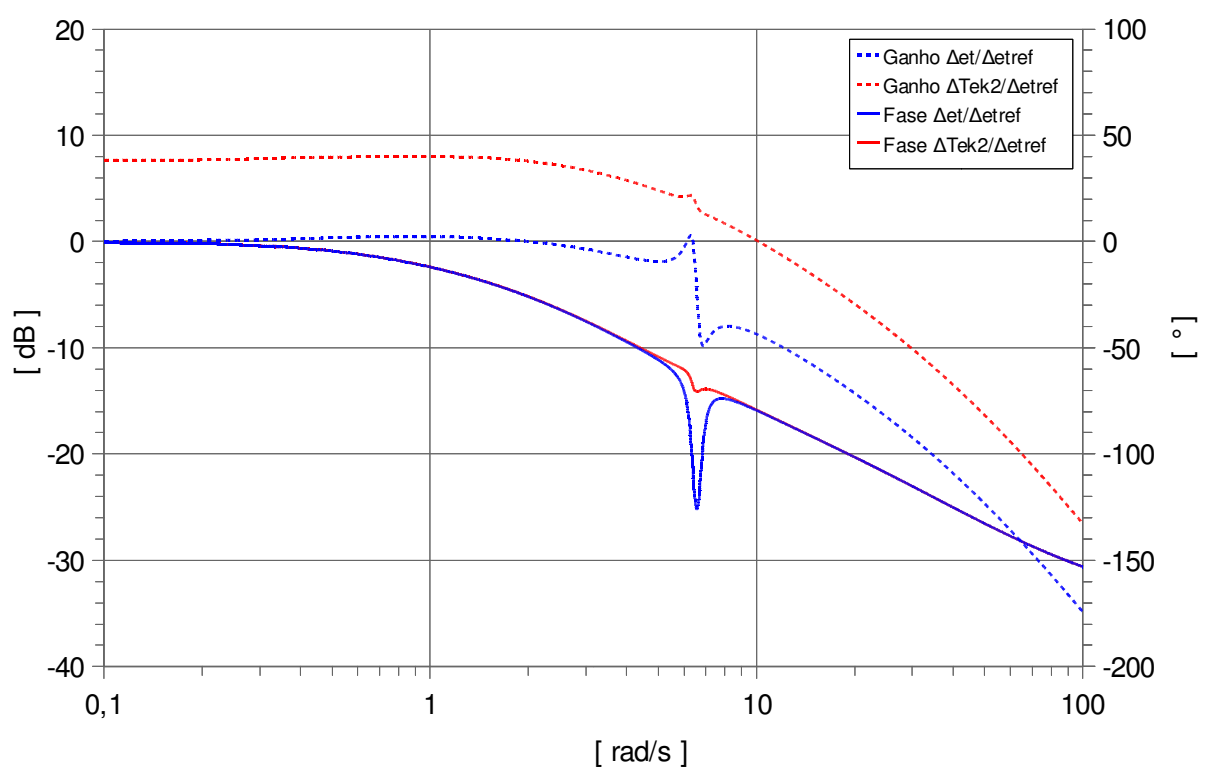

Figura 3.16: Respostas em frequência $\Delta e_{t} / \Delta e_{\text {tref }}$ e $\Delta T_{e K 2} / \Delta e_{t r e f}$, AVR ajustado com $K_{p}=10$; o ganho é expresso em $d B$ no eixo das ordenadas da esquerda e a fase em graus no eixo da direita.

O modelo simulado para a obtenção das respostas em frequência da fig. 3.16 tem as seguintes características:

- Modelo de uma máquina síncrona conectada a um barramento infinito conforme fig. 2.6 na pág. 20;

- Dados da máquina e do sistema de potência conforme a tab. 2.1 na pág. 13;

- Parâmetros do modelo do gerador definidos para a potência ativa de $0,8 p$.u. na tab. 2.3 na pág. 15;

- Considerado ganho $D=5$, representando a ação dos enrolamentos amortecedores (e estabilizando o sistema que era instável);

- Dados do sistema de excitação segundo a tab. 2.2 na pág. 15.

A fig. 3.16 mostra que a fase das respostas em frequência $\Delta T_{e K 2} / \Delta e_{t r e f}$ e $\Delta e_{t} / \Delta e_{\text {tref }}$ tem praticamente o mesmo comportamento. Há diferenças nas proximidades da frequência do modo local $(6,6 \mathrm{rad} / \mathrm{s})$.

As variações no ângulo de carga $\Delta \delta$ não são completamente desprezíveis, em especial nas proximidades do modo local. Para ilustrar tal afirmação, foi realizada uma simulação computacional no domínio do tempo. O sistema modelado foi o mesmo usado para a 
obtenção das respostas em frequência da fig. 3.16. Empregou-se um distúrbio senoidal de amplitude 0,01p.u. e frequência variável aplicado em $\Delta e_{t r e f}$. A frequência do distúrbio inicia em zero e aumenta linearmente com uma taxa de $2 \mathrm{rad} / \mathrm{s}$ a cada 10 segundos. Os resultados são mostrados na fig. 3.17. Nota-se um aumento considerável na amplitude das oscilações do ângulo de carga entre os instantes $t=30 \mathrm{~s}$ e $t=40 \mathrm{~s}$. Entre tais instantes, a frequência do distúrbio variou de $6 \mathrm{rad} / \mathrm{s}$ até $8 \mathrm{rad} / \mathrm{s}$.

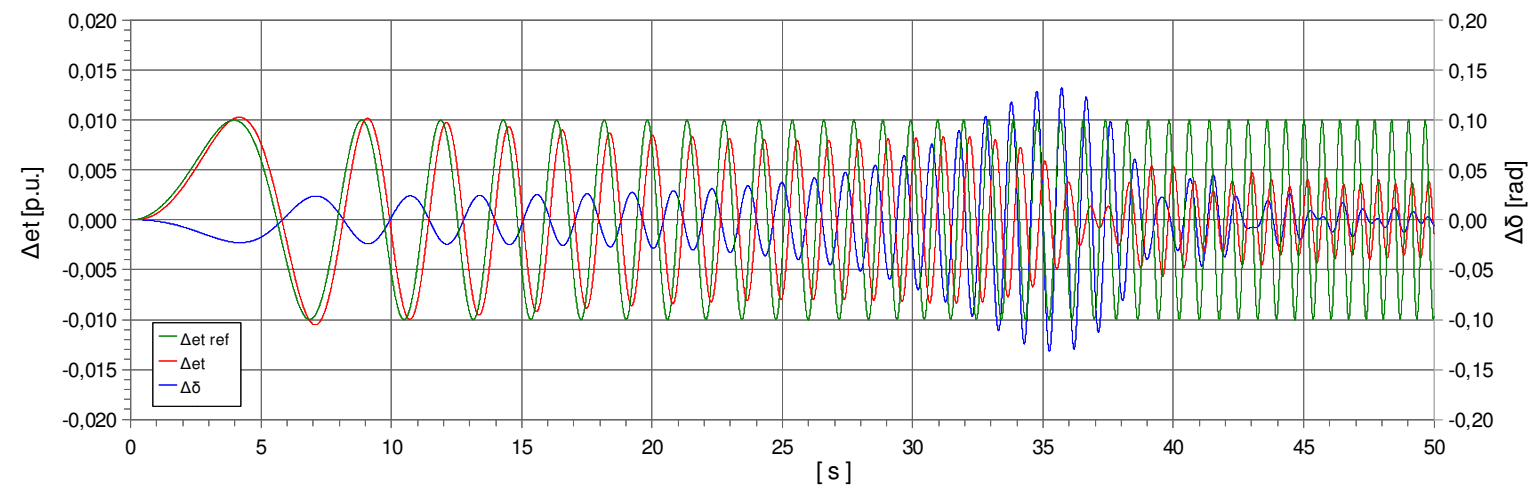

Figura 3.17: Resposta a um sinal senoidal com frequência variável, AVR ajustado com $K_{p}=10 ; \Delta e_{t}$ e $\Delta e_{t r e f}$ expressos em $p . u$. no eixo das ordenadas da esquerda e $\Delta \delta$ em rad no eixo da direita.

Há diferentes métodos para se levantar $\Delta e_{t} / \Delta e_{t r e f}$. Tais métodos baseiam-se na comparação manual ou computacional entre um estímulo inserido na referência de tensão e a resposta obtida na tensão terminal. Os equipamentos digitais de identificação de sistemas podem empregar distúrbios senoidais de frequência variante (sweep) ou sinais pseudo-aleatórios (pink noise) (MURDOCH; VENKATARAMAN; LAWSON, 1999).

\subsubsection{Influência do ajuste do AVR nos ajustes propostos pelo método de compensação de fase}

O método de compensação de fase depende da análise da função de transferência entre a referência de tensão do $\operatorname{AVR}\left(\Delta e_{t r e f}\right)$ e a tensão estatórica $\left(\Delta e_{t}\right)$. Os ajustes propostos por este método variam conforme diferentes ajustes são adotados para o regulador de tensão. Em resumo, AVRs com grandes ganhos transitórios ${ }^{5}$ necessitam de menos compensação (avanço de fase) do que AVRs com pequenos ganhos transitórios. Não é a intenção desta dissertação discutir em detalhes o ajuste da malha do AVR. Há outras fontes que abordam este assunto, como por exemplo, Senger (1983) e IEEE (1990). Ver também o anexo $\mathrm{C}$.

\footnotetext{
${ }^{5}$ Ver seção 2.1.2.2 e as equações 2.2 e 2.3.
} 
É interessante mostrar que o atraso de fase a ser compensado varia conforme o ajuste do AVR. Simulou-se computacionalmente o comportamento de um gerador conectado a um barramento infinito com as seguintes características:

- Modelo apresentado na fig. 2.6 na pág. 20;

- Dados da máquina e do sistema de potência conforme a tab. 2.1 na pág. 13;

- Considerado ganho $D=5$, representando a ação dos enrolamentos amortecedores;

- Parâmetros do modelo de gerador definidos para a potência ativa de 0,8p.u. na tab. 2.3 na pág. 15 ;

- Dados do sistema de excitação segundo a tab. 2.2 na pág. 15, porém com diferentes ganhos $K_{p}$ :

- $K_{p}=5$ : ganho transitório baixo;

- $K_{p}=20$ : ganho transitório alto.

A fig. 3.18 mostra a influência do ajuste do ganho proporcional do AVR $\left(K_{p}\right)$ na resposta do sistema. O sistema com $K_{p}=20$ apresenta uma maior largura de banda do que o sistema com $K_{p}=5$. Os blocos de avanço-atraso do PSS terão ajustes diferentes dependendo da opção do comissionador na hora de ajustar a malha do AVR.

As diferenças no comportamento da fase nas respostas em frequência da fig. 3.18a e da fig. 3.18b denotam também que a decisão de reajustar a malha de controle do AVR, pode implicar na necessidade de reajustar dos blocos de avanço-atraso do PSS. 


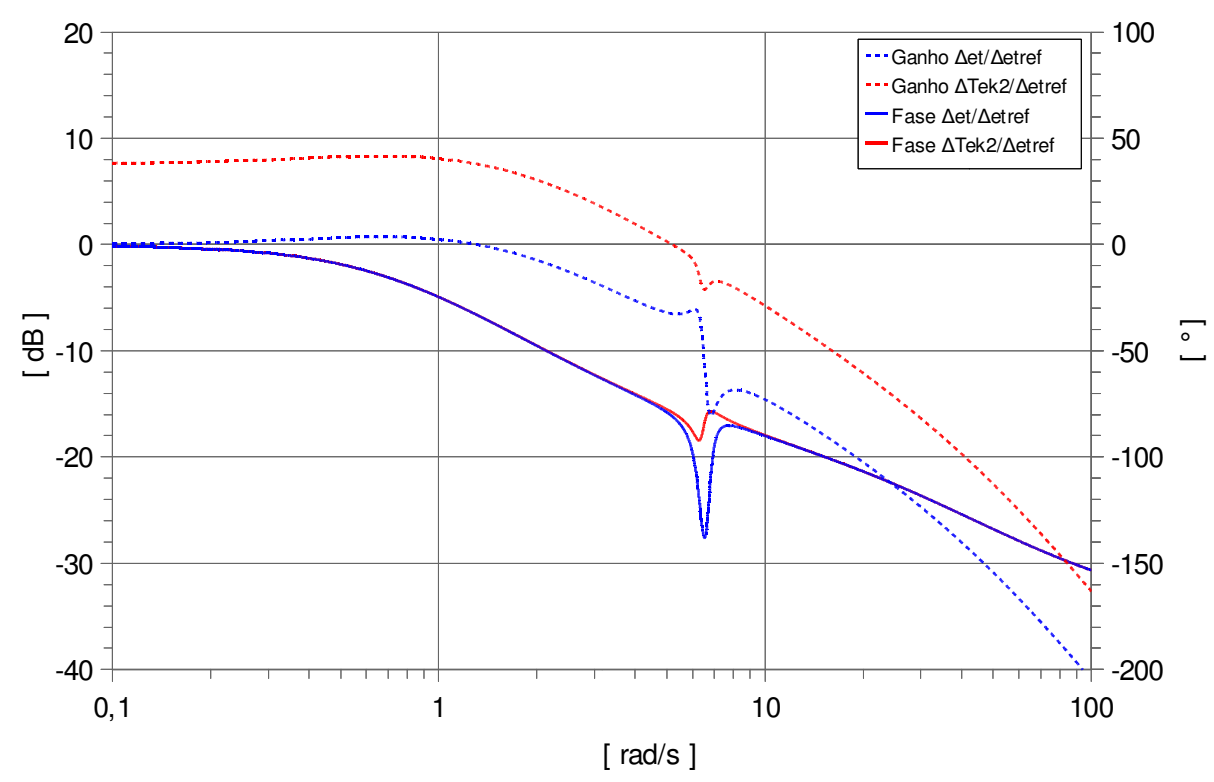

(a) Sistema lento com $K_{p}=5$

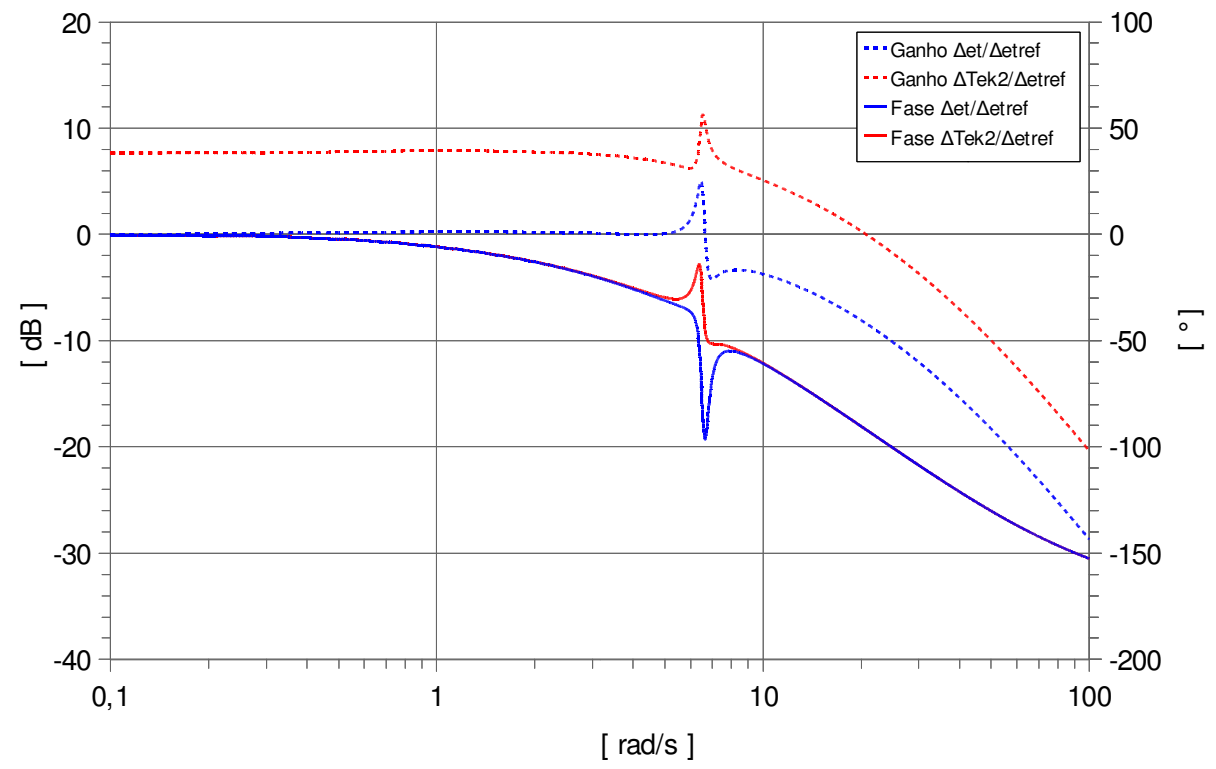

(b) Sistema rápido com $K_{p}=20$

Figura 3.18: Respostas em frequência $\Delta e_{t} / \Delta e_{\text {tref }}$ e $\Delta T_{e K 2} / \Delta e_{\text {tref }}$, AVR ajustado com $K_{p}=5$ e $K_{p}=20$; o ganho é expresso em $d B$ no eixo das ordenadas da esquerda e a fase em graus no eixo da direita.

\subsubsection{Aplicação do método de compensação de fase supondo que o trans- dutor de integral da potência acelerante é um transdutor ideal de velocidade}

Murdoch et al. (1999a) mostraram via simulações computacionais que a defasagem entre o sinal de velocidade do rotor e o sinal de integral de potência acelerante são des- 
prezíveis quando $T_{W}=10 \mathrm{~s}$. Pode-se tratar o PSS2B como um PSS baseado numa única entrada de velocidade do rotor. É possível empregar os blocos de avanço de fase para compensar os atrasos do AVR e do enrolamento de campo gerando torque elétrico em fase com a velocidade do rotor. Procura-se obter uma resposta entre velocidade $\left(\Delta \omega_{r}\right.$ ou a integral da potência acelerante) e torque elétrico $\left(\Delta T_{e}\right)$ com fase quase zero ou levemente atrasada em uma ampla faixa do espectro de oscilações.

Após o ajuste do AVR em carga, é necessário levantar a resposta em frequência entre referência de tensão e tensão estatórica. As constantes $T_{1}, T_{2}, T_{3}, T_{4}, T_{10}$ e $T_{11}$ devem ser ajustadas para que o bloco de avanço-atraso compense a defasagem da resposta em frequência $\Delta e_{t} / \Delta e_{\text {tref }}$. As oscilações bruscas na fase de $\Delta e_{t} / \Delta e_{t r e f}$ nas proximidades da frequência do modo local não devem ser compensadas.

Para ilustrar a aplicação do método de compensação de fase, foram realizadas simulações de uma máquina síncrona conectada a um barramento infinito a partir de uma impedância externa. A fig. 3.19 apresenta o modelo do sistema simulado, que possui as seguintes características:

- Dados da máquina e do sistema de potência conforme a tab. 2.1 na pág. 13;

- Dados do sistema de excitação segundo a tab. 2.2 na pág. 15;

- Parâmetros do modelo de gerador definidos para a potência ativa de $0,8 p$.u. na tab. 2.3 na pág. 2.3;

- Frequência da rede $(f)$ considerada constante e igual a $60 H z$.

- Ganho $D=5$, representando a ação dos enrolamentos amortecedores;

- Blocos de avanço-atraso ajustados com: $T_{1}=0,15 s, T_{2}=0,03 s, T_{3}=0,15 s$, $T_{4}=0,03 s, T_{10}=1 s$ e $T_{11}=1 s ;$

- Ganho $K_{S 1}=10$. 


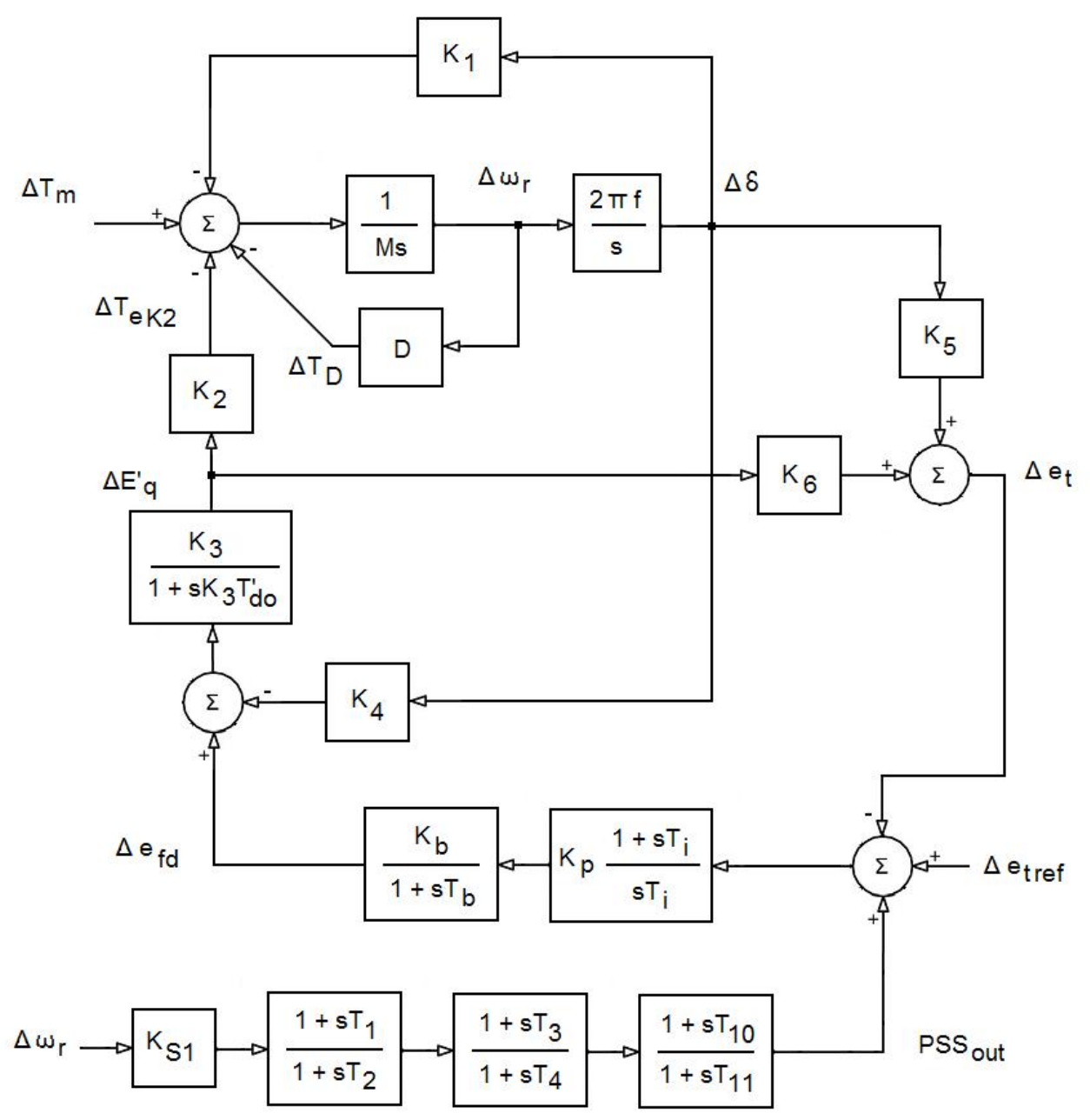

Figura 3.19: Modelo empregado para aplicação do método de compensação de fase; adaptado de DeMello e Concordia (1969) e de IEEE (2005).

A fig. 3.20 apresenta a fase da resposta em frequência obtida por simulação computacional entre referência do AVR e tensão estatórica $\left(\Delta e_{t} / \Delta e_{\text {tref }}\right)$. Nota-se um atraso de fase que aumenta com a frequência. Tal atraso deve ser compensado pelos blocos de avanço-atraso $\left(G_{\text {lead-lag }}\right)$.

É apresentada na fig. 3.20 a soma aritmética das fases de $\Delta e_{t} / \Delta e_{\text {tref }}$ e de $G_{\text {lead-lag. }}$. O objetivo é fazer com que a soma das fases fique próxima a zero graus dentro da faixa de frequência dos modos de oscilação interárea, local e intraunidades. Murdoch et al. (1999a) recomendam uma leve subcompensação, a soma das fases deve resultar entre $-30^{\circ}$ e $0^{\circ}$. Mais adiante, a seção 3.4.2.2 discutirá os efeitos da subcompensação e da supercompensação de fase. 


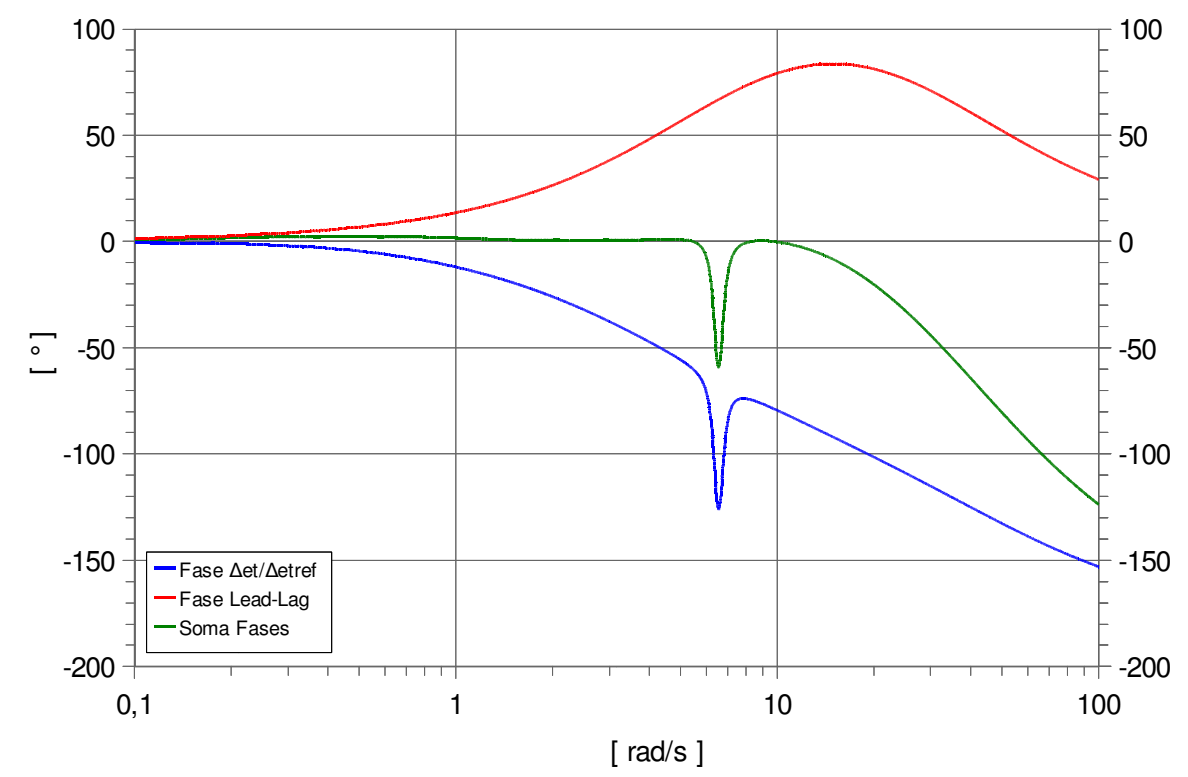

Figura 3.20: Fase das respostas em frequência $\Delta e_{t} / \Delta e_{\text {tref }}$ e $G_{\text {lead-lag }}$ e soma das características de fase.

Com o intuito de verificar a eficácia do método de ajuste por compensação de fase, foram realizadas simulações computacionais no domínio da frequência e no domínio do tempo com o sistema dado pela fig. 3.19.

A fig. 3.21 apresenta o resultado de simulações computacionais de resposta ao degrau de $0,01 p . u$. na referência de tensão do AVR. São mostradas a tensão terminal $\left(\Delta e_{t}\right)$ e o ângulo de carga $(\Delta \delta)$. As respostas do sistema sem PSS estão marcadas com o texto PSSoff. As respostas do sistema com PSS estão marcadas com PSSon. Percebe-se que a ação do PSS amortece as oscilações tanto em $\Delta e_{t}$ como em $\Delta \delta$. Convém salientar que o desempenho do PSS ainda pode ser melhorado, é necessário o ajuste do ganho proporcional $K_{S 1}$, tal tema será abordado na seção 3.3.5. 


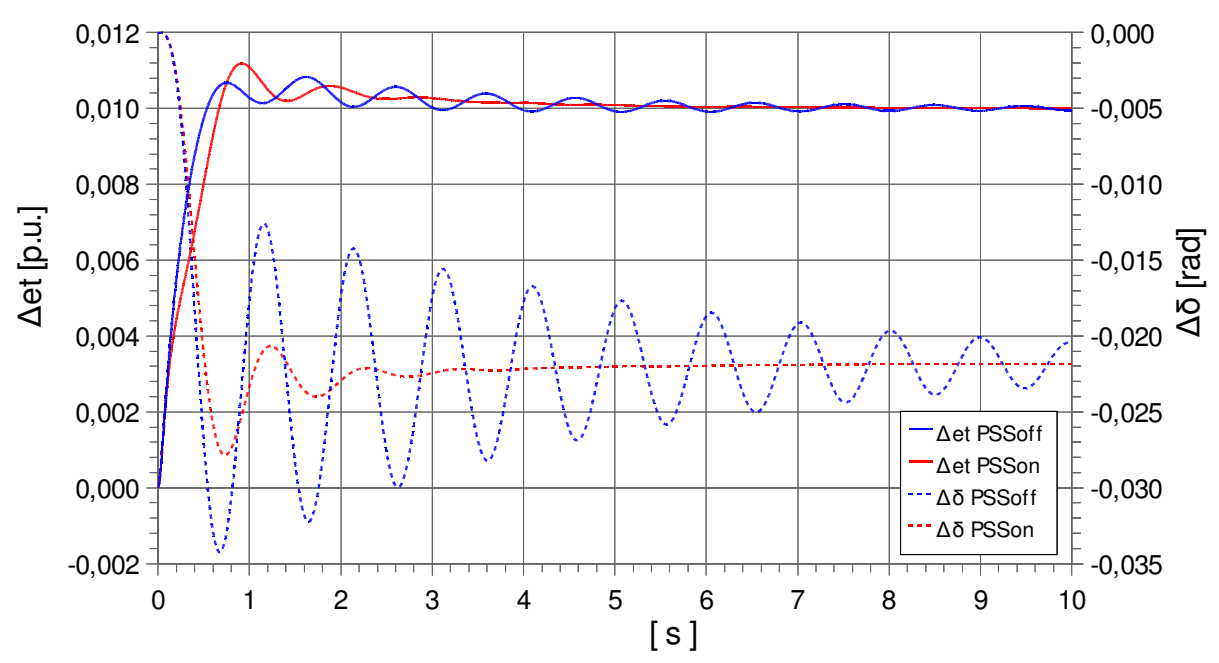

Figura 3.21: Resposta ao degrau de 0,01p.u. na referência de tensão do AVR com e sem PSS; aplicação do método de ajuste por compensação de fase.

É interessante apresentar a influência do PSS na resposta em frequência $\Delta e_{t} / \Delta e_{\text {tref }}$. A fig. 3.22 mostra as respostas em frequência obtidas por simulação computacional do sistema sem PSS (PSSoff) e do sistema com PSS (PSSon). Nota-se nas proximidades da frequência do modo local um súbito aumento do ganho. Tal comportamento será verificado também em ensaios em campo apresentados no capítulo 4. A inclusão do PSS remove o pico no ganho nas proximidades do modo local.

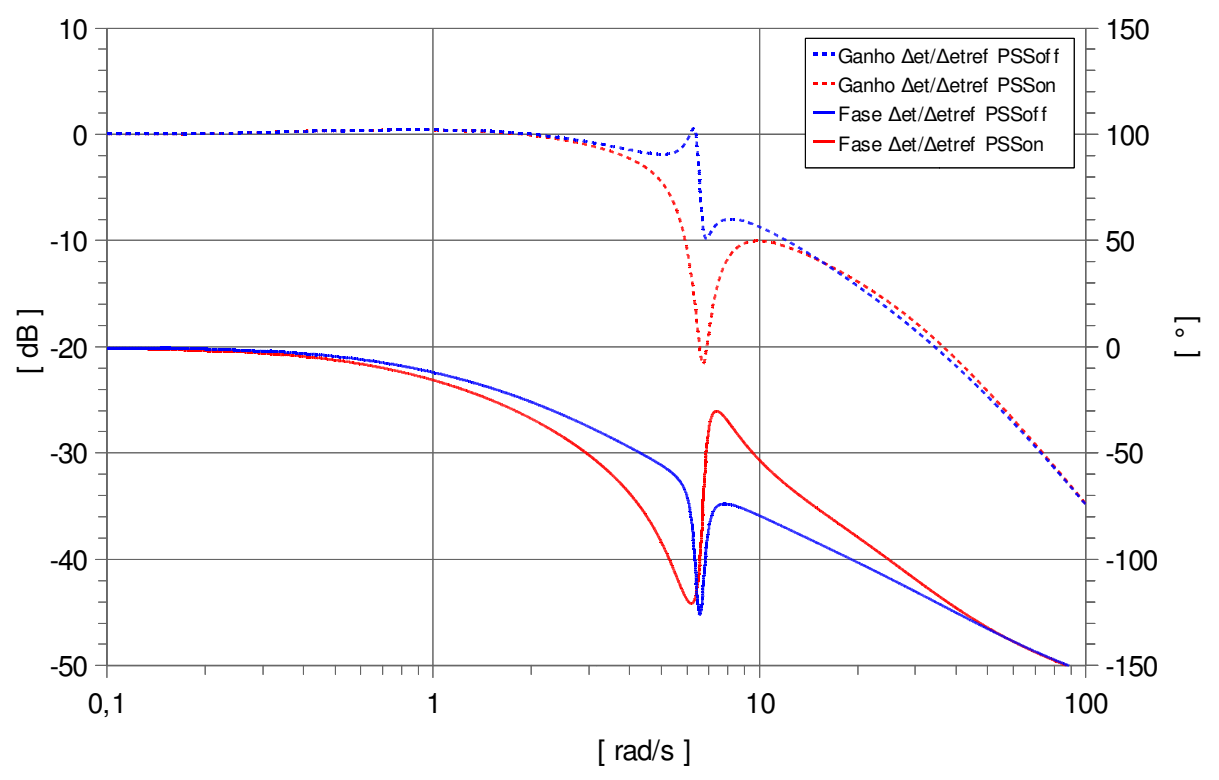

Figura 3.22: Respostas em frequência $\Delta e_{t} / \Delta e_{\text {tref }}$ com e sem PSS, resultado da aplicação do método de ajuste por compensação de fase; o ganho é expresso em $d B$ no eixo das ordenadas da esquerda e a fase em graus no eixo da direita. 


\subsubsection{Influência do carregamento na aplicação do método de compensação de fase}

É necessário que o comissionador escolha o nível de potência ativa no qual o ajuste do PSS será realizado. Uma escolha comum em campo é fazer os ensaios com a carga do gerador próxima da nominal. Esta é a condição que resulta em um comportamento mais oscilatório da máquina.

É interessante verificar qual a influência da potência ativa no comportamento do PSS. Com o objetivo de investigar tal influência, foram realizadas simulações computacionais do sistema apresentado na fig. 3.19 na pág. 58. As características do sistema simulado são dadas a seguir:

- Dados da máquina e do sistema de potência conforme a tab. 2.1 na pág. 13;

- Dados do sistema de excitação segundo a tab. 2.2 na pág. 15;

- Parâmetros do modelo de gerador definidos para a potência ativa de 0,2p.u., 0, 4p.u., 0,6p.u. e 0,8p.u. na tab. 2.3 na pág. 2.3;

- Ganho $D=5$, representando a ação dos enrolamentos amortecedores;

- As simulações com o PSS ativo consideraram:

- Blocos de avanço-atraso: $T_{1}=T_{3}=0,15 \mathrm{~s}, T_{2}=T_{4}=0,03 \mathrm{~s}, T_{10}=1 \mathrm{~s}$ e $T_{11}=1 s$

- Ganho: $K_{S 1}=10$.

A fig. 3.23 apresenta a função de transferência $\Delta e_{t} / \Delta e_{\text {tref }}$ obtida por simulação computacional para diferentes potências ativas. O PSS estava desligado. Há variações bruscas nas defasagens nas proximidades das frequências dos modos locais para cada um dos carregamentos. Tal comportamento já foi discutido na seção 3.3.4.1. É interessante notar como a frequência do modo local aumentou com a potência ativa. Tal fato foi discutido no capítulo 2. A característica da fase das respostas em frequência para $P=$ 0,2p.u., $P=0,4 p . u$., $P=0,6 p . u$. e $P=0,8 p$.u. são semelhantes. A opção por ensaiar a máquina em um destes pontos operacionais não resultaria em ajustes muito diferentes propostos pelo método de compensação de fase. 


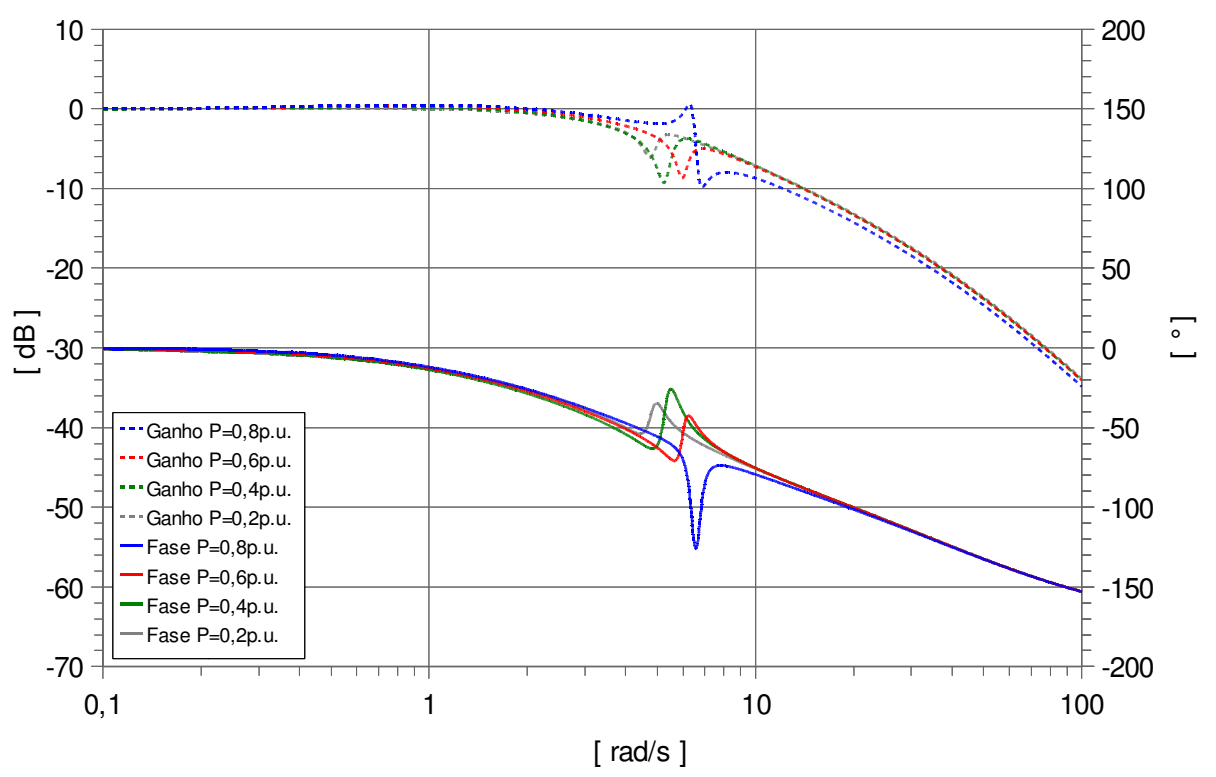

Figura 3.23: Respostas em frequência $\Delta e_{t} / \Delta e_{\text {tref }}$ sem PSS para diferentes carregamentos; o ganho é expresso em $d B$ no eixo das ordenadas da esquerda e a fase em graus no eixo da direita.

A fig. 3.24 mostra a resposta a um degrau na referência de tensão do AVR $\left(\Delta e_{\text {tref }}\right)$. As respostas com o PSS ativo estão marcadas com PSSon. As respostas com o PSS desligado estão marcadas com PSSoff. São mostradas a variação em torno do regime permanente da tensão do gerador $\left(\Delta e_{t}\right)$ e do ângulo de carga $(\Delta \delta)$. O ajuste do PSS feito para a potência de $0,8 p . u$. mostrou-se eficiente para cargas menores. As oscilações em $\Delta \delta$ foram amortecidas considerando $P=0,8 p . u$., $P=0,6 p . u ., P=0,4 p . u$. e $P=0,2 p . u$. 


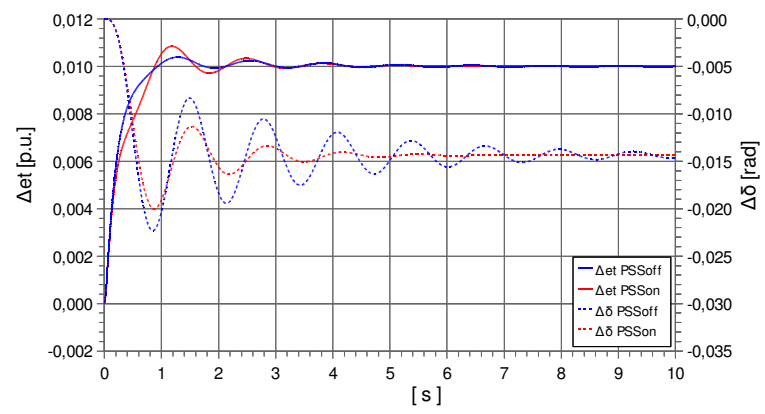

(a) Potência ativa $P=0,2 p . u$.

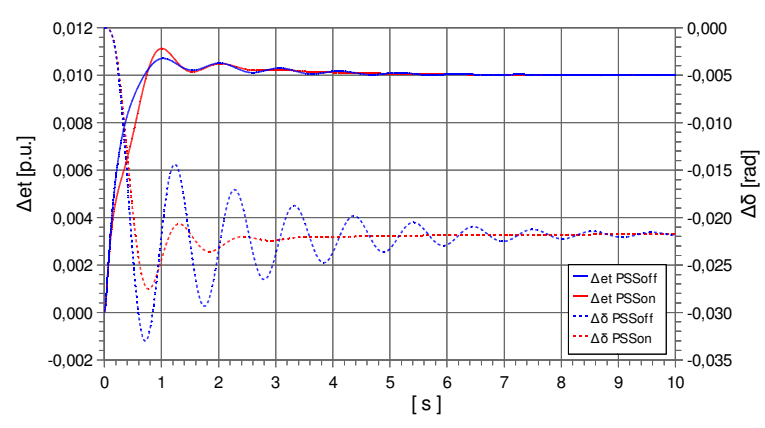

(c) Potência ativa $P=0,6 p . u$.

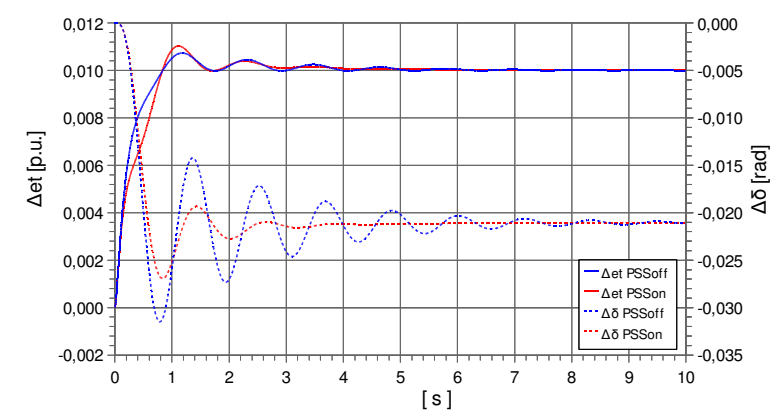

(b) Potência ativa $P=0,4 p . u$.

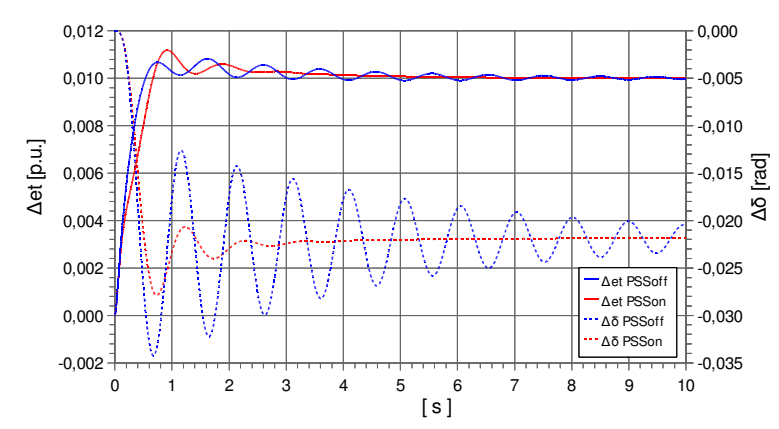

(d) Potência ativa $P=0,8 p . u$.

Figura 3.24: Resposta ao degrau de 0,01p.u. na referência de tensão do AVR com e sem PSS considerando diferentes carregamentos.

\subsubsection{Influência das constantes de washout na aplicação do método de com- pensação de fase}

O emprego de baixas constantes de tempo de washout $\left(T_{W}\right)$ introduz avanços de fase na parte baixa do espectro. A fig. 3.3 na pág. 35 mostra a influência da escolha das constantes de washout no sinal de integral da potência acelerante. O PSS deve causar oscilações de tensão em fase com as oscilações de frequência para amortecer oscilações interárea, ver seção 3.3.2.1.

Para contribuir com o amortecimento de oscilações interárea, o método de compensação de fase deve levar em conta os avanços de fase introduzidos pelos filtros de washout. Um bom exemplo da influência da escolha de $T_{W}$ na estabilidade do modo interárea é dado num artigo sobre o reajuste de PSSs para o amortecimento de oscilações de baixa frequência na conexão norte-sul do sistema elétrico brasileiro de Martins et al. (1999). Os autores empregaram um PSS de uma única entrada (velocidade do rotor) e um filtro de washout. A função de transferência de tal PSS é dada pela eq. 3.13.

$$
G_{P S S}=\frac{s T_{W}}{1+s T_{W}} K_{S 1} \frac{1+s T_{1}}{1+s T_{2}} \frac{1+s T_{3}}{1+s T_{4}} \frac{1+s T_{10}}{1+s T_{11}}
$$


Onde:

- $T_{W}=3 s$

- $K_{S 1}=20$;

- $T_{1}=T_{3}=0,12 s$

- $T_{2}=T_{4}=0,012 s$

- $T_{10}=0,25 s$;

- $T_{11}=0,75 s$.

Martins et al. (1999) optaram por empregar dois blocos de avanço de fase $\left(T_{1}=T_{3}=\right.$ $0,12 s$ e $\left.T_{2}=T_{4}=0,012 s\right)$ e um bloco de atraso de fase $\left(T_{10}=0,25 s\right.$ e $\left.T_{11}=0,75 s\right)$. Os blocos de avanço de fase foram ajustados com o objetivo de amortecer modos de oscilação na faixa dos $8 \mathrm{rad} / \mathrm{s}$. Havia também um modo de oscilação interárea (Norte / Sul) na faixa de $1 \mathrm{rad} / \mathrm{s}$, por causa deste modo foi necessário usar um bloco de atraso de fase.

A fig. 3.25 apresenta a fase da resposta em frequência obtida por simulação computacional de partes do PSS empregado por Martins et al. (1999). Os blocos de avanço-atraso (Lead-Lag) proporcionam um avanço de fase na parte mais alta do espectro e um atraso na parte mais baixa. O filtro de washout introduz avanços de fase na parte de baixa frequência do espectro. O conjunto de washout mais lead-lag apresenta pouca defasagem nas proximidades de $1 \mathrm{rad} / \mathrm{s}$ e cerca de $70^{\circ}$ de avanço próximo a $8 \mathrm{rad} / \mathrm{s}$. Revendo a fig. 3.3 na pág. 35, nota-se que as constantes de tempo de washout influem no ajuste do bloco de atraso de fase. Caso Martins et al. (1999) tivessem escolhido $T_{W}$ diferente de $3 s$, seria necessário um outro ajuste dos parâmetros $T_{10}$ e $T_{11}$. 


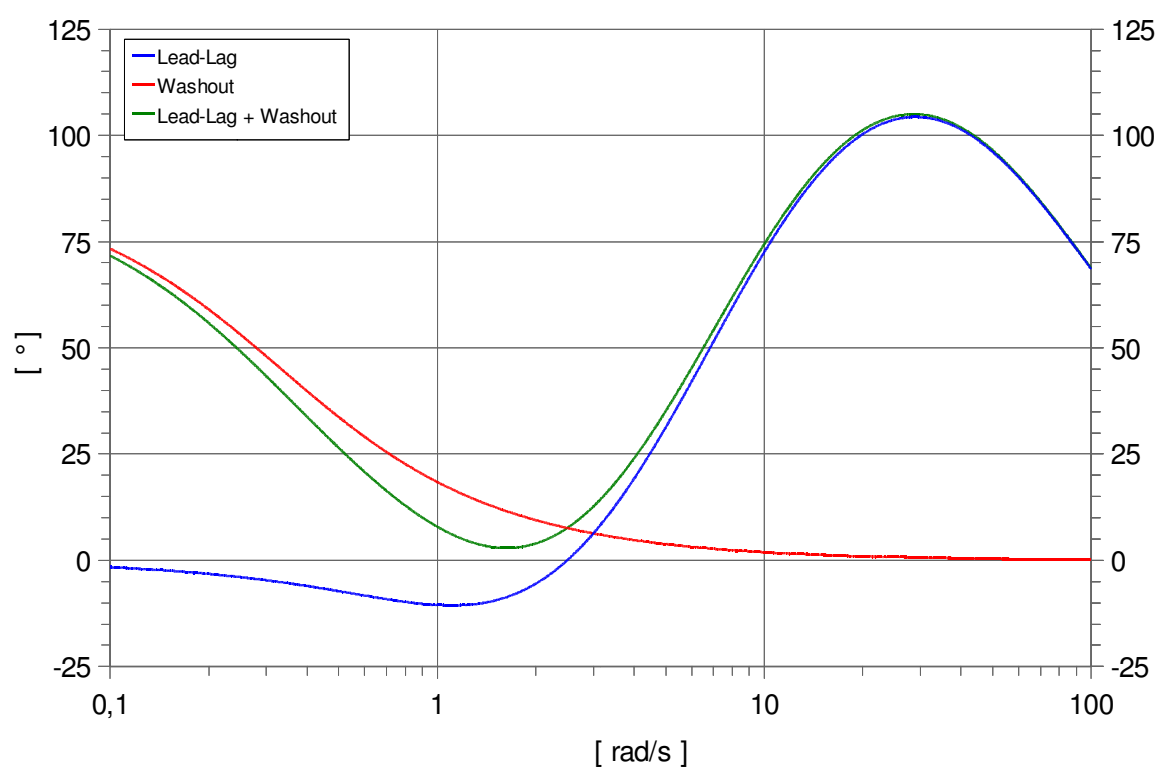

Figura 3.25: Fase das respostas em frequência dos blocos de avanço-atraso, do filtro de washout e soma das características de fase; adaptado de Martins et al. (1999).

\subsubsection{O ganho proporcional $K_{S 1}$}

A fig. 3.10 na pág. 41 apresenta os blocos de ajuste de ganho e de avanço-atraso de fase do PSS2B. O ganho do estabilizador é representado por $K_{S 1}$.

Há métodos computacionais de ajuste de $K_{S 1}$. Alguns destes métodos baseiam-se no deslocamento dos autovalores do sistema (SENGER, 1983; ZANETTA, 1984). O ganho $K_{S 1}$ é calculado para que os modos de oscilação do gerador (ou geradores) e do sistema de potência se tornem mais amortecidos. O objetivo é fazer com que os autovalores se desloquem para determinadas regiões do plano complexo.

Há problemas enfrentados em campo que não estão representados nas simulações computacionais. Um dos principais desafios práticos é a amplificação por $K_{S 1}$ do ruído presente nos sinais de entrada do PSS. Kundur et al. (2003) citam que o correto ajuste do ganho somente pode ser obtido durante o comissionamento.

Murdoch, Venkataraman e Lawson (1999) citam duas diferentes maneiras de se ajustar o ganho $K_{S 1}$. A primeira emprega a análise de funções de transferência e cálculo de margem de ganho. A segunda é empírica e certifica que o PSS é estável mesmo com ganhos $K_{S 1}$ duas ou três vezes maiores do que o escolhido. O último método é de mais fácil aplicação em campo.

WECC (2009) e Kundur et al. (2003) citam um método semelhante ao método empírico descrito por Murdoch, Venkataraman e Lawson (1999). Inicialmente o ganho 
deve ser aumentado aos poucos. Testes de respostas a pequenos distúrbios são realizados a cada aumento pequeno. Encontra-se assim o ganho apropriado. O sistema deve ser estável mesmo com $K_{S 1}$ igual a três vezes o valor ajustado. Desta maneira, garante-se que $K_{S 1}$ está bem abaixo de níveis que excitariam modos instáveis do AVR ou amplificariam demasiadamente o ruído. Testes e simulações realizados em diversos tipos de geradores de vários tamanhos consistentemente comprovaram que tal método de ajuste melhora a estabilidade do sistema para qualquer cenário razoável.

\subsubsection{Os limites de saída do PSS}

A fig. 3.10 na pág. 41 apresenta os blocos de ajuste de ganho e de avanço-atraso de fase do PSS2B. Os limites para o sinal de saída do PSS são representados por $V_{S T M A X}$ e $V_{S T M I N}$.

Kundur et al. (2003) recomendam o emprego de grandes limites positivos de saída para o sinal do PSS, por exemplo entre 0,1p.u. e 0,2p.u. Os autores sugerem o uso de um limitador de tensão terminal nestes casos. O ajuste recomendado para o limite negativo é mais conservador, entre -0,05p.u. e -0,1p.u. Evita-se assim que o PSS cause desligamentos inesperados da unidade geradora devido à subtensão ou por atuação da proteção contra a perda de excitação.

A experiência de Gu, Smulders e Mushens (2000) diz que o sinal de saída do PSS deve estar dentro de $20 \%$ dos limites após o transitório causado por um degrau de $2 \%$ na referência.

Os valores típicos para o ajuste dos limites de saída do PSS dados por IEEE (2005) são $V_{S T M A X}=0,1 p . u$. e $V_{S T M I N}=-0,1 p . u$. 


\subsection{Considerações sobre o ajuste de $K_{S 1}, T_{1}, T_{2}, T_{3}$, $T_{4}, T_{10}$ e $T_{11}$}

\subsubsection{As relações $T_{1} / T_{2}, T_{3} / T_{4}$ e $T_{10} / T_{11}$.}

As seção 3.3.4 mostrou a seguinte opção de ajuste para os blocos de avanço-atraso do PSS2B:

- Dois blocos são ajustados como avançadores de fase para amortecer as oscilações locais;

- Se necessário, um bloco pode ser ajustado como atrasador de fase para amortecer as oscilações interáreas.

O ajuste dos blocos de avanço-atraso como avançadores de fase requer $T_{1}>T_{2}$, ou $T_{3}>T_{4}$ ou $T_{10}>T_{11}$. A fig. 3.26 mostra a resposta em frequência obtida por simulação computacional do primeiro dos blocos de avanço-atraso, considerou-se $T_{1}=0,1 \mathrm{~s}$ e $T_{2}=0,01 s$.

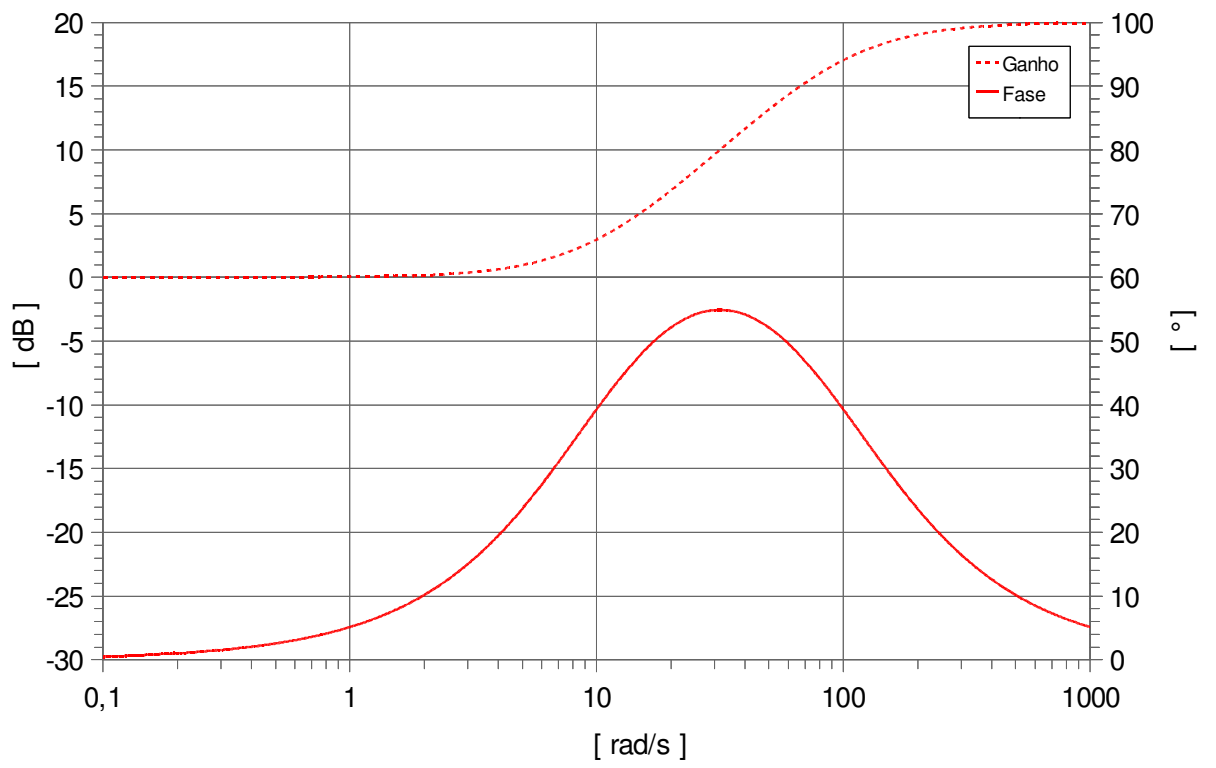

Figura 3.26: Resposta em frequência de um bloco de avanço de fase ajustado com $T_{1}=$ $0,1 s$ e $T_{2}=0,01 s$; o ganho é expresso em $d B$ no eixo das ordenadas da esquerda e a fase em graus no eixo da direita.

Quanto maior as relações $T_{1} / T_{2}$, maior será o ganho do bloco avançador na parte de alta frequência do espectro. Há um limite prático para tal relação que é imposto pela presença de ruído de medição e pela diminuição do amortecimento de modos de oscilação 
associados ao AVR e ao PSS. A seção 3.4.2 mostrará exemplos de como o ajuste $K_{S 1}$ pode tornar o sistema instável.

Anderson e Fouad (2003) recomendam que os parâmetros dos blocos de avanço de fase respeitem as relações dadas pela eq. 3.14.

$$
\frac{T_{1}}{T_{2}}<10
$$

O ganho $\left|G_{\text {lead }}\right|$ em $d B$ de um bloco de avanço de fase na parte mais alta do espectro é dado pela eq. 3.15 .

$$
\lim _{\omega \rightarrow \infty}\left|G_{\text {lead }}\right|=20 \log \frac{T_{1}}{T_{2}}
$$

O avanço máximo de fase $\phi_{\max }$ é dado pela eq. 3.16.

$$
\operatorname{sen}\left(\phi_{\max }\right)=\frac{\frac{T_{1}}{T_{2}}-1}{\frac{T_{1}}{T_{2}}+1}
$$

A frequência $\omega_{\phi \max } \mathrm{em} \mathrm{rad} / \mathrm{s}$ na qual o ocorre o máximo avanço de fase é dada pela eq. 3.17 .

$$
\omega_{\phi \max }=\frac{1}{\sqrt{T_{1} T_{2}}}
$$

As equações 3.14, 3.16 e 3.17 são igualmente válidas para as relações $T_{3} / T_{4}$ e $T_{10} / T_{11}$.

\subsubsection{Deslocamento dos autovalores do sistema em função do ajuste do PSS}

Senger (1983) e Zanetta (1984) descrevem métodos computacionais de ajuste do AVR e do PSS baseados em deslocamento dos autovalores do sistema gerador / rede de transmissão. Tais métodos buscam ajustar as constante de tempo dos blocos de avançoatraso e do ganho $K_{S 1}$ do PSS de modo que os autovalores do sistema se desloquem para determinadas regiões do plano complexo.

A verificação do deslocamento dos autovalores do sistema em função do ajuste do PSS é uma poderosa ferramenta para se compreender a influência de diferentes decisões tomadas pelo comissionador. É interessante verificar qual a influência do ajuste das constantes dos blocos de avanço-atraso e do ganho $K_{S 1}$ no amortecimento das oscilações 
eletromecânicas e na localização dos autovalores de um sistema composto por um gerador conectado a um barramento infinito por uma impedância externa. Simulou-se computacionalmente o modelo apresentado na fig. 3.19 na pág. 58. As características do modelo simulado são dadas a seguir:

- Dados da máquina e do sistema de potência conforme a tab. 2.1 na pág. 13;

- Dados do sistema de excitação segundo a tab. 2.2 na pág. 15 ;

- Parâmetros do modelo de gerador definidos para a potência ativa de $0,8 p$.u. na tab. 2.3 na pág. 2.3;

- Ganho $D=5$, representando a ação dos enrolamentos amortecedores.

\subsubsection{Influência do ganho $K_{S 1}$ na localização dos autovalores do sistema no plano complexo}

Com o intuito de verificar a influência do ajuste do ganho $K_{S 1}$ no amortecimento dos modos de oscilação do gerador e rede, simulou-se computacionalmente o modelo descrito na seção 3.4.2 com os ajustes dos blocos de avanço-atraso definidos na tab. 3.4.

Tabela 3.4: Ajuste dos blocos de avanço-atraso empregado para o estudo da influência do parâmetro $K_{S 1}$.

\begin{tabular}{cc} 
Parâmetro & Valor \\
\hline$T_{1}$ & $0,115 \mathrm{~s}$ \\
$T_{2}$ & $0,030 \mathrm{~s}$ \\
$T_{3}$ & $0,115 \mathrm{~s}$ \\
$T_{4}$ & $0,030 \mathrm{~s}$ \\
$T_{10}$ & $1 s$ \\
$T_{11}$ & $1 s$
\end{tabular}

As tab. 3.5 apresenta os autovalores do sistema simulado com o PSS desligado. A tab. 3.6 mostra os autovalores do sistema com o PSS ligado em função do ajuste do ganho $K_{S 1}$, variou-se $K_{S 1}$ de 5 até 40 . 
Tabela 3.5: Autovalores do modelo de um gerador conectado a um barramento infinito sem PSS.

$$
\begin{gathered}
K_{S 1}=0 \\
\hline-45,1970 \\
-0,1771+j 6,0152 \\
-0,1771-j 6,0152 \\
-4,3682 \\
-0,5439
\end{gathered}
$$

Tabela 3.6: Autovalores do modelo de um gerador conectado a um barramento infinito com PSS em função do ganho $K_{S 1}$.

\begin{tabular}{cccc}
$K_{S 1}=5$ & $K_{S 1}=10$ & $K_{S 1}=20$ & $K_{S 1}=40$ \\
\hline$-56,1030$ & $-60,5300$ & $-66,2710$ & $-73,6440$ \\
$-0,8884+j 6,3070$ & $-1,5105+j 6,1096$ & $-2,5614+j 5,5125$ & $-3,8992+j 4,1867$ \\
$-0,8884-j 6,3070$ & $-1,5105-j 6,1096$ & $-2,5314-j 5,5125$ & $-3,8992-j 4,1867$ \\
$-27,478+j 13,352$ & $-24,687+j 17,159$ & $-20,874+j 22,248$ & $-16,163+j 29,249$ \\
$-27,478-j 13,352$ & $-24,687-j 17,159$ & $-20,874-j 22,248$ & $-16,163-j 29,249$ \\
$-4,2427$ & $-4,1515$ & $-3,9334$ & $-3,3026$ \\
$-0,5513$ & $-0,5523$ & $-0,5542$ & $-0,5589$
\end{tabular}

O ajuste do ganho $K_{S 1}$ visa mover as raízes complexas da equação característica do sistema modelado para regiões do plano complexo que garantam um maior amortecimento dos modos de oscilação. Nota-se que o modo de oscilação representado pelos autovalores $-0,1771 \pm j 6,0152$ na tab. 3.5 são deslocados para uma regiões do plano complexo que representam um maior amortecimento quando se aumenta o ganho $K_{S 1}$. A tab. 3.6 mostra que estas raízes complexas conjugadas se deslocaram para $-3,8992 \pm j 4,1867$ quando $K_{S 1}=40$.

A ativação do PSS introduz um novo modo de oscilação no sistema. Tal modo é representado pelos autovalores complexos conjugados $-27,478 \pm j 13,352$ referentes ao ganho $K_{S 1}=5$ na tab. 3.6. O aumento de $K_{S 1}$ faz com que estas raízes complexas se desloquem para regiões de menor amortecimento do plano complexo. A diminuição do amortecimento deste novo modo de oscilação é um limite para o aumento de $K_{S 1}$. 
A fig. 3.27 apresenta a simulação computacional da resposta a um degrau de 0, 01p.u. na referência de tensão do AVR. É mostrada a variação em torno do regime permanente do ângulo de carga $(\Delta \delta)$. Verifica-se claramente que o aumento de $K_{S 1}$ torna o comportamento do sistema menos oscilatório.

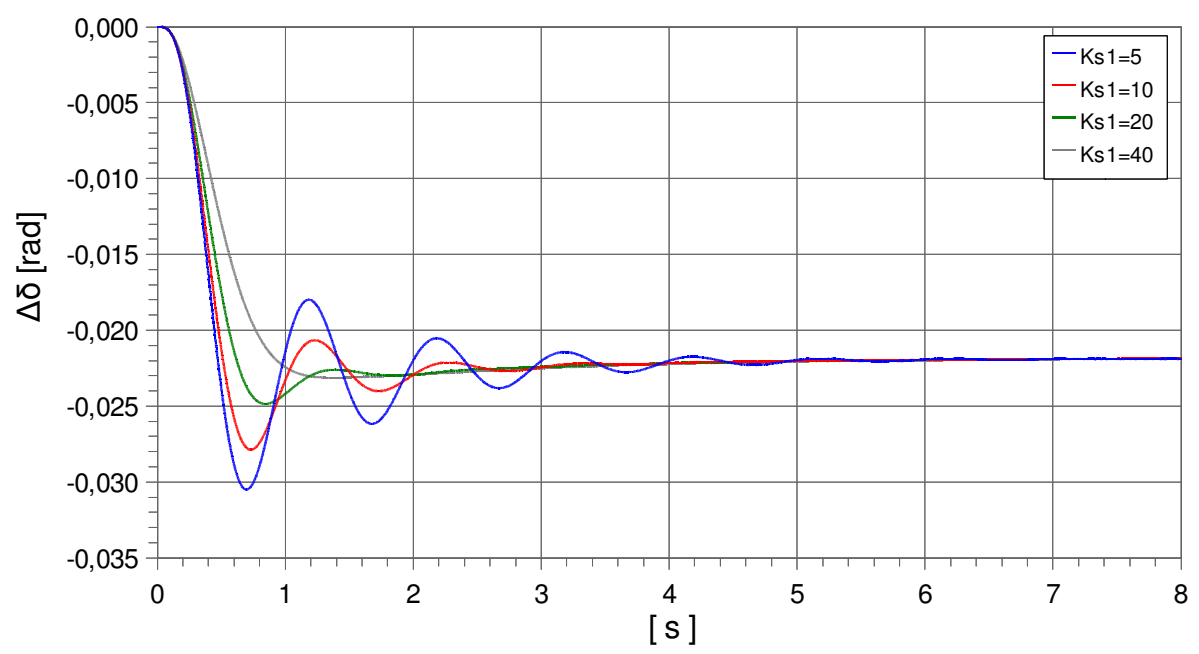

Figura 3.27: Comportamento do ângulo de carga após aplicação de degrau de 0,01p.u. na referência de tensão do AVR, ganho $K_{S 1}$ do PSS variando de 5 a 40 .

Nota-se na fig. 3.27 uma ligeira diminuição na frequência do modo de oscilação dominante devido ao aumento de $K_{S 1}$. Tal diminuição é notada também na tab. 3.6 na pág. 70. As raízes complexas conjugadas $-0,8884 \pm j 6,3070\left(K_{S 1}=5\right)$ movem-se para $-3,8992 \pm j 4,1867\left(K_{S 1}=40\right)$, o módulo da parte complexa destas raízes diminui.

A fig. 3.28 mostra o comportamento dos autovalores en função do ganho $K_{S 1}$. Tais autovalores foram mostrados na tab. 3.5 e na tab. 3.6. Considerou-se $K_{S 1}=0, K_{S 1}=5$, $K_{S 1}=10, K_{S 1}=20$ e $K_{S 1}=40$, não foram feitos cálculos para $K_{S 1}$ intermediários. As linhas de tendência conectando os autovalores são apenas ilustrativas. 


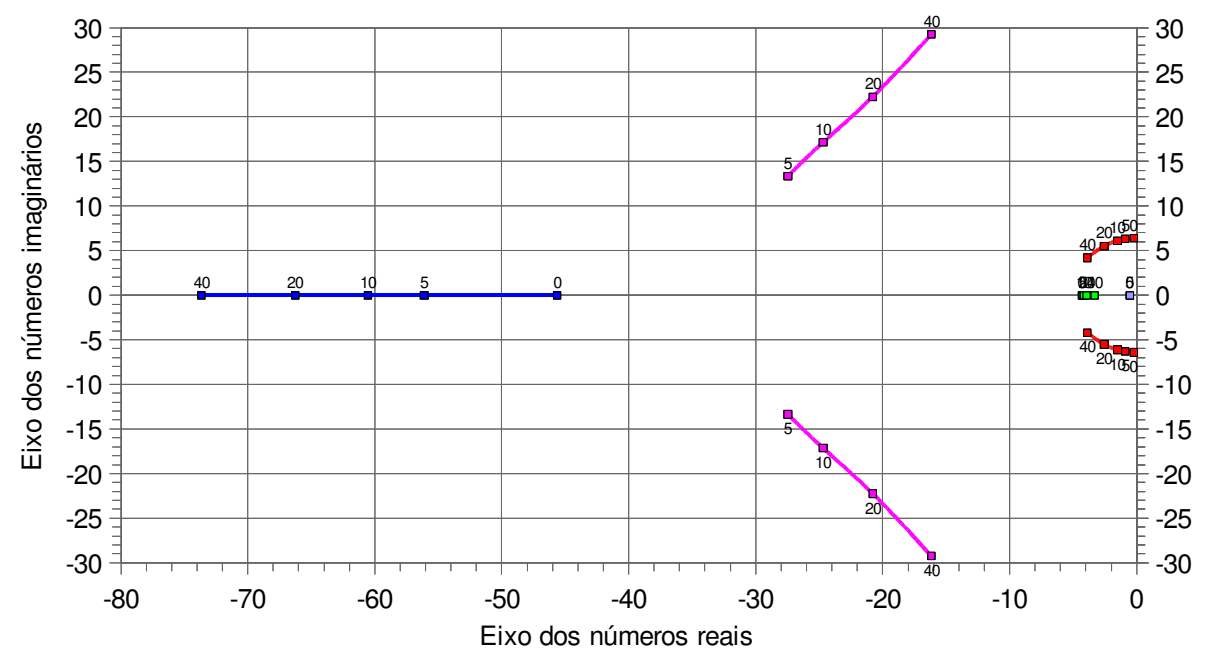

(a) Localização de todos os autovalores.

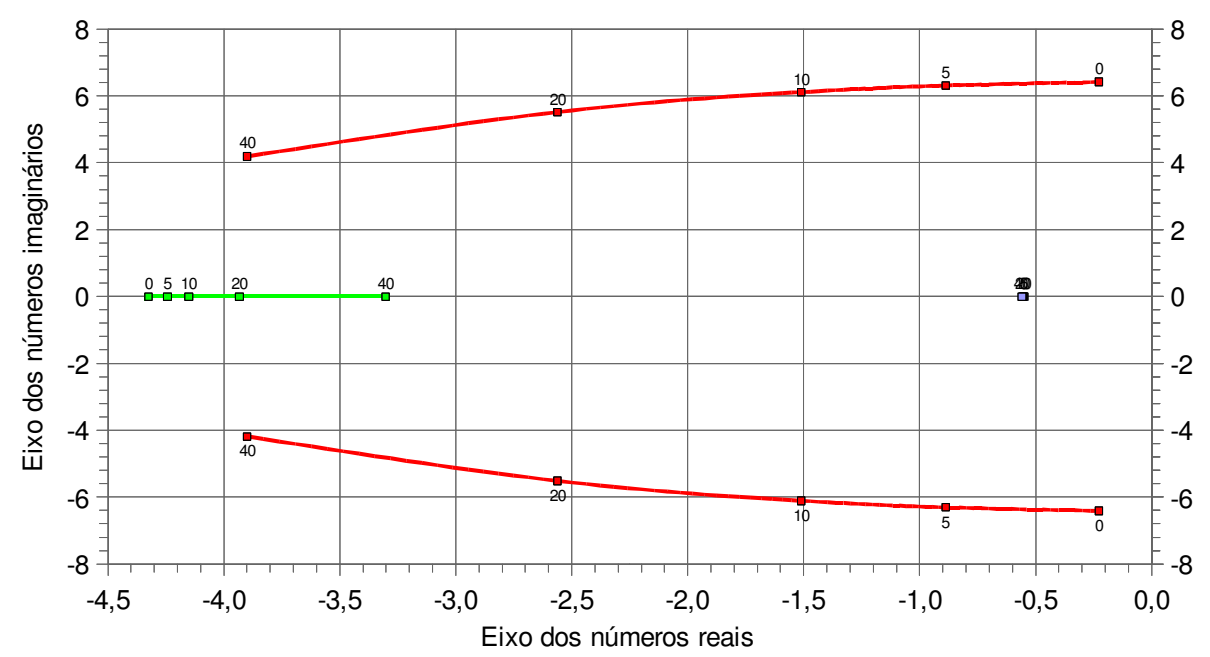

(b) Detalhe próximo a origem.

Figura 3.28: Localização no plano complexo dos autovalores do sistema em função do ganho $K_{S 1}$ do PSS.

\subsubsection{Influência da supercompensação ou da subcompensação de fase no amortecimento das oscilações locais}

O método de comparação entre potência ativa e saída do PSS (ver seção 3.3.3) assume que a defasagem entre e referência de tensão do AVR $\left(\Delta e_{t r e f}\right)$ e a tensão de campo $\left(\Delta E_{f d}\right)$ é praticamente nula. Tal método assume também qua há aproximadamente $90^{\circ}$ de atraso entre $\Delta E_{f d}$ e o torque elétrico $\left(\Delta T_{e}\right)$ na faixa de frequência do modo local.

O método de compensação de fase (ver seção 3.3.4) procura medir a defasagem entre $\Delta e_{\text {tref }}$ e $\Delta T_{e}$. Como tal medição não é possível em campo, assume-se que o comportamento da fase de $\Delta e_{t} / \Delta e_{t r e f}$ é semelhante ao comportamento da fase de $\Delta T_{e} / \Delta e_{t r e f}$. 
As aproximações adotadas pelo método de compensação de fase e pelo método de comparação de grandezas levam a pequenos "erros" no ajuste dos parâmetros dos blocos de avanço-atraso. Tais "erros" são denominados de subcompensação ou supercompensação de fase nesta dissertação.

Os modelos computacionais simulados no capítulo 2 e no capítulo 3 têm um modo de oscilação dominante, o modo local. É interessante verificar via simulações computacionais qual é a influência dos "erros" na compensação de fase na estabilidade do sistema e no amortecimento do modo local. Foram considerados quatro ajustes diferentes variando entre a subcompensação e a hipercompensação de fase. Tomou-se o mesmo modelo descrito na seção 3.4.2 com os ajustes dos blocos de avanço-atraso dados pela tab. 3.7.

Tabela 3.7: Ajustes empregados para os blocos de avanço-atraso no estudo da influência da supercompensação ou da subcompensação de fase.

\begin{tabular}{ccccc} 
Parâmetro & Subcompensado & Compensado & Supercompensado & Hipercompensado \\
\hline$T_{1}$ & $0,100 s$ & $0,115 s$ & $0,333 s$ & $1,000 s$ \\
$T_{2}$ & $0,030 s$ & $0,030 s$ & $0,033 s$ & $0,100 s$ \\
$T_{3}$ & $0,100 s$ & $0,115 s$ & $0,333 s$ & $1,000 s$ \\
$T_{4}$ & $0,030 s$ & $0,030 s$ & $0,033 s$ & $0,100 s$ \\
$T_{10}$ & $1,000 s$ & $1,000 s$ & $1,000 s$ & $1,000 s$ \\
$T_{11}$ & $1,000 s$ & $1,000 s$ & $1,000 s$ & $1,000 s$
\end{tabular}

A fig. 3.29 mostra a fase das respostas em frequência da função de transferência $\Delta e_{t} / \Delta e_{\text {tref }}$ e da função de transferência dos blocos de avanço-atraso $\left(G_{\text {lead-lag }}\right)$. É mostrado também o resultado da soma das fases destas duas funções de transferência. 


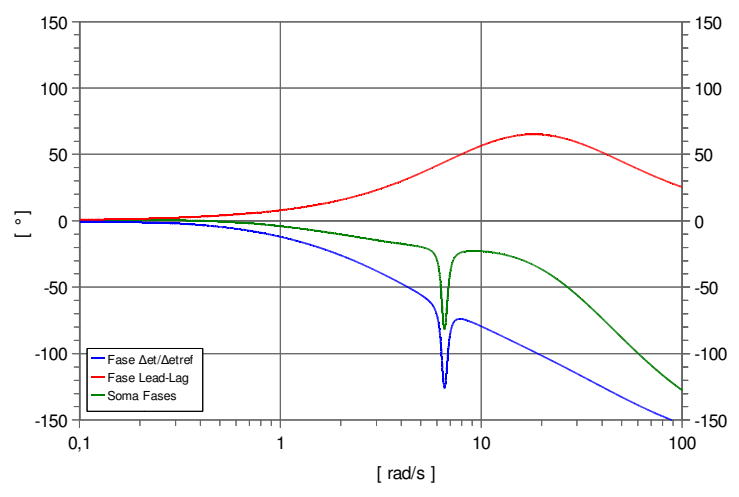

(a) Subcompensação de fase.

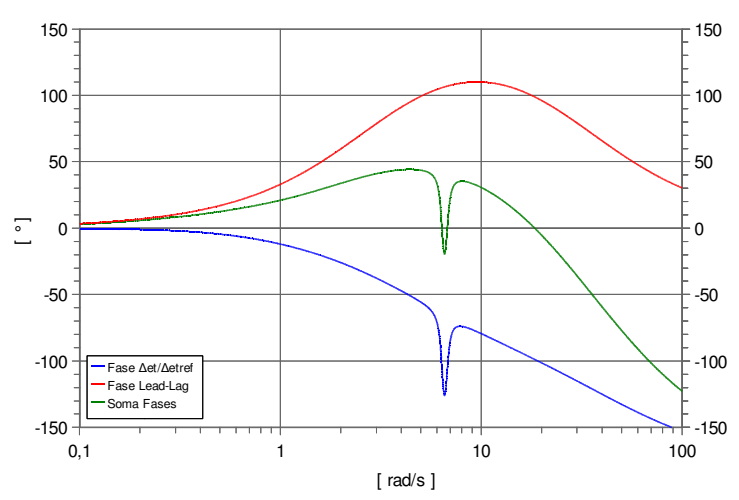

(c) Supercompensação de fase.

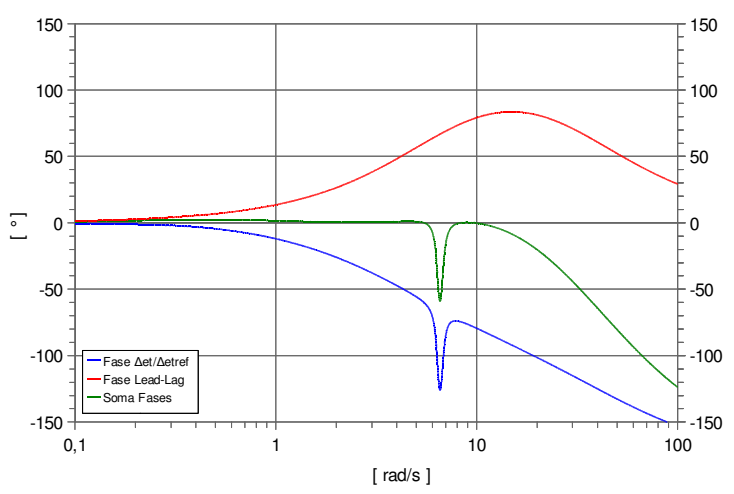

(b) Compensação de fase.

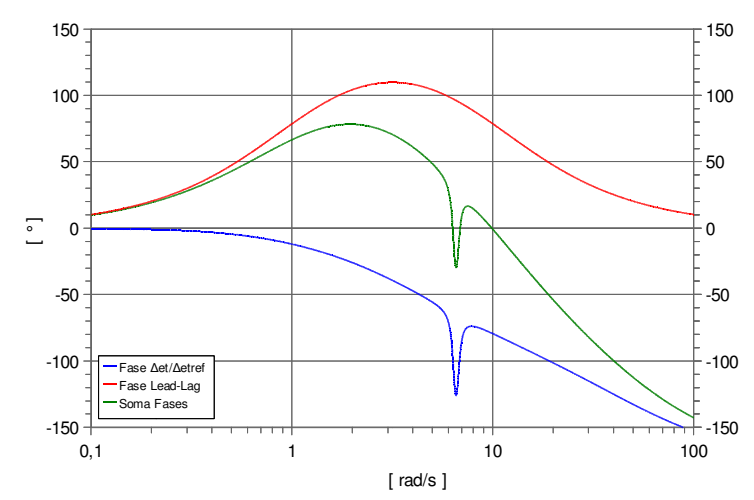

(d) Hipercompensação de fase.

Figura 3.29: Fase das respostas em frequência $\Delta e_{t} / \Delta e_{\text {tref }}, G_{\text {lead-lag }}$ e soma das características de fase empregadas no estudo da influência da sub e supercompensação de fase.

A alteração dos polos e zeros da função de transferência dos blocos de avanço-atraso $G_{\text {lead-lag }}$ altera a característica do ganho destes blocos. É fácil verificar com técnicas básicas de controle que a característica de ganho de $G_{\text {lead-lag }}$ depende das relações $T_{1} / T_{2}$, $T_{3} / T_{4}$ e $T_{10} / T_{11}$. Quanto maiores tais relações, maior será o ganho na parte alta do espectro de $G_{\text {lead-lag. }}$. Não se deve comparar o desempenho do PSS com as diferentes escolhas de $G_{\text {lead-lag }}$ e o mesmo ganho $K_{S 1}$. Deve-se levar em conta que o ganho $K_{S 1}$ ótimo varia conforme o ajuste definido para $T_{1}, T_{2}, T_{3}, T_{4}, T_{10}$ e $T_{11}$.

A fig. 3.30 mostra os autovalores em função do ganho $K_{S 1}$ do modelo de um gerador conectado a um barramento infinito com PSS. Os ajustes dos blocos de avanço-atraso foram feitos conforme a tab. 3.7 na pág. 73. 


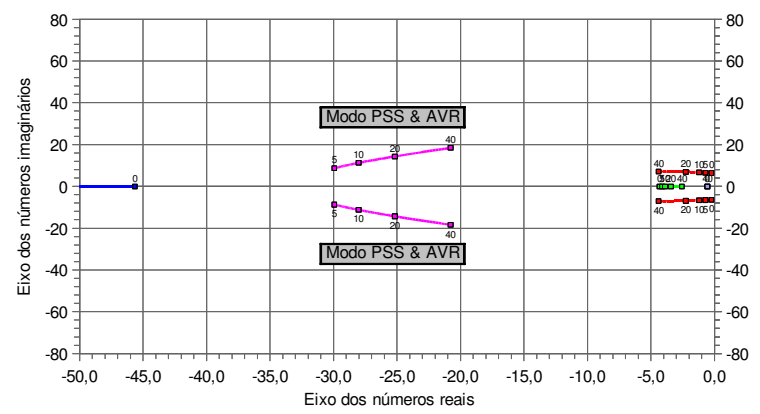

(a) Subcompensado - geral.

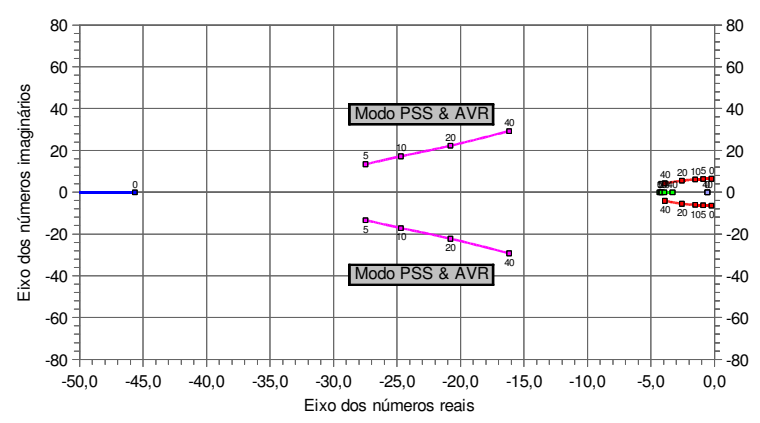

(c) Compensado - geral.

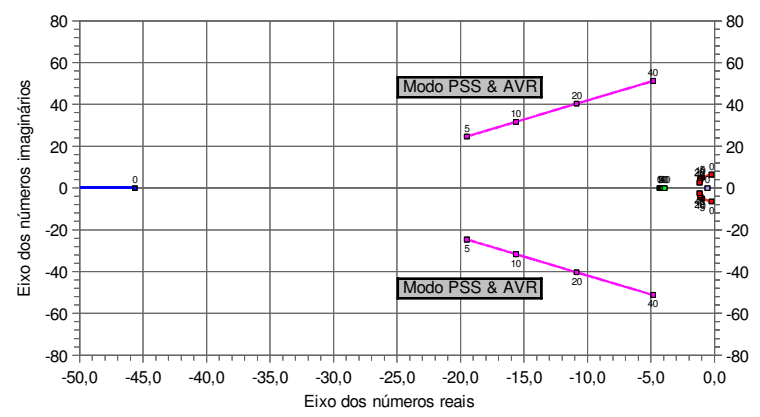

(e) Supercompensado - geral.

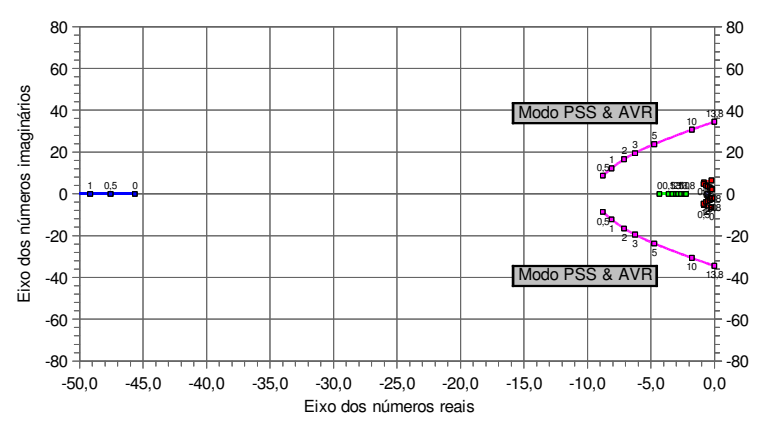

(g) Hipercompensado - geral.

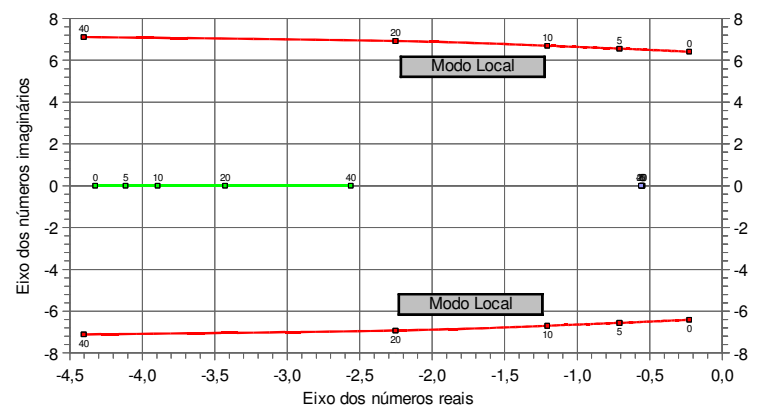

(b) Subcompensado - detalhe.

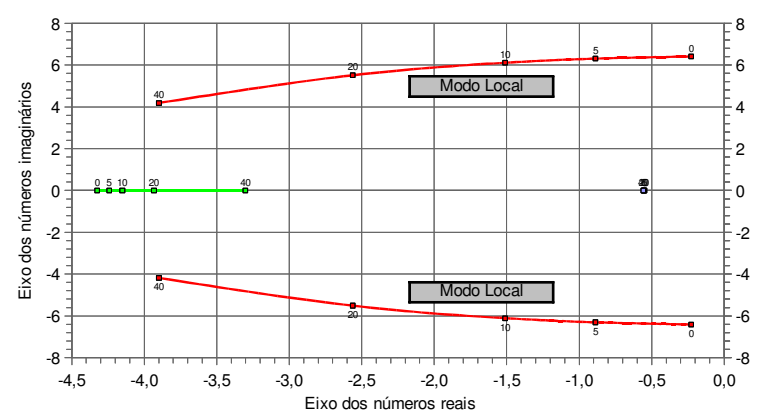

(d) Compensado - detalhe.

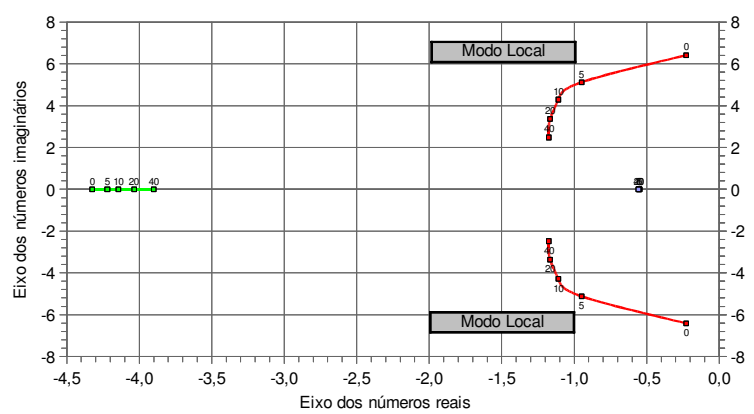

(f) Supercompensado - detalhe.

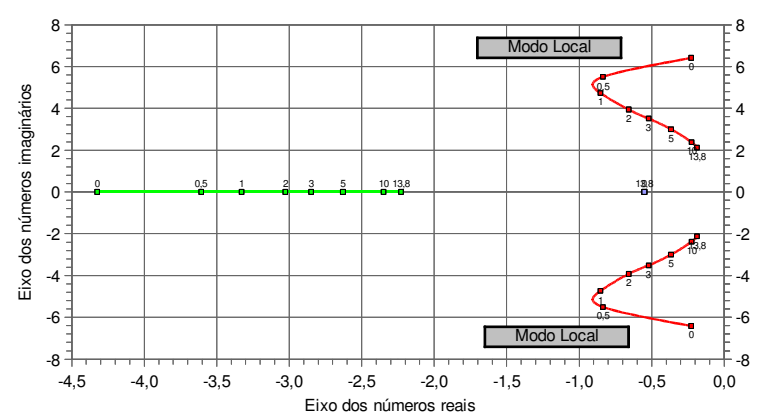

(h) Hipercompensado - detalhe.

Figura 3.30: Localização no plano complexo dos autovalores do sistema em função do ganho $K_{S 1}$ do PSS considerando diferentes ajustes dos blocos de avanço-atraso.

Os autovalores apresentados nas figuras 3.30a até 3.30f foram calculados computa- 
cionalmente para $K_{S 1}=0, K_{S 1}=5, K_{S 1}=10, K_{S 1}=20$ e $K_{S 1}=40$. Os autovalores apresentados nas fig. $3.30 \mathrm{~g}$ e na fig. $3.30 \mathrm{~h}$ foram calculados para $K_{S 1}=0, K_{S 1}=0,5$, $K_{S 1}=1, K_{S 1}=2, K_{S 1}=3, K_{S 1}=5$ e $K_{S 1}=13,8$. As linhas de tendência conectando os autovalores são apenas ilustrativas.

Comparando-se as figuras $3.30 \mathrm{~b}, 3.30 \mathrm{~d}$ e $3.30 \mathrm{e}$ verifica-se que para um mesmo ganho $K_{S 1}$ o amortecimento do modo local é diferente. O modo local é representado pelos autovalores complexos conjugados $-0,1771 \pm j 6,0152$ na tab. 3.5 na pág. 3.5. Pequenos "erros" de compensação de fase podem ser "corrigidos" pela otimização do ajuste de $K_{S 1}$.

A tab. 3.6 na pág. 70 e a fig. 3.28 na pág. 72 mostraram que o PSS introduz um novo modo de oscilação representado pelos autovalores complexos conjugados $-27,478 \pm$ $j 13,352\left(K_{S 1}=5\right)$. As figuras 3.30a, 3.30c, 3.30e e $3.30 \mathrm{~g}$ mostram nitidamente que supercompensar move os autovalores deste modo de oscilação para regiões de menor amortecimento. O sistema ajustado com hipercompensação de fase apresentou instabilidade para ganhos $K_{S 1}>13,8$. Os outros ajustes resultaram em sistemas estáveis mesmo com $K_{S 1}=40$.

A fig. 3.30e mostra que a margem de ajuste do ganho $K_{S 1}$ no sistema com supercompensação de fase é menor do que nos sistemas com subcompensação e compensação. Os autovalores complexos conjugados introduzido pelo PSS, no caso de supercompensação, se localizam regiões de menor amortecimento do plano complexo.

Murdoch et al. (1999a) e Murdoch, Venkataraman e Lawson (1999) citam que o método de compensação de fase deve ser empregado de maneira a se obter uma subcompensação de fase de até $30^{\circ}$. A soma das fases na fig. 3.29 na pág. 74 deve ficar entre $0^{\circ} \mathrm{e}$ $-30^{\circ}$. Vale lembrar que a introdução de avanços de fase na parte de mais baixa frequência do espectro é prejudicial para o amortecimento do modo de oscilações interárea. 


\section{Resultados práticos e análises}

Este capítulo apresenta resultados práticos obtidos durante os comissionamentos de três unidades geradoras em duas usinas hidrelétricas de médio porte. É feita uma análise das técnicas de ajuste de PSS apresentadas no capítulo 3.

\subsection{Sistema de excitação testado}

O sistema de excitação testado neste capítulo é de fabricação do grupo Voith Hydro. O sistema emprega conversores de corrente contínua programáveis equipados com uma ponte de tiristores totalmente controlada. O modelo computacional do sistema é mostrado na fig. 4.1.

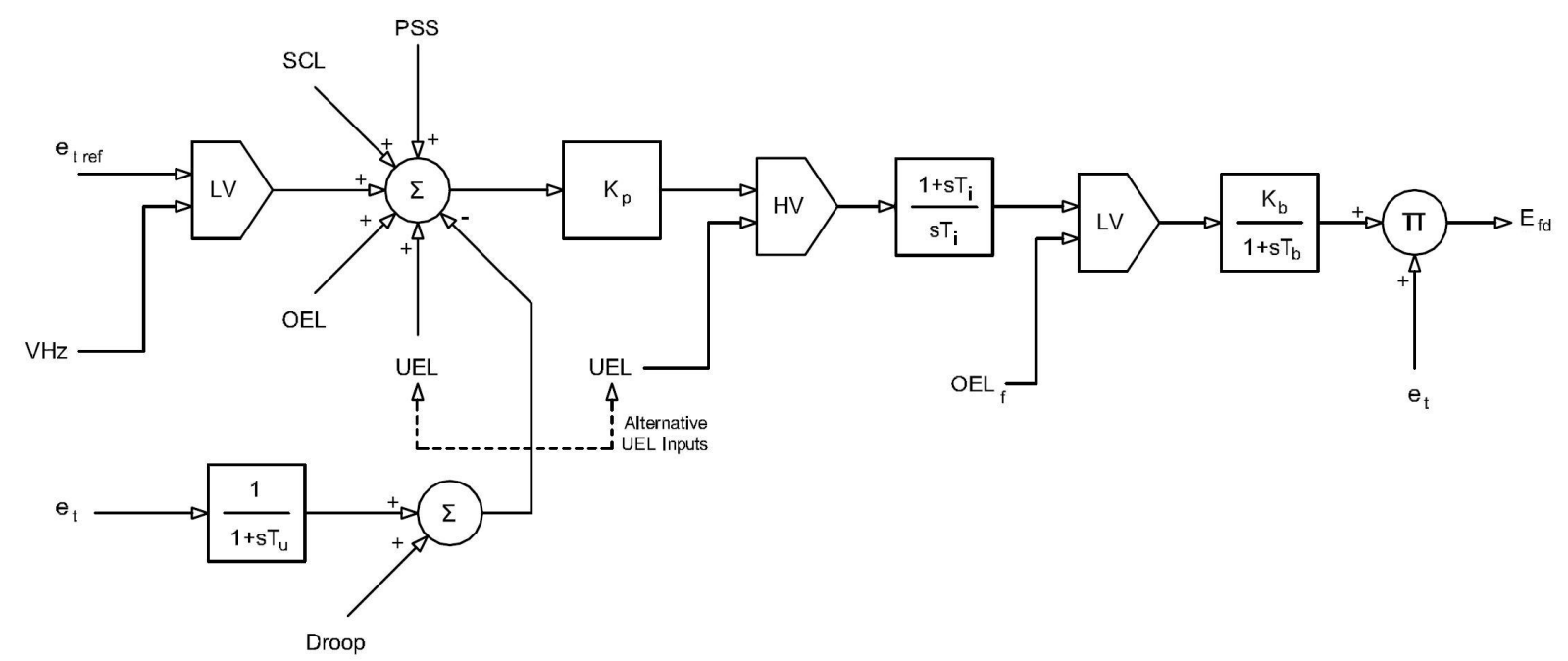

Figura 4.1: Modelo computacional do regulador de tensão testado neste capítulo.

As variáveis, parâmetros, entradas e saída do modelo computacional do sistema de excitação mostrado na fig. 4.1 são descritos a seguir:

- $e_{\text {tref }}$ : referência de tensão para o AVR;

- $e_{t}$ : tensão estatórica; 
- $E_{f d}$ : tensão de campo;

- Droop : sinal do compensador de reativos;

- VHz : sinal do limitador de Volts / Hertz;

- UEL : sinal do limitador de subexcitação;

- OEL : sinal do limitador de sobreexcitação;

- SCL : sinal do limitador de sobrecorrente estatórica;

- PSS : sinal do PSS;

- $\mathrm{OEL}_{f}$ : sinal do limitador rápido de sobreexcitação;

- LV : porta de mínimo valor, o menor valor passa;

- HV : porta de máximo valor, o maior valor passa;

- $\Sigma$ : bloco somador;

- $\Pi$ : bloco multiplicador;

- $T_{u}$ : constante de tempo do filtro do transdutor de tensão estatórica;

- $K_{p}$ : ganho proporcional do PI;

- $T_{i}$ : constante de integração do PI;

- $K_{b}$ : ganho proporcional do modelo da ponte de tiristores;

- $T_{b}$ : aproximação de primeira ordem para os pequenos atrasos inerentes ao sistema de excitação, incluindo tempo de processamento digital de sinais, disparo da ponte de tiristores, etc.

O regulador PI é equipado com um dispositivo anti-windup não representado na fig. 4.1. Tal dispositivo interrompe a integração se o sinal de saída do regulador PI ultrapassar limites pré-determinados.

Considerando que a tensão estatórica $\left(e_{t}\right)$ varia pouco em relação a nominal (1p.u.), que a constante de tempo do filtro de transdução de tensão $\left(T_{u}\right)$ é muito pequena e desconsiderando a influência dos sinais dos limitadores, verifica-se que a função de transferência do AVR testado neste capítulo se aproxima da função de transferência $G_{a v r P I}$ dada pela eq. 2.3 na pág. 14 . 


\subsection{Descrição das usinas hidrelétricas onde ocorre- ram os testes}

\subsubsection{Usina hidrelétrica Minas}

Parte dos resultados apresentados neste capítulo foram obtidos no início de 2006 durante o comissionamento de uma máquina de uma usina hidrelétrica no estado de Minas Gerais, Brasil. Tal usina é denominada UHE Minas nesta dissertação.

A UHE Minas possui 3 geradores de 85,5MVA. No início de 2006 foi realizado o comissionamento da primeira máquina. As unidades 2 e 3 estavam em fase final de montagem. A usina se conecta ao sistema de transmissão por uma linha de $138 \mathrm{kV}$. Tal linha, de menos de 50km, liga a usina a uma subestação de $138 \mathrm{kV}$ e $500 \mathrm{kV}$. Em um raio de cerca de $100 \mathrm{~km}$ ao redor da UHE Minas, há centrais hidrelétricas com potências instaladas de 510MW, 1192MW e 2280MW.

\subsubsection{Usina hidrelétrica Espanha}

São apresentados neste capítulo registros obtidos no fim de 2008 durante o comissionamento do regulador de tensão da unidade geradora 3 e dos PSSs das unidades geradoras 3 e 4 de uma usina hidrelétrica de médio porte na Espanha. Tal usina é denominada de UHE Espanha nesta dissertação.

A UHE Espanha possui 4 geradores de 90MVA. A turbina, os polos, o enrolamento estatórico e o sistema de excitação da unidade geradora 4 foram modernizados em 2007. Pequenas modificações também foram feitas nos reguladores de velocidade, sistemas de automação e de proteção. Empresas diferentes foram responsáveis por diferentes partes do fornecimento. A mesma modernização ocorreu na unidade 3 em 2008. Os PSSs das unidades 3 e 4 foram comissionados em dezembro de 2008.

A usina se conecta diretamente ao sistema de transmissão em 400kV. Em um raio de $200 \mathrm{~km}$ em torno da UHE Espanha há uma central térmica convencional, uma de ciclo combinado e duas nucleares de 1102MW, 1067MW, 1087MW e 2055MW respectivamente. Os novos reguladores de tensão e os antigos operam em modo de controle automático de tensão com um controlador superposto que mantém a potência reativa constante em torno de 0MVAr. 


\subsection{Ajuste da malha do AVR}

Não é o propósito desta dissertação discutir detalhadamente técnicas e resultados de ajustes da malha de controle do AVR. Porém, é interessante apresentar os ajustes do reguladores PI dos sistemas de excitação da UHE Minas e da UHE Espanha.

\subsubsection{Ajuste da malha do AVR da UHE Minas}

Foram realizados ensaios de resposta ao degrau na referência de tensão na unidade 1 da UHE Minas com o objetivo de otimizar o ajuste do PI da malha de controle do AVR. A potência ativa durante tais ensaios estava em 5MW. Testaram-se diferentes ganhos proporcionais $K_{p}$ e diferentes constantes de tempo de integração $T_{i}$. A fig. 4.2 apresenta as respostas ao degrau de $0,02 p . u$. na referência para três ajustes diferentes do regulador PI. Tais respostas foram realizadas em momentos diferentes, porém são apresentadas superpostas graficamente. A tab. 4.1 apresenta os valores de $K_{p}$ e $T_{i}$ testados.

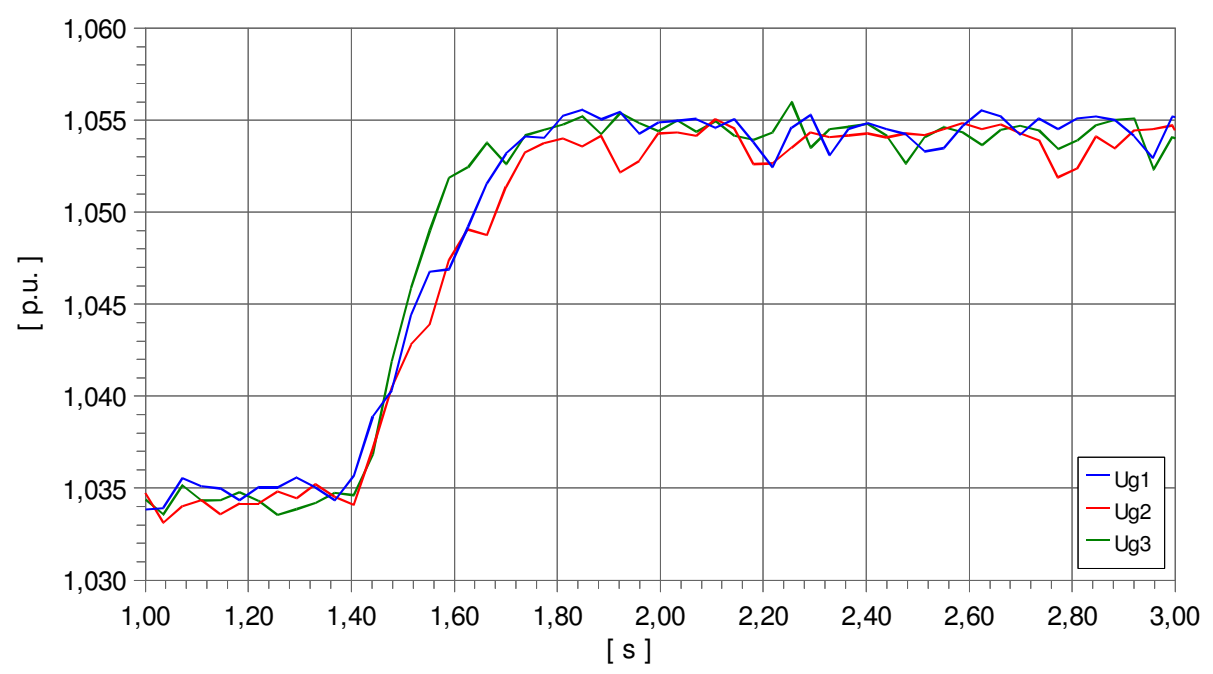

Figura 4.2: UHE Minas, respostas ao degrau de tensão com carga de 5MW com os parâmetros da tab. 4.1.

Tabela 4.1: Parâmetros usados para os testes apresentados na fig. 4.2.

\begin{tabular}{llcc} 
Comentário & Legenda da fig. 4.2 & $K_{p}$ & $T_{i}$ \\
\hline Teste com $T_{i}$ menor & $U g 1$ & 10 & $1,5 \mathrm{~s}$ \\
Ajuste adotado & $U g 2$ & 10 & $2,5 \mathrm{~s}$ \\
Teste com $K_{p}$ maior & $U g 3$ & 20 & $2,5 \mathrm{~s}$
\end{tabular}

As respostas ao degrau apresentadas na fig. 4.2 contêm ruído. Tal ruído dificulta a comparação dos tempos de subida ou eventuais sobressinais das respostas. Simulações 
computacionais permitem a escolha do ajuste do PI com base em diferenças de alguns milissegundos no tempo de subida. Tais decisões são mais difíceis em campo. A opinião pessoal do comissionador ou da engenharia do proprietário da usina são tão ou mais importantes que critérios puramente técnicos.

A resposta ao degrau marcada por Ug2 é a mais lenta das respostas apresentadas na fig. 4.2. Os outros ajustes do regulador PI resultaram num sistema mais rápido e sem sobressinal notável na resposta ao degrau. Por conservadorismo, o ajuste que resultou na resposta mais lenta foi adotado. O ajuste final dos parâmetros da malha de controle de tensão da UHE Minas é mostrado na tab. 4.2.

Tabela 4.2: Parâmetros da malha do AVR da UHE Minas.

\begin{tabular}{ll} 
Parâmetros & Valor \\
\hline$T_{u}$ & $16 \mathrm{~ms}$ \\
$K_{p}$ & 10 \\
$T_{i}$ & $2,5 \mathrm{~s}$ \\
$K_{b}$ & 6,25 \\
$T_{b}$ & $6,5 \mathrm{~ms}$
\end{tabular}

\subsubsection{Ajuste da malha do AVR da UHE Espanha}

Os testes realizados na UHE Espanha apresentados nesta dissertação foram realizados no final de 2008. Um ano antes, o AVR da unidade 4 havia sido comissionado. Adotou-se para a unidade 3 o mesmo ajuste da malha do AVR empregado para a unidade 4. Foram realizados ensaios de resposta ao degrau com o intuito de verificar os ajustes prévios da unidade 4. A resposta ao degrau na referência de tensão do AVR dos geradores 3 e 4 não apresentou sobressinal considerável.

A tab. 4.3 mostra o ajuste final da malha de controle do AVR da UHE Espanha.

Tabela 4.3: Parâmetros da malha do AVR das unidades 3 e 4 da UHE Espanha.

\begin{tabular}{ll} 
Parâmetros & Valor \\
\hline$T_{u}$ & $16 m s$ \\
$K_{p}$ & 12 \\
$T_{i}$ & $1,5 s$ \\
$K_{b}$ & 4,5 \\
$T_{b}$ & $7,3 \mathrm{~ms}$
\end{tabular}




\subsection{Ajuste do transdutor de integral da potência ace- lerante}

Em ambas as usinas hidrelétricas Minas e Espanha, o ajuste do transdutor de integral de potência acelerante foi feito visando o amortecimento do modo de oscilações local. As máquinas da UHE Minas têm uma potência aparente de 85,5MVA. Há centrais hidrelétricas ao redor da UHE Minas com potências instaladas de mais de 1GW. As máquinas da UHE Espanha (90MVA) são pequenas se comparadas aos turbogeradores das usinas térmicas e termonucleares próximas. Há pouca influência das máquinas testadas no sistema como um todo e nos modos de oscilação interárea.

O ajuste do transdutor de integral da potência acelerante da UHE Minas é apresentado na tab. 4.4. O valor das constantes de tempo dos filtros de washout foi escolhido pela engenharia do proprietário da usina. O valor do ganho $K_{S 2}$ do bloco integrador (ou passa-baixa, ver seção 3.2.3) resultou da aplicação da eq. 3.2 (pág. 37).

O filtro rastreador de rampa de ambas as usinas foi ajustado com os valores dados por Paiva et al. (1999), Ferraz et al. (2002) e ONS (2004b) na tab. 3.1 (pág. 41). O ajuste do transdutor de integral da potência acelerante da UHE Espanha é apresentado na tab. 4.4.

Tabela 4.4: Ajustes do transdutor de integral de potência acelerante da UHE Minas e da UHE Espanha.

\begin{tabular}{lll} 
Parâmetros & UHE Minas & UHE Espanha \\
\hline$T_{W 1}, T_{W 2}, T_{W 3}, T_{W 4}, T_{7}$ & $2 \mathrm{~s}$ & $3 \mathrm{~s}$ \\
$T_{6}$ & $0,02 \mathrm{~s}$ & $0,02 \mathrm{~s}$ \\
$K_{S 2}$ & 0,3 & 0,5 \\
$K_{S 3}$ & 1 & 1 \\
$T_{8}$ & $0,4 \mathrm{~s}$ & $0,4 \mathrm{~s}$ \\
$K_{9}$ & $0,1 \mathrm{~s}$ & $0,1 \mathrm{~s}$ \\
$N$ & 1 & 1 \\
$M$ & 4 & 4
\end{tabular}




\subsection{Ajuste do estágio de ganho e avanço-atraso de fase do PSS da UHE Minas}

O ajuste do estágio de ganho e avanço-atraso de fase do PSS da unidade 1 da UHE Minas foi realizado pelo método de tentativa e erro descrito na seção 3.3.1 na pág. 42.

O ganho $K_{S 1}$ do PSS da UHE Minas foi ajustado conforme o método empírico descrito na seção 3.3.5. Garantiu-se que o AVR e o PSS tinham um comportamento estável em regime permanente mesmo com um ganho $K_{S 1}$ três vezes maior do que o ganho escolhido.

\subsubsection{Método de ajuste de PSS baseado na tentativa e erro apli- cado na UHE Minas}

O comissionador do AVR e do PSS da UHE Minas sugeriu um ajuste inicial baseado em uma obra de porte semelhante. A engenharia do proprietário da usina sugeriu um ajuste inicial baseado em uma outra obra de porte semelhante. Realizaram-se ensaios de resposta ao degrau na referência de tensão do AVR $\left(e_{\text {tref }}\right)$ e registram-se grandezas como tensão terminal $\left(e_{t}\right)$, potência ativa $(P)$, potência reativa $(Q)$ e frequência $(f)$. Foram feitas pequenas modificações no ajuste inicial sugerido pela engenharia do proprietário. A cada pequena modificação, as oscilações em $P$ eram registradas e comparadas com os resultados obtidos anteriormente.

O ajuste final dos blocos de ganho e avanço-atraso do PSS da UHE Minas é apresentado na tab. 4.5.

Tabela 4.5: Ajustes dos blocos de ganho e avanço-atraso da UHE Minas.

\begin{tabular}{ll} 
Parâmetros & Valor \\
\hline$K_{S 1}$ & 7 \\
$T_{1}$ & $0,12 \mathrm{~s}$ \\
$T_{2}$ & $0,03 \mathrm{~s}$ \\
$T_{3}$ & $0,12 \mathrm{~s}$ \\
$T_{4}$ & $0,03 \mathrm{~s}$ \\
$T_{10}$ & $1 \mathrm{~s}$ \\
$T_{11}$ & $1 \mathrm{~s}$ \\
$V_{S T M A X}$ & 0,1 \\
$V_{S T M I N}$ & $-0,1$
\end{tabular}


A resposta da unidade 1 da UHE Minas com e sem PSS a um degrau de 0,04p.u. na referência de tensão do AVR é apresentada na fig. 4.3.

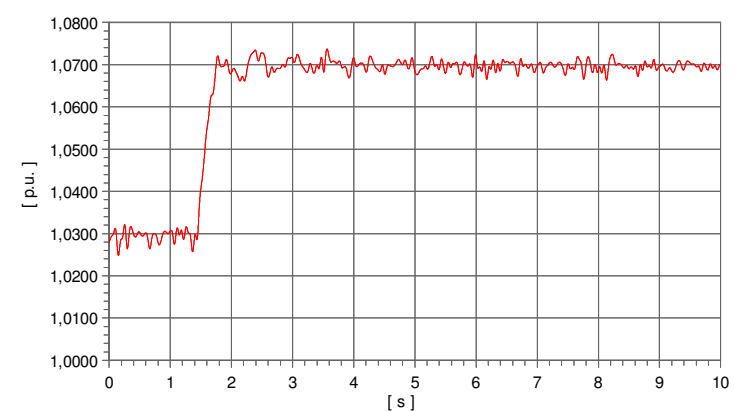

(a) Tensão terminal sem PSS

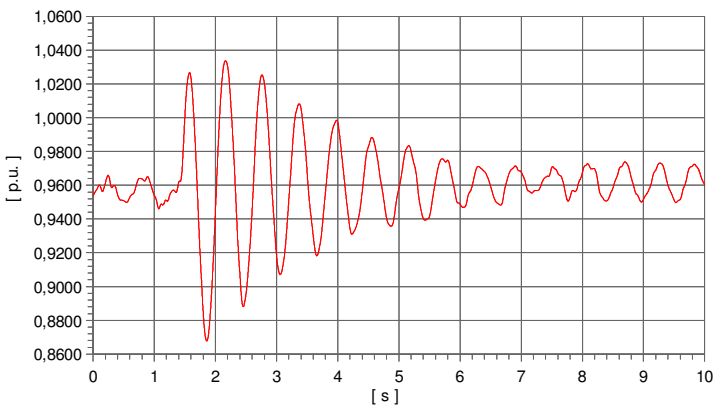

(c) Potência ativa sem PSS

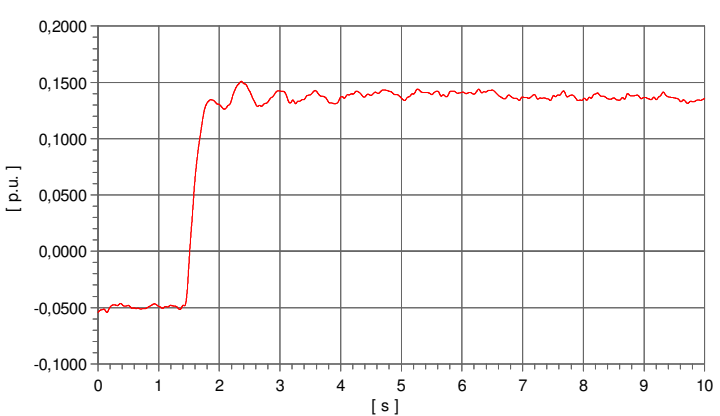

(e) Potência reativa sem PSS

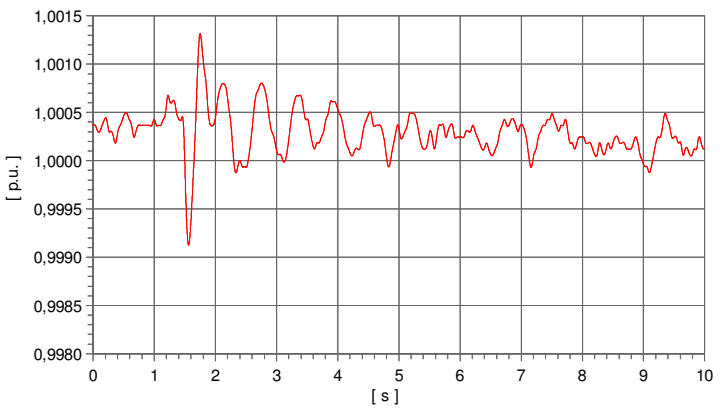

(g) Frequência terminal sem PSS

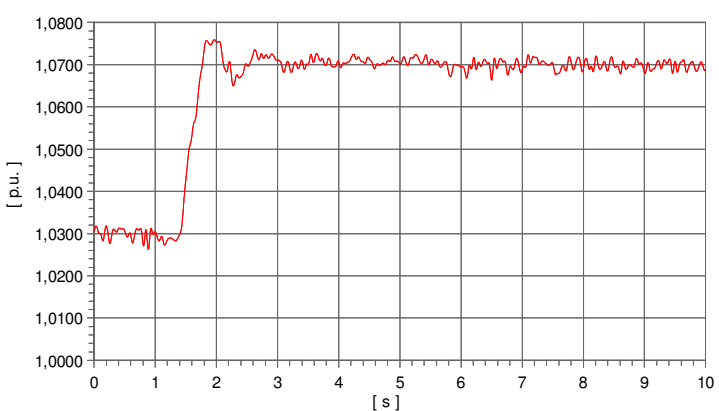

(b) Tensão terminal com PSS

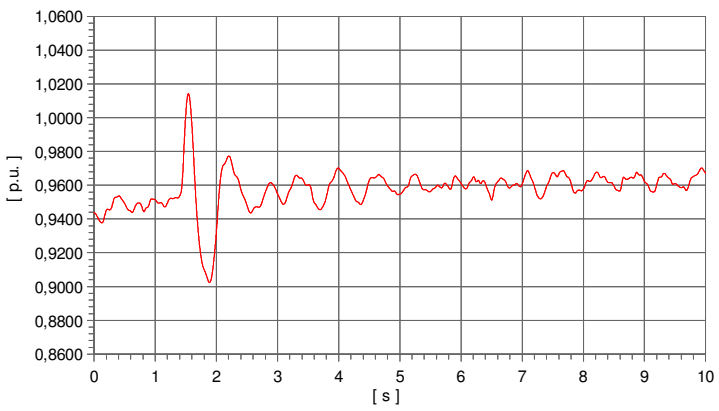

(d) Potência ativa com PSS

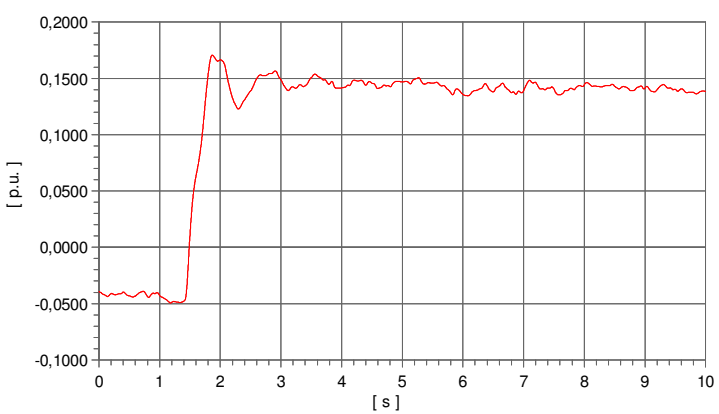

(f) Potência reativa com PSS

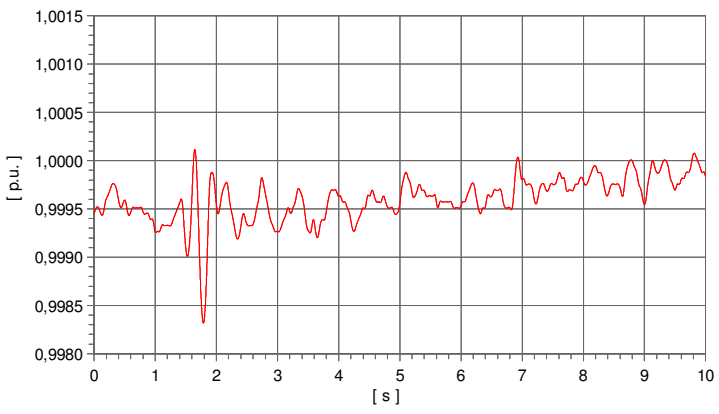

(h) Frequência terminal com PSS

Figura 4.3: UHE Minas, resposta ao degrau de 0,04p.u. na referência de tensão do AVR. 


\subsubsection{Comparação entre o ajuste realizado e o ajuste proposto pelo método de compensação de fase}

Durante o comissionamento do AVR e do PSS da UHE Minas foram levantadas as respostas em frequência entre a referência de tensão do $\operatorname{AVR}\left(\Delta e_{t r e f}\right)$ e a tensão estatórica $\left(\Delta e_{t}\right)$. Tais ensaios foram realizados com o objetivo de estudar posteriormente o comportamento do gerador com e sem PSS. Não houve o emprego do método de compensação de fase na obra.

Apesar de não utilizadas para o ajuste do PSS, as respostas em frequência $\Delta e_{t} / \Delta e_{\text {tref }}$ possibilitam uma comparação entre o ajuste escolhido durante o comissionamento e o ajuste que resultaria da aplicação do método de compensação de fase.

As respostas em frequência $\Delta e_{t} / \Delta e_{\text {tref }}$ foram obtidas com o emprego de um equipamento de aquisição de dados de propriedade da Voith Hydro. Tal equipamento possui uma saída analógica $( \pm 10 \mathrm{~V})$ que é usada para inserir um distúrbio senoidal de frequência variante no regulador de tensão. Há uma entrada analógica no equipamento que registra a resposta ao distúrbio. Pode-se introduzir o distúrbio em diversos pontos da malha de controle do AVR. É possível medir a influência do distúrbio em diferentes pontos da malha de controle e em diversas grandezas elétrica do gerador. A resposta em frequência desejada é obtida computacionalmente a partir da comparação do distúrbio e da resposta ao distúrbio. 
A fig. 4.4 apresenta o distúrbio senoidal de frequência variante inserido na referência de tensão do $\operatorname{AVR}\left(\Delta e_{\text {tref }}\right)$ e a variação causada na tensão estatórica $\left(\Delta e_{t}\right)$. Tais sinais são obtidos de saídas analógicas $( \pm 10 \mathrm{~V})$ do regulador de tensão. Há uma grande semelhança entre as respostas mostradas na fig. 4.4 e as respostas obtidas via simulação computacional apresentadas na fig. 3.17 na pág. 54 .

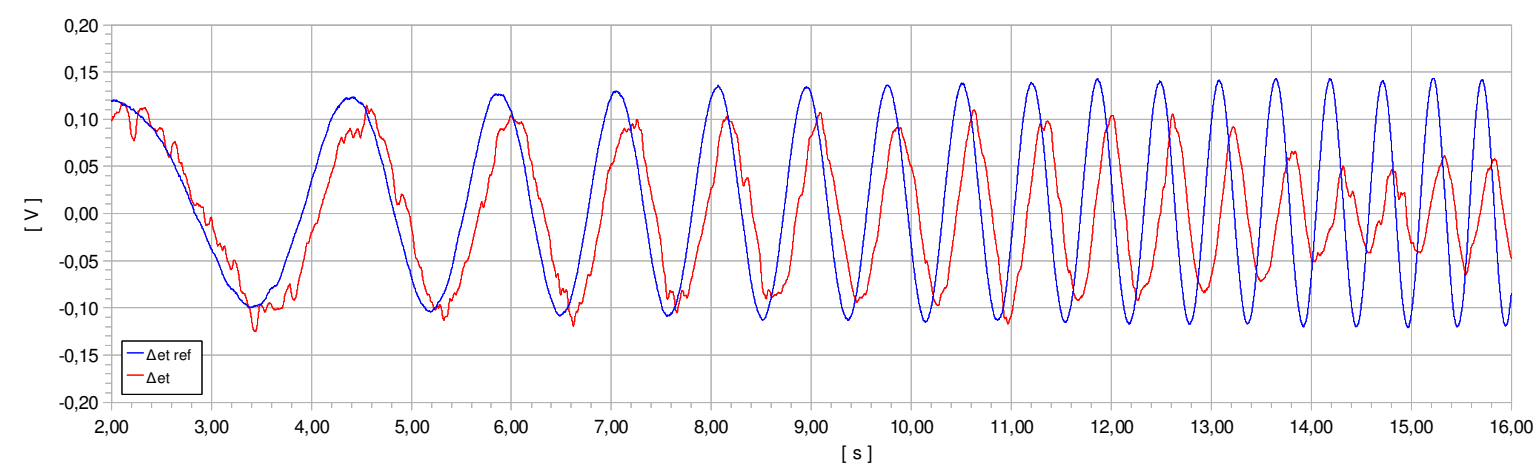

(a) $61 \mathrm{MW}$ sem PSS

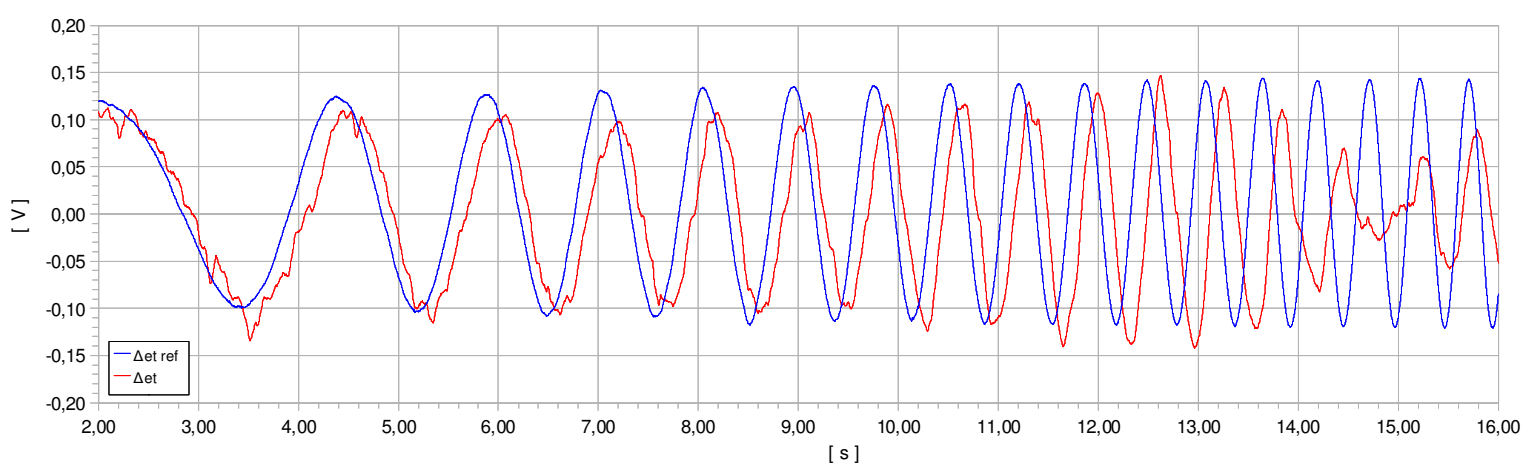

(b) $82 \mathrm{MW}$ sem PSS

Figura 4.4: UHE Minas, levantamento de resposta em frequência $\Delta e_{t} / \Delta e_{\text {tref }}$ sem PSS 
As respostas em frequência $\Delta e_{t} / \Delta e_{\text {tref }}$ com potência ativa de $61 \mathrm{MW}$ obtidas na UHE Minas são apresentadas na fig. $4.5^{1}$. O PSS estava desligado.

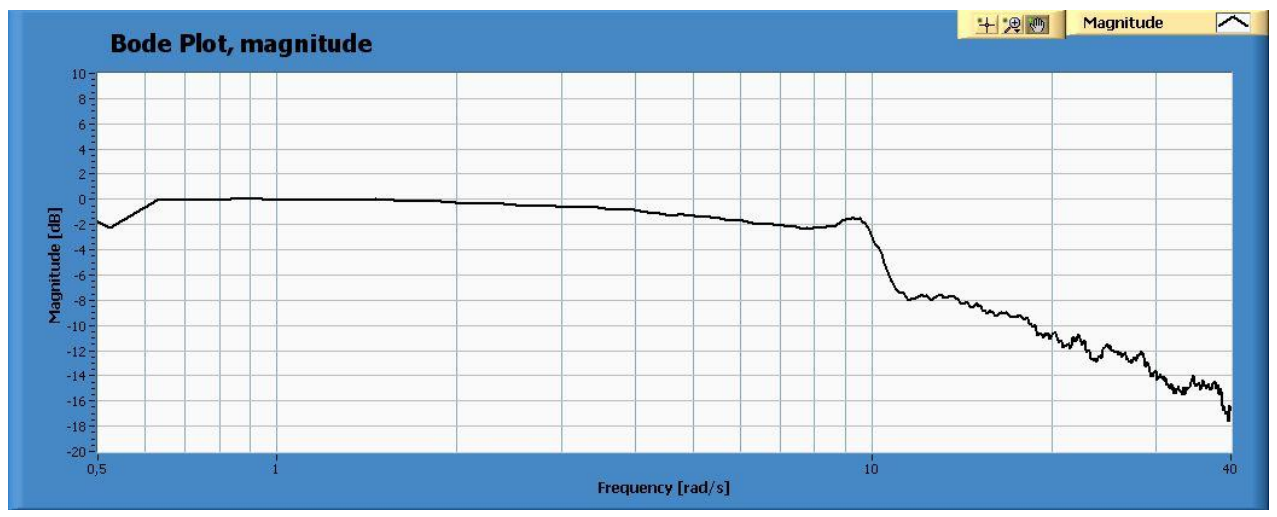

(a) Ganho em $d B$ - Sem PSS

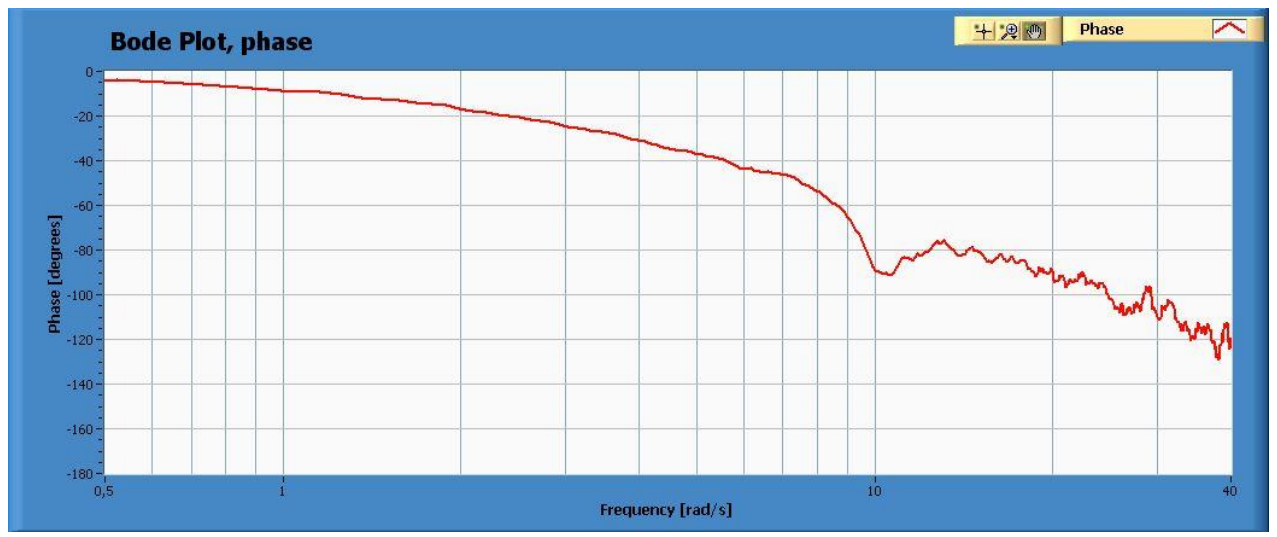

(b) Fase em ${ }^{\circ}-$ Sem PSS

Figura 4.5: UHE Minas, resposta em frequência $\Delta e_{t} / \Delta e_{\text {tref }}$ sem PSS com potência de $61 \mathrm{MW}$.

A frequência do modo local na UHE Minas é de aproximadamente 10rad/s. Tal frequência pode ser obtida a partir da fig. 4.3c na pág. 84 .

Nota-se na fig. 4.5 que há um aumento no ganho da resposta em frequência nas proximidades do modo local. Há também um aumento no atraso de fase na mesma faixa do espectro. Tal comportamento é ainda mais pronunciado quando se aumenta a carga do gerador para 82MW. Os geradores da UHE Minas são de 85,5MVA com fator de potência nominal de 0,95 .

\footnotetext{
${ }^{1}$ As figuras com o ganho e defasagem das funções de transferência $\Delta e_{t} / \Delta e_{\text {tref }}$ dos AVRs testados neste capítulo foram obtidas com um equipamento digital de propriedade da Voith Hydro. Esta ferramenta disponibiliza resultados apenas como imagens digitais, não em formato de tabela de dados
} 
A fig. 4.6 apresenta a resposta em frequência $\Delta e_{t} / \Delta e_{\text {tref }}$ do gerador 1 da UHE Minas com potência ativa de $82 \mathrm{MW}$. O PSS estava desligado. O aumento no ganho próximo à frequência do modo local é bem pronunciado. Nota-se também um aumento brusco no atraso de fase na mesma faixa do espectro. Tal comportamento foi previsto durante as simulações computacionais de um gerador conectado a um barramento infinito por uma impedância externa apresentadas no capítulo 3. É interessante verificar a semelhança entre a resposta obtida na UHE Minas e as respostas em frequêcia de modelos computacionais mostradas nas figuras 3.16 e 3.18 nas páginas 53 e 56, respectivamente.

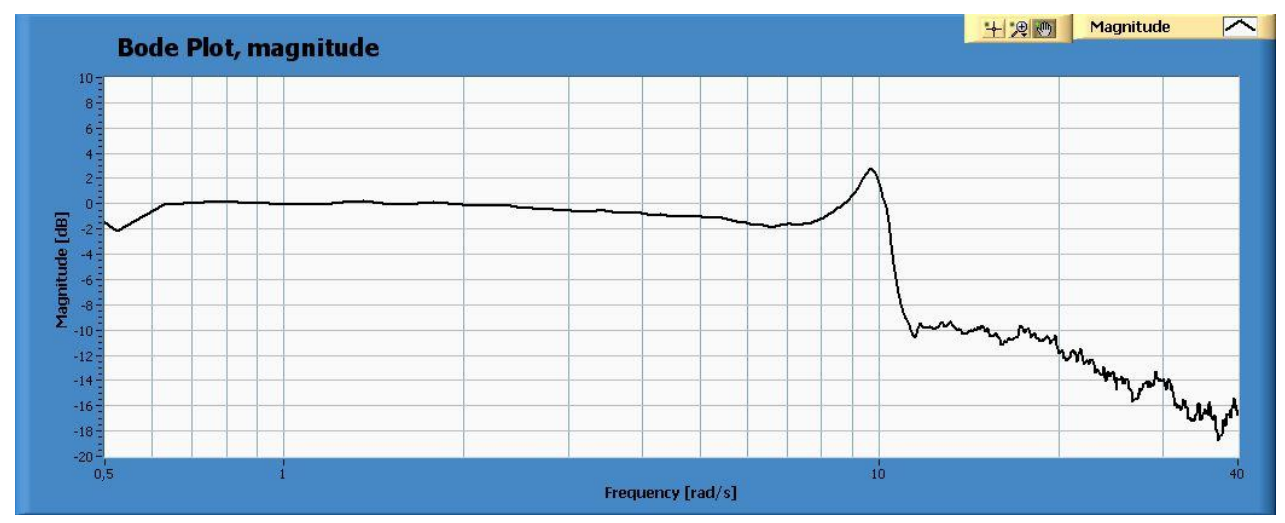

(a) Ganho em $d B$ - Sem PSS

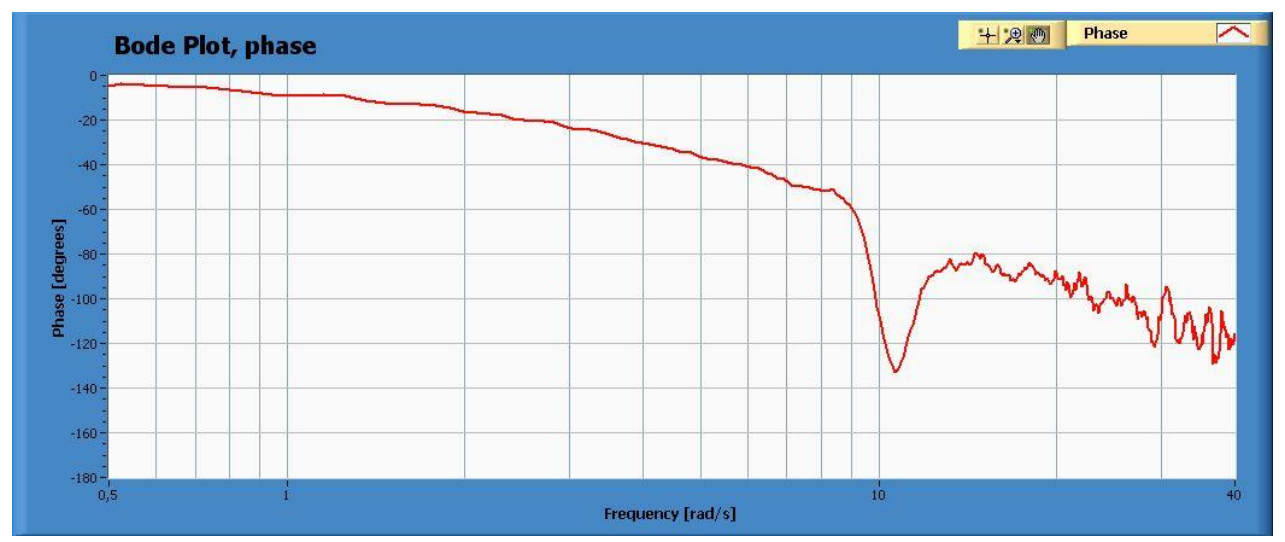

(b) Fase em ${ }^{\circ}-$ Sem PSS

Figura 4.6: UHE Minas, resposta em frequência $\Delta e_{t} / \Delta e_{t r e f}$ sem PSS com potência de $82 \mathrm{MW}$.

O método de compensação de fase consiste em ajustar os blocos de avanço-atraso para que estes compensem a defasagem medida na resposta em frequência $\Delta e_{t} / \Delta e_{\text {tref }}$, ver seção 3.3.4. Tal defasagem corresponde, considerando as devidas aproximações, à defasagem entre a referência de tensão do AVR e o torque elétrico. Assume-se também que o sinal de integral da potência acelerante é praticamente igual à velocidade do rotor do gerador. 
A fig. 4.7 apresenta o resultado da simulação computacional da fase da resposta em frequência dos blocos de avanço-atraso ajustados na UHE Minas. Mostra-se também a sugestão de defasagem proposta pelo método de compensação de fase considerando as respostas em frequência $\Delta e_{t} / \Delta e_{\text {tref }}$ do gerador com $61 \mathrm{MW}$ (fig 4.5) e com 82MW (fig.4.6).

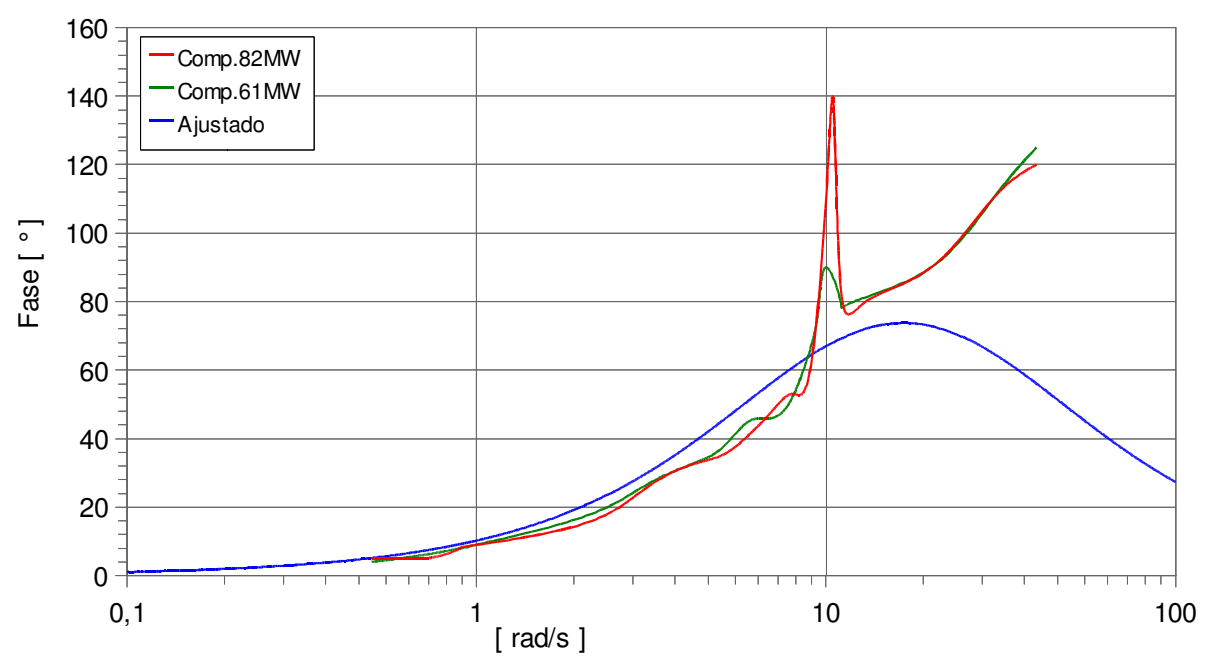

Figura 4.7: UHE Minas, comparação entre os blocos de avanço ajustados e a sugestão do método de compensação de fase.

Na faixa de frequência entre $0,5 \mathrm{rad} / \mathrm{s}$ e $20 \mathrm{rad} / \mathrm{s}$, o avanço de fase sugerido pelo método de compensação de fase coincide aproximadamente com o avanço de fase provocado pelos blocos de avanço-atraso da UHE Minas. Há discrepâncias nas proximidades da frequência do modo local. Estas discrepâncias foram previstas pelas simulações computacionais apresentadas na seção 3.3.4. A coincidência entre os resultados obtidos com o método de tentativa e erro e os sugeridos pela compensação de fase não prova que o primeiro método leva aos mesmos ajustes que segundo.

Durante o comissionamento do PSS da UHE Minas foram usados dois ajustes prévios de usinas de porte semelhante. A primeira usina usada como base fica no estado da Bahia, a segunda fica no estado de Minas Gerais. O segundo ajuste testado mostrou-se mais eficiente que o primeiro no amortecimento das oscilações de potência ativa. Caso nenhum dos ajustes iniciais fosse eficiente, apenas tentativas e erros levariam a horas de testes aleatórios, o emprego de métodos como os de comparação de grandezas ou o de compensação de fase é mais produtivo. 


\subsubsection{Resposta em frequência $\Delta e_{t} / \Delta e_{t r e f}$ da unidade 1 da UHE Minas equipada com PSS}

A seção 3.3.4.3 mostrou a aplicação do método de compensação de fase para o ajuste de PSS. A fig. 3.22 na pág. 60 mostrou a resposta em frequência obtida de um modelo computacional de um gerador conectado a um barramento infinito via uma impedância externa. Verificou-se que nas proximidades da frequência do modo local há um aumento súbito no ganho de $\Delta e_{t} / \Delta e_{\text {tref }}$ no caso do sistema sem PSS. Ao se empregar o método de compensação de fase para ajustar o PSS, houve uma redução drástica do ganho da função $\Delta e_{t} / \Delta e_{\text {tref }}$ nas proximidades da frequência das oscilações locais.

Durante o comissionamento da unidade 1 da UHE Minas, foi possível levantar as respostas em frequência $\Delta e_{t} / \Delta e_{\text {tref }}$ com o PSS em funcionamento. A fig. 4.8 mostra o estímulo senoidal de frequência variante inserido na referência de tensão do AVR e a resposta obtida na tensão estatórica com o PSS ativo. A potência ativa fornecida pelo gerador ao sistema de transmissão era de 61MW e de $82 \mathrm{MW}$.

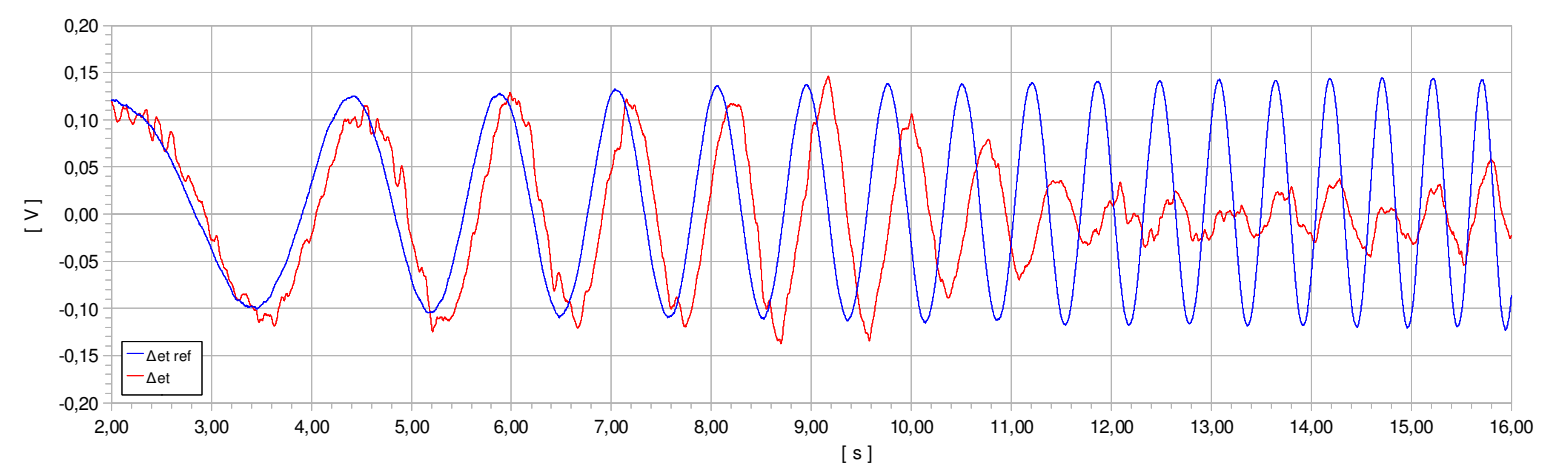

(a) $61 \mathrm{MW}$ com PSS

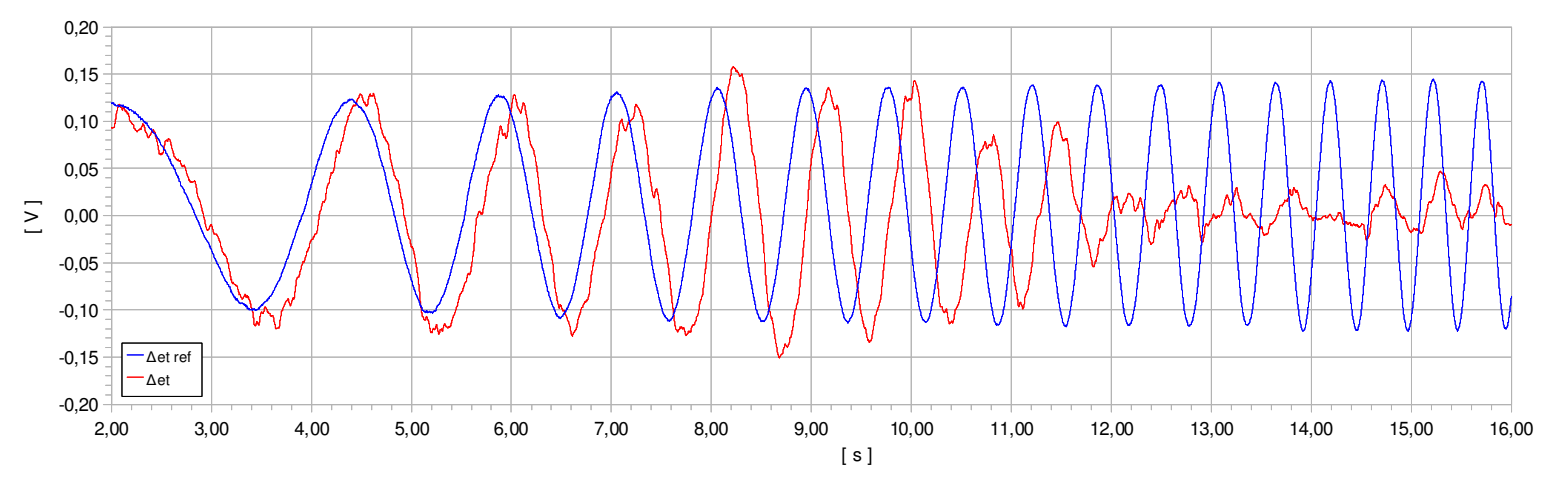

(b) $82 \mathrm{MW}$ com PSS

Figura 4.8: UHE Minas, levantamento da resposta em frequência $\Delta e_{t} / \Delta e_{\text {tref }}$ com PSS.

É interessante comparar a fig. 4.8 com a fig. 4.4 na pág. 86. É notável a diminuição 
na amplitude da variação da tensão estatórica $\left(\Delta e_{t}\right)$ a partir do instante $t=11 \mathrm{~s}$. Tal comportamento indica que o PSS diminui o ganho da função de transferência $\Delta e_{t} / \Delta e_{\text {tref }}$ em uma determinada faixa de frequência. Isto já era esperado segundo as respostas em frequência obtidas com modelos computacionais apresentadas na fig. 3.22 na pág. 60 .

A fig. 4.9 mostra a resposta em frequência $\Delta e_{t} / \Delta e_{\text {tref }}$ obtida da unidade 1 da UHE Minas carregada com 82MW e com o PSS ativo. A fig. 4.6 na pág. 88 mostra a mesma reposta em frequência com o PSS desligado. Houve uma redução no ganho da função de transferência entre $8 \mathrm{rad} / \mathrm{s}$ e $10 \mathrm{rad} / \mathrm{s}$.

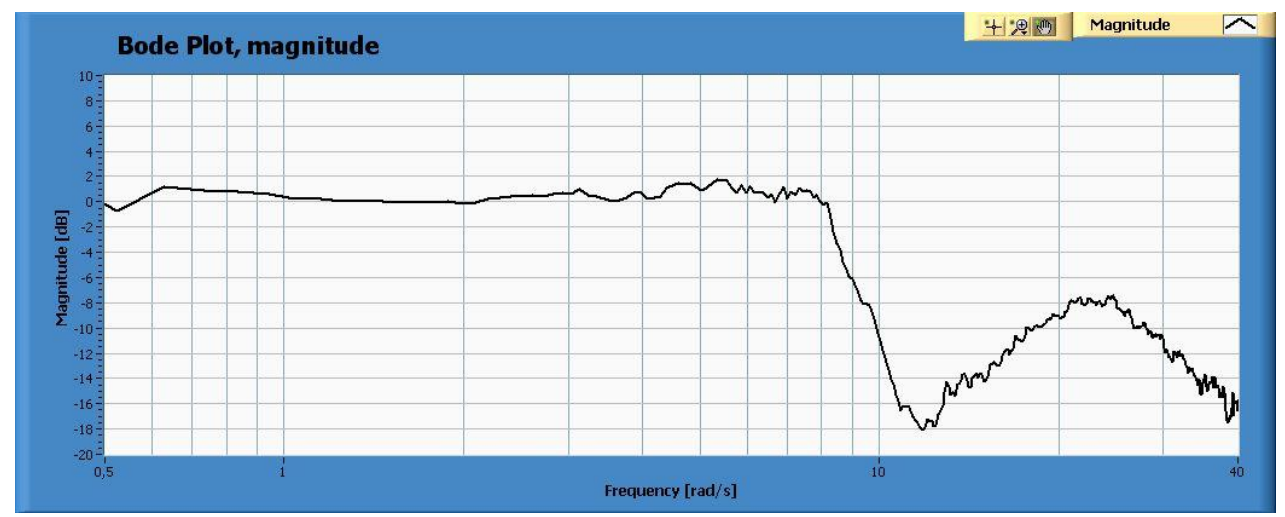

(a) Ganho em $d B$ - Com PSS

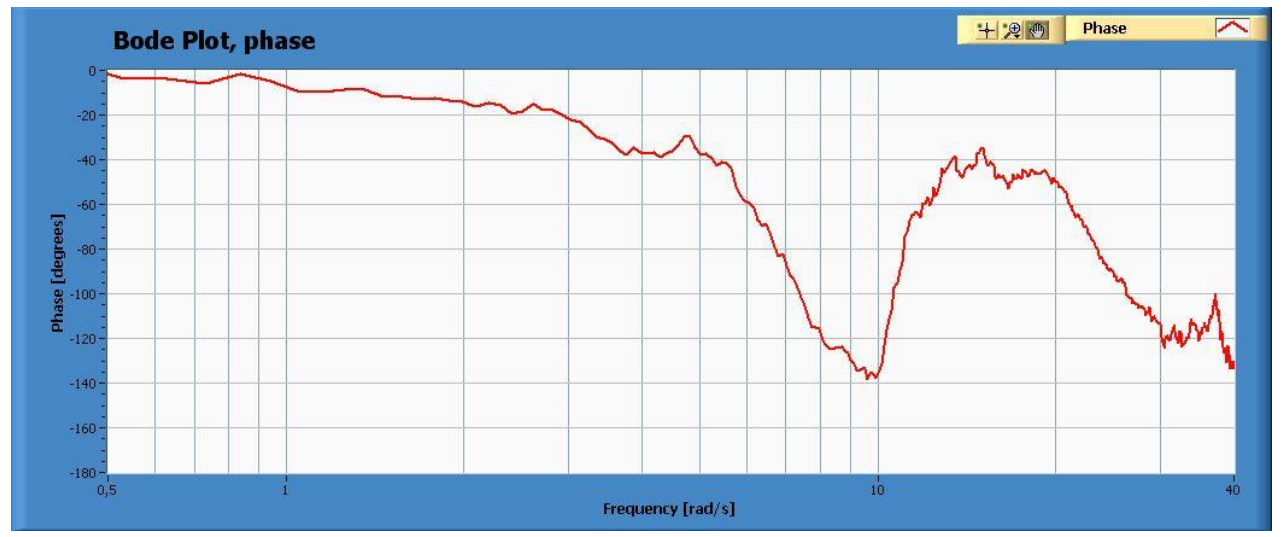

(b) Fase em ${ }^{\circ}-$ Com PSS

Figura 4.9: UHE Minas, resposta em frequência da tensão estatórica para o ajuste final do AVR e PSS com potência de 82MW.

Convém verificar as semelhanças entre o comportamento do ganho e da fase das respostas em frequência obtidas na UHE Minas e as respostas em frequência obtidas com um modelo computacional apresentadas na seção 3.3.4. A fig. 3.22 na pág. 60 mostra que o PSS diminui o ganho do AVR na região do espectro das oscilações locais. Um efeito semelhante, porém menos drástico, é visto na fig. 4.9a. A fase da função de transferência $\Delta e_{t} / \Delta e_{\text {tref }}$ apresenta um comportamento semelhante nos resultados práticos e nas simulações computacionais. Vale ressaltar que a escala de frequência da fig. 3.22 vai de 
$0,1 \mathrm{rad} / \mathrm{s}$ até $100 \mathrm{rad} / \mathrm{s}$ e a escala de frequência da fig. 4.9 vai de $0,5 \mathrm{rad} / \mathrm{s}$ até $40 \mathrm{rad} / \mathrm{s}$.

\subsection{Ajuste do estágio de ganho e avanço-atraso de fase do PSS da UHE Espanha}

O ajuste do estágio de ganho e avanço-atraso de fase do PSS da unidade 4 da UHE Espanha foi realizado pelo método de comparação de grandezas. O sinal de saída do PSS foi comparado com a potência ativa durante a resposta ao degrau na referência de tensão do AVR. Tal método foi descrito na seção 3.3.3.

O ganho $K_{S 1}$ do PSS da unidade 4 da UHE Espanha foi ajustado conforme o método empírico descrito na seção 3.3.5. Garantiu-se que o AVR e o PSS tinham um comportamento estável em regime permanente mesmo com um ganho $K_{S 1}$ três vezes maior do que o ganho escolhido.

Comissionou-se primeiro o PSS da unidade 4. A unidade 3 estava com o PSS desligado. As unidades 1 e 2 possuem sistemas de excitação rotativos com AVRs analógicos sem PSS. A unidade 1 foi modernizada em dezembro de 2009 e a unidade 2 deverá ser modernizada em dezembro de 2010.

O comissionamento do PSS da unidade 3 consistiu basicamente de ensaios de verificação do funcionamento do sistema empregando os mesmos ajustes empregados na unidade 4. Não foi feita uma otimização dos parâmetros da unidade 3. Não foi realizada uma otimização considerando os PSSs das unidades 3 e 4 operando em conjunto. 


\subsubsection{Método de comparação de grandezas aplicado no ajuste do PSS da UHE Espanha}

O método de ajuste de PSS utilizado na UHE Espanha é descrito a seguir:

- Desconecta-se o PSS da malha de controle do AVR;

- Emprega-se um ajuste inicial para os blocos de avanço-atraso tomado de alguma usina semelhante;

- Aplica-se um degrau na referência de tensão do AVR;

- Registra-se a potência ativa e o sinal de saída do PSS;

- Alteram-se os polos ou os zeros dos blocos de avanço-atraso para se modificar a defasagem entre a saída do PSS e a potência ativa;

- Aplicam-se novos degraus na referência de tensão;

- Busca-se obter $180^{\circ}$ de defasagem entre saída do PSS e potência ativa.

O ajuste final dos blocos de ganho e avanço-atraso do PSS da UHE Espanha é apresentado na tab. 4.6 .

Tabela 4.6: Ajustes dos blocos de ganho e avanço-atraso da UHE Espanha.

\begin{tabular}{ll} 
Parâmetros & Valor \\
\hline$K_{S 1}$ & 4 \\
$T_{1}$ & $0,115 \mathrm{~s}$ \\
$T_{2}$ & $0,03 \mathrm{~s}$ \\
$T_{3}$ & $0,115 \mathrm{~s}$ \\
$T_{4}$ & $0,03 \mathrm{~s}$ \\
$T_{10}$ & $1 \mathrm{~s}$ \\
$T_{11}$ & $1 \mathrm{~s}$ \\
$V_{S T M A X}$ & 0,04 \\
$V_{S T M I N}$ & $-0,04$
\end{tabular}


A fig. 4.10 mostra a resposta da potência ativa e da saída do PSS durante a aplicação de um degrau de 0,01p.u. na referência de tensão do AVR. O degrau foi aplicado pouco antes do instante $t=4 \mathrm{~s}$ e foi retirado $5 \mathrm{~s}$ depois. Os registros foram obtidos empregandose os parâmetros dos blocos de avanço-atraso mostrados na tab. 4.6. A fig. 4.10a mostra as respostas com o PSS desconectado da malha do AVR. A fig. 4.10b mostra a resposta com o PSS conectado à malha do AVR.

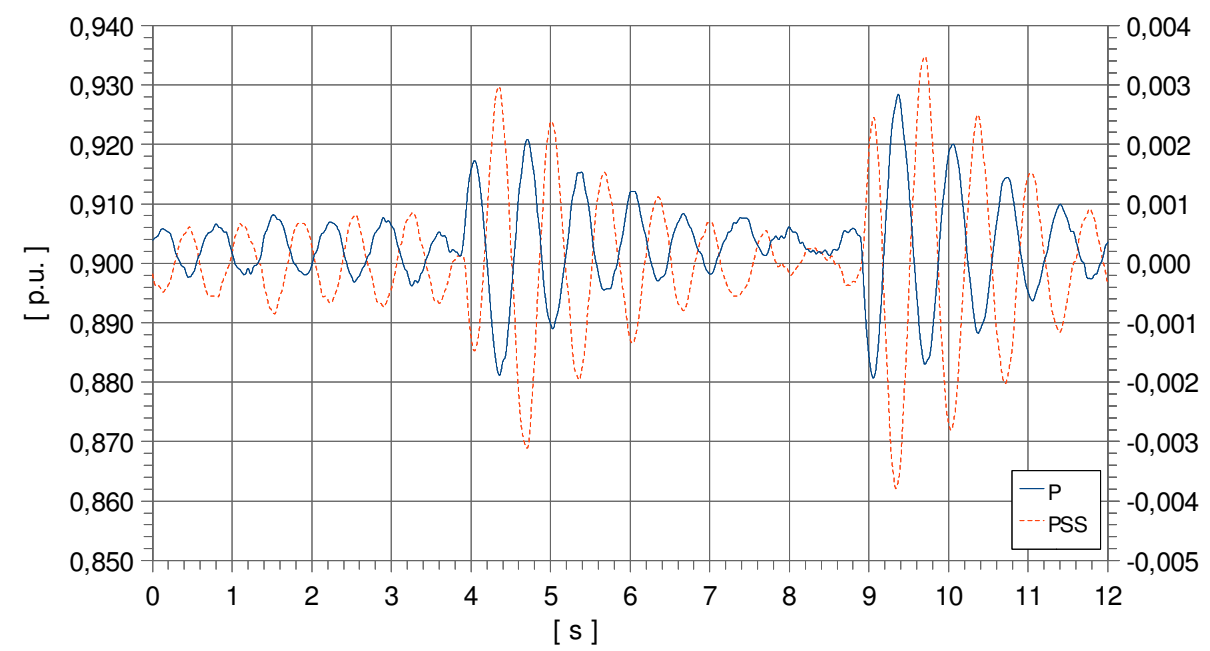

(a) PSS desligado

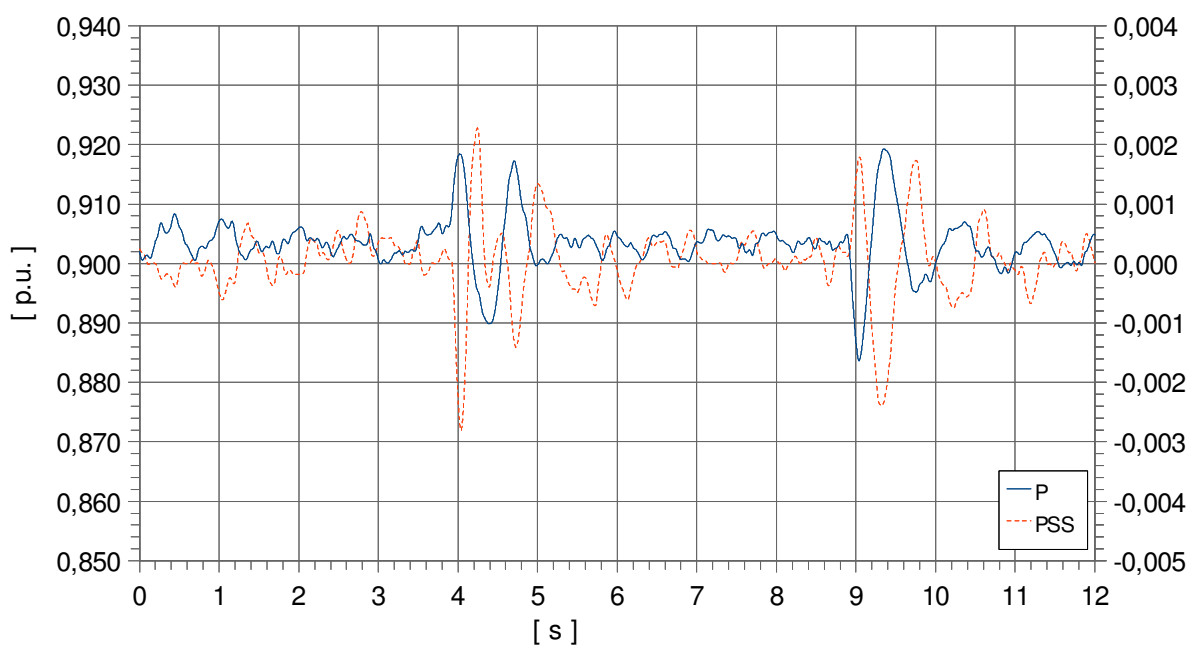

(b) PSS ligado

Figura 4.10: UHE Espanha, UG3, comparação da potência ativa e da saída do PSS após a aplicação de um degrau na referência do AVR; a potência ativa é apresentada em p.u. no eixo das ordenadas da esquerda, o sinal de saída do PSS em p.u. no eixo da direita.

A resposta da unidade 3 da UHE Espanha com e sem PSS a um degrau de 0,01p.u. na referência de tensão do AVR é apresentada na fig. 4.11. 


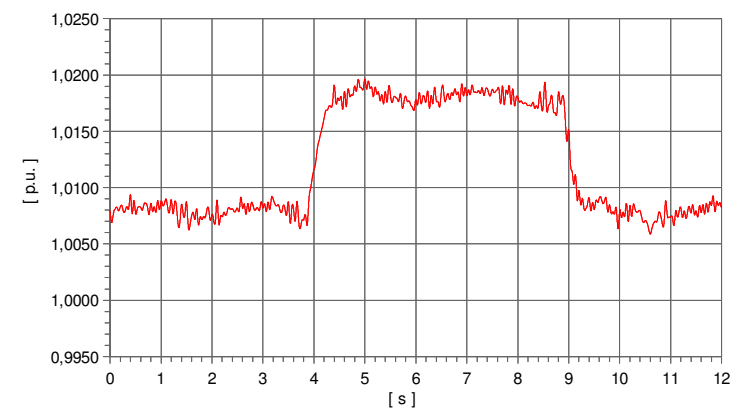

(a) Tensão terminal sem PSS

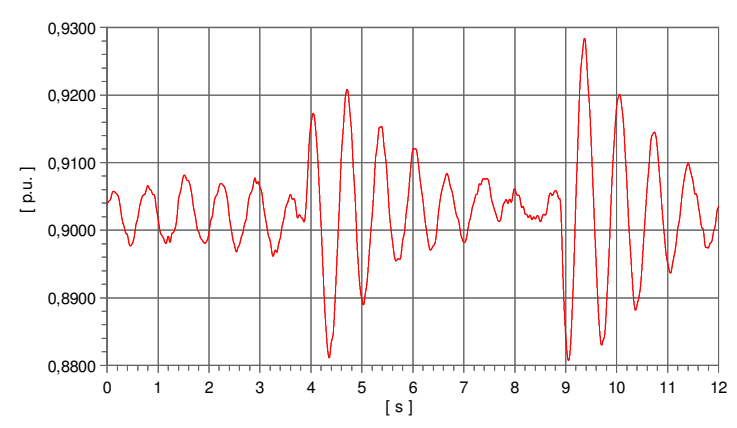

(c) Potência ativa sem PSS

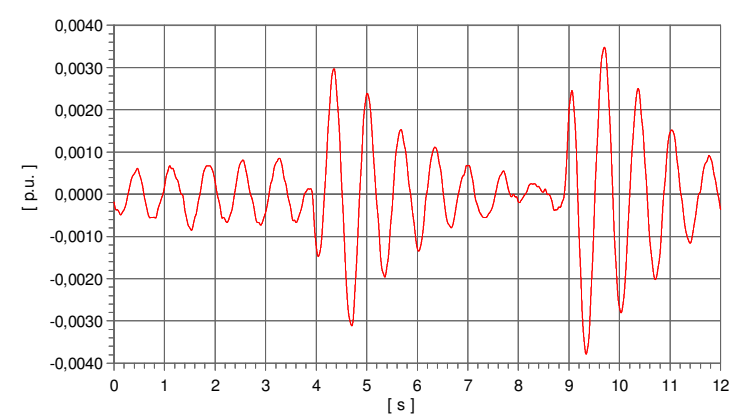

(e) Saída do PSS - PSS desconectado

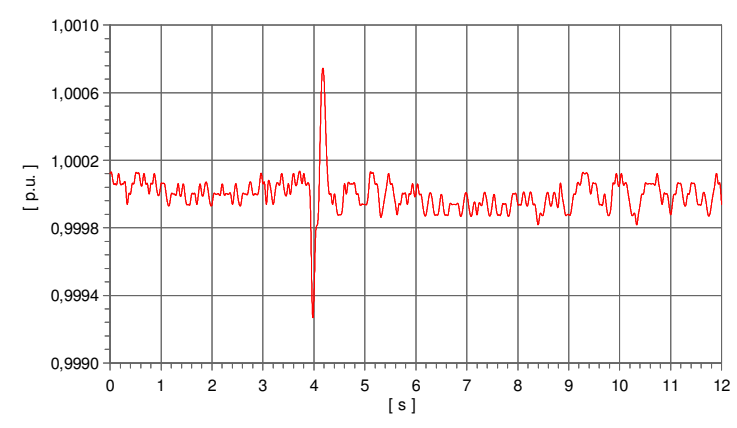

(g) Frequência terminal sem PSS

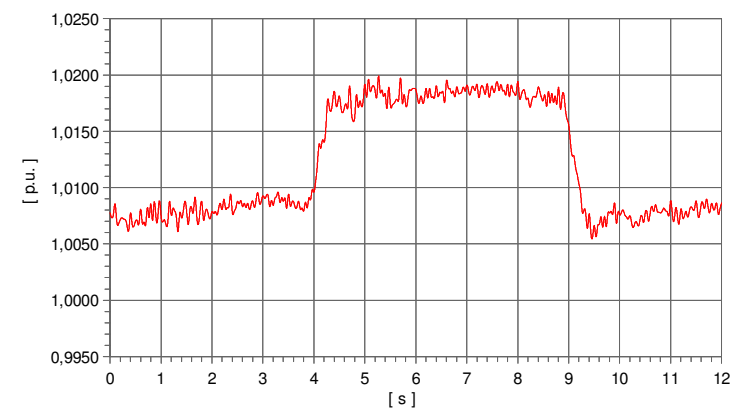

(b) Tensão terminal com PSS

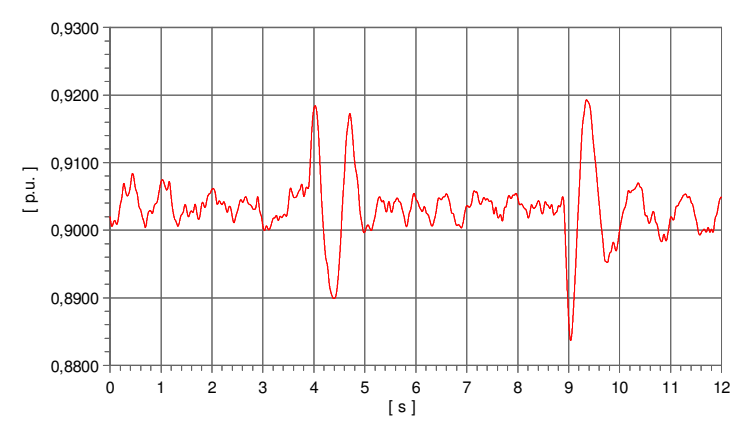

(d) Potência ativa com PSS

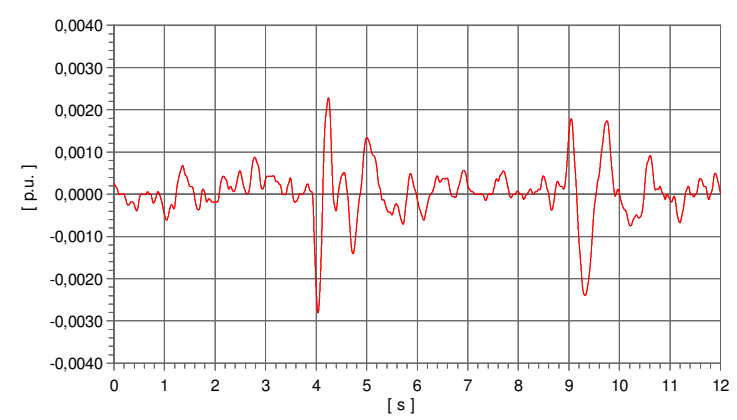

(f) Saída do PSS - PSS conectado

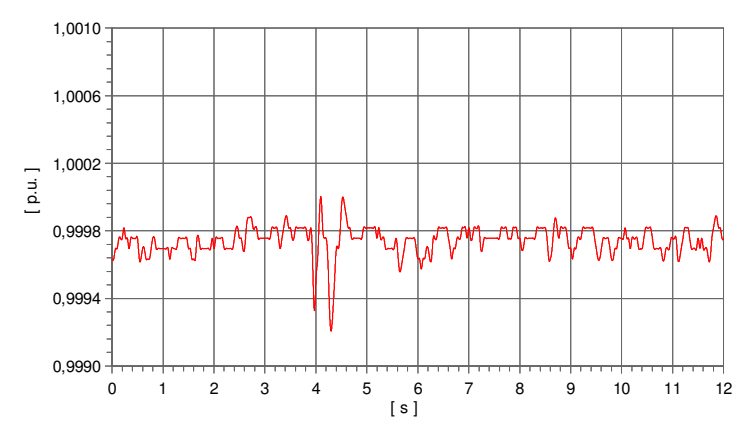

(h) Frequência terminal com PSS

Figura 4.11: UHE Espanha, UG3, resposta ao degrau de 0,01p.u. na referência de tensão do AVR. 
Com o intuito de comparar a ação do PSS nas unidades 3 e 4 da UHE Espanha, apresentam-se na fig. 4.12 as oscilações de potência ativa após um degrau de 0,01p.u. na referência de tensão do AVR. São mostradas as respostas com PSS e sem PSS. Os ensaios foram realizados em instantes diferentes, as curvas foram posteriormente sobrepostas para facilitar a comparação dos resultados.

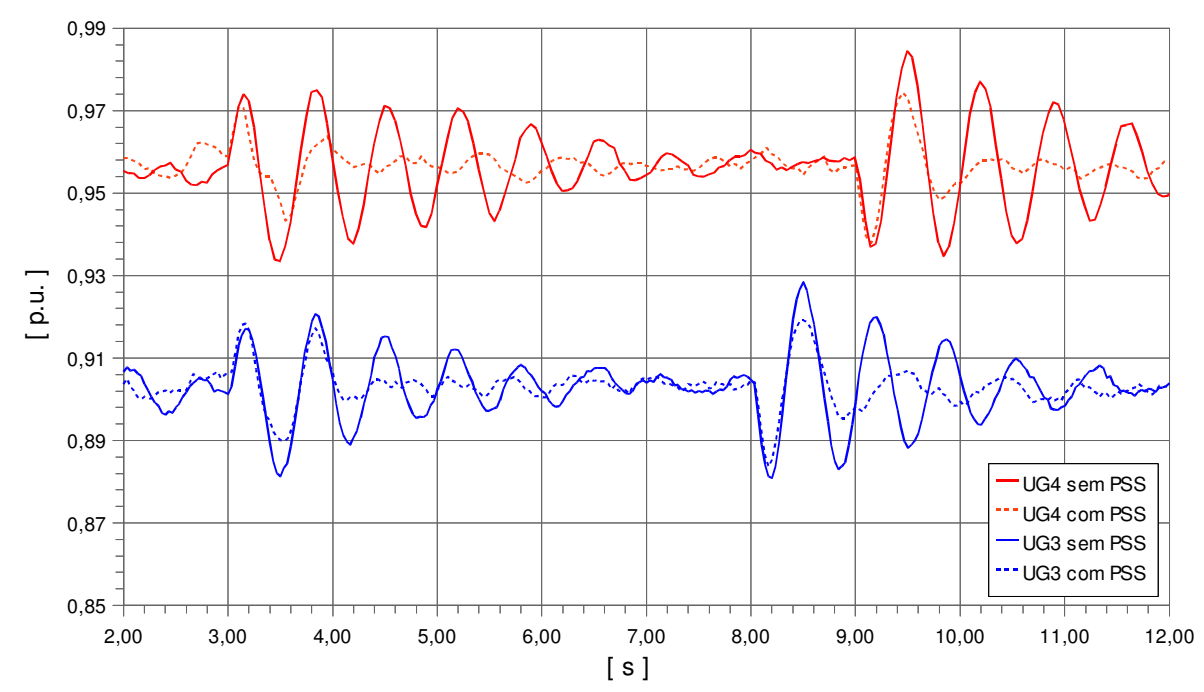

Figura 4.12: UHE Espanha, UG3 e UG4, oscilações na potência ativa durante a aplicação de um degrau de 0,01p.u. na referência de tensão do AVR.

Verifica-se na fig. 4.12 que o PSS da unidade 4 é mais eficiente do que o PSS da unidade 3. As oscilações de potência ativa após a introdução do degrau no instante $t=3 \mathrm{~s}$ são mais amortecidas na unidade 4 do que na unidade 3 . O mesmo se nota após os instantes nos quais os degraus são retirados da referência de tensão do AVR, $t=8 s$ e $t=9 \mathrm{~s}$. Vale lembrar que os resultados apresentados foram obtidos em condições diferentes de operação da UHE Espanha. As unidades 1 e 2, sem PSS, operaram durante todo o comissionamento com potência ativa nominal e potência reativa próxima de zero. A máquina 3 estava desligada durante os testes na unidade 4. Durante os ensaios da unidade 3, a unidade 4 estava operando em potência nominal e com o PSS ativado. Seria interessante realizar uma otimização dos ajustes considerando os PSSs das unidades 3 e 4 operando ao mesmo tempo. Tal otimização coordenada de PSSs não foi realizada na usina e não é abordada nesta dissertação.

Convém rever a fig. 3.15 na pág. 51 que mostra a defasagem entre a referência de tensão $\left(\Delta e_{\text {tref }}\right)$ e a tensão de campo $\left(\Delta E_{f d}\right)$ para diferentes ajustes das constantes de integração $\left(T_{i}\right)$ do regulador PI do AVR. Quanto menor $T_{i}$, maior é o atraso de fase entre $\Delta e_{\text {tref }}$ e $\Delta E_{f d}$. O método de comparação entre a saída do PSS e o sinal de potência ativa ignora atrasos de fase causados pelo AVR, isto pode levar a uma subcompensação 
de fase. A subcompensação ocorre e será verificada com o levantamento das respostas em frequência $\Delta e_{t} / \Delta e_{\text {tref }}$ mais adiante na seção 4.6.2. Vale lembrar que pequenos "erros" na compensação de fase podem ser "corrigidos" pelo ajuste do ganho $K_{S 1}$ conforme discutido na seção 3.4.2.2.

O desempenho dos PSSs das unidades 3 e 4 da UHE Espanha pode ser melhorado aumentando o ganho $K_{S 1}$. Não se deve esquecer dos critérios empíricos de ajuste do ganho $K_{S 1}$ apresentados na seção 3.3.5.

\subsubsection{Método de comparação de grandezas e o método de com- pensação de fase}

O método usado para o ajuste dos PSSs das unidades 3 e 4 da UHE Espanha foi o de comparação entre a saída do PSS e a potência ativa $(P)$. Tal método foi descrito na seção 3.3.3. É interessante comparar o ajuste realizado por este método com o ajuste que seria proposto pelo método de compensação de fase (descrito na seção 3.3.4).

Durante os ensaios realizados na unidade 4 da UHE Espanha foi possível levantar a resposta em frequência entre a referência de tensão do $\operatorname{AVR}\left(\Delta e_{t}\right)$ e a tensão estatórica $\left(\Delta e_{\text {tref }}\right)$. Os mesmos equipamentos digitais empregados na UHE Minas foram usados na UHE Espanha. A fig. 4.13 mostra a resposta em frequência $\Delta e_{t} / \Delta e_{\text {tref }}$ obtida.

É interessante verificar a semelhança entre a resposta obtida na UHE Espanha e as respostas em frequência de modelos computacionais mostradas nas figuras 3.16 e 3.18 nas páginas 53 e 56, respectivamente. Há semelhanças também com os resultados práticos obtidos na UHE Minas, fig. 4.6 na pág. 88.

A partir da resposta em frequência apresentada na fig. 4.13 é possível calcular o avanço de fase sugerido pelo método de compensação de fase. A fig. 4.14 apresenta a simulação computacional do avanço de fase proporcionado pelos blocos de avanço-atraso da UHE Espanha e o avanço de fase sugerido pelo método de compensação de fase.

A fig. 4.14 indica que o ajuste adotado para o PSS na UHE Espanha leva a uma subcompensação de fase na faixa de frequência das oscilações locais. A influência da subcompensação ou da supercompensação de fase é discutida na seção 3.4.2.2. 


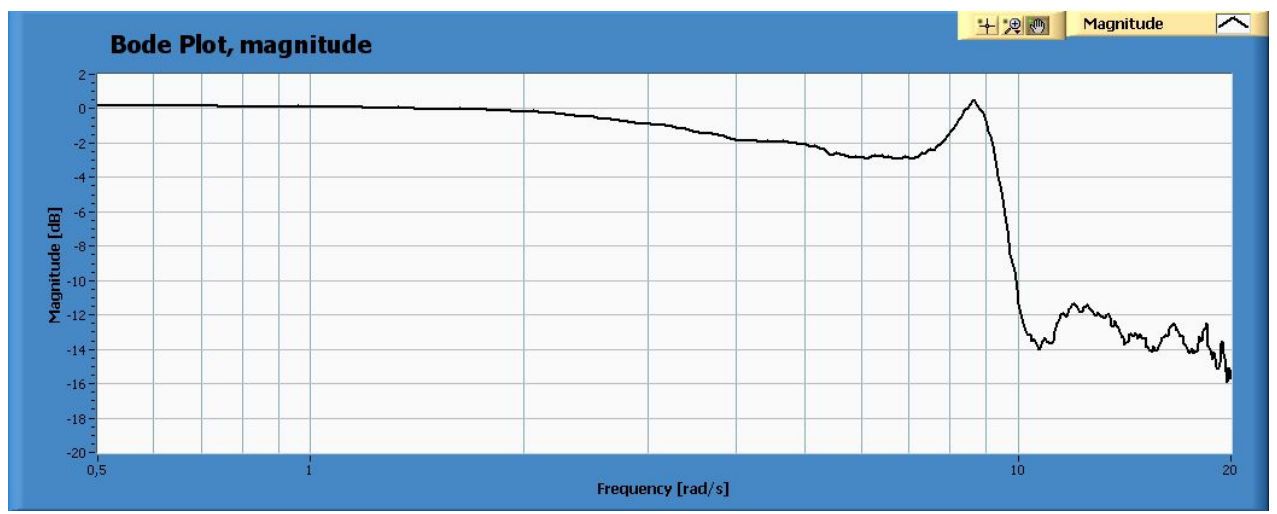

(a) Ganho em $d B$ - Sem PSS

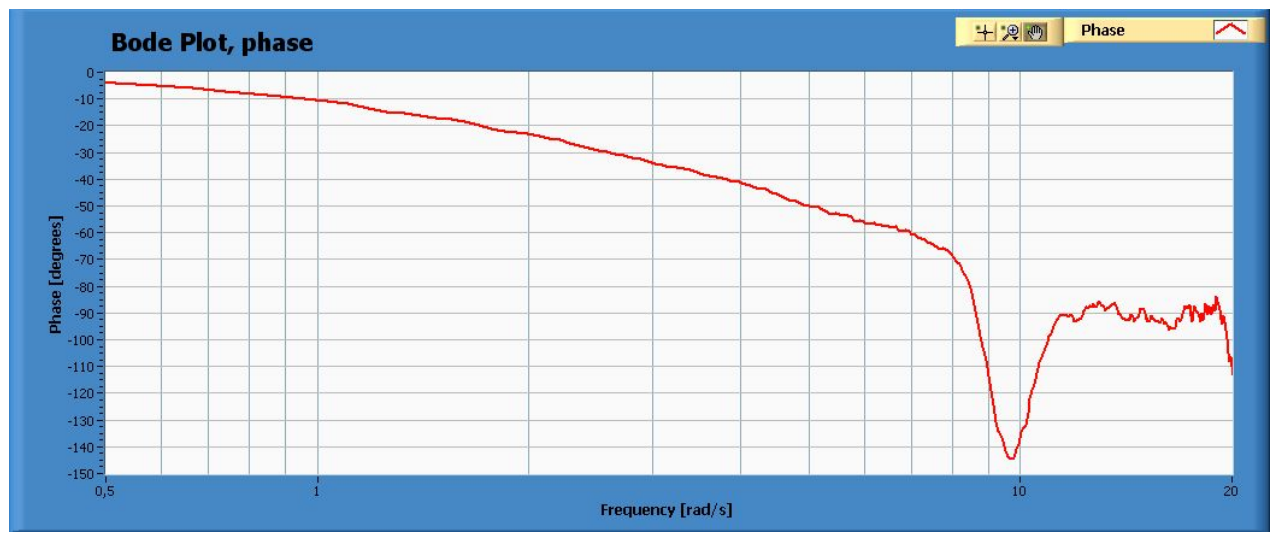

(b) Fase em ${ }^{\circ}-$ Sem PSS

Figura 4.13: UHE Espanha, UG4, resposta em frequência $\Delta e_{t} / \Delta e_{t r e f}$ sem PSS com potência de 86MW.

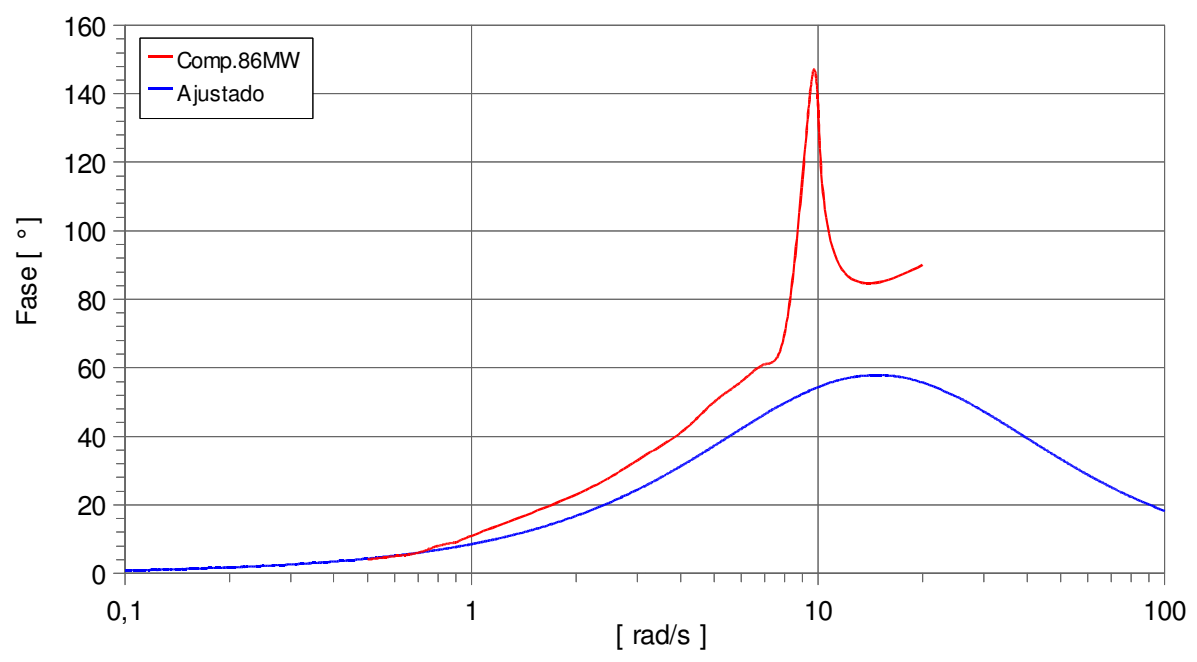

Figura 4.14: UHE Espanha, UG4, comparação entre os blocos de avanço ajustados e a sugestão do método de compensação de fase. 


\subsubsection{Resposta em frequência $\Delta e_{t} / \Delta e_{t r e f}$ da unidade 4 da UHE Espanha equipada com PSS}

A título de ilustração é mostrada na fig. 4.15 a resposta em frequência $\Delta e_{t} / \Delta e_{\text {tref }}$ da unidade 4 da UHE Espanha equipada com PSS e carregada com 86MW de potência ativa.

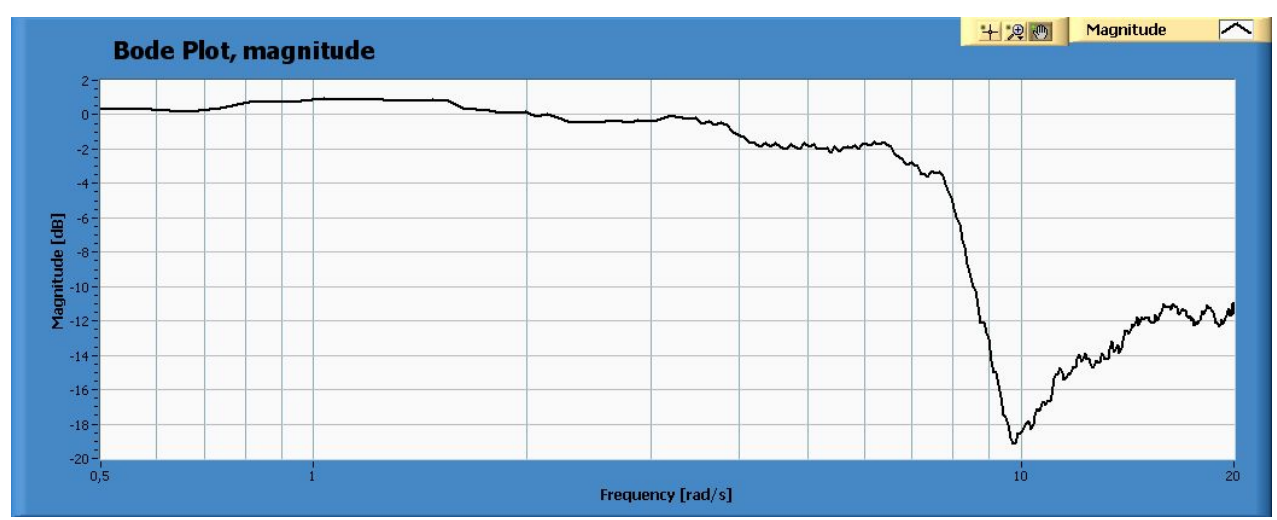

(a) Ganho em $d B$ - Com PSS

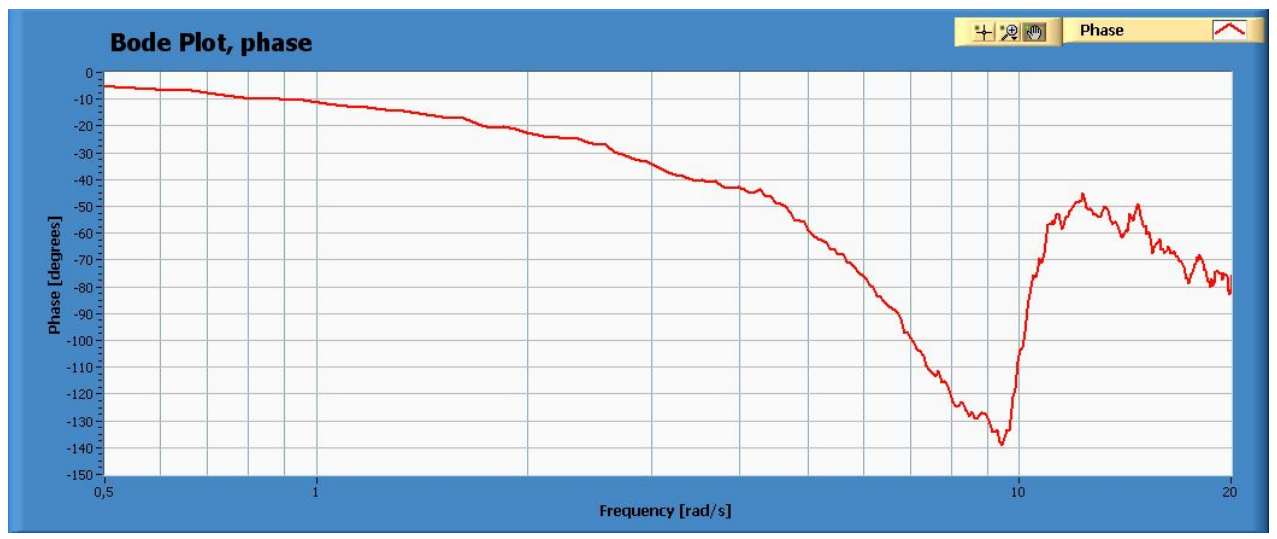

(b) Fase $\mathrm{em}^{\circ}-$ Com PSS

Figura 4.15: UHE Espanha, resposta em frequência da tensão estatórica para o ajuste final do AVR e PSS com potência de 82MW.

É interessante notar as semelhanças dos resultados obtidos na UHE Espanha com os resultados teóricos apresentados na fig. 3.22 na pág. 60. O comportamento observado na UHE Minas se repetiu na UHE Espanha, conforme se verifica na fig. 4.9 na pág. 91. Vale ressaltar que a escala de frequência da fig. 3.22 vai de $0,1 \mathrm{rad} / \mathrm{s}$ até $100 \mathrm{rad} / \mathrm{s}$, a escala da fig. 4.9 vai de $0,5 \mathrm{rad} / \mathrm{s}$ até $40 \mathrm{rad} / \mathrm{s}$ e a escala da fig. 4.15 vai de $0,5 \mathrm{rad} / \mathrm{s}$ até $20 \mathrm{rad} / \mathrm{s}$. 


\subsection{Análise do emprego dos diferentes métodos de ajuste de PSS}

A seção 4.5.2 comparou os resultados dos ajustes baseados na tentativa e erro e os resultados propostos pelo método de compensação de fase. A fig. 4.7 na pág. 89 mostra que a tentativa e erro levou a uma ligeira supercompensão de fase. Uma escolha diferente de valores iniciais para os parâmetros dos blocos de avanço-atraso poderia levar a uma leve subcompensação. Esta dissertação não recomenda o uso do método de tentativa e erros.

O método de compensação de fase descrito na seção 3.3.4 requer o levantamento da resposta em frequência entre a referência de tensão do $\operatorname{AVR}\left(\Delta e_{\text {tref }}\right)$ e a tensão estatórica $\left(\Delta e_{t}\right)$. Se realizado manualmente a partir de registros das respostas da tensão estatórica a diversos sinais senoidais de frequência diferentes, o levantamento de $\Delta e_{t} / \Delta e_{\text {tref }}$ demanda muito tempo. A alternativa é o emprego de equipamentos digitais que levantam $\Delta e_{t} / \Delta e_{\text {tref }}$ a partir da introdução na referência de tensão do AVR de distúrbios senoidais de frequência variante ou de distúrbios pseudo-aleatórios.

O método de comparação entre a saída do PSS e a potência ativa descrito na seção 3.3.3 é de mais simples aplicação do que o método de compensação de fase. Entretanto, é necessário assumir que o atraso entre $\Delta e_{t r e f}$ e a tensão de campo $\left(\Delta E_{f d}\right)$ é praticamente nulo nas proximidades da frequência de oscilação do modo local. Assume-se também que nesta faixa de frequência há um atraso de praticamente $90^{\circ}$ entre $\Delta E_{f d}$ e o torque elétrico $\left(\Delta T_{e}\right)$. Conforme mostraram os resultados práticos apresentados na seção 4.6.2, tais aproximações levam a uma subcompensação de fase na faixa do espetro das oscilações locais.

O modelo usado nos capítulos 2 e 3 para as simulações computacionais tem o modo local como dominante. Os resultados práticos apresentados neste capítulo foram obtidos em usinas que são pequenas quando comparadas com usinas próximas. A influência da UHE Espanha e da UHE Minas no amortecimento do modo interárea é pequena. Considerando o modo local de oscilações, a seção 3.4.2.2 mostrou que há uma margem para "erros" na compensação da defasagem entre referência de tensão do AVR e torque elétrico. O mesmo amortecimento do modo local pode ser obtido, para ajustes diferentes dos parâmetros dos blocos de avanço-atraso, se o ganho $K_{S 1}$ for otimizado para cada caso. Esta margem de "erros" no ajuste da defasagem explica o fato de que métodos baseados na tentativa e erro, ou métodos empíricos como o de comparação entre potência ativa e saída do PSS possam ser empregados. 


\section{Conclusões}

Esta dissertação abordou o tema de técnicas de ajuste de estabilizadores de sistemas de potência com um enfoque nos desafios encontrados por um engenheiro durante o comissionamento do sistema de excitação estático de uma unidade geradora de médio porte. Os métodos de ajuste tratados neste trabalho foram principalmente os aplicáveis a estabilizadores do tipo PSS2B de IEEE (2005). Foi dada prioridade às situações nas quais o engenheiro não dispõe de dados detalhados do modelo do gerador e do sistema de potência. Em tais situações há dificuldade para o emprego de métodos baseados em modelagem e simulação computacionais.

Empregou-se o modelo de Heffron e Phillips (1952) para a realização de simulações computacionais. Os resultados das simulações no domínio do tempo e no domínio da frequência foram utilizados com objetivos didáticos. Tais resultados ilustraram os conceitos básicos de funcionamento de estabilizadores de sistemas de potência.

A estrutura do PSS2B foi detalhada, explicitando-se a função de cada parâmetro. Foi mostrado que o PSS2B consiste de duas partes distintas. A primeira parte é um transdutor de velocidade do rotor do gerador. A segunda parte é um estágio de compensação de fase e ajuste de ganho.

Foram apresentados diferentes métodos de ajuste do PSS2B, dentre eles ressaltamse:

- Métodos de comparação de grandezas no domínio do tempo.

- Método de compensação de fase.

A análise da localização no plano complexo dos autovalores do modelo de um gerador equipado com PSS e conectado a um barramento infinito por uma impedância externa permitiu a discussão de critérios práticos para o ajuste dos parâmetros do estágio de compensação de fase e ajuste de ganho do PSS. 
Os resultados práticos obtidos durante comissionamentos em duas usinas hidrelétricas distintas foram apresentados. Mostrou-se a aplicação de métodos de tentativa e erro e de um método de comparação de grandezas. Comparou-se os ajustes realizados nas usinas hidrelétricas com os ajustes que seriam realizados caso o método de compensação de fase fosse empregado. O método de comparação entre grandezas é mais simples de ser aplicado. O método de compensação de fase requer o emprego de equipamentos dedicados para o levantamento da resposta em frequência entre a referência de tensão do AVR e a tensão estatórica, ou uma dispendiosa comparação entre diversos distúrbios senoidais inseridos na referência de tensão e respostas da tensão estatórica.

Verificou-se por simulações computacionais no capítulo 3 e por resultados práticos no capítulo 4 que há um margem de "erro" para o ajuste dos blocos de avanço-atraso do PSS. Estes pequenos erros podem ser "corrigidos" pela otimização do ganho proporcional $K_{S 1}$. A robustez em relação a variações na compensação de fase permite que métodos empíricos de ajuste possam ser empregados. O método de comparação entre a potência ativa e o sinal de saída do PSS é um bom exemplo. Este método tem as vantagens da simplicidade e da facilidade de aplicação.

Os métodos computacionais de ajuste de PSS esbarram na dificuldade de se obter em campo rapidamente um modelo confiável da máquina e do sistema de potência. Tal modelo necessita ser introduzido em um programa computacional para que um ajuste ótimo do PSS seja calculado. Estas dificuldades seriam contornadas pelo desenvolvimento de um equipamento dedicado capaz de identificar rapidamente o modelo da máquina e sugerir um ajuste inicial para o PSS.

A facilidade de aplicação de métodos como o de comparação de grandezas desestimula o investimento em pesquisa e desenvolvimento de equipamentos dedicados de identificação de sistemas e cálculo computacional de ajuste ótimo dos parâmetros do PSS. Uma alternativa é desenvolver rotinas de software para integrar a indentificação de sistemas e a otimização dos parâmetros do PSS nos microcontroladores ou controladores lógico programáveis dos atuais sistemas de excitação digitais. Tal linha de raciocínio conduz naturalmente a um PSS autoajustável ou adaptativo. Um dos grandes fabricantes de sistemas de excitação mundiais atualmente oferece PSSs adaptativos. 


\section{Apêndice A - Sistemas de excitação}

O controle de tensão de um gerador síncrono é feito pelos equipamentos que fornecem corrente contínua para o enrolamento rotórico ou enrolamento de campo. Conforme IEEE (2004), todos os equipamentos relacionados a tal tarefa, incluindo os dispositivos de potência, regulação, controle e proteção, compõem um sistema de excitação.

As primeiras usinas hidrelétricas a integrarem sistemas comerciais de geração de energia eram de pequeno porte. Nestas primeiras usinas, um barramento geral de corrente contínua alimentando os enrolamentos de campo e o controle manual de tensão via reostatos atendiam às necessidades de operação. Porém, com o crescimento do consumo e o aumento de potência das unidades geradoras, o controle manual via reostatos mostrou-se pouco confiável e antieconômico (CIGRÉ, 1998).

Novas alternativas surgiram, entre elas as excitatrizes rotativas, que são máquinas elétricas auxiliares empulsionadas por um motor elétrico ou pelo próprio eixo da unidade geradora. Neste caso, controla-se a corrente de campo da excitatriz. Tal corrente é dezenas ou centenas de vezes menor do que a corrente de campo do gerador.

O desenvolvimento de conversores de potência tiristorizados possibilitou o aparecimento de sistemas de excitação estáticos. Estes sistemas empregam pontes retificadoras controladas. Alimenta-se as pontes a partir de um transformador abaixador conectados aos terminais do estator do gerador. Uma das principais características destes sistemas é a rápida resposta a perturbações na tensão estatórica.

Um gerador de corrente contínua comum, confiável, controlado manualmente e com potência suficiente para alimentar o enrolamento de campo é capaz de controlar a tensão de um gerador síncrono. Para se manter a tensão estatórica em valores próximos ao nominal durante as lentas variações diárias que ocorrem num sistema elétrico, o sistema de excitação não necessita de qualidades excepcionais. A qualidade do fornecimento de energia elétrica depende da rapidez com a qual o sistema reage a condições adversas. Neste quesito, sistemas de excitação estáticos têm um desempenho superior aos sistemas 
rotativos (CIGRÉ, 1998).

\section{A.1 Limitadores e compensadores}

O regulador de tensão compara a tensão terminal do gerador com a tensão de referência e aumenta ou diminui a corrente fornecida ao enrolamento de campo. Se a tensão terminal é menor do que a referência, aumenta-se a corrente campo. Se maior, a corrente de campo é diminuída. A excitatriz e o rotor possuem limites térmicos de operação que determinam as correntes de campo máximas contínua e temporária. Há limites térmicos do estator e limites de estabilidade de operação do gerador. São empregados limitadores e compensadores para garantir uma operação segura do sistema de excitação e do gerador síncrono.

Os Requisitos Mínimos de Conexão à Rede Básica de ONS (2008) exigem os seguintes limitadores para o sistema de excitação:

- Compensação de corrente reativa;

- Limitação automática da relação V/Hz;

- Limitação automática da tensão de excitação em valores máximo e mínimo;

- Limitação de excitação mínima;

- Limitação de excitação máxima.

No Guia para a Preparação de Especificações de Sistemas de Excitação de IEEE (2004), são citadas as seguintes funções de compensação de reativos e de limitação do sistema de excitação:

- Compensadores de corrente reativa ou de queda de tensão na linha;

- Limitador de subexcitação - UEL - Underexcitation Limiter;

- Limitador de sobreexcitação - OEL - Overexcitation Limiter;

- Limitador de $V / H z$.

Uma breve explicação sobre os limitadores e compensadores citados por IEEE (2004) é feita a seguir. 


\section{A.1.1 Compensadores de reativos}

Os compensadores de corrente reativa forjam um aumento ou diminuição da realimentação de tensão estatórica proporcional à corrente reativa fornecida pelo gerador. Desta maneira, possibilita-se a operação de máquinas síncronas conectadas ao sistema de potência via um mesmo transformador elevador. No caso em que cada máquina é conectada ao sistema de potência via um transformador elevador, não é necessária a utilização de compensação de corrente reativa (IEEE, 2004).

\section{A.1.2 Limitador de subexcitação}

Os limitadores de subexcitação são empregados para impedir a operação da máquina nas regiões além dos limites de estabilidade. Na maioria das vezes, o limitador atua a partir da medição da impedância vista pelo gerador, porém os limites de operação são expressos em termos de potência ativa e reativa. É possível fazer a comparação direta com os limites de estabilidade da máquina síncrona expressos na curva de capabilidade. Alguns tipos de limitadores de subexcitação permitem a atuação do PSS, outros não (IEEE, 2004).

\section{A.1.3 Limitador de sobreexcitação}

Os limitadores de sobreexcitação são usados principalmente para evitar o aquecimento rotórico indevido. Como o tempo máximo permito de sobrecarga é inversamente proporcional à sobrecarga, a atuação deste limitador é muitas vezes temporizada. Em sistemas de excitação estáticos com altas de tensões de teto, limitadores de ação rápida são empregados (IEEE, 2004). Em geral, o limitador rápido permite sobrecarga específica e atua instantaneamente enquanto o limitador temporizado tem uma característica de tempo inverso.

\section{A.1.4 Limitador de $\mathrm{V} / \mathrm{Hz}$}

Os limitadores de $\mathrm{V} / \mathrm{Hz}$ têm este nome pois o fluxo magnético é proporcional à tensão terminal dividida pela frequência de operação do gerador (IEEE, 2004). O sobrefluxo devido à subfrequência ou sobretensão pode levar à saturação dos núcleos ferromagnéticos causando danos aos transformadores auxiliares, de excitação e elevador e ao próprio gerador. 


\section{Apêndice B - Sistemas de excitação adequados para o emprego de PSS}

Muito pouco foi discutido na literatura técnica sobre os critérios para julgar um sistema de excitação apto para o emprego de PSS (BEAULIEU; COULTES, 2003). Comentase em geral que os sistemas devem ser rápidos ou devem ter uma alta resposta inicial. IEEE (1986) define sistemas com alta resposta inicial como aqueles que são capazes de atingir $95 \%$ da diferença entre a máxima tensão de campo e a tensão de campo nominal sob determinadas condições em menos de 0,1s. Esta dissertação abrange principalmente sistemas de excitação estáticos equipados com reguladores de tensão digitais, tais sistemas têm alta resposta inicial.

Uma das poucas, porém muito boa, referências sobre critérios de adequação de sistemas de excitação para o emprego de PSS é o relatório de WSCC (1992) (BEAULIEU; COUlTES, 2003). É definido um critério para julgar "quão rápido" deve ser um sistema para que este seja "rápido o suficiente". A principal preocupação dos autores é com as oscilações interáreas observadas em meados da década de 1990 na rede da Western Systems Coordination Council (WSCC) ${ }^{1}$.

WSCC (1992) define uma função de transferência padrão dada pela eq. B.1. Para que o AVR seja apto a funcionar com um PSS, o atraso de fase entre a referência de tensão $\left(\Delta e_{t r e f}\right)$ e a tensão estatórica $\left(\Delta e_{t}\right)$ com o gerador próximo à carga nominal não deve ser maior do que o atraso de fase da função de transferência padrão. Opera-se com o AVR em malha fechada. A faixa de frequência considerada está entre $0,1 H z$ e $1 H z$. Os autores salientam que os eventuais aumentos abruptos no atraso de fase próximos à frequência do modo local não devem ser considerados na avaliação. Exemplos de respostas em frequência $\Delta e_{t} / \Delta e_{\text {tref }}$ podem ser vistos nas figuras apresentadas nas seções 3.3.4, 4.5

\footnotetext{
${ }^{1}$ Em 2002 foi formado nos Estados Unidos da América e Canadá o Western Electricity Coordinating Council (WECC) a partir da fusão do WSCC, da Southwest Regional Transmission Association (SWRTA) e da Western Regional Transmission Association (WRTA).
} 
e 4.6 .

$$
G_{\text {benchmark }}=\frac{6,28^{3}}{(s+0,628)(s+6,28)(s+62,8)}
$$

A fig. B.1 mostra a fase da resposta em frequência da função dada pela eq. B.12 . A faixa de interesse está entre $0,628 \mathrm{rad} / \mathrm{s}$ e $6,28 \mathrm{rad} / \mathrm{s}$. Sistemas de excitação estáticos não têm problemas para atender aos critério de WSCC (1992). Os resultados práticos obtidos no capítulo 4 mostram que os sistemas testados nesta dissertação atendem com folga a este critério de máxima defasagem.

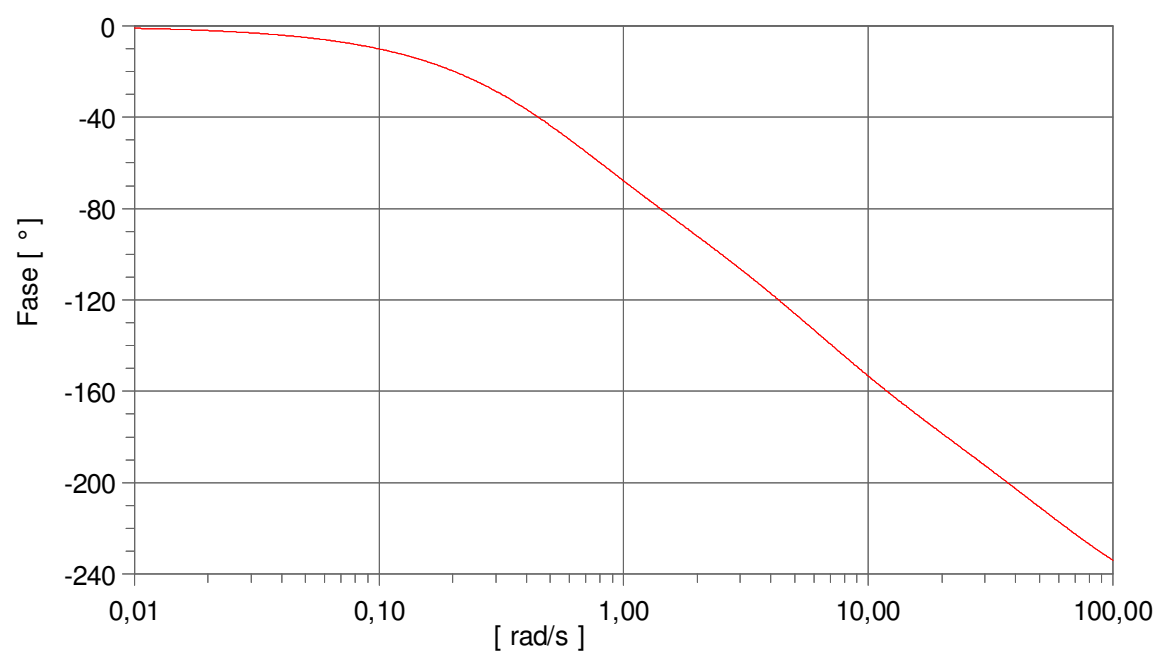

Figura B.1: Máxima defasagem na resposta em frequência $\Delta e_{t} / \Delta e_{\text {tref }}$ para que o AVR seja adequado para o emprego de PSS (WSCC, 1992).

\footnotetext{
${ }^{2}$ WSCC (1992) não especifica a origem dos coeficientes da eq. B.1. É interessante notar que $6,28 \approx 2 \pi$.
} 


\section{Apêndice C - Ajuste da malha do AVR}

O Guia para Identificação, Testes e Avaliação do Desempenho Dinâmico de Sistemas de Controle de Excitação de IEEE (1990) contém informações gerais sobre o ajuste da malha do AVR. A fig. C.1a mostra definições de termos relativos à resposta ao degrau na referência de tensão de um sistema de excitação. A fig. C.1b mostra uma resposta em frequência típica entre a referência de tensão $\left(\Delta e_{t r e f}\right)$ e a tensão terminal $\left(\Delta e_{t}\right)$ de um gerador em carga com o AVR em malha fechada.

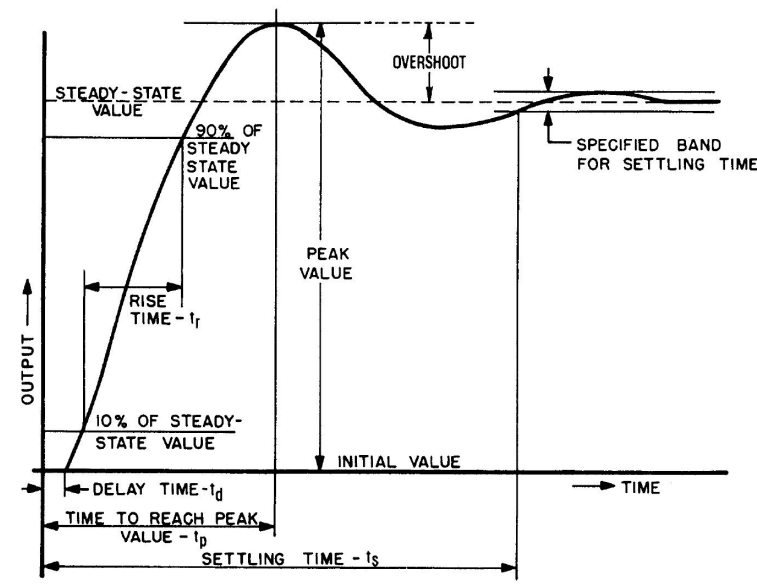

(a) Resposta ao degrau

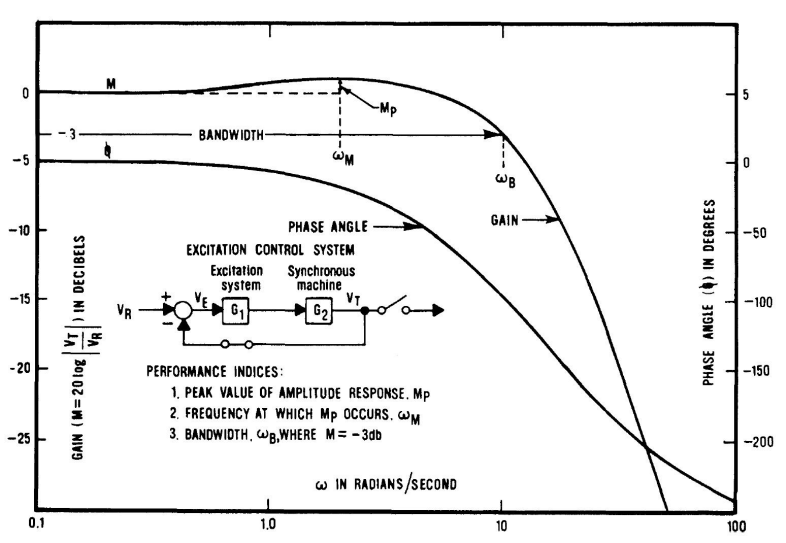

(b) Resposta em frequência em malha fechada

Figura C.1: Resposta do AVR ao degrau e resposta em frequência com o AVR em malha fechada; reimpresso de IEEE (1990).

Alguns valores presentes na resposta em frequência $\Delta e_{t} / \Delta e_{\text {tref }}$ são indicativos da estabilidade do sistema. Tais valores também são chamados de índices de desempenho frente a pequenas perturbações. Um comportamento oscilatório pode ser esperado de um sistema com ganho $M_{p}$ acima de $1,6 d B$. A banda passante $\omega_{B}$ está ligada ao tempo de subida $T_{r}$. Em sistemas com menos de $10 \%$ de sobressinal na resposta ao degrau, a banda passante em $\mathrm{Hz}$ e o tempo de subida em $s$ se relacionam aproximadamente por $T_{r} \omega_{B}=0,3$ até 0,45 . Vale lembrar que a otimização simultânea dos índices de desempenho não é possível. Pequeno $M_{p}$ e pequeno sobressinal não são compatíveis com grande banda passante (IEEE, 1990). 
Os modelos computacionais simulados nos capítulos 2 e 3 abrangem AVRs com reguladores do tipo proporcional-integral (PI). A função de tranferência simplificada destes sistemas é dada pela eq. C.1. Os resultados apresentados no capítulo 4 foram obtidos de sistemas de excitação que empregam esta a mesma filosofia de controle.

$$
G_{a v r P I}=\frac{K_{p}\left(1+s T_{i}\right)}{s T_{i}} \frac{K_{b}}{1+s T_{b}}
$$

DeMello e Concordia (1969) apresentam um modelo de AVR controlando a tensão de uma máquina conectada a um barramento infinito sem modificações no ângulo de carga, $\Delta \delta \approx 0$. Tal modelo simplifica a função de transferência entre tensão de campo e tensão terminal. Emprega-se um ganho igual a $K_{3} K_{6}$ e uma constante de tempo igual a $K_{3} T_{d 0}^{\prime}$. Uma versão deste modelo considerando a função de transferência do AVR dada pela eq. C.1 é apresentada na fig. C.2.

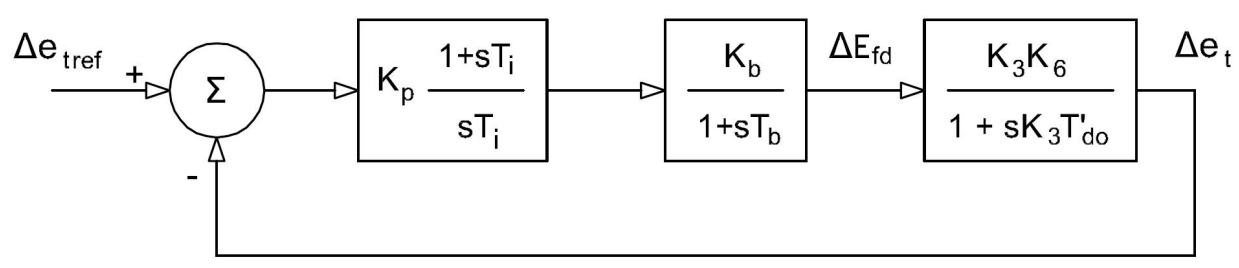

Figura C.2: Modelo simplificado de uma máquina conectada a um barramento infinito com ângulo de carga constante; adaptado de DeMello e Concordia (1969).

Pequenos atrasos e pequenos tempos mortos podem ser modelados utilizando um filtro passa-baixa de primeira ordem com uma constante de tempo igual à soma das pequenas constantes de tempo e tempos mortos (FRÖHR; ORTTENBURGER, 1970). Os pequenos atrasos de digitalização, processamento de sinais e tempo de resposta da ponte de tiristores são representados pela constante $T_{b}$ na fig. C.2. Bühler (1997) apresenta detalhadamente métodos de modelagem de pontes de tiristores.

O ajuste ótimo do PI da fig. C.2 é dado pelas equações C.2 e C.3 (FRÖHR; ORTTENBURGER, 1970; BÜHLER, 1979):

$$
\begin{gathered}
T_{i}=K_{3} T_{d 0}^{\prime} \\
\left(K_{b} K_{3} K_{6}\right) K_{p}=\frac{T_{i}}{2 T_{b}}
\end{gathered}
$$

A escolha de $T_{i}$ conforme a eq. C. 2 cancela o polo dominante do sistema representado 
por $K_{3} T_{d 0}^{\prime}$. A escolha de $K_{p}$ de acordo com a eq. C.3 faz com que o sistema em malha fechada tenha um sobressinal de no máximo 4,3\% na resposta ao degrau e que o tempo de subida $T_{r}$ seja igual a $4,71 T_{b}$. A rapidez de resposta do sistema depende apenas da soma das pequenas constantes de tempo (FRÖHR; ORTTENBURGER, 1970).

A técnica de ajuste de reguladores PI sugerida por Fröhr e Orttenburger (1970) fornece valores iniciais para os ensaios de comissionamento. Convém lembrar que tal abordagem desconsidera não-linearidades no sistema real e, principalmente, não leva em conta a presença de ruído de medição. São necessários ensaios em campo para o ajuste final da malha do AVR.

Nem sempre o modelo detalhado da máquina e do sistema de potência está disponível para o comissionador do AVR e do PSS. Em tais casos é necessário partir de valores empregados anteriormente em usinas de porte semelhante. Uma abordagem empírica usada pelo autor desta dissertação é descrita a seguir:

- Ajusta-se $T_{i}$ aproximadamente igual a $T_{d}^{\prime}$ da máquina;

- A partir de ensaios de resposta ao degrau, escolhe-se $K_{p}$ que resulte no máximo sobressinal aceitável;

- O valor máximo de sobressinal depende de solicitações dos representantes dos proprietários da usina, exigências do operador do sistema elétrico ou da experiência do comissionador;

- IEEE (1990) cita como boa prática de engenharia manter o sobressinal abaixo de $10 \%$ do degrau aplicado. 


\section{Apêndice D - A interação entre PSS e limitador UEL}

Testar a interação entre o limitador de subexcitação (underexcitation limiter - UEL) e o PSS é parte importante do processo de ajuste da malha de controle do sistema de excitação. Ver mais informações sobre limitadores no apêndice A.1.

Os limitadores de subexcitação normalmente são empregados com 3 propósitos:

1. Impedir a operação do gerador em regiões subexcitadas além dos limites térmicos do estator ou além dos limites de estabilidade devido às lentas mudanças diárias na tensão do sistema;

2. Impedir a operação do gerador em regiões subexcitadas além dos limites térmicos do estator ou além dos limites de estabilidade devido à ação do operador (alteração da referência de tensão do AVR);

3. Impedir que os limites de estabilidade dinâmica sejam ultrapassados durante transitórios, evitando a atuação da proteção contra a perda de excitação.

Um limitador UEL empregado para os dois primeiros propósitos pode ter a atuação muito lenta. Há pouca interação entre um UEL deste tipo e o PSS. Os limitadores UEL usados para o terceiro propósito têm que ser de rápida atuação (RIBEIRO, 1990; BÉRUBÉ; HAJAGOS; BEAULIEU, 1995). As interações entre o AVR, o PSS e o UEL devem ser levadas em conta na hora do comissionamento.

Não há um consenso na literatura sobre o emprego de limitadores UEL rápidos. Alguns autores simplesmente não recomendam este tipo de limitador (RIBEIRO, 1990; BÉRUBÉ; HAJAGOS; BEAULIEU, 1995). 
ONS (2008) exige que os sistemas de excitação de usinas de médio porte no Brasil sejam equipados com limitadores de excitação mínima:

- "O regulador automático de tensão deve ser equipado, no mínimo, com os seguintes limitadores de ação contínua:

- (a) excitação mínima - que atua sempre que a corrente de campo atingir valores abaixo dos quais a máquina possa perder o sincronismo ...

- ... A atuação desses limitadores deve ser estável, instantânea ... e deve ser coordenada dinamicamente com a atuação do sistema de proteção."

Há duas maneiras principais de inserção do limitador de subexcitação na malha de controle do AVR (RIBEIRO, 1990; BÉRUBÉ; HAJAGOS; BEAULIEU, 1995; MURDOCH; LAWSON; VENKATARAMAN, 1999):

- Summing point type: limitadores que atuam no somador da malha de controle do AVR;

- Take over control: limitadores se superpõem ao regulador de tensão tomando o controle e desconsiderando a realimentação de tensão estatórica.

Murdoch et al. (1999b) e Murdoch, Lawson e Venkataraman (1999) apresentam o funcionamento e métodos de ajuste dos limitadores do sistema de excitação. Os autores afirmam que as interações entre UEL do tipo somador com o PSS são benéficas para a estabilidade do sistema elétrico de potência. O UEL somador seria portanto melhor do que o UEL tomador de controle.

O sistema de excitação testado no capítulo 4 possui duas opções para o ponto de atuação do UEL na malha de controle do AVR, ver fig. 4.1 na pág. 77. O limitador UEL pode atuar no somador juntamente com o sinal do PSS, a referência de tensão e outros limitadores. Alternativamente, o sinal do UEL pode ser direcionado para uma porta de máximo valor ( $H V$ gate) após o ganho proporcional $\left(K_{p}\right)$ do regulador PI. Considerando a segunda opção, se o sinal do UEL for maior do que o sinal proveniente do bloco de ganho $K_{p}$, o UEL toma o controle.

Bérubé, Hajagos e Beaulieu (1995) são radicais com relação ao limitador de subexcitação. Segundos os autores não foi comprovado que o UEL é realmente capaz de ajudar na estabilidade da máquina durante transitórios severos no sistema. Na dúvida, 
escolhe-se deixar o AVR e o PSS atuarem sozinhos. A maioria das unidades da Ontario Hydro no Canadá opera sem limitador UEL. Emprega-se apenas a proteção contra perda de excitação, que desliga a máquina em caso de anormalidade.

As interações entre UEL e PSS são testadas durante o comissionamento a partir de respostas a degraus negativos de tensão. Tais degraus forçam o gerador a ultrapassar os limites parametrizáveis do UEL. A ação do limitador deve ser rápida e estável. A resposta do sistema não deve ser oscilatória quando ambos UEL e PSS estão ativos. Não é factível em campo produzir distúrbios que comprovariam a real eficácia do UEL em conjunto com o PSS durante transitórios severos no sistema de potência.

A título de ilustração são mostrados exemplos da interação entre o o PSS e o UEL. As figuras D.1, D.2, D.3 e D.4 mostram a tensão terminal $\left(e_{t r e f}\right)$, potência ativa $(P)$ e potência reativa $(Q)$ durante a aplicação de degraus negativos na referência de tensão do AVR. Foram feitos testes com o PSS ligado e desligado e com os dois tipos de UEL.

As figuras D.1, D.2 e D.4 mostram que não há diferenças significativas entre as respostas com e sem PSS no caso do emprego do UEL tomador de controle. Tal limitador remove o PSS, alguns limitadores e a realimentação de tensão da malha do AVR.

A fig. D.3 mostra que o PSS contribui para que a ação do UEL do tipo somador seja menos oscilatória. 


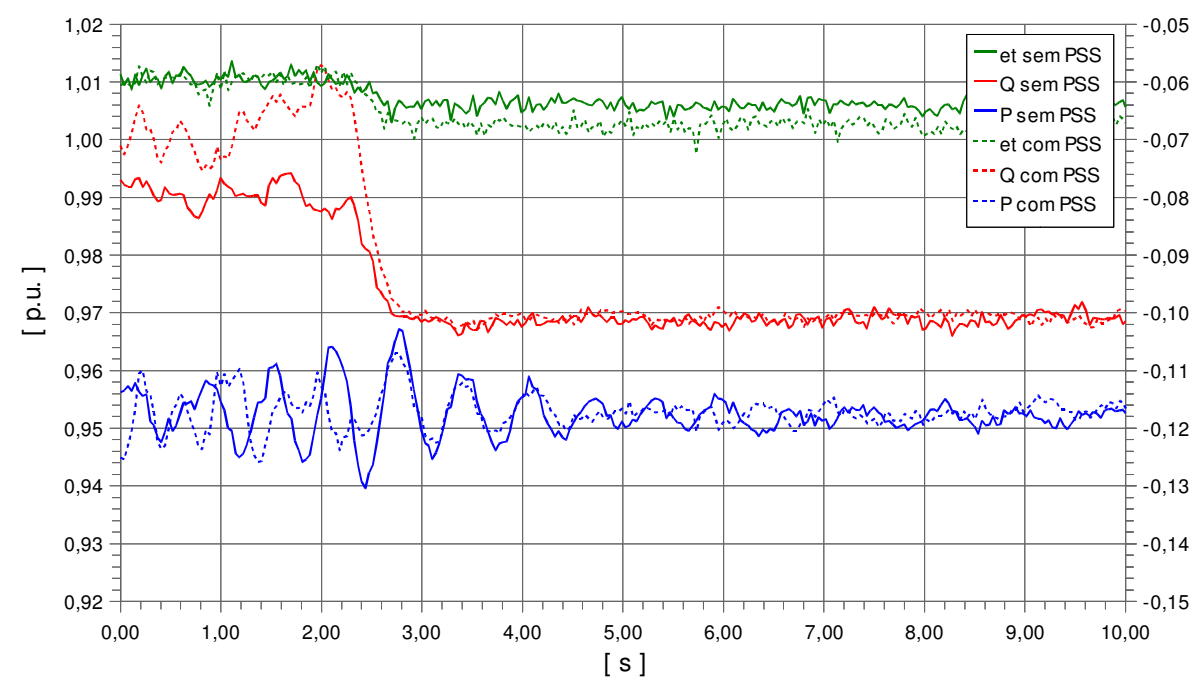

Figura D.1: UHE Minas, ação do limitador UEL do tipo tomador de controle com e sem PSS, aplicação de degrau negativo na referência de tensão do AVR; $e_{t}$ e $P$ estão representados no eixo das ordenadas da esquerda, $Q$ no eixo da direita.

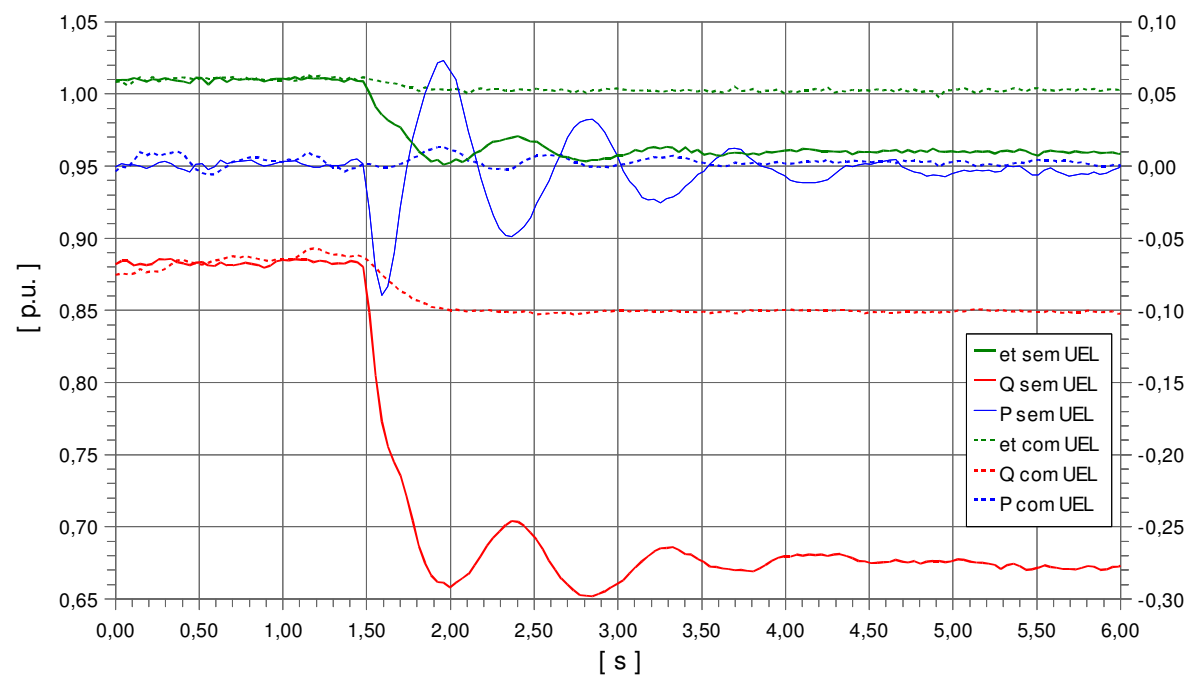

Figura D.2: UHE Minas, ação do PSS com e sem o limitador UEL do tipo tomador de controle, aplicação de degrau negativo na referência de tensão do AVR; $e_{t}$ e $P$ estão representados no eixo das ordenadas da esquerda, $Q$ no eixo da direita. 


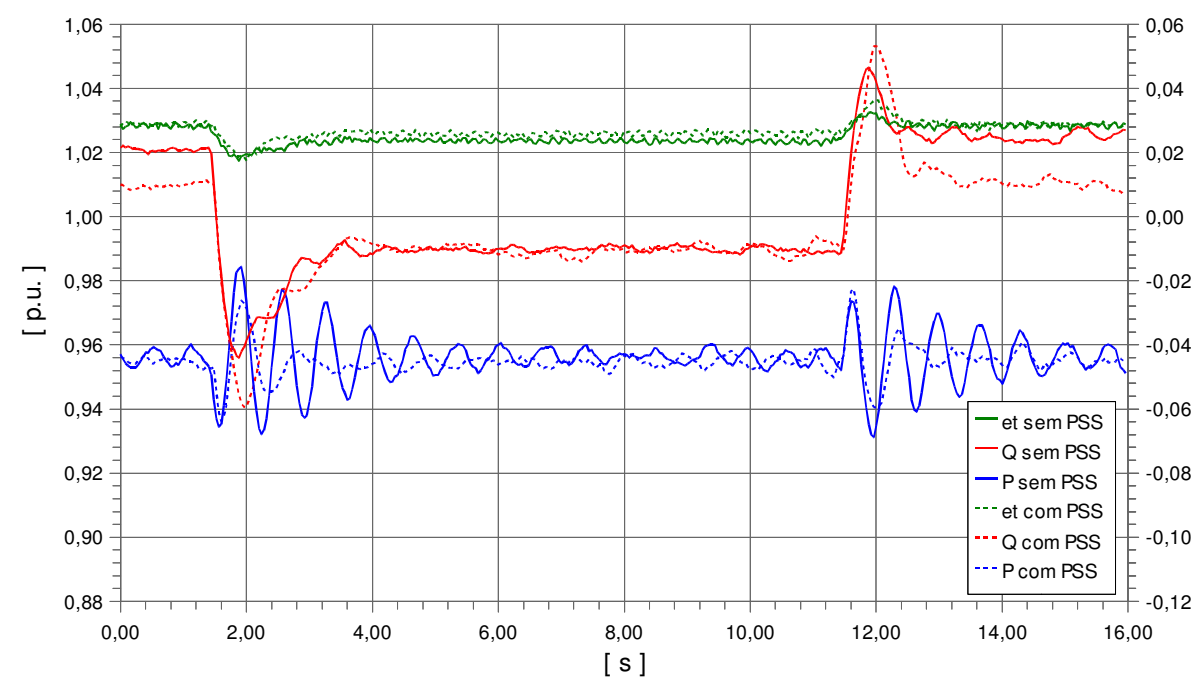

Figura D.3: UHE Espanha, UG3, ação do limitador UEL do tipo somador com e sem PSS, aplicação de degrau negativo na referência de tensão do AVR; $e_{t}$ e $P$ estão representados no eixo das ordenadas da esquerda, $Q$ no eixo da direita.

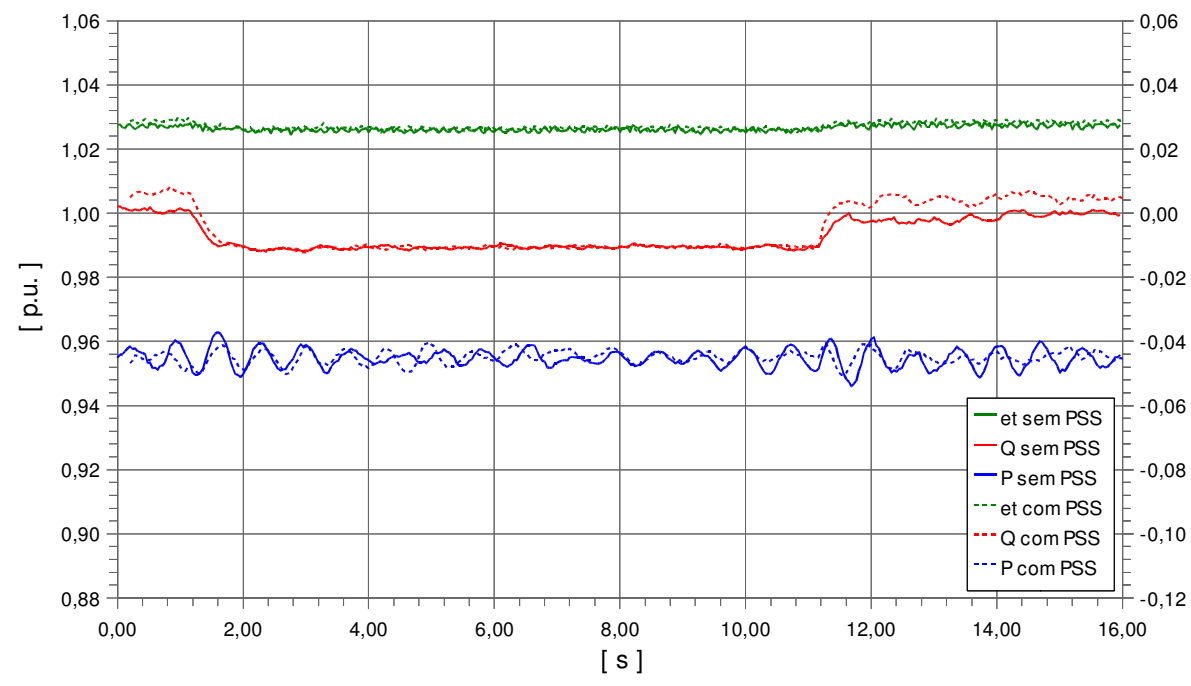

Figura D.4: UHE Espanha, UG3, ação do limitador UEL do tipo tomador de controle com e sem PSS, aplicação de degrau negativo na referência de tensão do AVR; $e_{t}$ e $P$ estão representados no eixo das ordenadas da esquerda, $Q$ no eixo da direita. 


\section{Referências}

ANDERSON, P. M.; FOUAD, A. A. Power System Control and Stability, Second Edition. Estados Unidos da América: IEEE Series on Power Engineering, 2003.

BEAUliEU, R. E.; COULTES, M. E. Suitability of excitation systems for PSS application. In: IEEE POWER ENGINEERING SOCIETY. General Meeting 2003. [S.1.], 2003. v. 3, p. 1791-1797.

BÉRUBÉ, G. R.; HAJAGOS, L. M.; BEAULIEU, R. A utility perspective on under-excitation limiters. IEEE Transactions on Energy Conversion, v. 10, p. 531-537, setembro 1995.

BÉRUBÉ, G. R.; HAJAGOS, L. M.; BEAULIEU, R. Practical utility experience with application of power system stabilizers. In: IEEE POWER ENGINEERING SOCIETY. Summer Meeting 1999. [S.l.], 1999. v. 1, p. 104-109.

BÜHLER, H. Électronique de réglage et de commande. Lausanne: Éditions Georgi, 1979. BÜHLER, H. Réglage de systèmes d'électronique de puissance. Volume 2: Entrâinements Réglés. Lausanne: Presses polytechniques et universitaires romandes, 1997.

CIGRÉ-BRASIL. Cigré-Brasil FT38.01.09 - Requisitos e desempenho de sistemas de excitação: Guia para especificação de sistemas de excitação para máquinas síncronas. Brasil, Setembro 1998.

DEMELLO, F. P.; CONCORDIA, C. Concepts of synchronous machine stability as affected by excitation control. IEEE Transactions on Power Apparatus and Systems, PAS-88, p. 316-329, abril 1969.

DEMELlO, F. P.; HANNET, L. N.; UNDRILL, J. M. Practical approaches to supplementary stabilizing from accelerating power. IEEE Transactions on Power Apparatus and Systems, PAS-97, p. 1515-1522, setembro / outubro 1978.

EL-SHERBINY, M. K.; MEHTA, D. M. Dynamic system stability part I - investigation of the effect of different loading and excitation systems. In: IEEE POWER ENGINEERING SOCIETY. Winter Meeting 1973. [S.1.], 1973. p. 1538-1546.

FERRAZ, J. C. R.; SOARES, J. M. C.; ZENI, N.; TARANTO, G. N. Adverse increase in generator terminal voltage and reactive power transients caused by power system stabilizers. In: IEEE POWER ENGINEERING SOCIETY. Winter Meeting 2002. [S.1.], 2002. v. 2, p. $747-752$.

FRÖHR, F.; ORTTENBURGER, F. Introduction to Electronic Control Engineering. Munique: Siemens-Aktiengesekkschaft and Heyden \& Son, 1970. 
GU, W.; SMULDERS, P.; MUSHENS, K. Power system stabilizer tuning-simulations and commissioning. In: IEEE POWER ENGINEERING SOCIETY. Summer Meeting 2000. [S.1.], 2000. v. 2, p. 925-930.

HAJAGOS, L. An update on power system stabilization via excitation control. In: IEEE POWER ENGINEERING SOCIETY. General Meeting 2003. [S.l.], 2003. v. 3, p. $1155-1157$.

HEFFRON, W. G.; PHILLIPS, A. R. Effect of a modern amplidyne voltage regulator on underexcited operation of large turbine generators. AIEE Transactions on Power Apparatus and Systems, PAS-71, p. 692-697, janeiro 1952.

IEEE POWER ENGINNERING SOCIETY. IEEE 421.1:1986: IEEE standard definitions for excitation systems for synchronous machines. Nova Iorque, NY, Estados Unidos da América, 1986.

IEEE POWER ENGINNERING SOCIETY. IEEE 421.2:1990: IEEE guide for identification, testing, and evaluation of the dynamic performance of excitation control systems. Nova Iorque, NY, Estados Unidos da América, 1990.

IEEE POWER ENGINNERING SOCIETY. IEEE 421.4:2004: IEEE guide for the preparation of excitation system specifications. Nova Iorque, NY, Estados Unidos da América, 2004.

IEEE POWER ENGINNERING SOCIETY. IEEE 421.5:2005: IEEE recommended practice for excitation system models for power system stability studies. Nova Iorque, NY, Estados Unidos da América, 2005.

KAMWA, I.; GRONDIN, R.; TRUDEL, G. IEEE PSS2B versus PSS4B: The limits of performance of modern power system stabilizers. IEEE Transactions on Power Systems, v. 20, p. 903-915, maio 2005.

KEAY, F. W.; SOUTH, W. H. Design of a power system stabilizer sensing frequency deviation. IEEE Transactions on Power Apparatus and Systems, PAS-90, p. 707-712, março 1971.

KUNDUR, P. Power System Stability and Control. Londres: MacGraw-Hill, Inc, 1993.

KUNDUR, P.; BÉRUBÉ, G. R.; HAJAGOS, L. M.; BEAULIEU, R. Practical utility experience with and effective use of power system stabilizers. In: IEEE POWER ENGINEERING SOCIETY. General Meeting 2003. [S.l.], 2003. v. 3, p. 1777-1785.

LARSEN, E. V.; SWANN, D. A. Applying power system stabilizers part I: General concepts. IEEE Transactions on Power Apparatus and Systems, PAS-100, p. 3017-3024, junho 1981.

LARSEN, E. V.; SWANN, D. A. Applying power system stabilizers part II: Performance objectives and tuning concepts. IEEE Transactions on Power Apparatus and Systems, PAS-100, p. 3025-3033, junho 1981.

MARTINS, N.; BARBOSA, A. A.; FERRAZ, J. C. R.; SANTOS, M. G. dos; BERGAMO, A. L. B.; YUNG, C. S.; OLIVEIRA, V. R.; MACEDO, N. J. P. Retuning stabilizers for the north-south brazilian interconnection. In: IEEE POWER ENGINEERING SOCIETY. Summer Meeting 1999. [S.l.], 1999. v. 1, p. 58-67. 
MURDOCH, A.; LAWSON, R. A.; VENKATARAMAN, S. 1999 IEEE PES WPM panel session sponsored by the excitation system subcommittee of ED\&PGC. In: IEEE POWER ENGINEERING SOCIETY. Winter Meeting 1999. [S.l.], 1999. v. 1, p. 182-186.

MURDOCH, A.; VENKATARAMAN, S.; LAWSON, R. A. Integral of accelerating power type PSS. II. field testing and performance verification. IEEE Transactions on Energy Conversion, v. 14, p. 1664-1672, dezembro 1999.

MURDOCH, A.; VENKATARAMAN, S.; LAWSON, R. A.; PEARSON, W. R. Integral of accelerating power type PSS. I. theory, design, and tuning methodology. IEEE Transactions on Energy Conversion, v. 14, p. 1658-1663, dezembro 1999.

MURDOCH, A.; VENKATARAMAN, S.; SANCHEZ-GASCA, J. J.; LAWSON, R. A. Practical application considerations for power system stabilizer (PSS) controls. In: IEEE POWER ENGINEERING SOCIETY. Summer Meeting 1999. [S.l.], 1999. v. 1, p. 83-87.

OPERADOR NACIONAL DO SISTEMA ELÉTRICO. Requisistos técnicos minimos para a conexão à rede básica: Submódulo 3.8. Brasil, março 2004.

OPERADOR NACIONAL DO SISTEMA ELÉTRICO. UHE Pedra do Cavalo - Ensaios de comissionamento e otimização do sistema de excitação: ONS RE 03/334/2004 validação dos modelos e otimização dos controladores. Brasil, 2004.

OPERADOR NACIONAL DO SISTEMA ELÉTRICO. Requisistos técnicos minimos para a conexão à rede básica: Submódulo 3.6. Rio de Janeiro, RJ, Brasil, julho 2008.

OPERADOR NACIONAL DO SISTEMA ELÉTRICO. Rede de operação áreas de controle da transmissão regiões Sul e Sudeste - Centro Oeste: DU-CT.SSE.01A revisão 75. Brasil, 2009. Publicado pelo ONS na internet em http://www.ons.org.br/.

ORSINI, L. Q. Introdução aos Sistemas Dinâmicos. 2. ed. São Paulo: EPUSP, 1980.

PAIVA, P. M.; SOARES, J. M.; ZENI, N.; PONS, F. H. Extensive PSS use in large systems: the argentinean case. In: IEEE POWER ENGINEERING SOCIETY. Summer Meeting 1999. [S.l.], 1999. v. 1, p. 68-75.

RIBEIRO, J. R. Minimum excitation limiter effects on generator response to system disturbances. IEEE Transactions on Energy Conversion, v. 6, p. 29-38, março 1990.

SCHLEIF, F. R.; HUNKINS, H. D.; HATTAN, E. E.; GISH, W. B. Control of rotating exciters for power system damping: Pilot applications and experience. IEEE Transactions on Power Apparatus and Systems, PAS-87, p. 1259-1266, agosto 1969.

SCHLEIF, F. R.; HUNKINS, H. D.; MARTIN, G. E.; HATTAN, E. E. Excitation control to improve powerline stability. IEEE Transactions on Power Apparatus and Systems, PAS-87, p. 1426-1434, junho 1968.

SENGER, E. C. Ajustes dos parâmetros de reguladores de tensão em alternadores - Uma abordagem por variáveis de estado. Dissertação (Mestrado) - Escola Politécnica, São Paulo, Brasil, 1983.

TAYLOR, C. W. Improving grid behaviour. In: IEEE POWER ENGINEERING SOCIETY. IEEE Spectrum. [S.l.], 1999. v. 36, p. 40-45. 
WESTERN ELECTRICITY COORDINATION COUNCIL. WECC Power System Stabilizer Tuning Guidelines. Estados Unidos da América, 2009. Publicado pelo WECC na internet em data não identificada no endereço http://www.wecc.biz/.

WESTERN SYSTEMS COORDINATION COUNCIL. Criteria to determine excitation system suitability for PSS in WSCC System. Phoenix, Arizona, Estados Unidos da América, 1992. Preparado pelo WSCC Modelling Work Group.

ZANETTA, L. C. Análise do controle da excitação da máquina síncrona a pequenas perturbações - Verificações com métodos lineares de resposta em frequência e autovalores. Dissertação (Mestrado) — Escola Politécnica, São Paulo, Brasil, 1984. 